\title{
TA7
}

W34c no. ITL-92-4

c. 3

US Army Corps of Engineers

Waterways Experiment Station

\section{Engineering Reliability of Navigation Structures}

\author{
by Thomas F. Wolff, Weijun Wang, Michigan State University
}

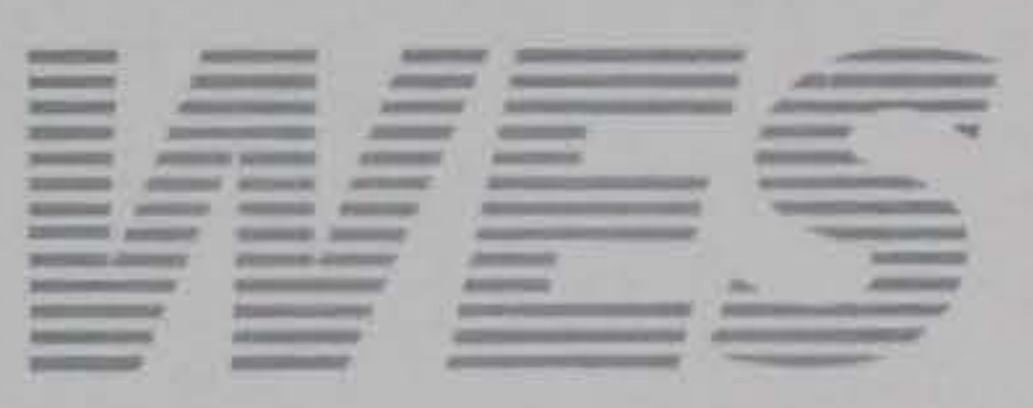

Approved For Public Release; Distribution Is Unlimited

Research Library

US Army Engineer Waterways

Experiment Station

Vicksburg. Mississippi

Prepared for Headquarters, U.S. Army Corps of Engineers 


\section{Engineering Reliability of Navigation Structures}

by Thomas F. Wolff, Weijun Wang

Michigan State University

East Lansing, MI 48824

\section{Final report}

Approved for public release; distribution is unlimited

Analyses in Parts VI, IX, X, and XIII of this report are superceded by the report entitled "Engineering Reliability of Navigation Structures, Supplement No. 1," Contract Report ITL-92-5.

Prepared for U.S. Army Corps of Engineers

Washington, DC 20314-1000

Under Contract No. DACW39-91-C-0041

Monitored by U.S. Army Engineer Waterways Experiment Station 3909 Halls Ferry Road

Vicksburg, MS 39180-6199 




\section{Waterways Experiment Station Cataloging-in-Publication Data}

Wolff, Thomas F.

Engineering reliability of navigation structures / by Thomas F. Wolff, Weijun Wang ; prepared for U.S. Army Corps of Engineers ; monitored by U.S. Army Engineer Waterways Experiment Station.

211 p. : ill. ; $28 \mathrm{~cm} .-$ (Contract report ; ITL-92-4)

Includes bibliographical references.

1. Locks (Hydraulic engineering) - Evaluation. 2. Reliability (Engineering) 3. Hydraulic structures - Evaluation. I. Wang, Weijun. II. United States. Army. Corps of Engineers. III. U.S. Army Engineer Waterways Experiment Station. IV. Information Technology Laboratory (U.S. Army Engineer Waterways Experiment Station) V. Title. VI. Series: Contract report (U.S. Army Engineer Waterways Experiment Station); ITL-92-4.

TA7 W34c no.ITL-92-4 


\section{Contents}

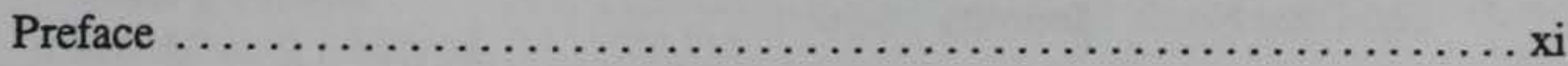

Conversion Factors, Non-SI to SI Units of Measurement $\ldots \ldots \ldots \ldots \ldots$ xii

Part I: Introduction $\ldots \ldots \ldots \ldots \ldots \ldots \ldots \ldots \ldots \ldots \ldots \ldots \ldots \ldots \ldots \ldots \ldots \ldots \ldots \ldots, 1$

Background $\ldots \ldots \ldots \ldots \ldots \ldots \ldots \ldots \ldots \ldots \ldots \ldots \ldots \ldots \ldots \ldots \ldots \ldots \ldots, 1-1$

Problem Statement $\ldots \ldots \ldots \ldots \ldots \ldots \ldots \ldots \ldots \ldots \ldots \ldots \ldots \ldots \ldots \ldots \ldots \ldots \ldots \ldots, 1-2$

Scope of this Report $\ldots \ldots \ldots \ldots \ldots \ldots \ldots \ldots \ldots \ldots \ldots \ldots \ldots \ldots \ldots \ldots \ldots, 1-3$

Part II: Applications of Reliability-based Engineering Analysis ........ 2-1

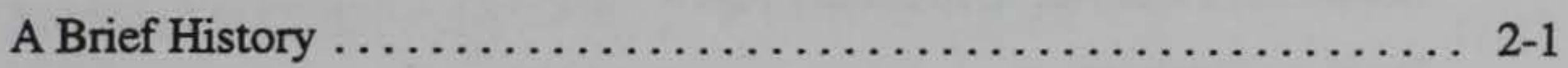

Application in Structural Design Codes $\ldots \ldots \ldots \ldots \ldots \ldots \ldots \ldots \ldots .2-2$

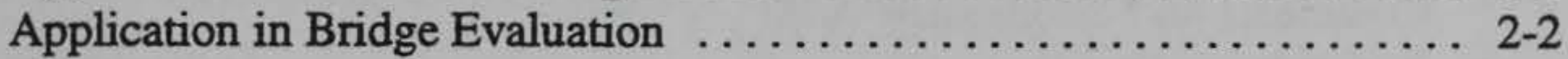

Some Previous Applications to Corps of Engineers' Projects ........ 2-3

Part III: Basic Principles . . . . . . . . . .

Basis of Reliability Analysis $\ldots \ldots \ldots \ldots \ldots \ldots \ldots \ldots \ldots \ldots \ldots, 3-1$

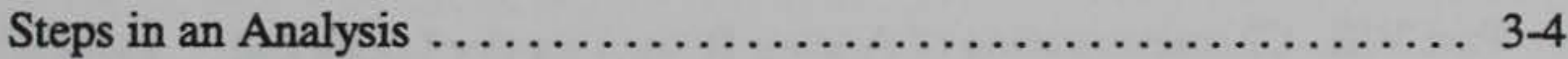

Selection of Random Variables ........................ 3-5

Moments of Random Variables ........................ 3-5

Probability Density Functions $\ldots \ldots \ldots \ldots \ldots \ldots \ldots \ldots \ldots \ldots \ldots \ldots \ldots \ldots \ldots, 3-9$

The Performance Function and Limit State . . . . . . . . . . . . . . . 3-15

Integration of the Performance Function $\ldots \ldots \ldots \ldots \ldots \ldots \ldots \ldots, 3-16$

Monte Carlo Simulation ............................. 3-17

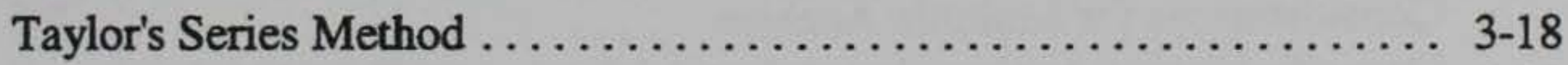

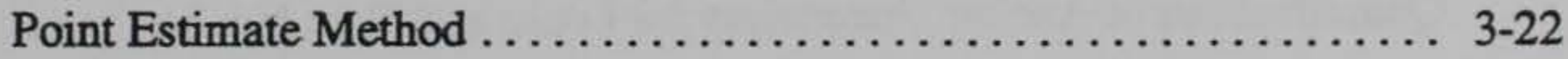

The Reliability Index and its Various Definitions ............ 3-22

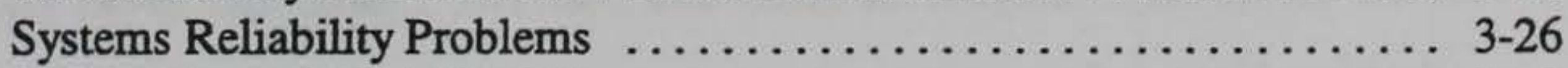

Setting Target Reliability Values ..................... 3-28

Time Variation of Reliability ........................ 3-29

Part IV: Probabilistic Characterization of Shale Strength $\ldots \ldots \ldots \ldots \ldots$ 4-1

Monongahela River Foundation Materials $\ldots \ldots \ldots \ldots \ldots \ldots \ldots \ldots$ 4-1

Grouping of Data $\ldots \ldots \ldots \ldots \ldots \ldots \ldots \ldots \ldots \ldots \ldots \ldots \ldots \ldots \ldots \ldots, 4,3$

Calculating the Moments of $c$ and $\tan \phi \ldots \ldots \ldots \ldots \ldots \ldots \ldots \ldots, 4,5$

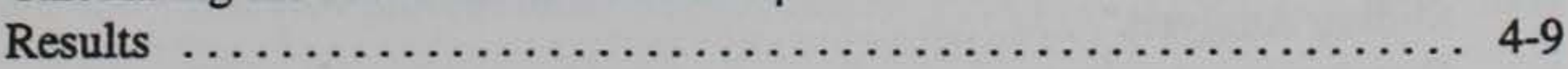


Assigned Strength Parameters $\ldots \ldots \ldots \ldots \ldots \ldots \ldots \ldots \ldots \ldots \ldots$ 4-10

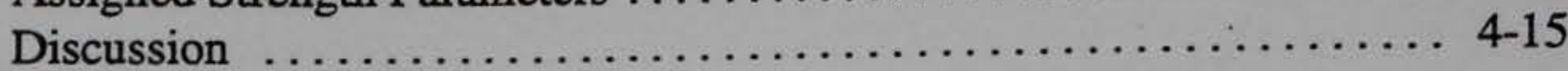

Part V: Development of a Methodology for Sliding Analysis: Locks and

Dam No. 2, Monolith M-16 ....................... 5-1

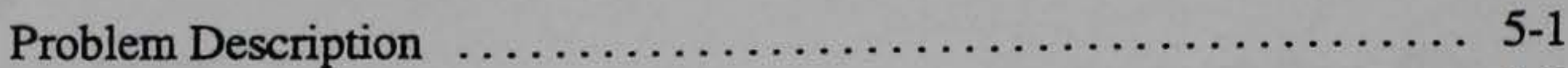

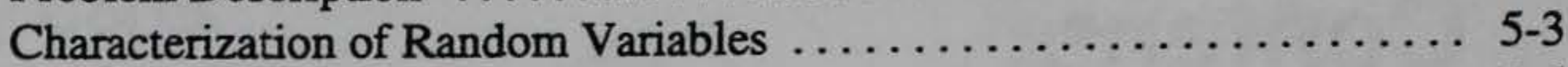

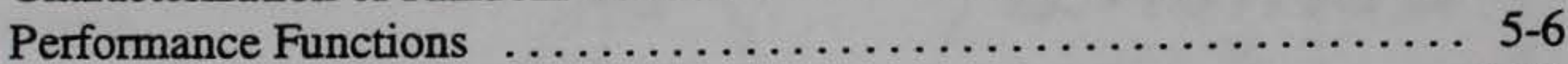

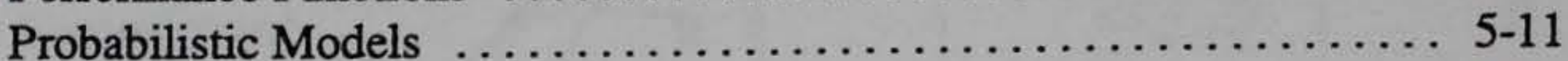

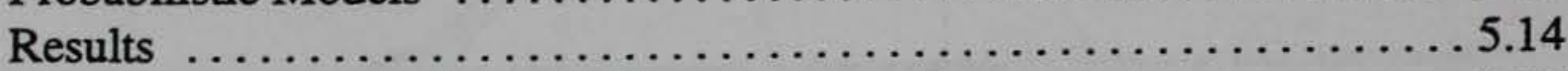

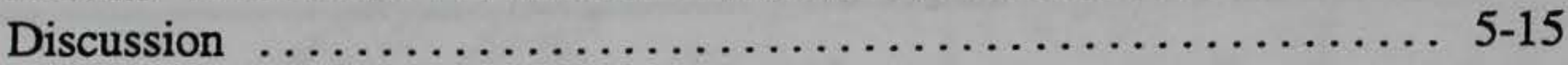

Part VI: Development of a Methodology for Overturning Analysis: Locks and Dam No. 2, Monolith M-16 $\ldots \ldots \ldots \ldots \ldots \ldots \ldots \ldots \ldots \ldots$ 6-1

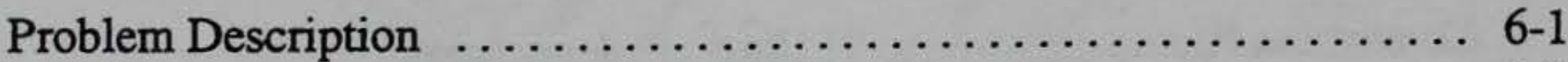

Characterization of Random Variables .................. 6-1

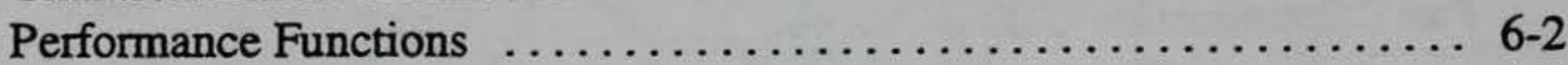

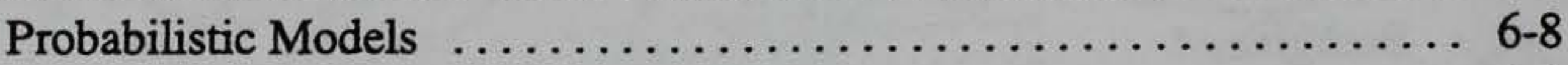

Results .................................. 6-9

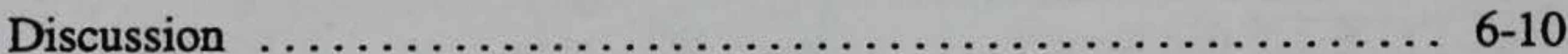

Part VII: Development of a Methodology for Bearing Capacity Analysis:

Locks and Dam No. 2, Monolith M-16 ............... 7-1

Problem Description $\ldots \ldots \ldots \ldots \ldots \ldots \ldots \ldots \ldots \ldots \ldots \ldots \ldots \ldots$ 7-1

Comments on Performance Mode $\ldots \ldots \ldots \ldots \ldots \ldots \ldots \ldots \ldots \ldots$ 7-1

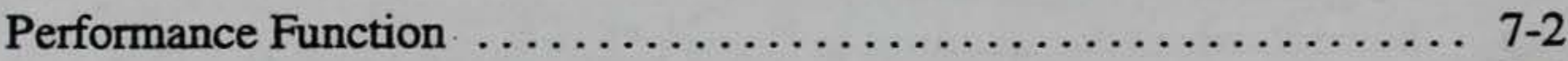

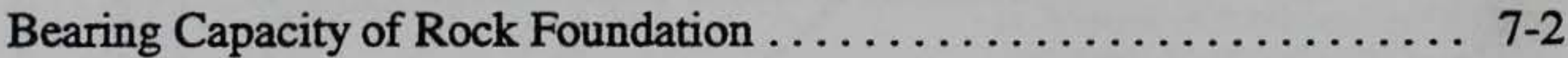

Bearing Capacity of Assumed Sand Foundation . . . . . . . . .

Discussion ............................... 7-6

Part VIII: Characterization of Anchor Reliability For Locks and

Dam No. 3 ............................. 8-1

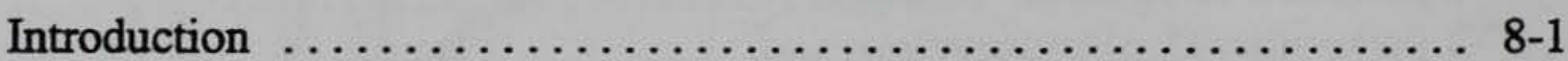

Potential Failure Modes . . . . . . . . . . . . . . . . . . . . 8-2

Uncertainty and Variability of Initial Anchor Load ............ 8-5

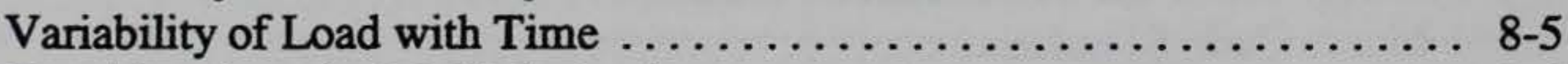

Considerations for Multiple Anchors $\ldots \ldots \ldots \ldots \ldots \ldots \ldots . \ldots .6 .6$

Quantification of Anchor Uncertainty for Locks and Dam No. 3 . . . . . 8 8-6

Part IX: Reliability Analyses for Locks and Dam No. 3, Monolith M-20 . . . 9-1

Problem Description $\ldots \ldots \ldots \ldots \ldots \ldots \ldots \ldots \ldots \ldots \ldots \ldots \ldots . \ldots \ldots$

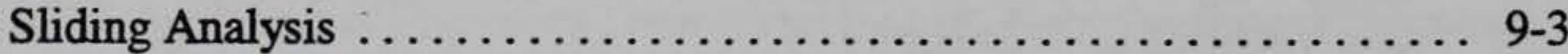

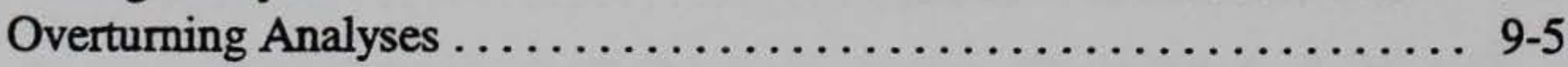

Summary and Discussion $\ldots \ldots \ldots \ldots \ldots \ldots \ldots \ldots \ldots \ldots \ldots . \ldots \ldots$

Part X: Reliability Analyses for Locks and Dam No. 3, Monolith L-8 . . . . 10-1

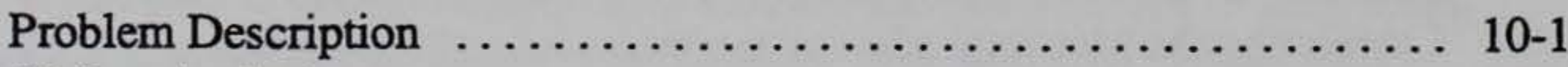

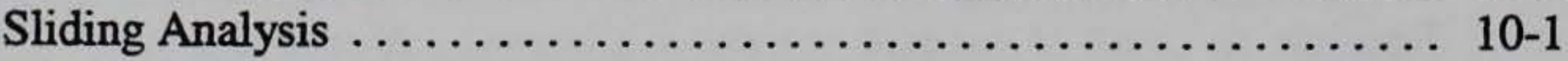

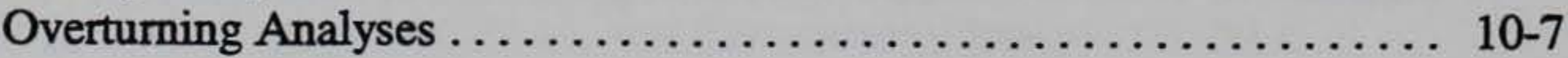


Bearing Capacity Analysis

Summary and Discussion

Part XI: Reliability Analyses for Locks and Dam No. 4, Dam Pier 3 ..... 11-1

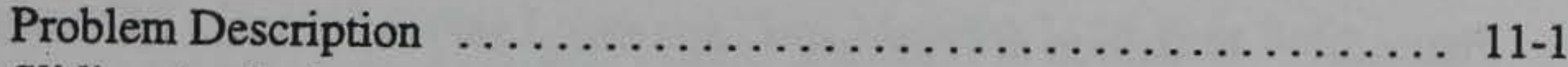

Sliding Analysis $\ldots \ldots \ldots \ldots \ldots \ldots \ldots \ldots \ldots \ldots \ldots \ldots \ldots \ldots \ldots \ldots \ldots, 11-3$

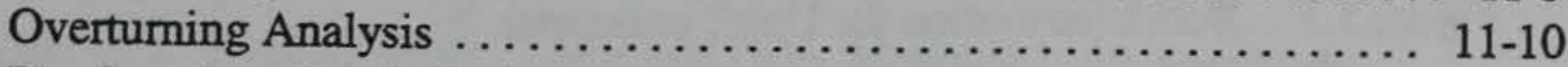

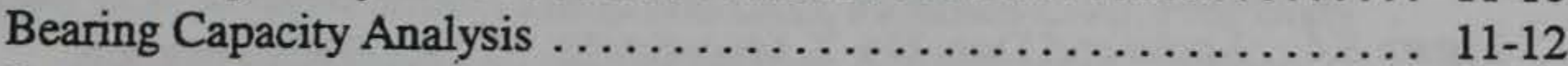

Summary and Discussion $\ldots \ldots \ldots \ldots \ldots \ldots \ldots \ldots \ldots \ldots, 11-12$

Part XII: Reliability Analyses for Gray's Landing, Monolith L-20 . . . . . . 12-1

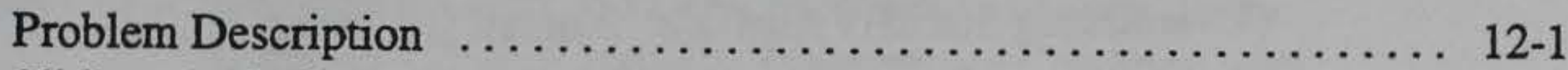

Sliding Analysis $\ldots \ldots \ldots \ldots \ldots \ldots \ldots \ldots \ldots \ldots \ldots \ldots \ldots \ldots \ldots, 12-3$

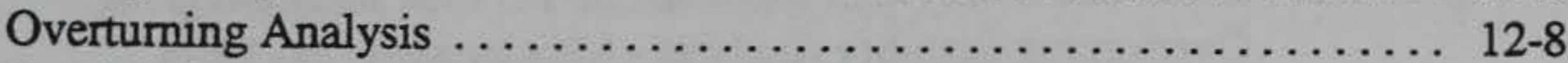

Bearing Capacity Analysis $\ldots \ldots \ldots \ldots \ldots \ldots \ldots \ldots \ldots \ldots \ldots \ldots \ldots \ldots \ldots \ldots, 12-13$

Summary and Discussion $\ldots \ldots \ldots \ldots \ldots \ldots \ldots \ldots \ldots \ldots \ldots \ldots \ldots \ldots \ldots \ldots, 12-15$

Part XIII: Reliability Analyses for Demopolis Locks and Dam,

Monolith L-17 ................................ 13-1

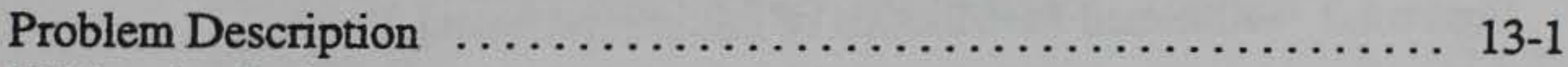

Sliding Analysis $\ldots \ldots \ldots \ldots \ldots \ldots \ldots \ldots \ldots \ldots \ldots \ldots \ldots \ldots \ldots \ldots \ldots, 13-3$

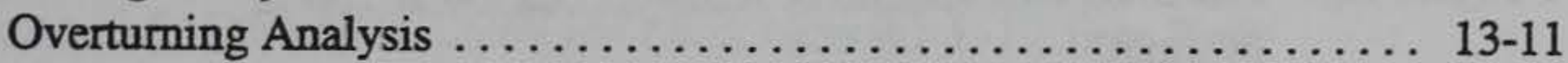

Summary and Discussion $\ldots \ldots \ldots \ldots \ldots \ldots \ldots \ldots \ldots \ldots \ldots \ldots \ldots \ldots \ldots \ldots \ldots, 13-17$

Part XIV: Discussion, Conclusions, and Recommendations .......... 14-1

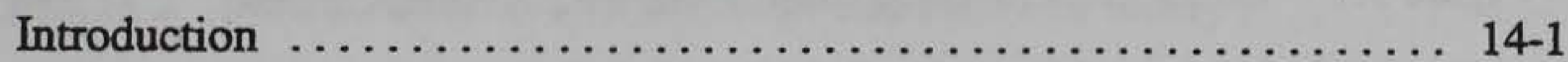

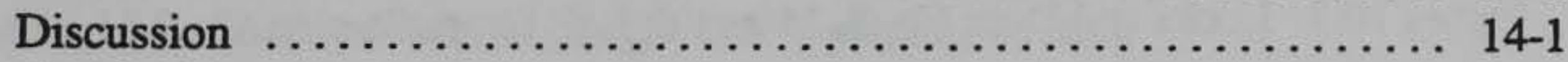

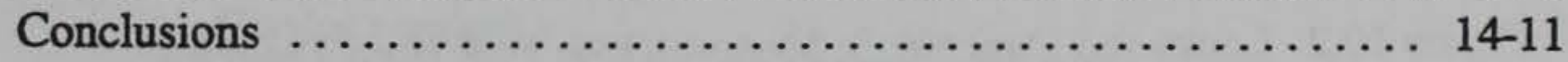

Recommendations $\ldots \ldots \ldots \ldots \ldots \ldots \ldots \ldots \ldots \ldots \ldots \ldots \ldots \ldots \ldots, 14,15$

References

Appendix A: Example Sliding Analysis, Locks and Dam No. 2,

Monolith M-16 . . . . . . . . . . . . . . . . . .

Appendix B: Example Overturning Analysis, Locks and Dam No. 2,

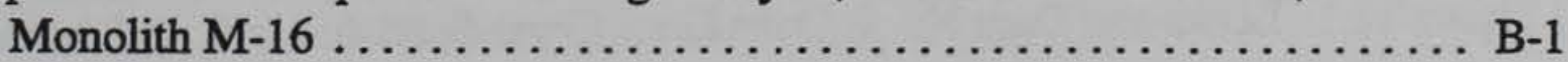

SF 298

\section{List of Figures}

Figure 3.1 The Reliability Analysis Process $\ldots \ldots \ldots \ldots \ldots \ldots \ldots \ldots$ 3-2

Figure 3.2 Some Common Probability Distributions $\ldots \ldots \ldots \ldots \ldots .3-12$

Figure 3.3 Alternative Definitions of the Reliability Index ......... 3-23

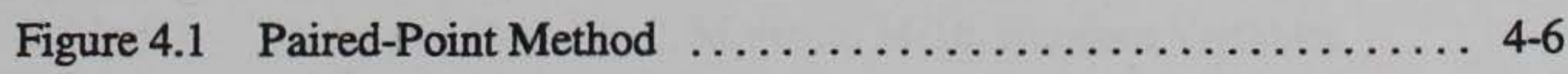

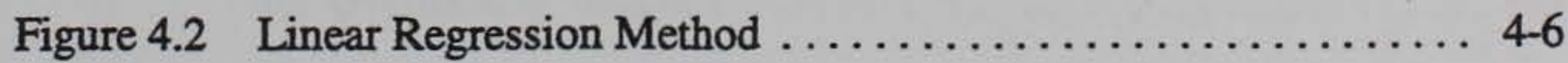


Figure 4.3 Example Regression Analysis for Locks and Dam No. 4,

Group defg

Figure 5.1 Locks and Dam No. 2, Monolith M-16, Cross-Section . . . . . . 5-2

Figure 5.2 Definition of Hydraulic Uplift Force $\ldots \ldots \ldots \ldots \ldots \ldots \ldots .7$

Figure 5.3 Beta Distribution for Uplift parameter, E $\ldots \ldots \ldots \ldots \ldots \ldots$ 5-8

Figure 5.4 Locks and Dam No. 2, Monolith M-16, Free Body Diagram,

Sliding Stability Analysis, Maintenance Condition ........ 5-10

Figure 6.1 Locks and Dam No.2, Monolith M-16, Free Body Diagram,

Overturning Stability Analysis - Normal Operating . ........ 6-3

Figure 6.2 Locks and Dam No.2, Monolith M-16, Free Body Diagram,

Overturning Stability Analysis - Maintenance Condition ...... 6-4

Figure 6.3 Locks and Dam No.2, Monolith M-16, Free Body Diagram,

Overturning Stability Analysis - High Water Condition ...... 6-5

Figure 8.1 Assumed Variation of Expected Anchor Force with Time . . . . 8 8-8

Figure 8.2 Assumed Distribution of Initial Prestressing Force . . . . . . . . 8-8

Figure 8.3 Assumed Distribution of Anchor Location at Top of Monolith ......................... $8-9$

Figure 8.4 Assumed Distribution of Anchor Inclination . . . . . . . . . . 8-9

Figure 9.1 Locks and Dam No. 3, Monolith M-20, Cross-Section ........ 9-2

Figure 10.1 Locks and Dam No. 3, Monolith L-8, Cross-Section . . . . . . 10-2

Figure 10.2 Locks and Dam No. 3, Monolith L-8, Free Body Diagram, Sliding Stability Analysis - Normal operating with Hawser

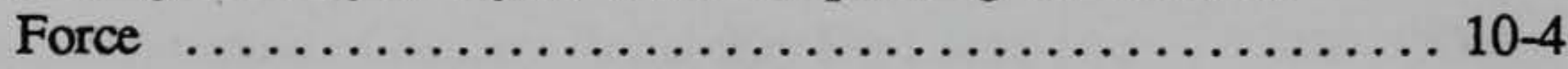

Figure 10.3 Locks and Dam No 3, Monolith L-8, Free Body Diagram, Overturning Stability Analysis - Normal Operating with

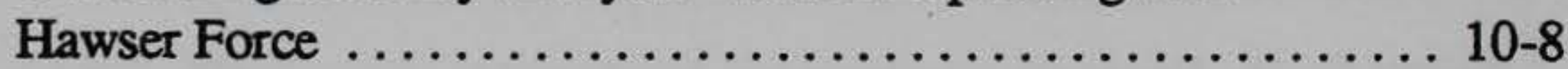

Figure 11.1 Locks and Dam No. 4, Dam Piers, Cross-Section . . . . . . . . . 11-2

Figure 11.2 Locks and Dam No. 4, Dam Piers, Free Body Diagram, Sliding Stability Analysis, Normal Operating with Impact

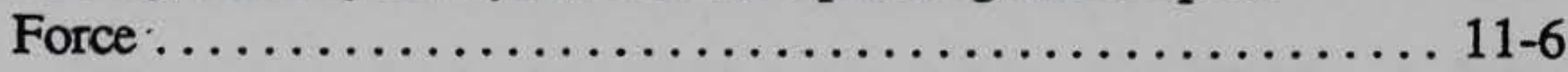

Figure 11.3 Locks and Dam No. 4, Dam Piers, Free Body Diagram, Sliding Stability Analysis, Maintenance Condition . . . . . . 11-7

Figure 11.4 Locks and Dam No. 4, Dam Piers, Free Body Diagram, Overturning stability Analysis, Maintenance Condition ...... 11-10

Figure 12.1 Gray's Landing Locks and Dam, Monolith L-20, Cross-Section 
Figure 12.2 Gray's Landing Locks and Dam, Monolith L-20, Free Body Diagram - Sliding Stability, Normal Operating with Hawser Force

Figure 12.3 Gray's Landing Locks and Dam, Monolith L-20, Free Body Diagram - Sliding Stability, Maintenance Condition

Figure 12.4 Gray's Landing Locks and Dam, Monolith L-20, Free Body Diagram - Overturning Stability, Maintenance Condition ..... 12-11

Figure 13.1 Demopolis Locks and Dam, Monolith L-17, Cross-Section . . . . 13-2

Fiugre 13.2 Demopolis Locks and Dam, Monolith L-17, Free-Body Diagram - Sliding Stability, Maintenance Condition with Backfill ................................. 13-6

Figure 13.3 Demopolis Locks and Dam, Monolith L-17, Free-Body Diagram - Sliding Stability, Maintenance Condition Removing 20' Backfill ........................ 13-6

Figure 13.4 Demopolis Locks and Dam, Monolith L-17, Free-Body Diagram - Overturning Stability, Maintenance Condition with Backfill . . . . . . . . . . . . . . . . . . . . . . . . . 13-13

Figure 13.5 Demopolis Locks and Dam, Monolith L-17, Free-Body Diagram - Overturning Stability, Maintenance Condition Removing 20' Backfill ........................ 13-14

Figure 14.1 Sliding Analysis - Beta vs Expected Factor of Safety ........ 14-3

Figure 14.2 Sliding Analysis - Beta (Point estimate) vs Beta

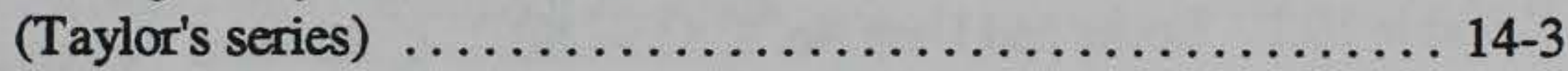

Figure 14.3 Overturning - Beta vs Expected Factor of Safety ......... 14-8

\section{List of Tables}

Table 4.1 Probabilistic Moments for Peak Shear Strength .......... 4-11

Table 4.2 Probabilistic Moments for Residual Shear Strength ......... 4-14

Table 4.3 Selected Shale Strengths $\ldots \ldots \ldots \ldots \ldots \ldots \ldots \ldots \ldots \ldots \ldots \ldots, 4.15$

Table 5.1 Locks and Dam No. 2, Monolith M-16, Random Variables for Sliding Analysis . . . . . . . . . . . 5

Table 5.2 Locks and Dam No. 2, Monolith M-16,Results of Sliding Analyses Using Peak Strengths $\ldots \ldots \ldots \ldots \ldots \ldots \ldots \ldots, 5-16$

Table 5.3 Locks and Dam No. 2, Monolith M-16, Results of Sliding Analyses Using Residual Strengths ................ 5-17

Table 6.1 Locks and Dam No. 2, Monolith M-16, Random Variables for Overturning Analysis $\ldots \ldots \ldots \ldots \ldots \ldots \ldots \ldots \ldots, 6-2$ 
Table 6.2 Locks and Dam No.2, Monolith M-16, Results of

Overturning Analyses - Factor of Safety $\ldots \ldots \ldots \ldots \ldots \ldots \ldots .6 .6$

Table 6.3 Locks and Dam No.2, Monolith M-16, Results of

Overturning Analyses - Resultant Location ............. 6-7

Table 7.1 Locks and Dam No. 2, Monolith M-16, Random Variables

for Bearing Analysis on Rock Foundation ............. 7-3

Table 7.2 Locks and Dam No.2, Monolith M-16, Results of Bearing

Analyses for Rock Foundation ................... 7-5

Table 7.3 L \& D No.3, Man M-16, Results of Bearing Analysis for

Assumed Sand Foundation ..................... 7-5

Table 8.1 Characteristics of Anchors at Locks and Dam No. ......... 8-2

Table 9.1 Locks and Dam No. 3, Monolith M-20, Random Variables

for Sliding Analysis . . . . . . . . . .

Table 9.2 Locks and Dam No. 3, Monolith M-20, Results of Sliding Analyses Using Peak Strengths $\ldots \ldots \ldots \ldots \ldots \ldots \ldots \ldots . .6$ 9-5

Table 9.3 Locks and Dam No. 3, Monolith M-20, Random Variables for Overturning Analysis ...................... 9-6

Table 9.4 Locks and Dam No. 3, Monolith M-20, Results of Overturning Analyses - Factor of Safety $\ldots \ldots \ldots \ldots \ldots \ldots \ldots, 9-8$

Table 9.5 Locks and Dam No. 3, Monolith M-20, Results of Overturning Analyses - Resultant Location ............. 9-9

Table 10.1 Locks and Dam No. 3, Monolith L-8, Random Variables for Sliding Analyses .......................... 10-5

Table 10.2 Locks and Dam No. 3, Monolith L-8, Results of Sliding Analyses Using Peak Strengths . . . . . . . 10.6...........

Table 10.3 Locks and Dam No. 3, Monolith L-8, Results of Sliding Analyses Using Residual Strengths $\ldots \ldots \ldots \ldots \ldots \ldots \ldots \ldots$ 10-6

Table 10.4 Locks and Dam No. 3, Monolith L-8, Random Variables for Overturning Analyses . . . . . . . . . .

Table 10.5 Locks and Dam No. 3, Monolith L-8, Results of Overturning Analyses - Factor of Safety . . . . . . . . . . 10

Table 10.6 Locks and Dam No. 3, Monolith L-8, Results of Overturning Analyses - Resultant Location .

Table 10.7 Locks and Dam No. 3, Monolith L-8, Random Variables for Bearing Analyses $\ldots \ldots \ldots \ldots \ldots \ldots \ldots \ldots \ldots \ldots, 10-11$

Table 10.8 Locks and Dam No. 3, Monolith L-8, Results of Bearing Analyses

Table 11.1 Locks and Dam No. 4, Dam Pier 3, Random Variables for Sliding Analyses ..................... 11-4 
Table 11.2 Locks and Dam No. 4, Dam Pier 3, Results of Sliding

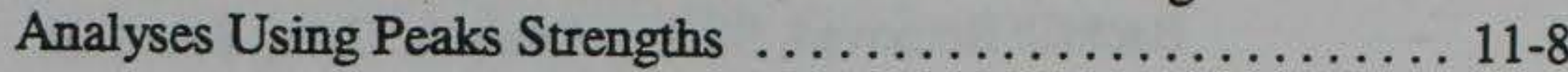

Table 11.3 Locks and Dam No. 4, Dam Pier 3, Results of Sliding Analyses Using Residual Strengths

Table 11.4 Locks and Dam No. 4, Dam Pier 3, Random Variables for Overturning Analysis

Table 11.5 Locks and Dam No. 4, Dam Pier 3, Results of Overturning Analyses - Factor of Safety

Table 11.6 Locks and Dam No. 4, Dam Pier 3, Results of Overturning Analyses - Resultant Location .................... 11-11

Table 11.7 Locks and Dam No. 4, Dam Pier 3, Random Variables for Bearing Analyses . . . . . . . . . . . 11-13

Table 11.8 Locks and Dam No. 4, Dam Pier 3, Results of Bearing Anadyses .............................. 114

Table 12.1 Gray's Landing Locks and Dam, Monolith L-20, Random Variables for Sliding Analysis . . . . . . . . . . . . . . .

Table 12.2 Gray's Landing Locks and Dam, Monolith L-20, Results of Sliding Analyses Using Peak Strengths . . . . . . . . . . 12-8

Table 12.3 Gray's Landing Locks and Dam, Monolith L-20, Results of Sliding Analyses Using Residual Strengths ........... 12-9

Table 12.4 Gray's Landing Locks and Dam, Monolith L-20, Random Variables for Overturning Analyses ............... 12-10

Table 12.5 Gray's Landing Locks and Dam, Monolith L-20, Results of Overturning Analyses - Factor of Safety . . . . . . . 12-12

Table 12.6 Gray's Landing Locks and Dam, Monolith L-20, Results of Overtirning Analyses - Resultant Location . . . . . . . . . 12-13

Table 12.7 Gray's Landing Locks and Dam, Monolith L-20, Random Variables for Bearing Analyses . . . . . . . . . . . 12-14

Table 12.8 Gray's Landing Locks and Dam, Monolith L-20, Results of Bearing Analyses . . . . . . . 12-15

Table 13.1 Demopolis Locks and Dam, Monolith, Random Variables

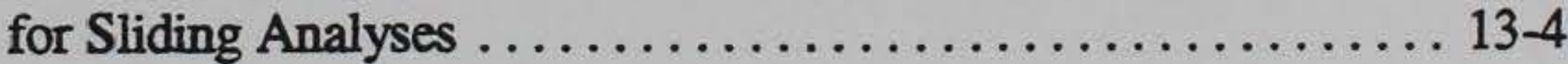

Table 13.2 Demopolis Locks and Dam, Monolith L-17, Before Backfill Removed, Sliding Analysis Using Peak Strengths . . . . . . . . . . . . . . . . . . . . . .

Table 13.3 Demopolis Locks and Dam, Monolith L-17, Before Backfill Removal, Sliding Analysis Using Residual Strengths

Table 13.4 Demopolis Locks and Dam, Monolith L-17, After Backfill Removal, Sliding Analysis Using Peak Strengths ........ 13-10 
Table 13.5 Demopolis Locks and Dam, Monolith L-17, Before Backfill Removed, Sliding Analysis Using Residual

Strengths . . . . . . . . . . . . . . . . .

Table 13.6 Demopolis Locks and Dam, Monolith L-17, Random

Variables for Overturning Analysis

Table 13.7 Demopolis Locks and Dam, Monolith L-17, Results of Overturning Analyses - Factor of Safety $\ldots \ldots \ldots \ldots \ldots \ldots \ldots \ldots \ldots$

Table 13.8 Demopolis Locks and Dam, Monolith L-17, Results of Overturning Analyses - Resultant Location ............ 13-16

Table 14.1 Summary Results of Sliding Analyses . . . . . . . . . . . .

Table 14.2 Summary Results of Overturning Analyses ........... 14-10 


\section{Preface}

The work reported herein was performed at Michigan State University under Contract No. DACW-39-91-C-0041 during the period May through September 1991. Funding was provided by the Condition Analysis and Evaluation work unit at the U.S. Army Engineer Waterways Experiment Station (WES). The principal investigator for the project was Dr. Thomas F. Wolff, Associate Professor, Department of Civil and Environmental Engineering. Much of the methodology development and the majority of supporting analyses were performed by Mr. Weijun Wang, Graduate Research Assistant. Additional analyses were performed by Messrs. William Kussro and Bassem Khafagi and other technical assistance was provided by Dr. Nasrullah Abeer. The technical monitor for the Corps of Engineers was Dr. Mary Ann Leggett, Scientific and Engineering Applications Center (S\&EAC), Computer-Aided Engineering Division (CAED), Information Technology Laboratory (TTL), WES. The work was requested by Mr. Don Dressler of the Engineering Division, Directorate of Civil Works, Headquarters, U.S. Army Corps of Engineers (USACE), and Dr. George Antle of the Institute for Water Resources, Water Resources Support Center, USACE. Helpful guidance and comments were provided by Messrs. Dressler; Reed Mosher, CAED, ITL, WES; Giuseppe G. (Joe) Colett, consultant; and Thruman Gaddie, consultant. The work was performed under the general supervision of Mr. H. Wayne Jones, Chief, S\&EAC, and Dr. N. Radhakrishnan, Director, ITL.

At the time of publication of this report, Director of WES was Dr. Robert W. Whalin. Commander and Deputy Director was COL Leonard G. Hassel, EN.

The contents of this report are not to be used for advertising, publication, or promotional purposes. Citation of trade names does not constitute an official endorsement or approval of the use of such commercial products. 


\section{Conversion Factors, Non-SI to SI Units of Measurement}

Non-SI units of measurements used in this report can be converted to SI units as follows:

\begin{tabular}{||l|l|l||}
\hline Multiply & By & To Obtain \\
\hline \hline degrees (angle) & 0.017455329 & radians \\
\hline feet & 0.3048 & meters \\
\hline inches & 2.54 & centimeters \\
\hline pounds & 4.448222 & newtons \\
\hline kips & 4.448222 & kilonewtons \\
\hline tons & 2.224111 & kilonewtons \\
\hline kips per square foot & 47.880260 & kilopascals \\
\hline ton per square foot & 23.940130 & kilopascals \\
\hline
\end{tabular}




\section{PART I: INTRODUCTION}

\section{Background}

1.1. Many of the locks and dams on the nation's waterway systems are nearing or have exceeded the "design life" envisioned at the time of their construction. Major rehabilitation or replacement projects have been undertaken at several locations; however the system as a whole continues to age and will require continuing expenditures to maintain its serviceability and operational adequacy at current levels. In a recent article in Civil Engineering magazine, Tarricone (1991) noted that navigation locks on the inland waterway system:

"...range in age from less than three to 151 years old. The median age for all chambers is 37 years, but over $40 \%$ are more than 50 years old - the danger zone for design life. Another problem is that locks on any given waterway tend to be from the same era."

The same article notes that funding for major rehabilitation projects comes from both federal appropriations and the Waterway Trust Fund, which receives money from fuel taxes paid by barge operators. Nevertheless, anticipated funds are only sufficient to fund four to six major rehabilitation projects per decade, fewer than the number justified by condition of the structures. Given these circumstances, expenditures for rehabilitation of navigation structures must be prioritized in order to reap the greatest benefits (or avoid the most unsatisfactory consequences) to the waterway system.

1.2. A number of factors must be considered when prioritizing expenditures for rehabilitation. Projects can be ranked on the basis of traffic volume, delay time and system throughput. Likewise, projects can be ranked on structural condition. Prioritization based on traffic considerations is accomplished by Corps planners using the performance monitoring system (PMS) and other tools; the study summarized herein was concerned with the development of techniques suitable for prioritizing investments need based on current and anticipated structural reliability. 


\section{Problem Statement}

1.3. The objective of this research effort was to develop practical methods to quantify the reliability of gravity monolith at navigation structures for various modes of performance. The results obtained from these methods are intended to be sufficiently accurate and consistent to be suitable for use in prioritizing structural rehabilitation investments. The developed methodology is drawn from the engineering reliability literature and adapted to the specific characteristics of navigational structures.

1.4. Traditionally, evaluations of structural adequacy have been expressed by factors of safety. Although the factor of safety may be defined differently for various modes of performance, it can always be expressed as the ratio of some measure of capacity to some measure of demand. Although the factor of safety concept results in safe designs, it has certain shortcomings for comparing the relative reliability of different structures or components for different performance modes. A primary deficiency is that parameters (material properties, strengths, loads, etc.) must be represented by precise values when the appropriate values may in fact be uncertain. Thus, the calculated factor of safety reflects both the condition of the structure as well as the engineer's judgment and degree of conservatism in assigning parameter values.

1.5. The use of precisely-defined single values in analysis is referred to as the deterministic approach. In this report, it is proposed that the use of the probabilistic approach will provide a more consistent basis for ranking structural reliability. The probabilistic approach extends the factor of safety concept to explicitly incorporate uncertainty regarding the parameter values. Uncertainty can be quantified from statistical analysis of data or judgmentally assigned. Even when judgmentally assigned, the results of a probabilistic analysis will be more meaningful than for deterministic analysis because a measure of the certainty of the engineer's judgment is explicitly incorporated. 


\section{Scope of this Report}

1.6. This report includes several major components. Part II provides a brief summary of previous and currently evolving applications of reliability theory, such as the use of reliability analysis to evaluate bridges (a concern similar in some respects to locks and dams) and as the basis for steel design codes. Part III provides a brief review of the mathematical basis of reliability analysis with a view toward practical application to Corps structures. In Parts IV through XIII, detailed summaries are provided of sliding, overturning, and bearing analysis for selected gravity monoliths from a number of locks and dams, primarily on the Lower Monongahela River in Pennsylvania. These problems were selected to illustrate a variety of conditions including new and old structures, anchored monoliths, and various quantities of available data. Finally, in Part XIV, findings are summarized and critically reviewed, conclusions are drawn, and recommendation made for further research. 


\section{PART II: APPLICATIONS OF RELIABILITY-BASED ENGINEERING ANALYSIS}

\section{$\underline{\text { A Brief History }}$}

2.1. The concept of a probabilistic approach to engineering analysis and design dates back to the 1940 's. Freudenthal (1947) noted that uncertainties exist in civil engineering analysis and design and cited uncertainty of loading, imperfection of manufactured products, imperfection of intellectual concept, as well as the imperfection of human observations and actions. Fruedenthal proposed the development of a rational method to evaluate the safety of structures; that is, applying statistical concepts in structural design and analysis. Although these ideas did not see application in practice until about 30 years later, his paper was a landmark in the application of probability theory in civil engineering.

2.2. A second paper by Freudenthal (1956) considered the application of probability theory to load analysis, structural analysis and the definition of failure. The idea of "margin of safety" or safety margin (as the difference between resistance and load) was presented and the distribution of these variables (load and resistance) was considered. A third paper by Freudenthal (1961) emphasized reliability in conjunction with the safety factor. Once again, different probability distributions were considered, such as the normal, lognormal distribution, Weibull, and Frechet distributions. Also, the reliability for a structural system with more than one component was studied.

2.3. In 1966, Freudenthal, Garrelts and Shinozuka (1966) published the final report of the ASCE Task Committee on Factors of Safety, ASCE. The main purpose of this report was try to develop " $a$ widespread interest in the topic and motivate additional engineers to study the problem of developing a rational procedure for determining the factor of safety of structures" and "provide guidance by suggesting and illustrating techniques that may be of considerable value in studying certain phases of the safety (reliability) problem".

2.4. In the 1970's and 1980's a number of important reference books were published emphasizing the application of probabilistic methods to civil engineering analysis and design. Notable among these are works by Benjamin and Cornell (1970), 
Ang and Tang (1975, 1984), and Harr (1987). These works provide extensive discussion of probability theory, distributions, moments, functions of random variables and related topics in a civil engineering framework and should be consulted for a more complete treatment of the material summarized in Part III.

\section{Application in Structural Design Codes}

2.5. The recently implemented Load and Resistance Factor Design (LRFD) method for structural steel design has its basis in reliability theory and is summarized in a number of papers by Galambos, Ellingwood and their colleagues. (e.g., Ellingwood, et al., 1980). In the LRFD method, various loads on structures and the resistance of structural members are factored separately in order to obtain a design. The magnitude of these factors depends on the degree of uncertainty and is different for dead loads and various types of live loads. Although the procedure can be implemented by merely using tabulated loads and resistance factors, the result is to design structural components for a consistent reliability index even where the ratio of dead loads to live loads may differ.

\section{Application in Bridge Evaluation}

\subsection{Concerns with prioritizing rehabilitation or replacement of highway bridges} are similar to the concerns with navigation structures; needs exceed available funds and a consistent basis of prioritization is desired. A number of studies have been directed toward the use of probabilistic methods to prioritize the maintenance and rehabilitation of bridges. One such study, performed for the National Cooperative Highway Research Program by Moses and Verma (1987) provides a comprehensive example of the methodology coming into practice. Similar to LRFD design method and the method proposed herein, the basis of the techniques is the concept that load and resistance are random variables and that reliability can be measured in term of the reliability index (defined and discussed in paragraph 3.33 of this report). The report by Moses and Verma describes how the procedure was "calibrated" by determining the reliability index values associated 
with existing structures, how these were used to develop recommended "target" values, and how load and resistance factors were set to provide consistent reliability values.

\section{Some Previous Applications to Corps of Engineer's Projects}

2.7. Several previous studies have used probabilistic methods to evaluate Corps of Engineers' structures. For the most part, these have been directed at very specific structures and concerns and hence were not performed with the intent of developing general methods for prioritizing repair and rehabilitation of different structures. Some of these previous studies are summarized in the following paragraphs.

2.8. Woodward Clyde Consultants (1981), investigated the reliability of several geotechnical components of Clarence Cannon Dam in the northeast Missouri for the St. Louis District. These components included a shale-founded concrete monolith, a section of the earth embankment, a rockfill end-cone section, and seepage conditions in the abutment. Results were expressed as probabilities of failure and probabilities of not meeting certain performance criteria. Calculated probabilities of failure were typically less than $10^{-9}$, indicating a high reliability.

2.9. Wolff (1985) and Wolff and Harr (1987), applied probabilistic methods to slope stability analysis of earth dams. Extensive example analyses were performed for Clarence Cannon Dam. It was shown that the probability of failure may vary by many orders of magnitude for various loading conditions such as end-of-construction, steady seepage, partial pool, etc., even though factors of safety may be similar. The differences in the probability of failure were attributed to different levels of uncertainty inherent in the strength representations (i.e., drained or undrained) used for various cases.

2.10. Wolff $(1985,1991)$ assessed changes in factor of safety and probability of failure following the repair of an earth slide failure using a rock berm at Shelbyville Dam in central Illinois. It was demonstrated that minor increases in factor of safety may in some cases equate to a reduction in the probability of failure by several orders of magnitude.

2.11. Wolff, et. al., (1988) reported on a probabilistic analysis of the likelihood of 
pool release due to earthquake-induced foundation liquefaction at Wappapello Dam in southeastern Missouri near the New Madrid seismic zone. The dam is a flood control dam for which the pool is often as much as $59 \mathrm{ft}$ below the spillway. It was shown that the probability of the joint occurrence of an earthquake-induced embankment failure and a sufficiently-high pool to overtop the remnant embankment was several orders of magnitude lower than the probability of occurrence of the individual component events. Based on the low joint probability of pool release, no remedial action was undertaken by the St. Louis District.

2.12. McCann and Boissonade (1987) prepared a relatively comprehensive reliability analysis for Emsworth Lock and Dam on the Ohio River in the Pittsburgh District. The focus of the study was the assessment of the frequency of lock closure and probability of loss of pool on an annual basis. This in turn was developed from probabilistic assessment of individual components and events. The reliability of gravity structures was expressed by probability of failure values. However, the characterization of the underlying random variables was very judgmental.

2.13. A current research effort within the Corps of Engineers is the development of Load and Resistance Factor Design (LRFD) criteria for hydraulic structures. This effort is aimed at developing a design method similar to the AISC LRFD design code, but with load and resistance factors specifically chosen to meet the unique characteristics for structures such as miter gates, tainter gates, etc. 


\section{PART III: BASIC PRINCIPLES}

\section{Basis of Reliability Analysis}

3.1. Random Variables. In the probabilistic approach to analysis and design, loads, material properties and parameters are taken as random variables. Instead being assigned precise single values, random variables assume a range of values in accordance with a probability density function or probability distribution. Although the value of a random variable is uncertain, the probability density function quantifies the likelihood that its value lies in any given interval. Figure 3.1(a) illustrates some probability density functions for random variables such as $\phi_{\text {soil, }}^{\prime} \tan \phi_{\text {base, }}^{\prime}$, and $\gamma_{\text {concrete }}$ that may occur in a sliding analysis. As illustrated in figure 3.1 (b), when parameters are defined as random variables, functions of these parameters are also random variables and can be represented as probability density functions. In the case of sliding the capacity, C, (or shear resistance), may be a function of several random variables including $\tan \phi_{\text {base }}$ and $\gamma_{\text {concrete- }}$ The net force causing shear or demand, D, may be a function of several random variables including $\phi_{\text {soil }}^{\prime}$ and $\gamma_{\text {soil }}$.

\subsection{Probability of Failure, Limit State, and Safety Margin. In its basic develop-} ment, engineering reliability analysis seeks to find the probability of failure, $\operatorname{Pr}(\mathrm{f})$, defined as the probability that the value of some function characterizing the performance of the system (the performance function) exceeds some limit state. The reliability, $\mathrm{R}$, is the probability that the limit state will not be achieved or crossed. As the system must either be reliable or must fail, the reliability and probability of failure sum to unity; thus:

$$
R=1-\operatorname{Pr}(f) \text {. }
$$

The limit state for sliding of a monolith could be taken as the event that the forces resisting sliding equal the forces causing sliding. The probability of failure would be then be the probability that the sum of the forces causing sliding exceed the sum of the forces 


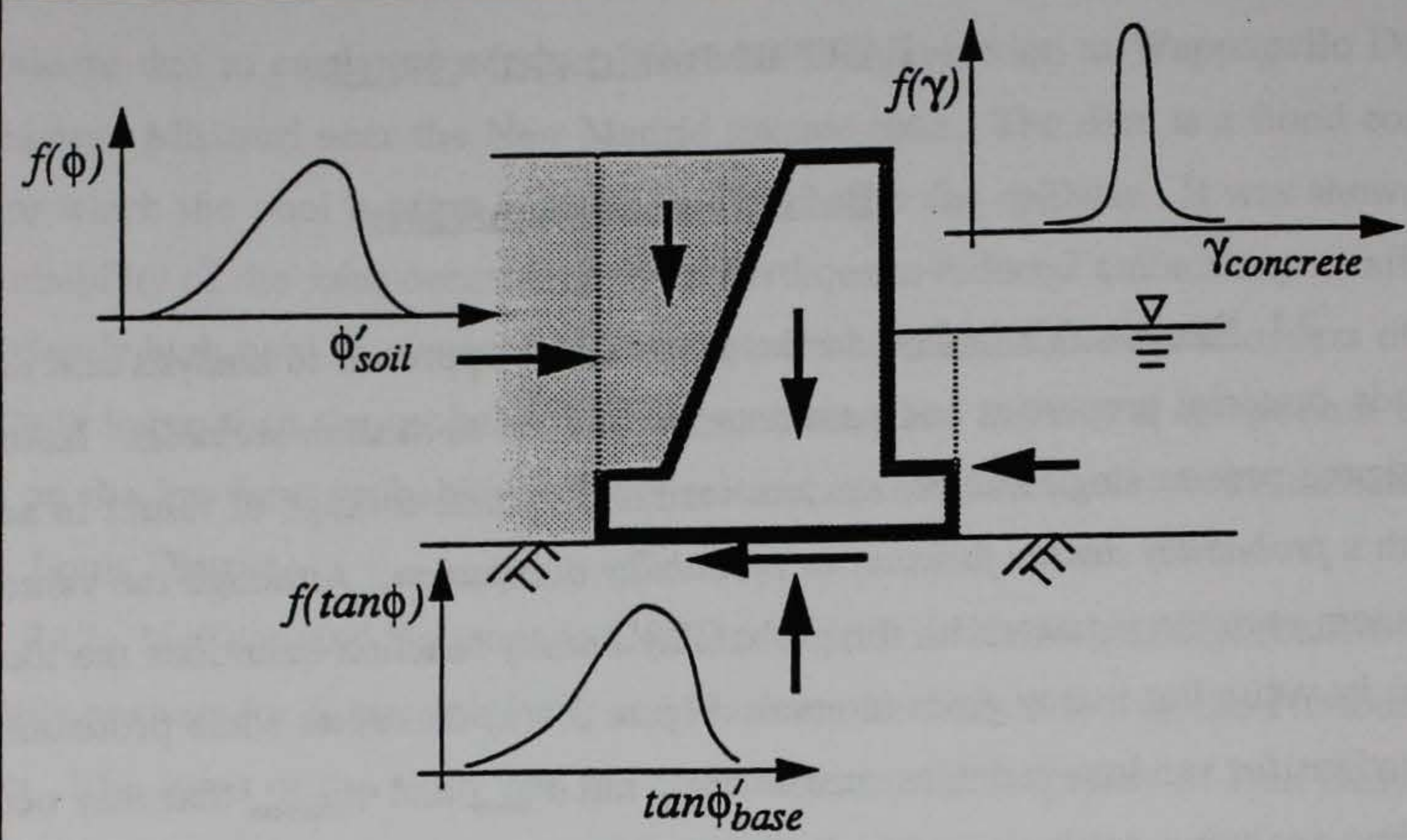

(a) Random Variables

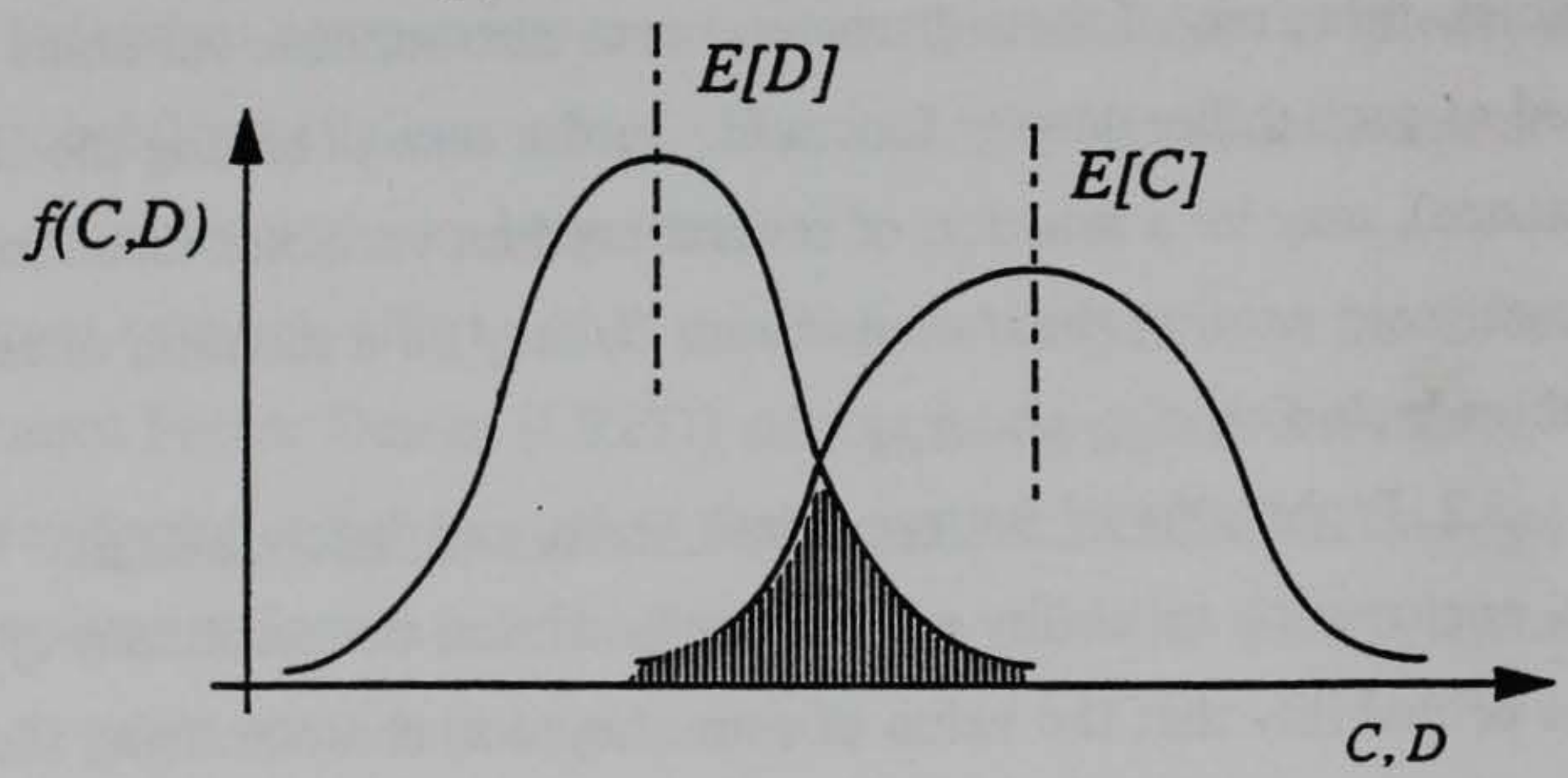

(b) Capacity and Demand Distribution

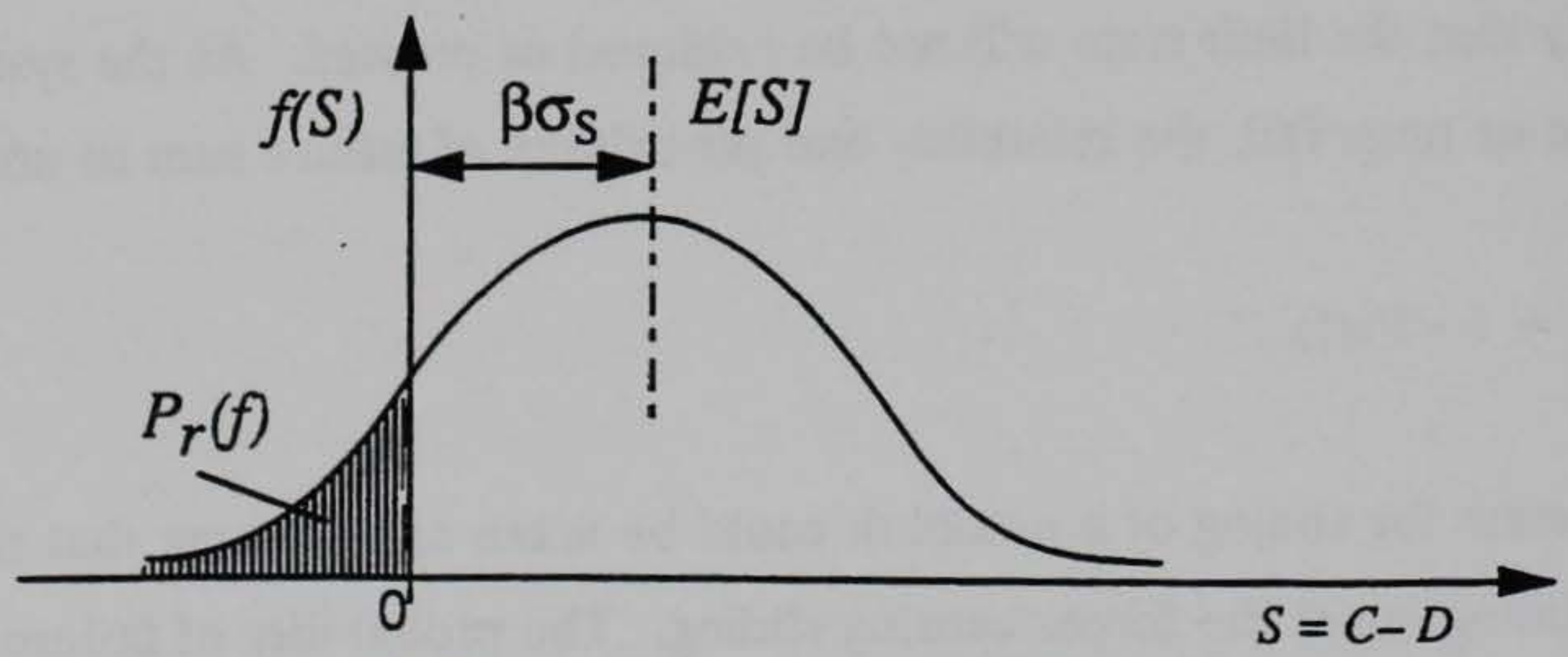

(c) Safety Margin and Reliability Index

Figure 3.1 The Reliability Analysis Process 
resisting sliding. Generalizing these two sets of forces as capacity and demand, C and D, a new random variable, the safety margin $\mathrm{S}$, can be defined as the difference between the capacity and demand, or between resistance and load. The probability of failure would then be:

$$
\operatorname{Pr}(\mathrm{f})=\operatorname{Pr}(\mathrm{S}<0)=\operatorname{Pr}[(\mathrm{C}-\mathrm{D})<0]
$$

As shown in figure $3.1(\mathrm{c})$, the probability of failure is the area of the probability density function for the safety margin where $S<0$.

3.3. Reliability Index. The reliability index is an alternative quantification of reliability commonly preferred over the probability of failure. The exact shape of the density functions for capacity and demand are usually not known. Even if known, the mathematics required to obtain the exact density function for the safety margin can be extremely complex. Thus, the results of probabilistic analyses are commonly expressed as a reliability index, denoted as $\beta$ (beta). As shown in figure 3.1 (c), in its simplest form the reliability index is a measure of how much the expected value (average value) of the safety margin exceeds the limit state, measured in standard deviations of the safety margin. A $\beta$ value of 3.0 implies that the expected condition or expected value of the performance function lies three standard deviations from the limit state. Expressing reliability in terms of the reliability index rather than an actual probability value is preferred for several reasons:

1. The reliability index can be calculated without knowing the actual distributions of the random variables; using the first-order second-moment (FOSM) approach, only the means, standard deviations and correlation coefficients of the random variables are réquired.

2. The physical significance of the "probability of failure" is difficult Hx comprehend for unique structures and components. For recurring events and replicate components (such as failure of mechanical parts or electric power), the probability of failure has a measurable frequency basis; this is not the case for rare or nonrecurring events and unique components such as sliding of a gravity monolith. 
3. In the context of this study, navigation structures operated by the Corps of Engineers are not expected to fail due to foreseeable rare events for which observations and analyses can be made; inevitably some remedial action will be undertaken before the reliability drops below some tolerable value.

Accordingly, the methods developed are directed toward the calculation of a reliability index, $\beta$. However, as will be discussed in section 3.34 , an alternative definition of the reliability index based on the lognormal distribution will be used, and still other definitions exist. The lognormal definition is consistent with recent trends in structural engineering.

3.4. Accuracy of Calculated Reliability Indices. The methods developed herein for obtaining a reliability index are intended to be sufficiently accurate for ranking the relative reliability of various navigation structures and components; they should not be used to make direct comparisons with other published values such as those for a bridge or building member. Undoubtedly, more experience analyzing navigation structures will lead to refinement of these techniques. Nevertheless, navigation structures, components and performance modes with higher reliability indices should be considered more reliable than those with lower indices.

\section{Steps in an Analysis}

3.5. Reliability analysis for a typical mode of performance (e.g. sliding) includes the following steps:

(1) The variables to be taken as random variables are identified and characterized by statistical parameters or moments such as their means, standard deviations, and correlation coefficients.

(2) A performance function and limit state are identified for the mode of performance being assessed. For example, the performance function for sliding could be taken as the ratio of resistance to drive (the factor of safety); in this case the limit state would be a value of one.

(3) The mean and standard deviation of the performance function are calculated. In concept, this involves integrating the performance function over the probability 
density functions of the random variables. In practice, approximate values are calculated using the mean, standard deviation, and correlation coefficients of the random variables.

(4) The reliability index, $\beta$, is calculated as a function of the mean and standard deviation of the performance function.

These steps and the related mathematics are described in the following sections.

\section{Selection of Random Variables}

3.6. In concept, virtually every variable in an analysis is random as most properties and parameters have some inherent variability and uncertainty. However, the uncertainty associated with a few random variables will usually dominate the analysis. As the number of required calculations increases with the number of random variables, including insignificant random variables may unnecessarily complicate calculations without a significant effect on the results. When in doubt, a few analyses with the additional random variables will quickly illustrate which random variables are significant. For reliability analysis of navigation structures, significant random variables typically include material strengths and the magnitudes and locations of loads. Material properties such as concrete and soil density may be significant, but where strength and density both appear in an analysis, strength may dominate. An example of a variable that can be represented deterministically (non-random) is the density of water; variables such as structure geometry can usually be taken as deterministic. To quantify random variables for use in analysis, one must calculate or estimate their expected value (mean) and standard deviation. For random variables which are not independent of each other, but tend to vary together, correlation coefficients must also be assigned.

\section{Moments of Random Variables}

3.7. Although random variables are in fact functions, probabilistic moments provide a convenient means to quantify them. Probabilistic moments are explained in 
detail in numerous probability and statistics texts (e.g., Benjamin and Cornell, 1970, Harr, 1987). Their definitions are summarized below for convenience.

3.8. Mean. The mean value, $\mu_{x}$ of a set of measured values for the random variable $\mathrm{X}$ is:

$$
\mu_{X}=\frac{\Sigma X_{i}}{N}
$$

where $\mathrm{N}$ is the number of measurements or values for $\mathrm{X}$. The mean is the same as the arithmetic average.

3.9. Expected Value. The expected value, $\mathrm{E}[\mathrm{X}]$, of a random variable is the mean value one would obtain if all possible values of the random variable were considered. Where a mean can be calculated, the mean provides an unbiased estimate of the expected value and they are numerically the same. Thus,

$$
E[X]=\mu_{X}=\int X f(X) d x=\Sigma X_{i} p\left(X_{i}\right)
$$

where $f(X)$ is the probability density function of $X$ and $p\left(X_{i}\right)$ is the probability of the value $X_{i}$. The integral representation holds for both continuous and discrete random variables; the summation form is equivalent for discrete random variables. Although numerically equivalent, the expected value has a broader definition than the mean; if data are not available, an expected value can be assigned based on judgment and experience from similar problems. In probability theory, the mean or expected value is termed the first moment with respect to the origin; it corresponds to the centroid of a probability density function or distribution and is analogous to the centriod of a section in mechanics.

3.10. Variance. The variance, $\operatorname{Var}[\mathrm{X}]$, of a set of measurements of the random variable $\mathrm{X}$ is obtained by finding the expected value of the square of the differences between the data values and the mean: 


$$
\operatorname{Var}[X]=E\left[\left(X-\mu_{X}\right)^{2}\right]=\int\left(X-\mu_{X}\right)^{2} f(X) d X=\frac{\sum\left[\left(X_{i}-\mu_{X}\right)^{2}\right]}{N}
$$

The summation form above involving the $\mathrm{X}_{\mathrm{i}}$ term provides the variance of a sample or population containing exactly $\mathrm{N}$ elements. Usually, a sample of size $\mathrm{N}$ is used to obtain an estimate of the variance of the associated random variable which represents an entire (infinite) population. To obtain an unbiased estimate, the $\mathrm{N}$ is replaced by $\mathrm{N}-1$ :

$$
\operatorname{Var}[X]=\frac{\sum\left[\left(X_{i}-\mu_{X}\right)^{2}\right]}{N-1}
$$

The above equation has two important implications: the unbiased estimate of the variance of a population is always greater than the variance of a sample drawn from that population and the difference between the two variables decreases with increasing sample size. The variance is termed the second central moment; second because of the exponent " 2 " and central because differences are measured from the mean rather than the origin. The variance in probability theory is analogous to the central moment of inertia in mechanics.

3.11. Standard Deviation. To express the scatter of a random variable in the same units as the random variable itself, the standard deviation is taken as the square root of the variance; thus:

$$
\sigma_{x}=\sqrt{\operatorname{Var}[X]}
$$

The standard deviation in probability theory is analogous to the radius of gyration in mechanics.

3.12. Coefficient of Variation. To provide a convenient dimensionless expression of the uncertainty inherent in a random variable the standard deviation is divided by the expected value to obtain the coefficient of variation, usually expressed as a percent:

$$
V_{X}=\frac{\sigma_{X}}{E[X]} \times 100 \%
$$

The expected value, standard deviation and coefficient of variation are interdependent: 
knowing any two, the third is known. In civil engineering reliability applications where insufficient data are available to accurately calculate moments, the coefficient of variation is often estimated as a convenient round number based on experience from other published data or similar problems.

3.13. Covariance and Correlation Coefficient. Pairs of random variables may be correlated or independent; if correlated, the likelihood of a certain value of the random variable $\mathrm{Y}$ depends on the value of the random variable $\mathrm{X}$. For example, the strength of sand may be correlated with density or the lower pool level at a dam may be correlated with the upper pool level. The covariance is analogous to the variance but measures the combined effect of how two variables vary together:

$$
\begin{gathered}
\operatorname{Cov}[X, Y]=E\left[\left(X-\mu_{X}\right)\left(Y-\mu_{Y}\right)\right] \\
\operatorname{Cov}[X, Y]=\iint\left(X-\mu_{X}\right)\left(Y-\mu_{Y}\right) f(X, Y) d Y d X \\
\operatorname{Cov}[X, Y]=\frac{1}{N} \sum\left(X_{i}-\mu_{X}\right)\left(Y_{i}-\mu_{Y}\right)
\end{gathered}
$$

In the above equations, $f(X, Y)$ is the joint probability density function of the random variables $\mathrm{X}$ and $\mathrm{Y}$. To provide a non-dimensional measure of the degree of correlation between $\mathrm{X}$ and $\mathrm{Y}$, the correlation coefficient, $\rho_{\mathrm{X}, \mathrm{Y}}$, is obtained by dividing the covariance by the product of the standard deviations:

$$
\rho_{X, Y}=\frac{\operatorname{Cov}[X, Y]}{\sigma_{X} \sigma_{Y}}
$$

The correlation coefficient may assume values from -1.0 to +1.0 . A value of 1.0 or -1.0 indicates there is perfect linear correlation; given a value of $\mathrm{X}$, the value of $\mathrm{Y}$ is known and hence is not random. A value of zero indicates no linear correlation between 
variables. A positive value indicates the variables increase and decrease together; a negative value indicates that one variable decreases as the other increases. Pairs of independent random variables have zero correlation coefficients.

3.14. Higher moments. The third central moment is the expected value of the cubes of the differences between measured values and the mean value. When divided by the standard deviation raised to the three-halves power, the result is the coefficient of skewness, a measure of the asymmetry of a probability density function. For symmetrical density functions, the skewness coefficient is zero. The fourth central moment and associated coefficient of kurtosis provide a measure of the peakedness or flatness of a probability density function. The techniques developed in this report for reliability analysis of navigation structures depend only on the first two moments and assume that the values of higher moments have negligible effects on the results.

\section{Probability Density Functions}

3.15. Definitions. The terms probability distribution, probability density function, $p d f$, or the notation $\mathrm{f}_{\mathbf{X}}(\mathrm{X})$ refer to a function that defines a random variable. Usually, the term probability distribution refers to discrete random variables and the term probability density function refers to continuous random variables. The probability density function is constructed such that for any $\mathrm{X}$, its value is proportional to the likelihood of $\mathrm{X}$. The area under the pdf is unity. The probability that the random variable $X$ lies between two values $X_{1}$ and $X_{2}$ is the integral of the probability density function taken between the two values. Hence:

$$
P I\left(X_{1}<X<X_{2}\right)=\int_{X_{1}}^{X_{2}} f_{X}(X) d X
$$

The cumulative distribution function, $C D F$, or $\mathrm{F}_{\mathrm{X}}(\mathrm{X})$ measures the integral of the probability density function over its entire range. Its value for any $\mathrm{X}$ is the integral of the pdf from minus infinity to $X$ : 


$$
F_{X}(X)=\int_{-\infty}^{X} f_{X}(X) d x
$$

Thus for any value $\mathrm{X}, \mathrm{F}_{\mathrm{X}}(\mathrm{X})$ is the probability that the random variable $\mathrm{X}$ is less than the given $\mathrm{x}$.

3.16. Application in Analysis. Although probabilistic analyses methods used herein require only the mean and standard deviation of random variables and their correlation coefficients, an understanding of the properties of a few common density functions and their related moments is useful for several reasons:

1. Plotting an assumed probability density function proviHxs a clear means to visualize the variability of the random variable.

2. Values of the cumulative distribution function provide a convenient means to check the reasonableness of estimated moments.

3. An engineer inexperienced in probability analysis may be better able to identify points on the cumulative distribution (e.g. he or she may be able to define a minimum or maximum value with 90 percent confidence) or to visually assess whether the shape of a distribution is reasonable, than to directly estimate probabilistic moments.

Considering the above, a suggested method to assign or check assumed moments for random variables is to:

1. Assume trial moments and/or limits and assume a standard form for the probability density function,

2. Plot the resulting density function and tabulate the resulting cumulative distribution function,

3. Assess the reasonableness of the shape of the pdf and the values of the CDF, and

4. Repeat steps 1 through 3 with successively improved trial moments and/or limits until the moments reflect an appropriate pdf and CDF. 
Plotting and tabulating commonly-used density functions and cumulative distribution functions is easily performed with small microcomputer programs or spreadsheet templates.

3.17. Common Distributions Certain probability density functions are favored because they are easily calculated, extensively tabulated, or have some basis in probability theory. The following paragraphs provide a brief discussion of several of these distributions, which are illustrated in figures 3.2.

3.18. Uniform Distribution. The uniform distribution (Figure 3.2.a) assumes that the random variable assumes values from a lower limit, a, to an upper limit, b, and all values are equally likely. The pdf can be expressed as:

$$
f_{X}(X)=\frac{1}{b-a}
$$

The uniform distribution can be shown to be the least biased choice for the case where the only information known about a random variable are its upper and lower limit. The expected value of the uniform distribution is:

$$
E[X]=\frac{a+b}{2}
$$

and the standard deviation is:

$$
\sigma_{x}=\frac{(b-a)}{\sqrt{12}}
$$

3.19. Triangular Distributions. The triangular distribution implies (Figure 3.2.b) that a random variable has upper and lower and upper limits $\mathrm{a}$ and $\mathrm{b}$ and that the likelihood of a given value increases linearly with distance from one or both limits. The triangular distribution can be shown to be the least biased distribution where one knows only the minimum, maximum, and most likely value of a variable. For a symmetric triangular distribution, the expected value is : 


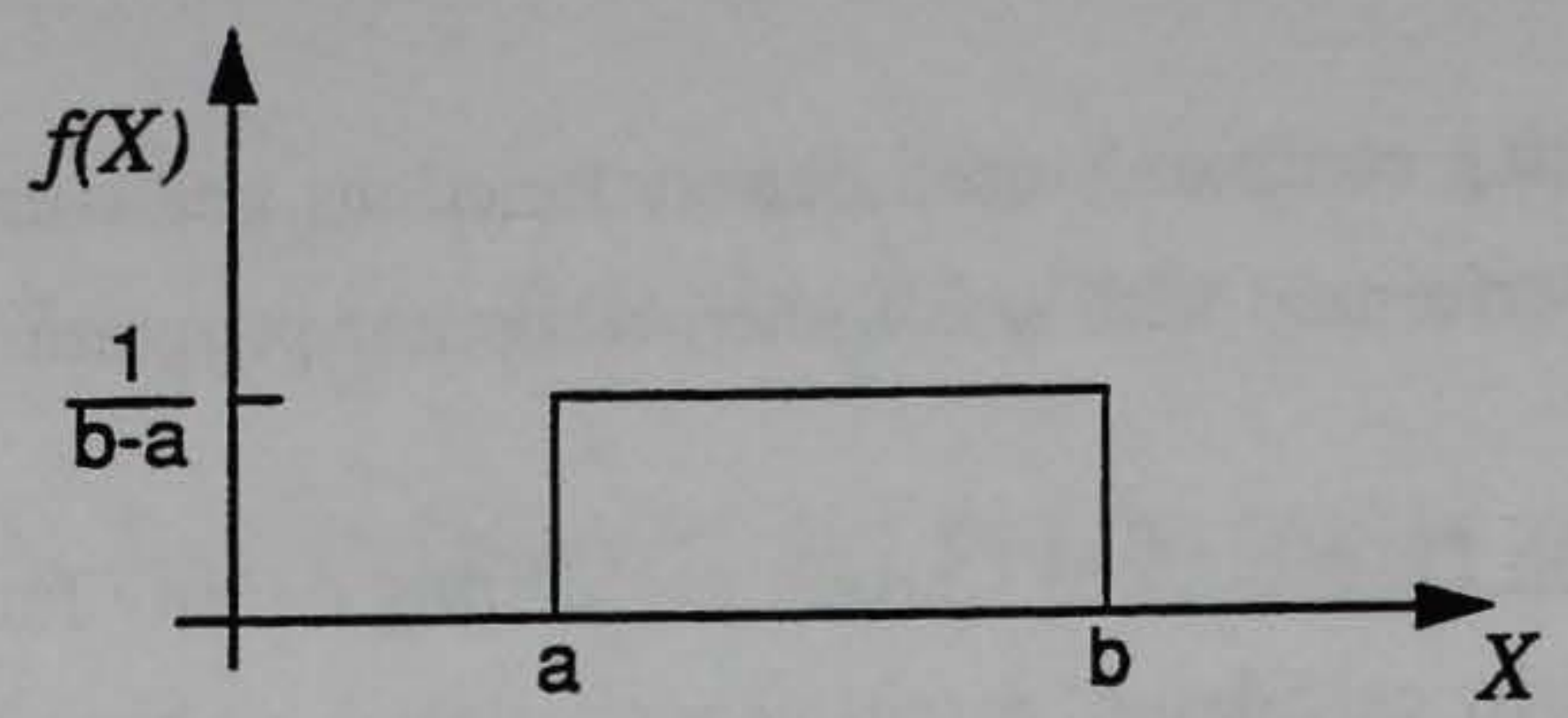

(a) Uniform Distribution
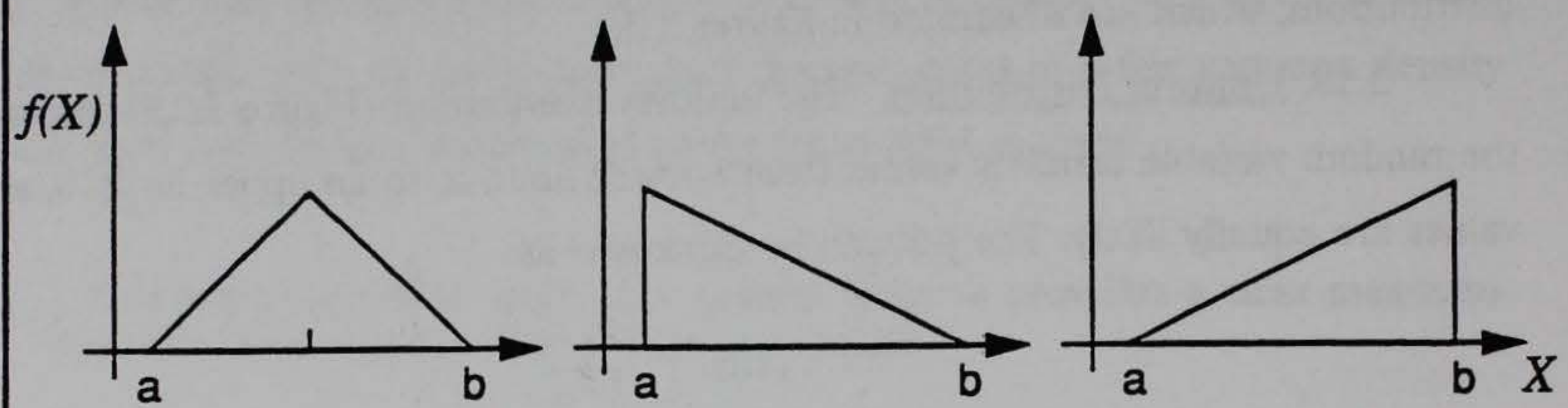

(b) Some Triangular Distributions

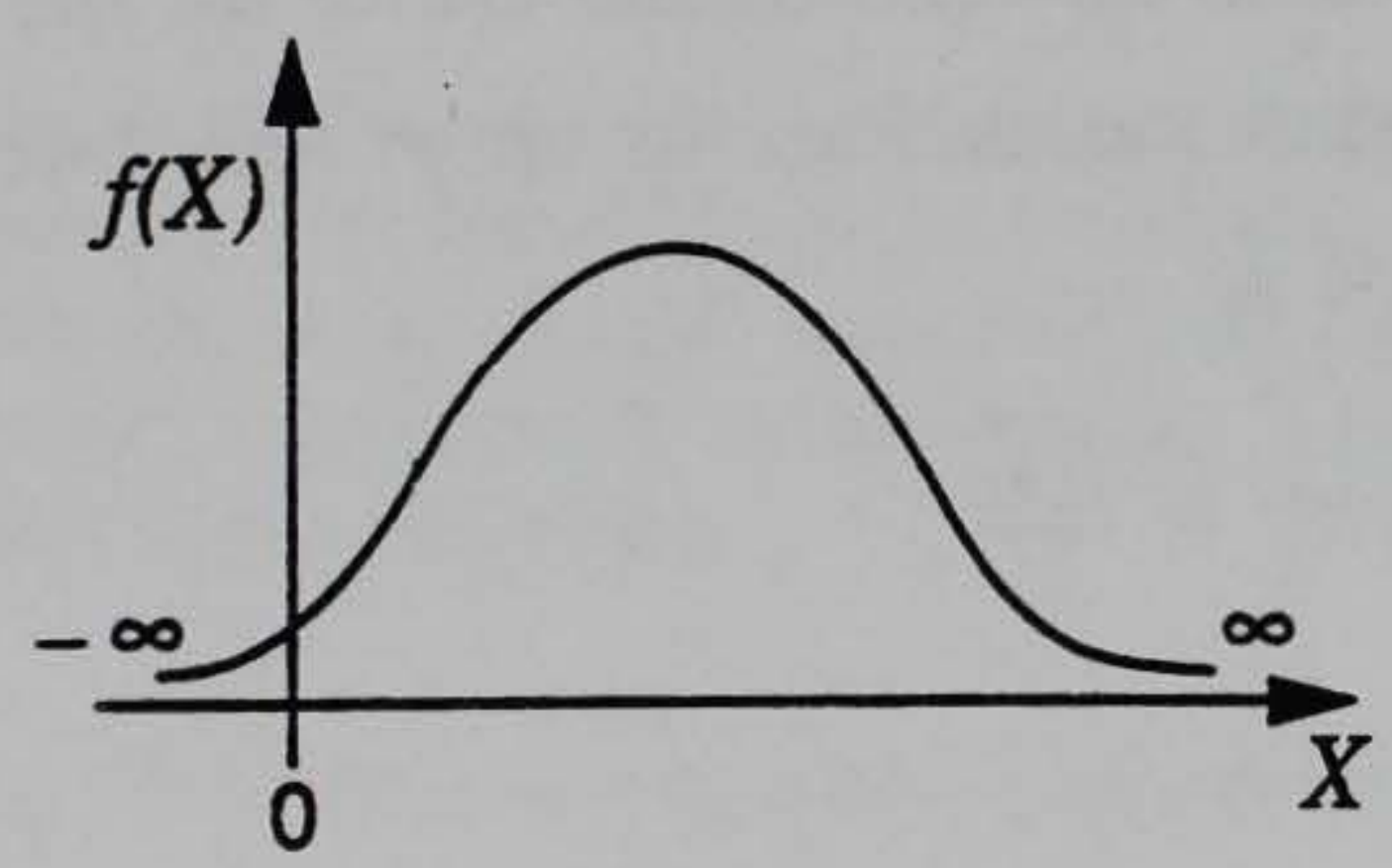

(c) Normal Distribution

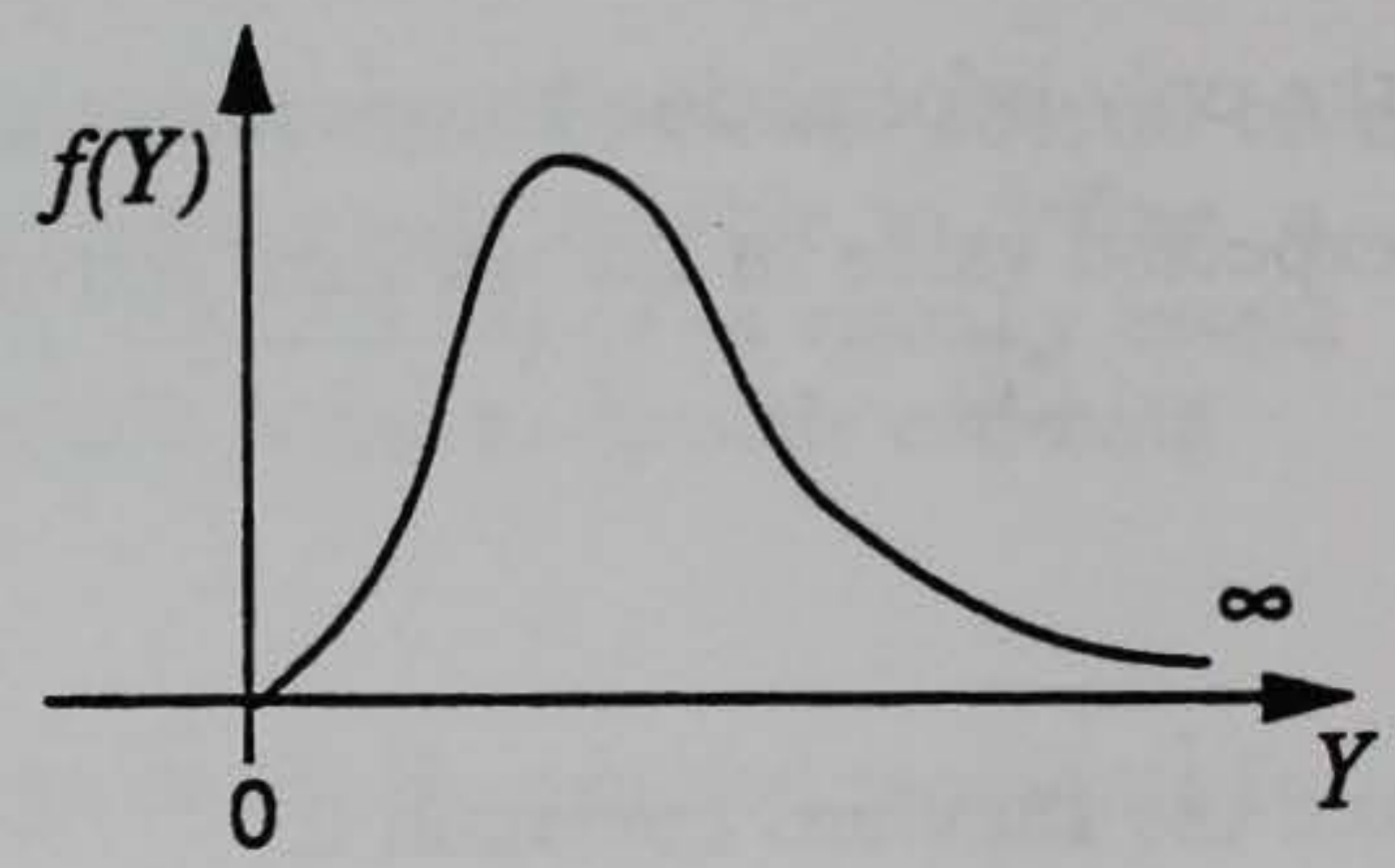

(d) Lognormal Distribution
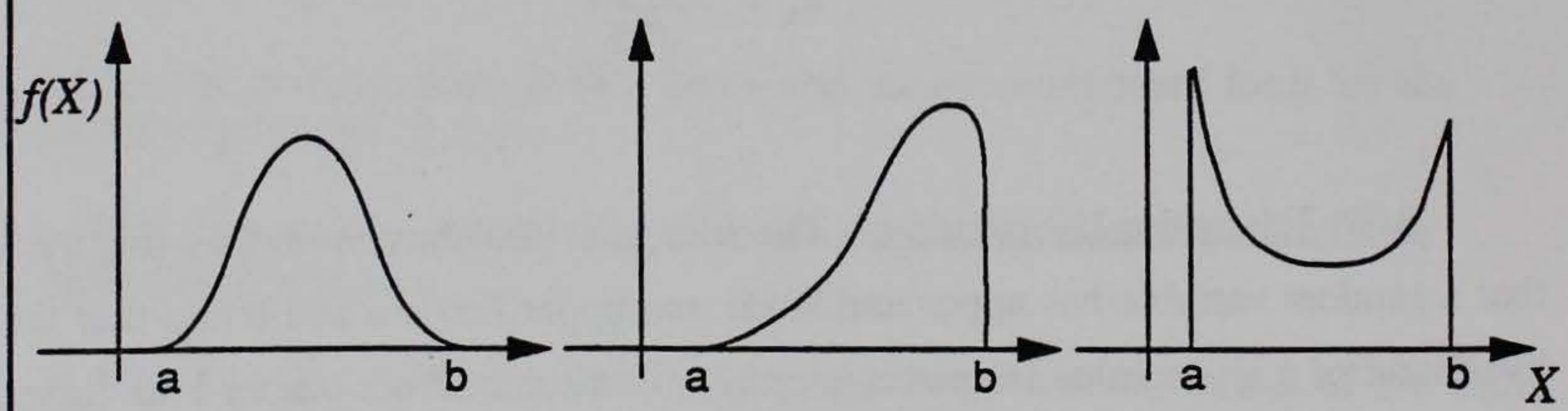

(e) Some Beta ( $\beta$ ) Distributions

Figure 3.2 Some Common Probability Distributions 


$$
E[x]=\frac{a+b}{2}
$$

and the standard deviation is:

$$
\sigma_{x}=\frac{(b-a)}{\sqrt{24}}
$$

For an upper triangular distribution, the expected value is

$$
E[X]=\frac{1}{3}(a+2 b)
$$

and the standard deviation is:

$$
\sigma_{x}=\frac{(b-a)}{\sqrt{18}}
$$

For a lower triangular distribution, the expected value is:

$$
E[X]=\frac{1}{3}(2 a+b)
$$

and the standard deviation is:

$$
\sigma_{x}=\frac{(b-a)}{\sqrt{18}}
$$

3.20. Normal Distribution. The normal or Gaussian distribution (Figure 3.2.c) is probably the most well-known probability density function. Its probability density function is defined in terms of the mean, $\mu_{\mathrm{X}}$, and standard deviation, $\sigma_{\mathrm{X}}$, of a random variable:

$$
f_{X}(X)=\frac{1}{\sigma \sqrt{2 \pi}} \exp \left[-\frac{(x-\mu)^{2}}{2 \sigma^{2}}\right]
$$

The cumulative distribution function for the normal distribution is not conveniently 
expressed in closed form but is widely tabulated and can be readily computed by numerical approximation. Although the normal distribution has limits of plus and minus infinity, values more than 3 or 4 standard deviations from the mean have very low probability. The normal distribution is commonly assumed to characterize many random variables where the coefficient of variation is less than about 30 percent. Where the mean and standard deviation are the only information known, it can be shown that the normal distribution is the most unbiased choice. Selection of the normal distribution may also be justified on the basis of the central limit theorem, which states that the distribution of sums of random variables approaches the normal distribution as the number of random variables increases, regardless of the distributions of the variables themselves.

3.21. The Lognormal Distribution. When a random variable $X$ is lognormally distributed, its natural logarithm, $\ln \mathrm{X}$, is normally distributed. The lognormal distribution has several properties which often favor its selection to model certain random variables in engineering analysis:

1. As $\mathrm{X}$ is positive for any value of $\ln \mathrm{X}$, lognormally distributed random variables cannot assume values below zero.

2. It often provides a reasonable shape in cases where the coefficient of variation is large or the random variable may assume values over one or more orders of magnitude.

3. As the log of the product of several variables equals the sum of the logs of the variables, the central limit theorem implies that the distribution of products or ratios of random variables approaches the lognormal distribution as the number of random variables increases.

If the random variable $\mathrm{X}$ is lognormally distributed, then the random variable $\mathrm{Y}=\ln \mathrm{X}$ is normally distributed with parameters $\mathrm{E}[\mathrm{Y}]=\mathrm{E}[\ln \mathrm{X}]$ and $\sigma_{\mathrm{Y}}=\sigma_{\ln \mathrm{X}}$. To obtain the parameters of the random variable $\mathrm{Y}$, first the coefficient of variation of $\mathrm{X}$ is calculated:

$$
V_{X}=\frac{\sigma_{X}}{E[X]}
$$


The standard deviation of $\mathrm{Y}$ is then calculated as:

$$
\sigma_{Y}=\sigma_{\ln X}=\sqrt{\ln \left(1+V_{X}^{2}\right)}
$$

The term $\sigma_{\mathrm{Y}}$ is in turn used to obtain the expected value of $\mathrm{Y}$ :

$$
E[Y]=E[\ln X]=\ln E[X]-\frac{\sigma_{Y}^{2}}{2}
$$

The density function of the lognormal variate $\mathrm{X}$ is:

$$
f(X)=\frac{1}{X \sigma_{Y} \sqrt{2 \pi}} \exp \left[-\frac{1}{2}\left(\frac{\ln X-E[Y]}{\sigma_{Y}}\right)^{2}\right]
$$

3.22. The Beta Distribution. The beta distribution was originally developed by Pearson in 1886 to fit the first four moments of a random variable. An adaptation by Harr and others (Harr, 1987) provides a method to fit the beta distribution to the mean, standard deviation, and upper and lower limits of a random variable. The beta distribution is very flexible, and can assume a variety of shapes including the normal, uniform, and triangular distributions as special cases. Offsetting the flexibility is the fact that four parameters must be known or assumed. The beta distribution (Figure 3.2.c) may be favored where a particular shape for the probability density function is desired or where the limits of the random variable are known with reasonable certainty. In the past, the beta distribution has seen little application because calculating the density function and cumulative distribution has been difficult. However, these can now be readily obtained using relatively simple computer programs or spreadsheet templates.

\section{The Performance Function and Limit State}

3.23. The performance function is a function selected to numerically characterize a mode of performance for a structure or component. A certain value of the performance function represents the limit state. For the studies herein, several performance 
functions limit state and performance modes were evaluated as described below.

3.24. Sliding Stability. For sliding stability two performance functions were considered. The first performance function was the ratio of resisting forces to driving forces, with a value of 1.0 taken as the limit state. The second was the factor of safety obtained using the program CSLIDE (Pace and Noddin, 1987). In this case, a value of 1.0 also was taken as the limit state but the calculated reliability index usually differed as the performance function was different.

3.25. Overturning Stability. For rotational or overturning stability, the first performance function considered was the ratio of resisting moments to overturning moments and the limit state was taken as a ratio of 1.0. The second performance function considered was the location of the effective resultant force on the base. For this function, a number of criteria were considered; these were the events that the resultant fell in the middle one-third, one-half, and two-thirds of the base; or only within the base. These correspond to 100 percent, 75 percent, 50 percent, and zero percent of the base being in compression, respectively.

3.26. Bearing Capacity. For bearing capacity analysis, the performance function was taken as the factor of safety defined as ratio of the ultimate bearing pressure times the effective base area to the effective base resultant force. The limit state was taken as a value of 1.0 .

\section{Integration of the Performance Function}

3.27. As previously noted, the reliability index is calculated from the expected value and standard deviation of the performance function. There are a number of techniques for calculating the exact or approximate values. These are summarized below.

3.28. Direct Integration. Given a function $Y=g(X)$, of a random variable $X$, the expected value of the function is defined as the integral of the product of the function and the probability density function of the random variable; thus: 


$$
E[Y]=E[g(X)]=\int_{-\infty}^{\infty} g(X) f_{X}(X) d X
$$

for more than one random variable, the above equation generalizes to:

$$
E[Y]=\iint \ldots \int g\left(X_{1}, X_{2}, \ldots X_{n}\right) f_{X}\left(X_{1}, X_{2}, \ldots X_{n}\right) d x_{1} d x_{2} \ldots d x_{n}
$$

The expected value of $\mathrm{Y}^{2}$ can be obtained as :

$$
E\left[Y^{2}\right]=\int_{-\infty}^{\infty}[g(X)]^{2} f_{x}(X) d x
$$

A similar expression is used for multivariate functions. The variance of $\mathrm{Y}$ can be found using the identity:

$$
\operatorname{Var}[Y]=E\left[Y^{2}\right]-(E[Y])^{2}
$$

and the square root of the variance is the standard deviation. For most functions encountered in engineering applications, direct integration is difficult and the mean and the standard deviation are obtained by approximation using one of the methods in the next three sections.

\section{Monte Carlo Simulation}

3.29. In Monte Carlo simulation (see e.g., Ang and Tang 1984), a very large number of values for the random variables are generated in a manner such that these values, in the long run, are distributed according to their assumed probability distributions and correlation coefficient. For each set of values, the performance function is 
evaluated and the mean and standard deviation is calculated from the set of results. Simulation methods have some advantage where information regarding the shape of the distribution of the performance function is desired or where the event of interest is not easily represented as a function. For example, simulation has been used to assess the probability of pile intersection (Wolff, 1990). Disadvantages of simulation methods include the need for very large numbers of analyses to obtain statistically significant results, complexity in generating random variables to fit assumed distributions, and complexity in generating correlated random variables.

\section{Taylor's Series Method}

3.30. The Taylor's series method is based on a Taylor's series expansion of the performance function about some point. For the analysis herein, the expansion is performed about the expected values of the random variables. The Taylor's series method is termed a first order, second moment method as only first-order (linear) terms of the series are retained and only the first two moments (mean and the standard deviation) are considered. Given a function $Y=g\left(X_{1}, X_{2}, \ldots X_{n}\right)$, where all $X_{i}$ are independent, the expected value of the function is obtained by evaluating the function at the expected values of the random variables:

$$
E[Y]=g\left(E\left[X_{1}\right], E\left[X_{2}\right], \ldots E\left[X_{n}\right]\right)
$$

For a function such as the factor of safety, this implies that the factor of safety is calculated using the mean of the random variables:

$$
E[F S]=F S\left(X_{1}, X_{2}, \ldots X_{n}\right)
$$

The variance is taken as:

$$
\operatorname{Var}[Y]=\Sigma\left[\left(\frac{\partial Y}{\partial X_{i}}\right)^{2} \operatorname{Var} X_{i}\right]
$$

with the partial derivatives taken at the expansion point (in this case the mean value). 
Using the factor of safety as an example performance function, the variance is obtained by finding the partial derivative of the factor of safety with respect to each random variable evaluated at its mean, squaring it, multiplying it by the variance of that random variable, and summing these terms over all of the random variables:

$$
\operatorname{Var}[F S]=\Sigma\left[\left(\frac{\partial F S}{\partial X_{i}}\right)^{2} \operatorname{Var} X_{i}\right]
$$

The standard deviation of the factor of safety is then simply the square root of the variance. Advantages of the Taylor's Series method include the fact that the terms in the above summation provide an explicit indication of contribution of uncertainty of each variable and the method is exact for linear performance functions. Disadvantages of the Taylor Series method include the fact that it is necessary to obtain derivatives and the neglect of higher order terms introduces errors for non-linear functions.

3.31. Evaluation of Derivatives in Taylor's series. Although analytical expressions for derivatives of performance functions may be difficult to obtain, derivatives can be obtained numerically by evaluating the performance function at several points. The function is evaluated at one increment above and below the mean of the random variable $\mathrm{X}_{\mathrm{i}}$ and the difference of the results is divided by the distance between the two values of $\mathrm{X}_{\mathrm{i}}$. Although the derivative at the mean is most precisely evaluated using a very small increment, taking the increment as one standard deviation may better represent the behavior of the function over a range of likely values. Thus the derivative may be calculated as follows:

$$
\frac{\partial Y}{\partial X_{i}}=\frac{g\left(E\left[X_{i}\right]+\sigma_{X}\right)-g\left(E\left[X_{i}\right]-\sigma_{X}\right)}{2 \sigma_{X_{i}}}
$$

Where random variables are correlated, solution is more complex. The expression for the expected value, retaining second order terms is: 


$$
E[Y]=g\left(E\left[X_{1}\right], E\left[X_{2}\right], \ldots . E\left[X_{n}\right]+\frac{1}{2} \Sigma \frac{\partial^{2} Y}{\partial X_{i} \partial X_{j}} \operatorname{Cov}\left(X_{i} X_{j}\right)\right.
$$

However, in keeping with the first order approach, the second order terms are generally neglected. The variance is taken as:

$$
\operatorname{Var}[Y]=\Sigma\left[\left(\frac{\partial Y}{\partial x_{i}}\right)^{2} \operatorname{Var} X_{i}\right]+2 \Sigma\left[\frac{\partial Y}{\partial X_{i}} \frac{\partial Y}{\partial X_{j}} \operatorname{Cov}\left(X_{i} X_{j}\right)\right]
$$

For the cases evaluated in this study, only the random variable $c$ and $\phi$ (or $\tan \phi$ ) were considered to be correlated.

\section{Point Estimate Method}

3.32. Point estimate methods are procedures where probability distributions for continuous random variable are represented by discrete distributions having two or more values. The elements of these discrete distributions have specific values with defined probabilities such that the first few moments of the discrete distribution match that of the continuous random variable. Having such few values over which to integrate, the moments of the performance function are easily obtained.

3.33. Rosenblueth's Two-point Estimate Method. A simple and straightforward point estimate method has been proposed by Rosenblueth $(1975,1981)$ and has been summarized by Harr (1987). A continuous random variable $\mathrm{X}_{\mathrm{i}}$ is represented by two point estimates, $\mathrm{X}_{\mathrm{i}+}$ and $\mathrm{X}_{\mathrm{i}}$, with probability concentrations $\mathrm{P}_{\mathrm{i}+}$ and $\mathrm{P}_{\mathrm{i}-\mathrm{s}}$, respectively. As the two point estimates and their probability concentrations form an equivalent probability distribution for the random variable, the two $\mathbf{P}$ values must sum to unity. The two point estimates and probability concentrations are chosen to match three moments of the random variable. For symmetrically distributed random variables, the point estimates are taken at the mean plus or minus one standard deviation: 


$$
\begin{aligned}
& X_{i+}=E\left[X_{i}\right]+\sigma_{X_{i}} \\
& X_{i-}=E\left[X_{i}\right]-\sigma_{X_{i}}
\end{aligned}
$$

For independent random variables, the associated probability concentrations are each one-half:

$$
P_{i+}=P_{i-}=0.50
$$

Using the point estimates and their probability concentrations for each variable, the expected value of a function of the random variables raised to any power $M$ can be approximated by evaluating the function for each possible combination of the point estimates (e.g. $\mathrm{X}_{1+}, \mathrm{X}_{2,}, \mathrm{X}_{3, \cdots}, \mathrm{X}_{\mathrm{n}+}$ ), multiplying each result by the product of the associated probability concentrations (e.g. $\mathrm{P}+-\ldots+\ldots=\mathrm{P}_{1+} \mathrm{P}_{2-} \mathrm{P}_{3} \ldots \mathrm{P}_{\mathrm{n}}$ ) and summing the terms. For example, two random variables result in four combinations of point estimates and four terms:

$$
E\left[Y^{M}\right]=P_{++} g\left(X_{1+}, X_{2+}\right)^{M}+P_{+-} g\left(X_{1+}, X_{2}\right)^{M}+P_{-+} g\left(X_{1,}, X_{2+}\right)^{M}+P_{-} g\left(X_{1,}, X_{2-}\right)^{M}
$$

For $\mathrm{N}$ random variables, there are $2^{\mathrm{N}}$ combinations of the point estimates and $2^{\mathrm{N}}$ terms. To obtain the expected value of the performance function, the function is calculated $2^{\mathrm{N}}$ times using all the combinations and the exponent $M$ is 1 . To obtain the standard deviation of the performance function, the exponent $M$ is taken as 2 and the squares of the obtained results are weighted and summed to obtain $E\left[\mathrm{Y}^{2}\right]$. The variance can then be obtained from the identity:

$$
\operatorname{Var}[Y]=E\left[Y^{2}\right]-(E[Y])^{2}
$$

and the standard deviation is the square root of the variance. Correlation between symmetrically distributed random variables is treated by adjusting the probability concentrations ( $\mathrm{P} \pm \pm \ldots . . \pm$ ). A detailed discussion is provided by Rosenblueth (1975) and summarized by Harr (1987). For analysis herein, at most two random variables (c and $\tan \phi)$ were taken to be correlated. For two correlated random variables within a 
group of two or more, the product of their concentrations is modified by adding a correlation term:

$$
\begin{aligned}
& P_{i+j+}=P_{i-j-}=\left(P_{i+}\right)\left(P_{j+}\right)+\frac{\rho}{4}=\frac{1+\rho}{4} \\
& P_{i+j-}=P_{i-j+}=\left(P_{i}\right)\left(P_{j+}\right)-\frac{\rho}{4}=\frac{1-\rho}{4}
\end{aligned}
$$

\section{The Reliability Index and its Various Definitions}

3.34. Definition based on normal distribution. As illustrated in Figure 3.3a, a simple definition of the reliability index is based on the assumption that capacity and demand are normally distributed and the limit state is the event that their difference, the safety margin $\mathrm{S}$, is zero. The random variable $\mathrm{S}$ is then also normally distributed and the reliability index is the distance by which $\mathrm{E}[\mathrm{S}]$ exceeds zero in units of $\sigma_{\mathrm{S}}$ :

$$
\beta=\frac{E[S]}{\sigma_{S}}=\frac{E[C-D]}{\sqrt{\sigma_{C}^{2}+\sigma_{D}^{2}}}
$$

3.35. Definition based on lognormal distribution. An alternative formulation of the reliability implies that capacity, C, and demand, D, are lognormally distributed random variables. In this case $\ln \mathrm{C}$ and $\ln \mathrm{D}$ are normally distributed. Defining the factor of safety, FS, as the ratio C/D, then $\ln F S=(\ln C)-(\ln D)$ and $\ln$ FS is normally distributed. Defining the reliability index as the distance by which ln FS exceeds zero in terms of the standard deviation of $\ln$ FS, it is: 


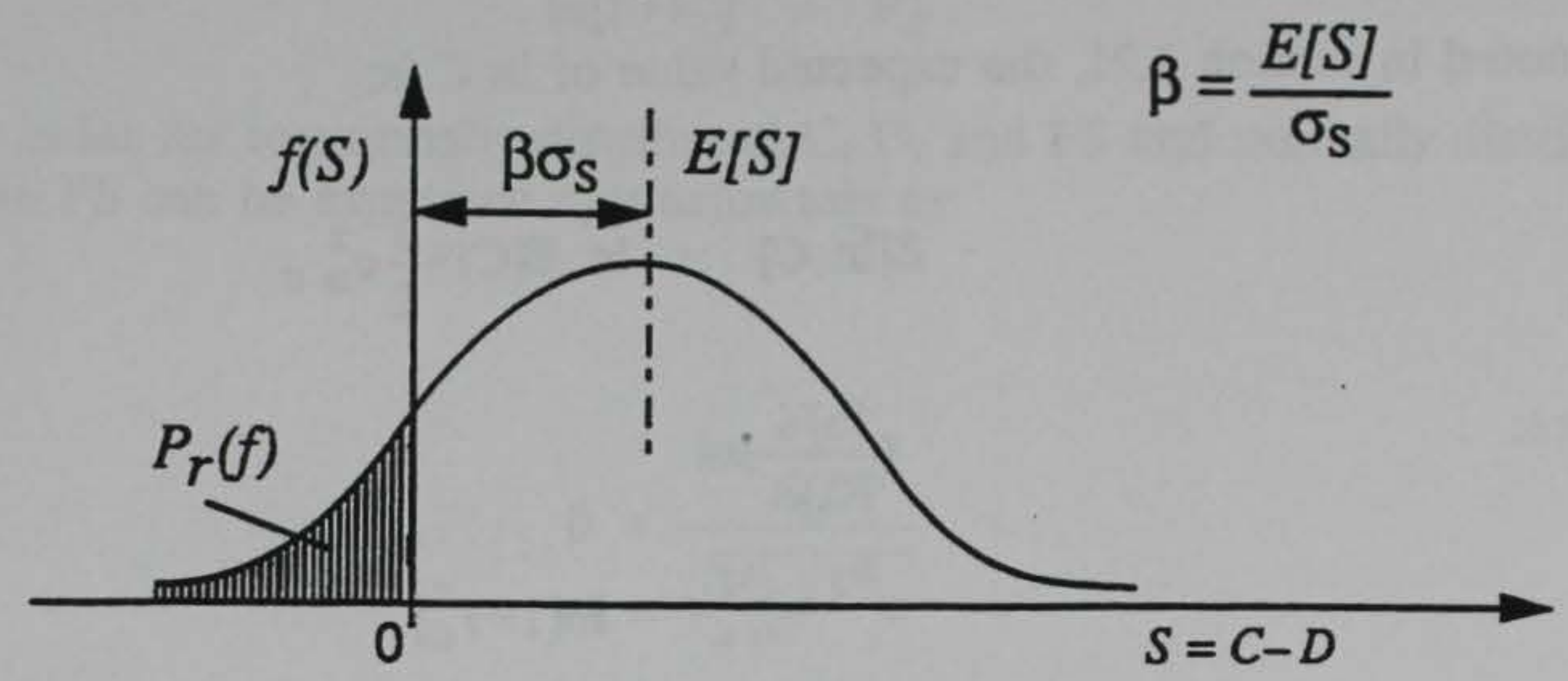

(a) Normal Definition

$$
\beta=\frac{E[\ln F S]}{\sigma_{\ln F S}}=\ln \left(\frac{E[F S]}{\sqrt{1+V_{F S}^{2}}}\right) / \sqrt{\ln \left(1+V_{F S}^{2}\right)}
$$
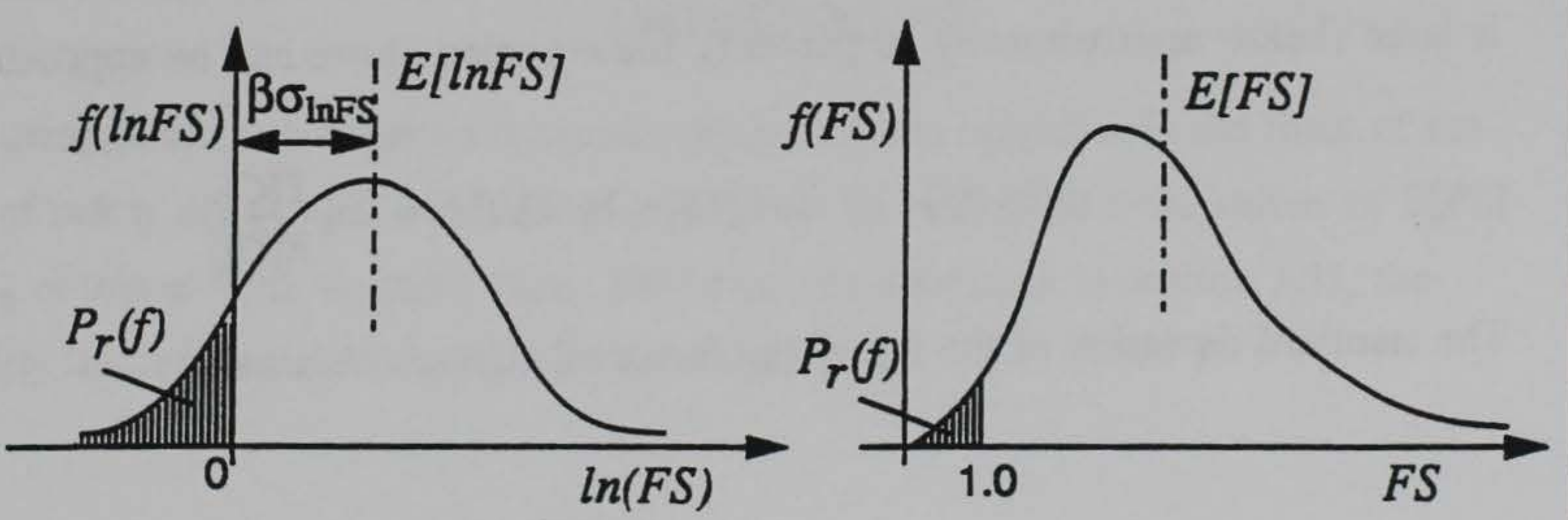

(b) Lognormal Definition

Figure 3.3 Alternative Definitions of the Reliability Index 


$$
\beta=\frac{E[\ln C-\ln D]}{\sigma_{(\ln C-\ln D)}}=\frac{E[\ln (C / D)]}{\sigma_{\ln (C / D)}}=\frac{E[\ln F S]}{\sigma_{\ln F S}}
$$

As noted in section 3.21 , the expected value of $\ln \mathrm{C}$ is:

$$
E[\ln C]=\ln E[C]-\frac{1}{2} \sigma_{\ln }^{2} C
$$

where:

$$
\sigma_{\ln c}^{2}=\ln \left[1+V_{C}^{2}\right]
$$

A similar expression provides E[D].

The expected value of the log of the factor of safety is then:

$$
E[\ln F S]=\ln E[C]-\ln E[D]-\frac{1}{2} \ln \left[1+V_{C}^{2}\right]+\frac{1}{2} \ln \left[1+V_{D}^{2}\right]
$$

As the second order terms are small when the coefficients of variation are not exceedingly large (below approximately 30 percent), the equation above can be approximated:

$$
E[\ln F S] \approx \ln E[C]-\ln E[D]=\ln \left[\frac{E[C]}{E[D]}\right]
$$

The standard deviation of the $\log$ of the factor of safety is obtained as:

$$
\begin{gathered}
\sigma_{\ln F S}=\sqrt{\sigma_{\ln C}^{2}+\sigma_{\ln D}^{2}} \\
\sigma_{\ln F S}=\sqrt{\ln \left[1+V_{C}^{2}\right]+\ln \left[1+v_{D}^{2}\right]}
\end{gathered}
$$


Introducing an approximation,

$$
\ln \left[1+V_{c}^{2}\right] \approx V_{c}^{2}
$$

the reliability index for lognormally distributed C, D, and FS and normally distributed in $\mathrm{C}$, ln D, and $\ln$ FS can be expressed approximately as:

$$
\beta=\frac{\ln \left(\frac{E[c]}{E[D]}\right)}{\sqrt{V_{c}^{2}+V_{D}^{2}}}
$$

The exact expression is:

$$
\beta=\frac{\ln \left[\frac{E[C] \sqrt{1+V_{D}^{2}}}{E[D] \sqrt{1+V_{C}^{2}}}\right]}{\sqrt{\ln \left[1+V_{C}^{2}\right]+\ln \left[1+v_{D}^{2}\right]}}
$$

When using many deterministic computer programs, the output is in the form of the factor of safety only and the reliability index must be calculated from values of E[FS] and $\sigma_{\mathrm{FS}}$ obtained from multiple runs. Based on the equations in section 3.21, the reliability index is obtained using the following steps:

$$
\begin{gathered}
V_{F S}=\frac{\sigma_{F S}}{E[F S]} \\
\sigma_{\ln F S}=\sqrt{\ln \left(1+V_{F S}^{2}\right)}
\end{gathered}
$$




$$
\begin{aligned}
& E[\ln F S]=\ln E[F S]-\frac{1}{2} \ln \left(1+V_{F S}^{2}\right) \\
& \beta=\frac{E[\ln F S]}{\sigma_{\ln F S}}=\frac{\ln \left[E[F S] \sqrt{1+v_{F S}^{2}}\right]}{\sqrt{\ln \left(1+v_{F S}^{2}\right)}}
\end{aligned}
$$

For the study herein, the lognormal definition was used to calculate $\beta$. This is consistent with current trends in structural reliability engineering.

3.36. Hasofer-Lind Definition. For non-linear performance functions, the calculated $\beta$ value using the mean and the standard deviation obtained from a Taylor's Series expansion is dependent on the point about which the expansion is performed. For reasonably "safe" structures, the mean may be statistically "far" from the failure or limit condition, and derivatives evaluated at the mean introduce inaccuracy. Hasofer and Lind (1974) proposed an iterative procedure for determining a $\beta$ value that is invariant for non-linear functions. In their procedure, expansion is performed not about the mean but about a "most likely failure point," $\mathrm{X}=\mathrm{X}_{1}{ }^{*}, \mathrm{X}_{2}{ }^{*}, \ldots \mathrm{X}_{2}{ }^{*}$. The Hasofer-Lind procedure is beyond the scope of this study but may merit future consideration for significantly nonlinear problems such as bearing capacity.

\section{Systems Reliability Problems}

3.37. Assuming the reliability of a particular component can be quantified with respect to a particular performance mode, it follows that interest would arise in assessing the overall reliability of a structure considering all of its components and performance modes. The most basic systems are simple parallel and series systems. Although navigation systems are much more complex, some insight into the reliability of complex systems can be gained by an understanding of simple series and parallel systems.

3.38. Simple Series System. For a simple series system, all components are considered independent. The reliability of the system is the probability that all compo- 
nents function and is equal to product of the reliability of the individual components.

$$
R=R_{1} R_{2} \ldots R_{n}
$$

The probability of failure for a series system is then:

$$
\mathrm{p}_{\mathrm{r}}(\mathrm{f})=1-\mathrm{R}=1-\mathrm{R}_{1} \mathrm{R}_{2} \ldots \mathrm{R}_{\mathrm{n}}
$$

If a chain has twenty independent links each with reliability $R_{i}=0.99$ and probability of failure 0.01 , then the reliability of the chain is $(0.99)^{20}=0.8179$. It is evident that series systems can become unreliable rapidly as the number of their components increases. A waterway system with locks and dams at a number of locations can be viewed as a series system between the origin and the destination of a given trip.

3.39. Simple Parallel System. For parallel systems comprised of $\mathbf{N}$ components where failure of the system requires failure of all components, the probability of failure is:

$$
P_{r}(f)=P_{r}\left(f_{1}\right) P_{r}\left(f_{2}\right) \ldots . . P_{r}\left(f_{n}\right)
$$

The reliability of a parallel system is then:

$$
R=1-P_{r}(f)=1-P_{r}\left(f_{1}\right) P_{r}\left(f_{2}\right) \ldots . . P_{r}\left(f_{n}\right)
$$

For a set of three generators in parallel, each with reliability $R_{i}=0.99$ and $\operatorname{Pr}(f)=0.01$, the probability of total loss of power is $0.01^{3}=0.000001$. It is likewise evident that parallel systems become increasingly reliable as the number of components increase. Multiple locks at a given dam site represent a simple parallel system and result in a reliability (with respect to passage) much greater than that for a single lock.

Solutions are also available for systems where more than on of a group of components are required for performance. This is termed an "R-out-of-N system" (see, e.g., Harr, 1987). 
3.40. Navigation structures and their components are complex systems which may include series and parallel components, redundant components, and correlated performance modes. Furthermore, a number of events can occur which may reduce the efficiency of lock but not stop its operation. Thus, it is beyond the scope of the present research to develop a comprehensive method to determine overall system reliability. Complex fault-tree and event-tree analyses have been applied to similarly complex systems (See, e.g., Ang and Tang, 1984). One simple but convenient approach to estimate the lower-bound reliability of a system would be to is merely to take the minimum reliability of any component:

$$
\mathbf{R}=\min \left(\mathbf{R}_{\mathrm{i}}\right)
$$

Likewise, the reliability index of a system, in the first approximation, might be taken as the minimum reliability index of any component or performance mode.

$$
\beta=\beta_{\min }
$$

\section{Setting Target Reliability Values}

3.41. Given that the reliability of structural components and performance mode are expressed as a reliability indices, $\beta$, and these the $\beta$ values are to be used to prioritize rehabilitation, target $\beta$ values must be defined that represent acceptable or desirable levels of performance. As target $\beta$ values have not previously been defined for navigation structure components and performance modes, one goal of this study was to make preliminary recommendations regarding target $\beta$ values. To assign rational target values, several sources of information can be considered; these include values used in structural design codes, values used in bridge evaluation, and experience from this study. The task of recommendating target B values is addressed in Part XIV of this report. 


\section{Time Variation of Reliability}

3.42. A common concern is that structures may become less reliable with time. The time -dependence is evident for mechanical and electrical components with a finite (but uncertain) life. In fact, reliability may increase or decrease with time. The basis of the reliability analysis procedures developed herein is to quantify uncertainty regarding performance as a function of uncertainty in the variables used in the analysis. For reliability to change with time, the expected value or standard deviation of one or more of the random variables must be a function of time. For example, in the case of monoliths secured by rock anchors, the uncertainty of the anchor force may be modeled as increasing with time in which case decreasing $\beta$ values would be obtained at increasing times. In the case of a soil where strength is modeled as increasing with time due to consolidation, the $\beta$ value would increase with time. 


\section{PART IV: PROBABILISTIC CHARACTERIZATION OF SHALE STRENGTH}

\section{Monongahela River Foundation Materials}

4.1. Introduction. One of the most significant random variables in the sliding analysis of a gravity monolith is the shear strength of the foundation material. The monoliths investigated at Monongahela River Locks and Dams Nos. 2, 3, 4 are typically founded on shales of various hardness and descriptions. Related sedimentary rocks (siltstone, claystone, etc.) are also present. Strength data for the shales were available in the form of direct shear tests. At Locks and Dam No. 3, triaxial test data were also available. The test results are published in three separate Engineering Condition Surveys prepared by the Waterways Experiment Station, Structures Laboratory, for the Pittsburgh District. This section describes how expected values, standard deviations and correlation coefficients were assigned for the strength parameters of these materials.

\subsection{Foundation Rock at Locks and Dam No. 2. The condition survey for Lock and}

Dam No. 2 (Wong, et. al., 1988 ) summarizes drilling and testing performed at the site. The foundation materials are predominately Pennsylvanian shales, variously described as shale, fractured shale, clay shale, silty shale, clay shale with slickensides, and rubble. Rock specimens selected for direct shear testing were intact specimens and were divided into two groups: (a) soft to moderately hard shale and (b) moderately hard shale. Seven specimens from each group were tested at one normal stress each, either $3.6,7.2$, or 10.8 ton per square foot (tsf). Both peak and residual shear strengths were obtained for each test. The results of a regression analysis by WES were reported in the condition survey; the best fit strength parameters for the soft to moderately hard shale are given as $c=5.4$ tsf and $\phi=51.9$ degrees for peak strength, and $c=2.1$ tsf and $\phi=25.0$ degrees for residual strength. (Note: the text of the condition survey shows the units for the c parameter as psi; examination of the data tables and plots indicate that the numbers shown must actually be tsf). No regression analysis had been performed by moderately hard shale group due to wide scatter in the data. However, a regression analysis had been performed on the two groups taken together (ab), 
and the best fit strengths were given as $c=6.4$ tsf and $\phi=47.5$ degrees for peak strength and $c=1.32$ tsf and $\phi=25.8$ degrees for residual strength.

4.3. Foundation Rocks at Lock and Dam No. 3. The condition survey for Locks and Dam No. 3 (U.S. Army Waterways Experiment Station, 1976) summarizes rock testing from borings M-7 and M-8, drilled in the fall of 1974. The material tested is representative of the material at the foundation contact and is described as a uniform, competent grayish shale with no unusual planes of weakness. Testing included a seven-stage triaxial test on a single specimen with a failure plane pre-cut at 45 degrees, a seven sample unconfined/triaxial test set, and six direct shear tests. The staged triaxial test on the pre-cut material indicated a drained friction angle ( $\phi$ ') of 32.5 degrees. The triaxial testing on intact samples yielded very high strengths; the actual envelope is curved but the initial portion is characterized by parameters $c=61.2$ tsf and $\phi=45$ degrees. The best fit strength parameter obtained from a regression analysis by WES for the direct shear testing has $c=8.06$ tsf and $\phi=69$ degrees. The direct shear testing was considered most applicable to the sliding analysis and was analyzed in detail as discussed later in this part. Below the foundation shale is found strata of more carboniferous shale and coal.

4.4. Foundation Rocks at Lock and Dam No. 4 The condition survey for Lock and Dam No. 4 (Wong, et. al, undated) describes three borings made into the foundation rock, which generally consists of red and gray shales and clayey shales. Significant amounts of material described as rubble were logged in these borings, and a number of core breaks were recorded, especially along bedding planes. Direct shear test results expressed as both peak and residual strengths are available for four materials of different descriptions: (d) moderately hard clayey red shale ( 3 specimens), (e) moderately hard red shale (6 specimens), (f) moderately hard clayey gray shale ( 3 specimens) and ( $\mathrm{g}$ ) hard gray shale ( 3 specimens). Within each group, there were few data points and hence was relatively little data scatter; good fits could be made for the strength envelope. For the three moderately hard groups (def), the peak strength $\phi$ parameter was reported to be between 53 and 59 degrees and the peak strength c parameter between 5.8 and 8.5 tsf. For the hard gray shale $(\mathrm{g})$, the peak strength was reported as $c=8$ tsf and $\phi=69$ degrees. For the clayey shales (df), the residual strength parameters were reported as $c=0$ and $\phi=15.5$ degrees. For the hard gray shale (g), 
the residual friction angle was reported as 39 degrees and for the moderately hard red shale (e), 25.9 degrees.

\section{Grouping of Data}

4.5. Nature of Data. The usual practice for determining $c$ and $\phi$ values for a soil sample tested in direct shear is to plot shear stress at failure versus normal stress and fit a straight line to the results of three or more specimens cut from a single sample and sheared under different normal stresses. From a group of $\mathrm{c}$ and $\phi$ values so obtained for a number of samples, a design value for $\mathrm{c}$ and $\phi$ is assigned. Within the Corps of Engineers, a common selection criterion is that two-thirds of the measured strength values should fall above the design strength envelope. In the case of the shale materials considered herein, most shale samples were tested at only one normal stress, typically $3.6,7.2$, or 10.8 tsf. Except at Locks and Dam No. 4, individual test specimens had not been specifically matched with other specimens to provide a set of $c, \phi$ pairs. While a single design strength envelope can be drawn through a group of $\sigma, \tau$ data, determining the probabilistic moments of $c$ and $\phi$ is not so straightforward. For any single data point $(\sigma, \tau)$, an infinite number of combinations of $c$ and $\phi$ will define line that pass through the point. Some of the uncertainty in the shear strength function $\tau_{\mathrm{f}}=\mathrm{c}+\sigma \tan \phi$ must be assigned to $\mathrm{c}$ as a variance or coefficient of variation, some likewise to $\phi$ (or $\tan \phi$ ), and some to the joint behavior of $c$ and $\phi$ (or $\tan \phi$ ) as a covariance or correlation coefficient, $\rho_{c, \phi}$ or $\rho_{c, \text { tan } \phi}$. Thus, a consistent method and some judgment is required to obtain appropriate probabilistic moments for $c$ and $\tan \phi$ working from a group of scattered points.

4.6. Number of Foundation Materials. The number of different foundation materials to be modeled in an analysis must also be decided. For example, a site may have soft shales and hard shales, each with their own expected properties and associated uncertainty. A monolith known to be founded on certain material would most appropriately be analyzed using the probabilistic moments representative of the known foundation material. However, in a case where the founding material itself is uncertain, such as a monolith between borings, the probabilistic moments of the strength parameters should reflect the additional uncertainty 
regarding the type of material. This would imply that the expected value of the strength should be taken somewhere between the expected values of two or more materials, but the coefficient of variation should be larger than for any of the materials.

4.7. Selected Grouping. In virtually no case was data available directly under a selected monolith; it was thus necessarily to estimate the appropriate probabilistic moments based on data elsewhere at the site that might be considered "representative" In this regard data were first grouped in a number of ways based primarily on location and shale hardness. Within each group, shear stresses at failure were usually available as both peak strength and residual strength. As summarized in the condition surveys previously discussed, the rock tested had been divided into the following groups:
a. Lock and Dam No. 2, Soft to moderately hard shale
b. Lock and Dam No. 2, Moderately hard shale
c. Lock and Dam No. 3, Hard shale
d. Lock and Dam No. 4, Moderately hard clayey red shale
e. Lock and Dam No. 4, Moderately hard red shale
f. Lock and Dam No. 4, Moderately hard clayey gray shale
g. Lock and Dam No. 4, Hard gray shale

Because of the limited amount of data, the results of one unusually strong or weak sample could unduly influence the analysis. To see if more consistent data sets could be obtained, the following additional groups were created by combining various data from the above groups:

(ab). Lock and Dam No. 2, all data combined (def). Lock and Dam No. 4, all moderately hard shale and moderately hard clayey shale combined (abdef). Locks and Dams Nos. 2 and 4, all soft to moderately hard and moderately hard shale and clayey shale combined. 
In each group, statistical "outliers" were eliminated from the data sets before analysis. A statistical outlier is a value that lies statistically "far" from the remaining data points. A number of statistical references provide tests to determine and remove outliers. The few outliers involved in the present data were quite obvious and were removed by inspection.

\section{Calculating the Moments of $\mathrm{c}$ and $\tan \phi$}

4.8. Peak strength data. As the data were available in the form of $(\sigma, \tau)$ pairs, and not (c, $\phi$ ) pairs, two methods were developed and compared for obtaining the probabilistic moments of $c$ and $\tan \phi$ for peak strength data. These are termed the paired-point method and the linear regression method. They are illustrated in figures 4.1 and 4.2 , respectively, and discussed below.

4.9 Paired-point method. In the paired-point method, it is reasoned that any sample sheared at a given normal stress might be paired with any other sample sheared at a different normal stress. Each pair of points so considered provides one value of $c$ and $\tan \phi$, and the probabilistic moments of $c$ and $\tan \phi$ are calculated using these (c, $\tan \phi)$ values. Pairs of points that result in unreasonable values, such as negative values of $c$ and $\tan \phi$, are eliminated. To illustrate the paired point method assume that 5 samples are tested at the first normal stress, 3 are tested at a second normal stress, and 2 are tested at a third normal stress. Each of the first five can be combined with the next three, and then the next two. There are a total of $[(5)(3)+(5)(2)+(3)(2)]=31$ combinations. Advantages of the paired-point method include the following:

a. The method is simple to understand and explain

b. The moments of $\tan \phi$ and $\phi$ can be determined separately without need to convert from one to another.

Disadvantages of the paired-point method are:

a. Considerable judgment may be required regarding which combinations of $\mathrm{c}$, and tan 


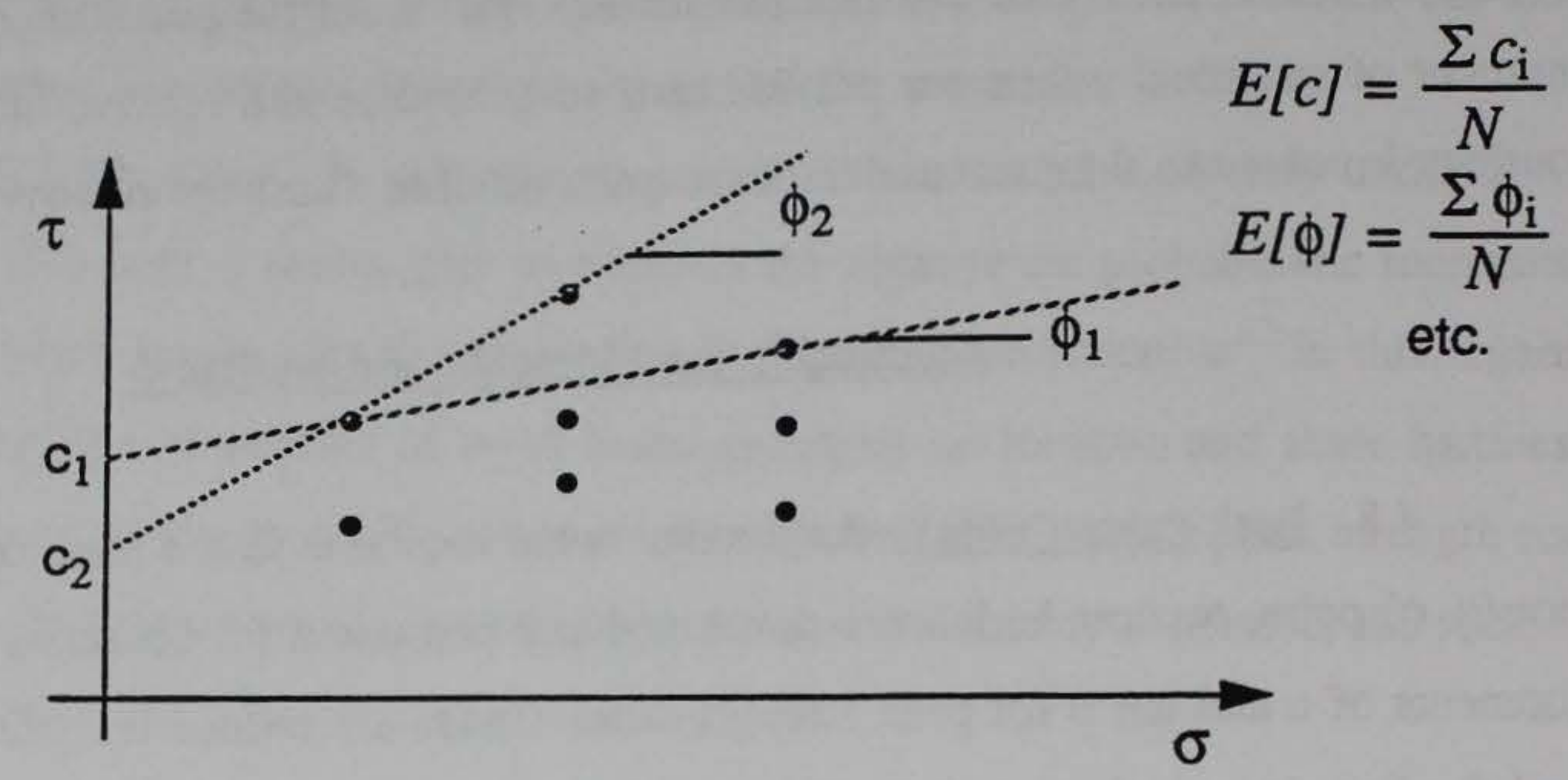

Figure 4.1 Paired-Point Method

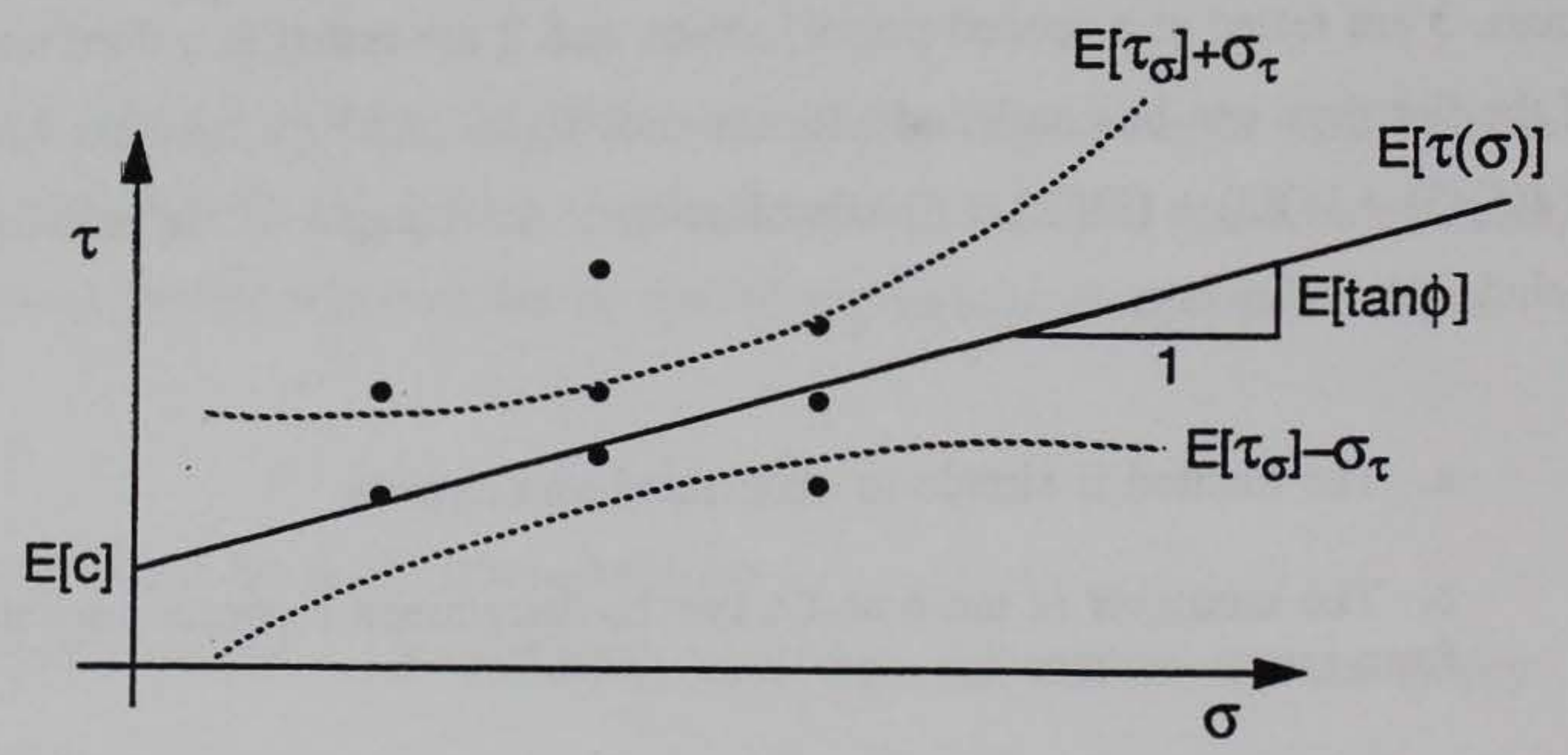

Figure 4.2 Linear Regression Method 
$\phi$ should be considered unreasonable and eliminated.

b. As the number of data points increases, the number of combinations to be considered increases geometrically.

c. If the number of samples tested at each normal stress is not the same, the data points are not equally weighted in the analysis.

d. If the number of data points is small and the scatter is great, unreasonable values may be obtained for $\phi$ and $\tan \phi$.

4.10. Linear Regression Method. In the linear regression method, a best fit line is determined using standard linear regression analysis (see, e.g. Harr, 1987; Draper and Smith, 1981) of all the data points. This line can be represented in the form:

$$
\begin{aligned}
& \tau=\mathrm{c}+(\tan \phi) \sigma \\
& \mathrm{y}=\mathrm{a}+\mathrm{bx}
\end{aligned}
$$

where :

$y$ corresponds to the shear stress, $\tau$

a corresponds to the $c$ parameter or cohesion

$\mathrm{b}$ is the slope of the regression line and corresponds to the strength parameter tan $\phi$, and

$\mathrm{x}$ corresponds to the normal stress, $\sigma$.

The values of $\mathrm{a}$ and $\mathrm{b}$ obtained from the regression analysis define the best fit line and thus correspond to the mean or expected value of the parameters $c$ and $\tan \phi$. The value of $\tau$ obtained for any $\sigma$ corresponds to the conditional expected value $E\left[\tau_{\mathrm{f}} \mid \sigma\right]$ However, there is uncertainty in the true value of $\mathrm{a}$ and $\mathrm{b}$ (or $\mathrm{c}$ and $\tan \phi$ ); sampling different collections of samples drawn from an infinitely large population of statistically homogeneous shale bedrock would result somewhat different $\mathrm{a}$ and $\mathrm{b}$ values for each collection. Although not found in many statistical references, solutions are available (e.g., Draper and Smith, 1981) for the variance of $a$ and $b$ and their correlation coefficient. These can be determined as follows: 
Obtain the standard error of $y$ :

$$
\sigma_{y / x}=\sqrt{\frac{\Sigma y^{2}-a \Sigma y-b \Sigma x y}{n-2}}
$$

The variance of $b$ is then:

$$
\operatorname{Var}(b)=\frac{\left(\sigma_{y / x}\right)^{2}}{\sum\left(x^{2}\right)-n\left(\mu_{x}\right)^{2}}
$$

The variance of a is:

$$
\operatorname{Var}(a)=\frac{\operatorname{Var}(b)\left(\Sigma x^{2}\right)}{n}
$$

The covariance of $(a, b)$ is:

$$
\operatorname{Cov}(a, b)=[\operatorname{Var}(b)]\left[-\mu_{x}\right]
$$

Finally the correlation coefficient $\rho_{a, b}\left(\rho_{c, \tan \phi}\right)$ is:

$$
\rho_{a, b}=\frac{\operatorname{Cov}(a, b)}{\sqrt{\operatorname{Var}(a) \operatorname{Var}(b)}}
$$

Having determined the variance of $\mathrm{a}$ and $\mathrm{b}$ and their covariance, the conditional variance associated with $y$ given any value of $x$ (or in the present case, the conditional variance of the shear stress, $\tau$, at a given normal stress $\sigma$ ) is: 


$$
\operatorname{Var}(y)=\operatorname{Var}(a)+2 x \operatorname{Cov}(a, b)+x^{2} \operatorname{Var}(b)
$$

For the peak strength parameters $\mathrm{c}$ and $\tan \phi$ from drained tests, the resulting correlation coefficient $\rho_{c, \text { tan } \phi}$ are found to be strongly negative. This is consistent with previous studies (Wolff, 1985; Harr, 1987). As a result of such negative correlation, the uncertainty in (or coefficient of variation of) the shear strength at stress levels in the range where data were obtained is typically much smaller than the uncertainty associated with $\mathrm{c}$ or $\tan \phi$ taken separately. Expressed another way, one can be relatively confident in the strength $\tau$ at a given stress level $\sigma$, even though one is less confident regarding the appropriate values for $c$ and $\tan \phi$ that predict that strength. For negatively correlated parameters if $\mathrm{c}$ is high, $\tan \phi$ must be low and vice versa. Advantages of the linear regression method include the following:

a. The method is consistent with established statistical procedures; it can readily be programmed or parameters can be obtained from general-purpose statistical program packages.

b. The resulting uncertainty in the shear strength is smallest at the mean confining stress of the obtained data and increases with distance from this mean.

4.11. Residual Strength Data. For residual strength data, the c parameter was assumed in all cases to be zero, and the tangent of the residual friction angle, $\tan \phi_{r}$, for each specimen was taken as the ratio of the shear stress at residual shear failure to the applied normal stress. As only one variable is involved, calculation of the mean and standard deviation is straightforward (see paragraphs 3.8 through 3.10 ).

\section{$\underline{\text { Results }}$}

4.12. The means and coefficients of variation of $c$ and $\tan \phi$ and their correlation coefficients were calculated for data groups and are summarized in Table 4.1 for both the 
paired-point method and the linear regression method. An example plot of the data points and fitted lines for the linear regression method is provided in Figure 4.3. The means and coefficients of variation for $\tan \phi$ for residual strength data are summarized in Table 4.2.

4.13 Peak strengths, Locks and Dam No. 2. The moments of the peak strength parameters selected for Locks and Dam No. 2 reflect consideration of both the soft to moderately hard shale and the data for all shale taken together. Taking $\rho_{c, \operatorname{san} \phi}$ as -0.70 , which is slightly lower than most values obtained, provides some conservatism. The less negative the correlation coefficient $\rho_{c, \text { tan } \phi}$, the greater is the variance of the shear strength $\tau=c+\sigma$ $\tan \phi$ at any normal stress $\sigma$.

4.14. Peak strengths, Locks and Dams Nos. 3 and 4. The moments of the assigned strength parameters selected for Locks and Dams No. 3 and 4 reflect the same reasoning as for Locks and Dam No. 2. After reviewing the moments of the variously grouped data, and considering the relatively small amount of overall data, it was judged that differences among the calculated moments were small relative to the overall uncertainty and the same moments for peak strength parameters could be used at all three sites. Because these peak strength parameter moments were taken the same, the differences in reliability index from one structure to another are solely attributable to differences in structural geometry. water levels, and loading conditions.

4.15. Residual Strengths. The moments of the residual strength parameters are rounded values based directly on the results of the regression analyses.

\section{Assigned Strength Parameters}

4.16. Based on the results shown in Tables 4.1 and 4.2 for various groupings, selected probabilistic moments for use in the forthcoming analyses were assigned as given in Table 4.3. 


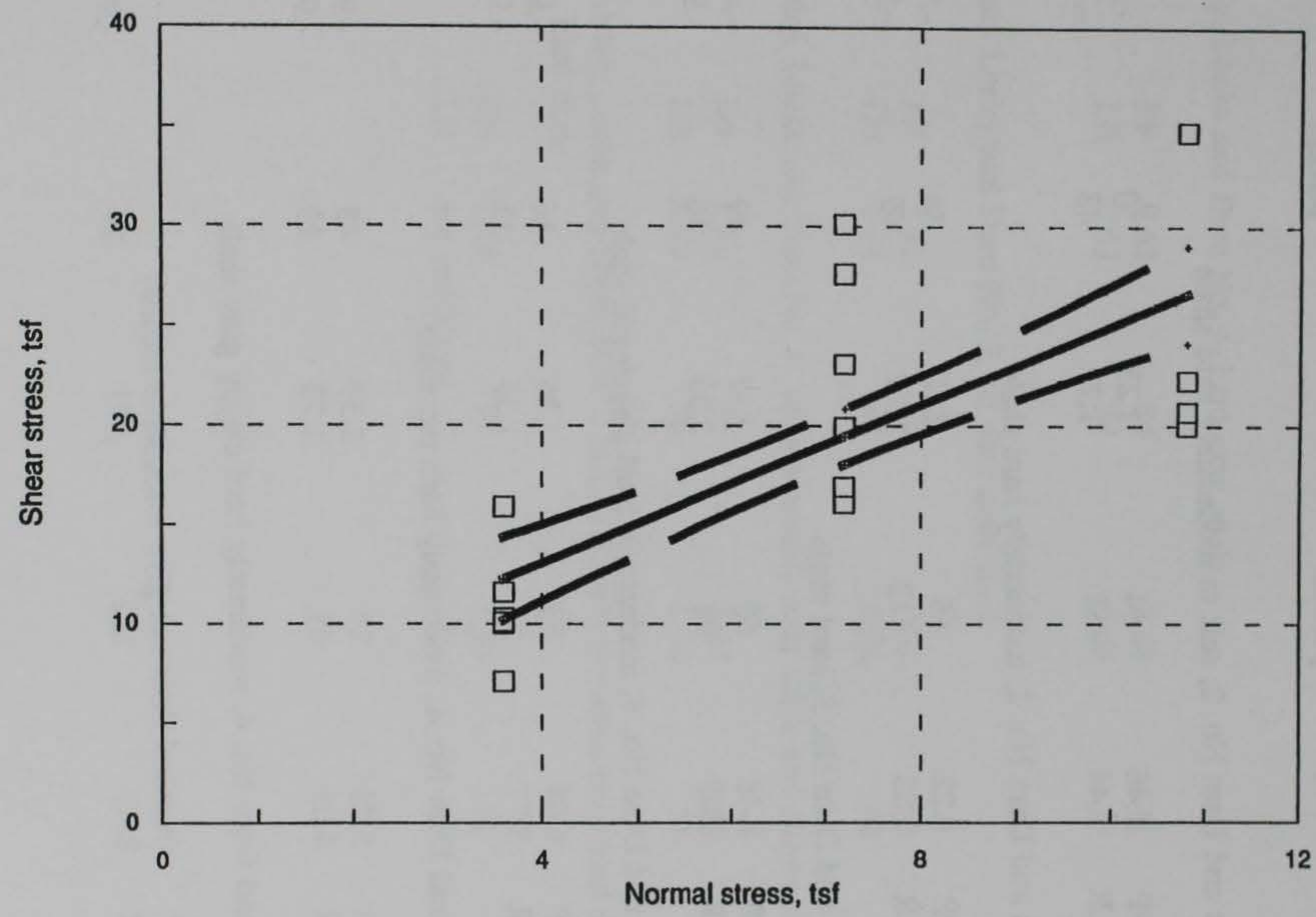

Figure 4.3 Regression Results for Group defg (L\&D 4, all shale) 
Table 4.1

\section{Probabilistic Moments for Peak Shear Strength}

Group

Method
$\mathrm{E}[\mathrm{c}]$
(tsf)
$\underline{\mathrm{V}_{c}}$
$\underline{E[\tan \phi]}$
$\underline{\mathrm{V}}_{\mathrm{tan} \phi}$
$\rho \underline{c, t a n} \phi$

a. Locks and Dam No. 2, soft to moderately hard shale

$\begin{array}{llllll}\text { PP } & 5.46 & 54 & 1.23 & 50 & -.64 \\ \text { LR } & 5.44 & 68 & 1.27 & 48 & -.89\end{array}$

b. Locks and Dam No. 2, moderately hard shale

$\begin{array}{llllll}\text { PP } & 9.22 & 65 & 2.68 & 34 & -.72 \\ \text { LR } & 7.33 & 112 & 2.67 & 49 & -.91\end{array}$

c. Locks and Dam No. 3, hard shale

$\begin{array}{llllll}\text { PP } & 8.48 & 60 & 2.52 & 49 & -.48 \\ \text { LR } & 8.05 & 91 & 2.55 & 56 & -.92\end{array}$

d. Locks and Dam No. 4, moderately hard clayey red shale

$\begin{array}{llllll}\text { PP } & 6.08 & 53 & 1.35 & 16 & -.96 \\ \text { LR } & 5.77 & 20 & 1.35 & 11 & -.93\end{array}$

e. Locks and Dam No. 4, moderately hard red shale

$\begin{array}{llllll}\text { PP } & 5.88 & 89 & 1.59 & 43 & -.92 \\ \text { LR } & 4.05 & 65 & 1.72 & 23 & -.91\end{array}$

f. Locks and Dam No. 4, moderately hard clayey gray shale

PP (method does not give reasonable results)

$\begin{array}{llllll}\text { LR } & 8.45 & 122 & 1.71 & 79 & -.94\end{array}$ 
Table 4.1 (continued)

\section{Probabilistic Moments for Peak Shear Strength}

Group

Method
$\underline{E[c]}$
$\underline{V_{c}}$
$\underline{E[\tan \phi]}$
$\underline{\mathrm{V}}_{\tan \phi}$
$\varrho_{c, t \tan \phi}$

g. Locks and Dam No. 4, hard gray shale
PP $\quad 9.62$
84
2.63
41
$-.96$
LR $\quad 8.03$
74
2.63
29
$-.93$

ab. Locks and Dam No. 2, all data combined
$\begin{array}{ll}\text { PP } & 7.51\end{array}$
69
2.02
53
$-.24$
LR $\quad 6.26$
88
2.08
43
$-.90$

def. Locks and Dam No. 4, all moderately hard shale and clayey shale combined

$\begin{array}{llllll}\text { PP } & 5.63 & 79 & 1.57 & 40 & -.90 \\ \text { LR } & 5.29 & 56 & 1.70 & 24 & -.92\end{array}$

abdef. Locks and Dams Nos. 2 and 4, all soft to moderately hard and moderately hard data.

$\begin{array}{llrrrr}\text { PP } & 7.38 & 75 & 1.37 & 55 & -.77 \\ \text { LR } & \text { not calculated } & & & & \end{array}$


Table 4.2

\section{Probabilistic Moments for Residual Shear Strength}

Group

$\underline{E}[\tan \phi] \quad \underline{V_{\tan } \phi}$

a. Locks and Dam No. 2, $\begin{array}{lll}\text { soft to moderately hard shale } & 0.878 & 48\end{array}$

b. Locks and Dam No. 2,

0.798

49 moderately hard shale

g. Locks and Dam No. 4, hard gray shale

ab. Locks and Dam No. 2,

0.838 all data combined

def. Locks and Dam No. 4,

0.504

all moderately hard shale and

clayey shale combined

defg. Locks and Dam No. 4,

0.518

22

all shale

abdef. Locks and Dams Nos. 2 and 4, all shale 


\section{Selected Shale Strengths}

$\underline{\text { Structure }}$

$$
\frac{E[c]}{\text { tsf }} \frac{V_{c}}{\text { percent }} \quad \underline{E[\tan \phi]} \quad \frac{V_{\tan } \phi \varrho_{\text {c,tan }} \phi}{\text { percent }}
$$

Locks and Dam No. 2

$\begin{array}{lccccc}\text { peak strength } & 5.5 & 70 & 1.50 & 45 & -.70 \\ \text { residual strength } & - & - & 0.80 & 50 & --\end{array}$

Locks and Dam No. 3

$\begin{array}{lccccc}\text { peak strength } & 5.5 & 70 & 1.50 & 45 & -.70 \\ \text { residual strength } & - & & 0.64 & 50 & --\end{array}$

Locks and Dam No. 4

$\begin{array}{lccccc}\text { peak strength } & 5.5 & 70 & 1.50 & 45 & -.70 \\ \text { residual strength } & - & - & 0.50 & 25 & --\end{array}$

\section{Discussion}

4.17. The analyses reported herein utilized relatively common statistical procedures based on published existing test results in order to obtain probability moments for a pilot reliability study. As reliability analysis becomes better developed, additional factors should be considered; these are discussed below.

4.18. Bias in Procedure. An important factor not explicitly accounted for in the analyses herein is potential sampling bias. The calculated statistics and probabilistic moments derived therefrom are for the tested materials; it is implied that the untested materials are statistically similar. For shear testing of foundation rocks, this often may be the case, as samples of poor rock may not suitable for testing, and very poor rock may not be recovered. On the other hand, among the rock for which samples are available, weaker samples may be 
deliberately selected for testing. In future analyses used for investment decisions, probabilistic moments should be assigned by.geotechnical professionals knowledgeable about the sitespecific materials. As the purpose and scope of the present study focused on the development of analytical procedures, the test data were assumed to be unbiased.

4.19. Correlation between $c$ and $\tan \phi$. This and previous studies indicated strong negative correlation between $c$ and $\tan \phi$. Neglecting such negative correlation is conservative, but given the relatively high degree of negative correlation, would appear to be overconservative.

4.20. Spatial Correlation. When the mean and standard deviation from test data are used as predictors of the expected value and standard deviation of the strength of the foundation strength of a monolith, an implicit assumption is made that the uncertainty regarding strength at the foundation is as great as the uncertainty regarding a point in the foundation. It has been argued that the variability or uncertainty of strength (or other properties) should decrease as the length or area over which the strength is considered increases. Over large areas, there may be zones of strong and weak materials and the tendency to slide may be dependent on the uncertainty in the average strength over the considered area as opposed to the strength at a point. Considerable research on variance reduction functions has been published, notably by VanMarcke and his colleagues (e.g., VanMarcke, 1977). For the analysis herein, data are typically widely spaced relative to the size of a monolith, and no reduction has been applied to the strength variance to account for spatial correlation. Such techniques may merit further consideration as methodology for navigation structures is further refined. 
PART V: DEVELOPMENT OF A METHODOLOGY FOR SLIDING ANALYSIS LOCKS AND DAM NO. 2, MONOLITH M-16

\section{Problem Description}

5.1. Locks and Dam No. 2. Locks and Dam No. 2 are located at mile 11.2 above the mouth of the Monongahela River. The structure includes a concrete overflow dam and two lock chambers; the landward chamber is $110 \times 720 \mathrm{ft}$ and the riverward chamber is $56 \times 360 \mathrm{ft}$. The structure was originally placed in operation in 1905 . During the period 1949 through 1953, the dam was shortened and new locks were constructed. The present river chamber was placed in service in 1951 and the present land chamber was placed in service in 1953. The dam is founded on piles and timber cribbing; the locks are founded on sedimentary rock comprised of sandstone, siltstone, shale and clay shale. As noted in Part IV, the rock at the base of the lock monoliths is predominately soft to moderately hard shale.

5.2. Monolith M-16 and Rationale for Selection. M-16 is a shale-founded gravity monolith forming a part of the middle wall between the two chambers. A cross-section through the monolith is shown in figure 5.1. The section contains two openings, a filling and emptying culvert and a pipe gallery. The monolith is founded at elevation 672.0, about $2.5 \mathrm{ft}$ below the top of the shale. Soil backfill extends to elevation 690.5 on both sides and is covered by a $1.0 \mathrm{ft}$ concrete fill forming the chamber floor at elevation 691.5. Monolith M-16 was selected as the first monolith for analysis because it provided a relatively simple case for analysis; it is basically a gravity block subjected to horizontal soil and water loads.

5.3. Performance Modes. Monolith M-16 was analyzed for sliding stability, overturning stability, and bearing capacity. For each of these three performance modes, analyses were performed using several performance functions, limit state definitions and probabilistic analysis methods and results were compared. The results of the sliding analyses are reported herein; results of overturning and bearing analysis are reported in Parts VI and VII, respectively. 


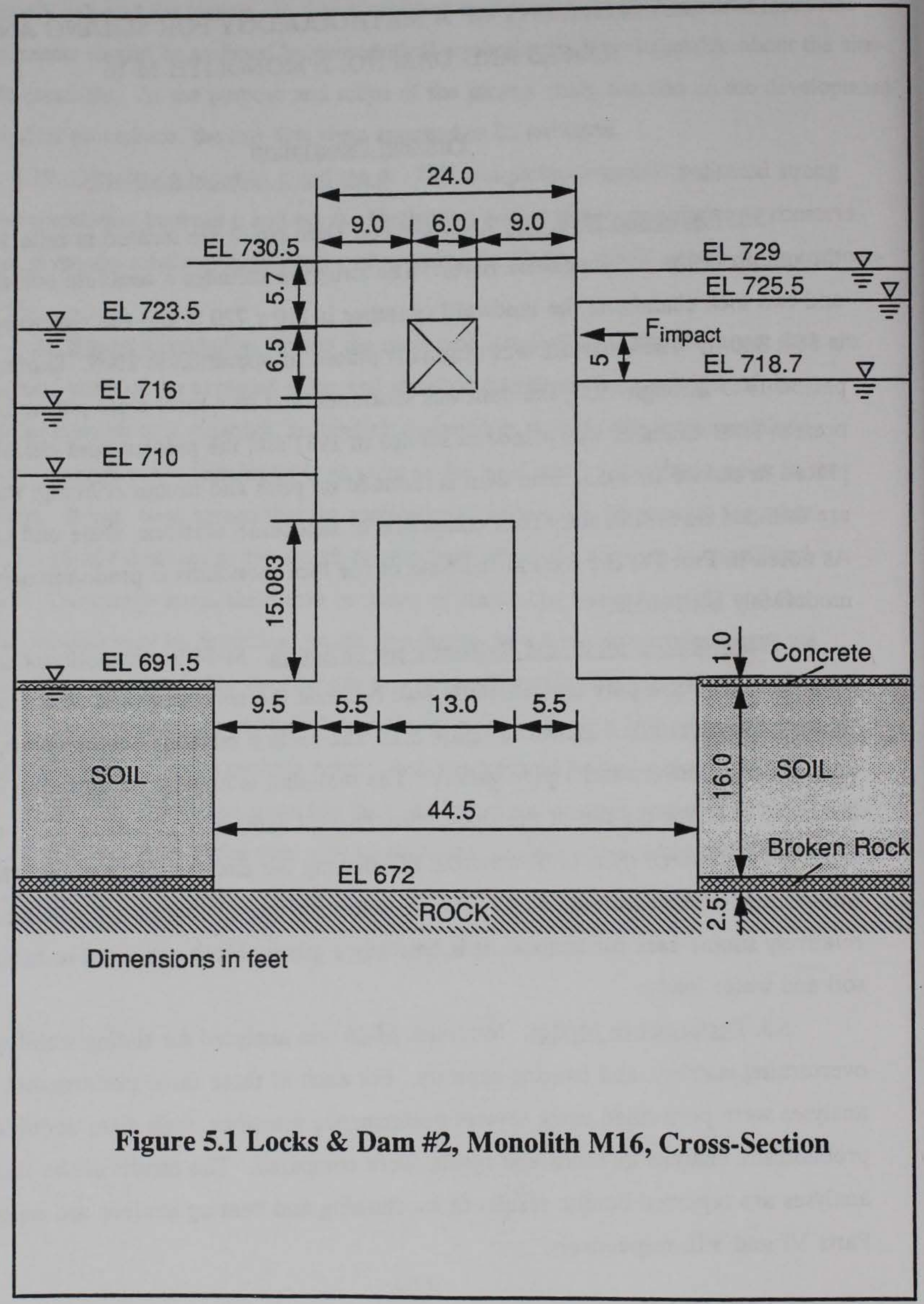


5.4. Water Levels for Analysis. As M-16 is a middle wall monolith, the upper pool is assumed to act on one side and the lower pool on the other side. The following water levels were used for analysis:

$\begin{array}{llll}\text { Case } & \text { Upper Pool } & & \text { Lower Pool } \\ \text { Normal Operating (A) } & 718.7 & & 710.0 \\ \text { Maintenance (A) } & 718.7 & 691.5 \\ \text { High Water (A) } & 729.0 & 723.5 \\ \text { Normal Operating (B) } & 725.5 & 716.0 \\ \text { Maintenance (B) } & 724.7 & 691.5\end{array}$

There may be intermediate combinations of water levels more critical than those analyzed; the scope of the present study was limited to the cases cited. The normal operating cases represent commonly-prevailing conditions at the lock. The maintenance cases correspond to the lock chamber being dewatered for inspection or maintenance with the river at a normal or moderately high level. The high water case corresponds to water levels just before the locks would go out of operation. The three (A) conditions were analyzed first and water levels are consistent with those assumed in various analyses previously performed by the Corps. The two (B) conditions were added later as the research work progressed and represent water levels which could occur and may correspond to lower reliability indices. The (B) conditions also assume a more adverse uplift pressure distribution.

\section{Characterization of Random Variables}

5.5. Variables taken as random variables for the sliding analyses include the submerged soil density, $\gamma_{\text {soil }}$, the strength parameter $\phi_{\text {soil, }}$, the foundation rock strength parameters $c_{\text {rock }}^{\prime}$ and $\tan \phi_{\text {rock }}^{\prime}$ the density of concrete, $\gamma_{\text {concrete, }}$ and an uplift parameter, E. These variables were assigned mean values and standard deviations based on analysis of actual data, experience, and judgment. In addition, a negatively-valued correlation 
correlation coefficient, $\rho_{c, \tan \phi}$, was assigned to characterize the joint probability of $c_{\text {rock }}$ and $\tan \phi_{\text {rock. }}^{\prime}$ The values assigned are listed in Table 5.1; the rationale for their selection is given in the following paragraphs.

5.6. Variables such as the density of water and geometric dimensions were assigned deterministic values due to their very low coefficients of variation. The impact force was taken as a deterministic variable for sliding analysis; despite its relatively large uncertainty, its magnitude is small compared to other forces causing sliding.

5.7. Soil and concrete density. The expected value of the submerged soil density, $0.0755 \mathrm{kcf}$, corresponds to a total soil density of $138 \mathrm{pcf}$ which is the value given in the condition survey. The expected value of concrete density was taken as $0.15 \mathrm{kcf}$. The coefficient of variation of 5 percent for both parameters is based on experience. It will be shown later in this Part that uncertainty in density contributes little to the overall uncertainty and could be neglected in the analysis.

5.8. Soil strength parameters. The moments of the soil strength parameters $\phi$ ' and $\tan \phi^{\prime}$ were assigned based on experience and judgment. The reader is referred to Harr (1987) for typical coefficients of variation for soil parameters. First, the strength parameter $\phi$ ' was assumed to have a mean of 33 degrees and a coefficient of variation of 10 percent, which corresponds to a standard deviation of 3.3 degrees. For probabilistic analyses in geotechnical engineering, taking the parameter $\tan \phi^{\prime}$ as the random variable rather than $\phi$ ' is often preferred as it simplifies calculations and has physical significance as it represents the coefficient of internal friction. For the assumed mean and standard deviation of $\phi^{\prime}$, the corresponding mean and standard deviation of $\tan \phi^{\prime}$, (which may be estimated by Taylor's series or the point estimate method as described in paragraphs 3.30 and 3.32 ) are 0.6525 and 0.08209 respectively.

5.9. Rock strength parameters. The probabilistic moments of the rock strength parameters c' and $\tan \phi$ ' for various data groupings have been discussed in detail in part IV. The means, standard deviations, and correlation coefficients selected and shown in Table 5.1 were chosen to model a rock strength somewhat greater than that for the soft shale group (a) but somewhat less than that of the soft and moderately hard shale groups (ab) taken together. 
Table 5.1

Locks and Dam No. 2, Monolith M-16

Random Variables for Sliding Analysis

$\underline{\text { Variable }}$

(1) $\gamma_{\text {soil }}^{\prime}$

(2) $\phi_{\text {soil }}^{\prime}$

(2) $\tan \phi_{\text {soil }}^{\prime}$

(3A) $c_{\text {rock }}$ (peak)

(4A) $\tan \phi_{\text {rock }}^{\prime}$

(peak)

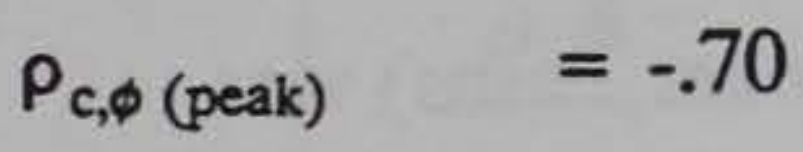

Mean

$0.0755 \mathrm{kcf}$

$33 \mathrm{deg}$

0.6525

$11.0 \mathrm{ksf}$

1.50 $\underline{\sigma}$

0.003775

$3.3 \mathrm{deg}$

0.08209

0.77

0.675

0

0

(residual)

(4B) $\tan \phi_{\text {rock }}^{\prime}$ (residual)

(5) $\gamma_{\text {concrete }}$

$.15 \mathrm{kcf}$

(6A) Uplift parameter, E 0.6667

(6B)

0.250

0.40

5

10

0.80

$.0075 \mathrm{kcf}$

5

0.1047

0.1443

50

$\mathrm{V}, \%$

12.58

70

45

15.7

57.7 
5.10. Uplift Factor. The distribution of uplift pressure on the base of a monolith may be significantly uncertain. For design purposes, the variation of uplift pressure is often taken to be linearly decreasing from headwater pressure at one side of the base to tailwater pressure at the other side of the base. However, observations at dam structures where piezometric data are available show that actual uplift pressures may often be lower than this assumption. Conversely, uplift pressures could be higher than the straight-line assumption where drainage is blocked. Uncertainty in the uplift pressure distribution is modeled by a random variable $\mathrm{E}$, which might be considered a drainage efficiency. The definition of $\mathrm{E}$ is in figure 5.2. The common assumption of a linearlyvarying uplift distribution from headwater to tailwater corresponds to the condition $\mathrm{E}=$ 0 ; the assumption of the uplift pressure equaling tailwater pressure across the entire base is represented by the condition $\mathrm{E}=1.0$, and the assumption of headwater pressure across the base is represented by $E=-1.0$. Intermediate $E$ values correspond to conditions between these conditons. For the initial analyses, or (A) water levels, a "default" the value of $\mathrm{E}$ reflecting some degree of drainage (as observed under dams) was assumed. For this case, E was judged to be closer to 1.0 than 0.0 . Therefore, it was taken to have a beta distribution, with limits of 0.0 and 1.0, and an expected value of $2 / 3$. To obtain a reasonable standard deviation, a spreadsheet program was used to plot the distribution, and a value of 0.1047 provided a reasonable shape as shown in Figure 5.3. For the later analyses using the (B) water levels, it was decided model a lower and perhaps more realistic $\mathrm{E}$ value. $\mathrm{E}$ was taken to be uniformly distributed on the interval $(0,0.50)$ which corresponds to an expected value and standard deviation of 0.25 and 0.1443 respectively.

\section{Performance Functions}

5.11. Two performance functions were used to assess sliding. The first, termed the simple method, takes the limit state as the event that the ratio of driving and resisting forces equals one. The second, termed the CSLIDE method is based on the Corps of Engineers' current design guidance found in ETL 1110-2-256 (U.S. Army, 1981) 

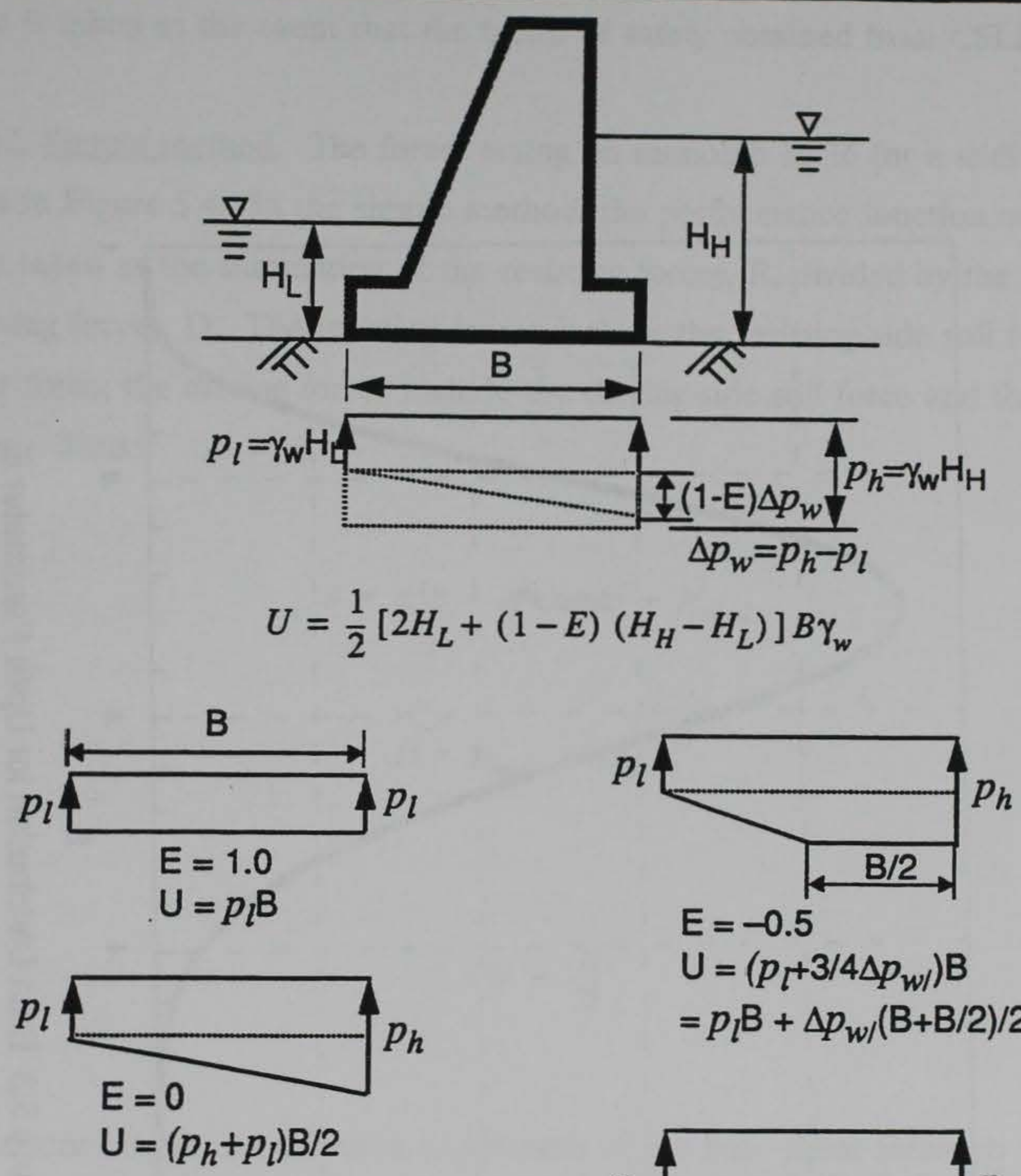

$E=-0.5$

$\mathrm{U}=\left(p_{l}+3 / 4 \Delta p_{w /}\right) \mathrm{B}$

$=p_{l} \mathrm{~B}+\Delta p_{w /}(\mathrm{B}+\mathrm{B} / 2) / 2$
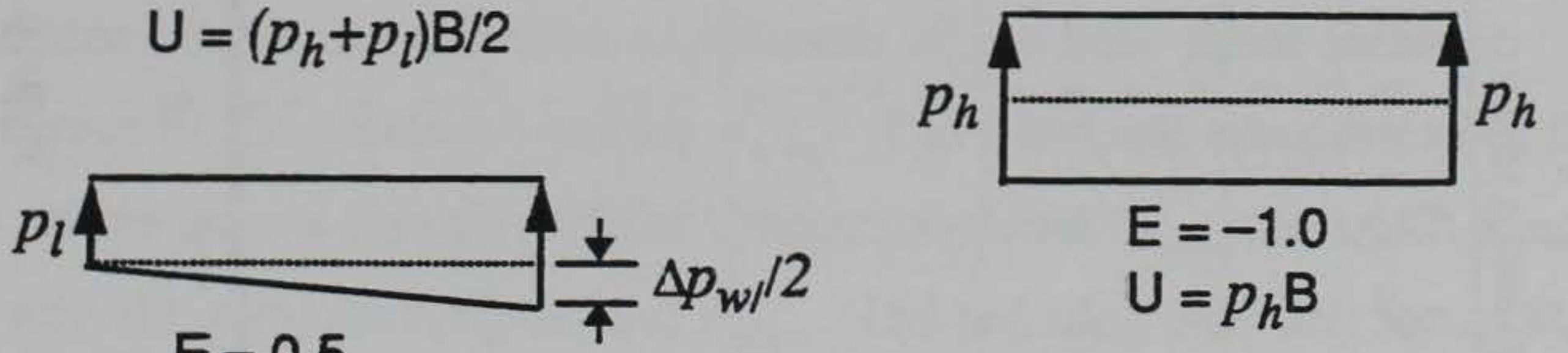

$E=0.5$

$$
\begin{aligned}
& \mathrm{E}=-1.0 \\
& \mathrm{U}=p_{h} \mathrm{~B}
\end{aligned}
$$

$\mathrm{U}=\left(2 p_{l}+\Delta p_{w /} / 2\right) \mathrm{B} / 2$

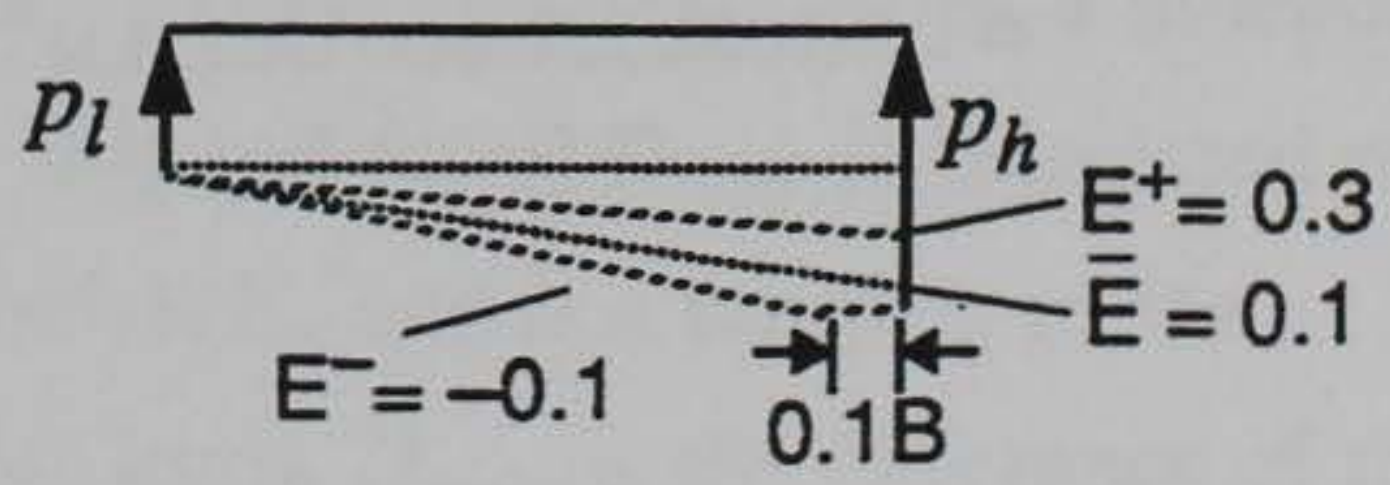

Figure 5.2 Definition of Hydraulic Uplift Force 


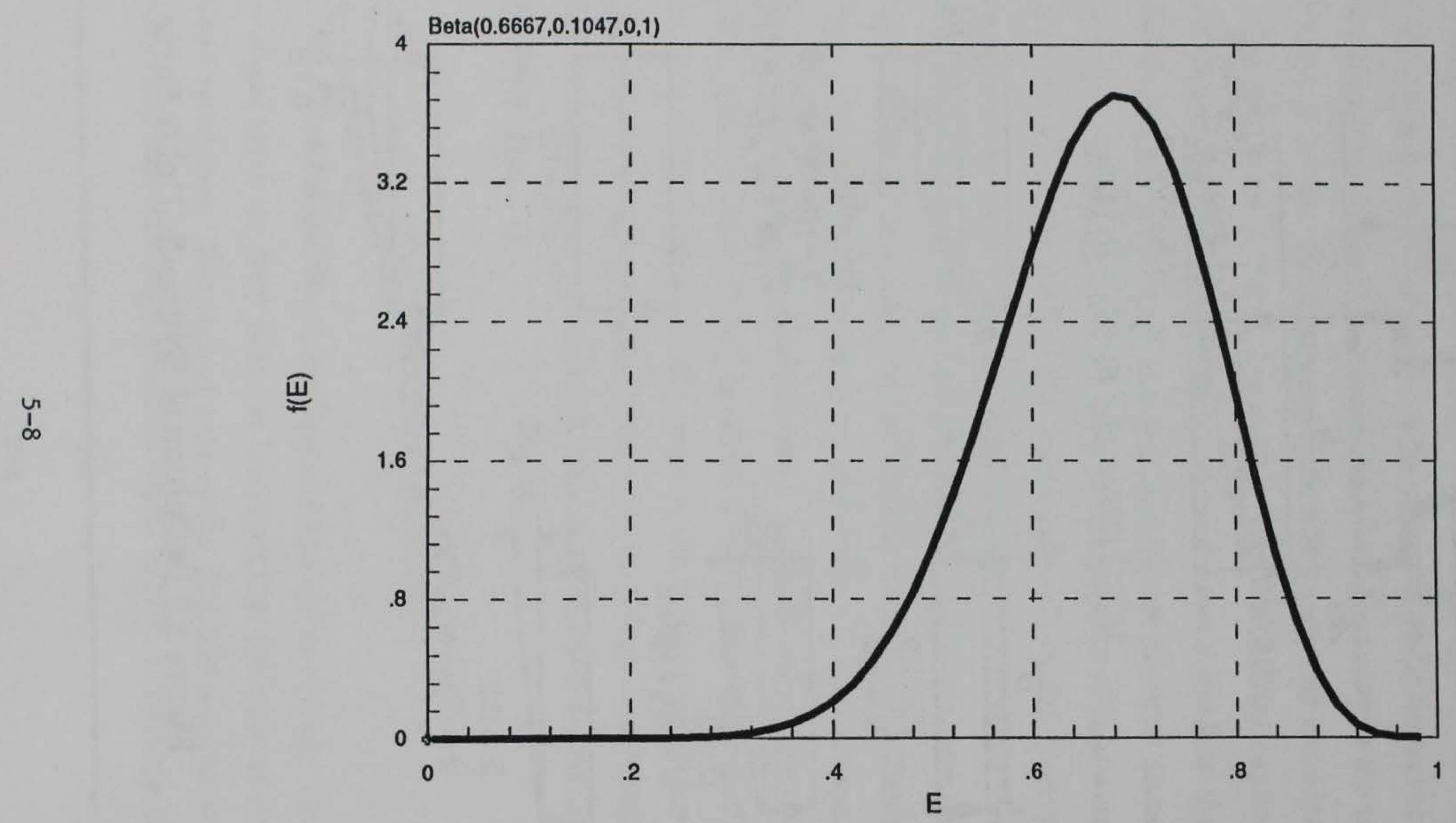

Figure 5.3 Beta Distribution for Uplift Parameter E 
and implemented in the program CSLIDE (Pace and Noddin, 1987). In this method the limit state is taken as the event that the factor of safety obtained from CSLIDE equals one.

5.12. Simple method. The forces acting on monolith M-16 for a sliding analysis are shown in Figure 5.4. In the simple method, the performance function or factor of safety was taken as the summation of the resisting forces, $R$, divided by the summation of the driving forces, D. The resisting forces include the resisting-side soil force and base shear force; the driving forces include the driving-side soil force and the net driving water force. Thus:

$$
\begin{gathered}
R=C^{\prime} B+N^{\prime} \tan \phi^{\prime}+R_{\text {soi } 1} \\
D=D_{\text {soil }}+D_{\text {pool }}
\end{gathered}
$$

and

$$
F S=\frac{R}{D}
$$

In the equations above, the cohesion component of the base shear force, $c^{\prime} \mathrm{B}$, is a function of the random variable $\mathrm{c}_{\text {rock- }}$. The frictional component of the base shear force, $N^{\prime} \tan \phi$, is a function of the random variable $\gamma_{\text {conc }}$ the uplift random variable $U$ and the random variable tan $\phi_{\text {rock }}$. The resisting side soil force, $R_{\mathrm{SR}}$ is calculated using the passive pressure coefficient, $\mathrm{K}_{\mathrm{p}}=\tan ^{2}(45+\phi / 2)$, and is a function of the random variables $\gamma_{\text {soil }}^{\prime}$ and $\phi_{\text {soil. }}^{\prime}$ The driving side soil force, $\mathrm{D}_{\text {soil }}$ is calculated using the active passive pressure coefficient, $K_{a}=\tan ^{2}(45-\phi / 2)$, and is a function of the random variables $\gamma_{\text {soil }}^{\prime}$ and $\phi_{\text {soil }}^{\prime}$. The driving water force, $\mathrm{D}_{\text {pool }}$, is the difference of the horizontal water forces on the two sides of the structure. The effective base resultant force, $N^{\prime}$ is: 


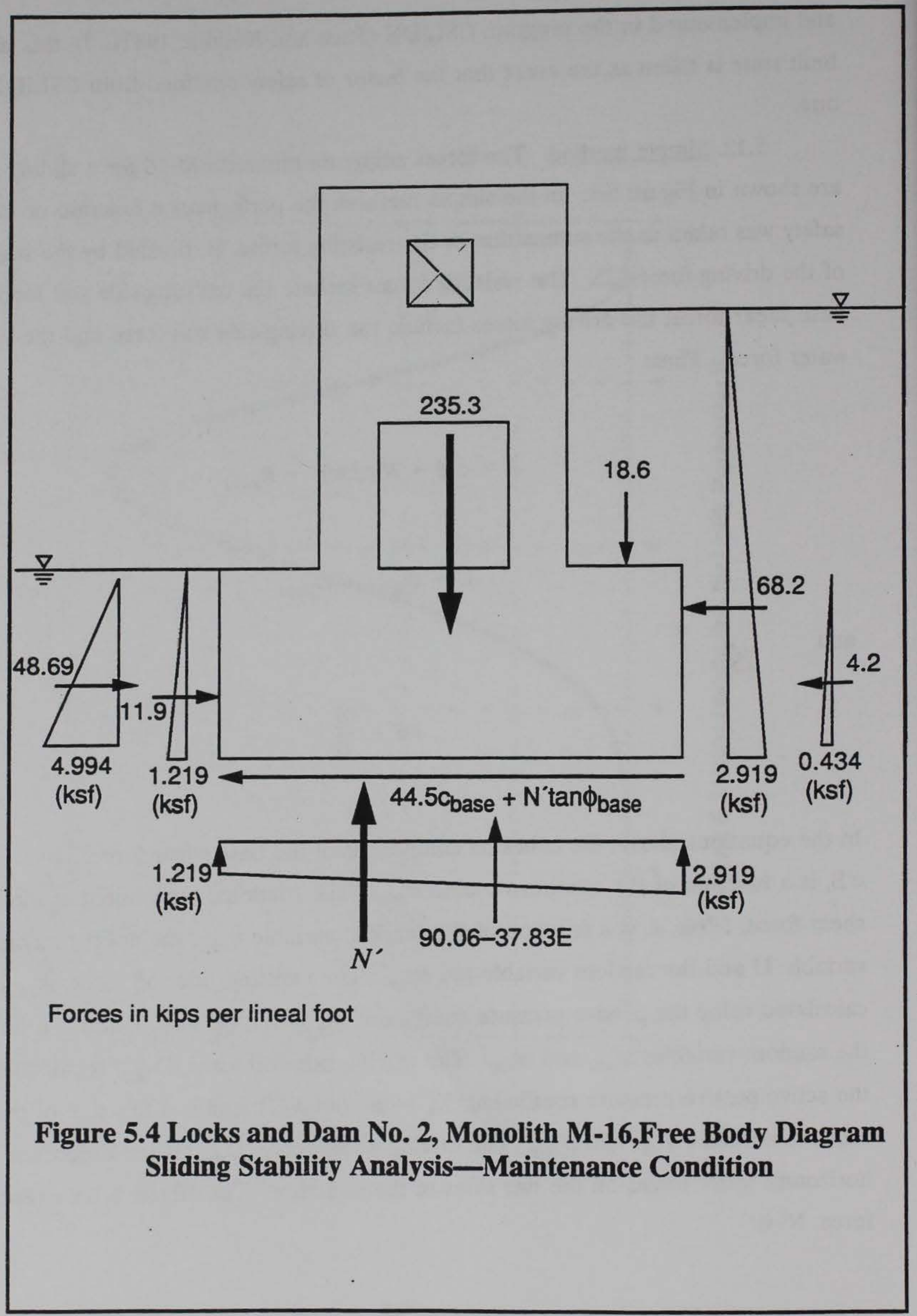




$$
N^{\prime}=A_{\text {conc }} \gamma_{\text {conc }}+A_{\text {water }} \gamma_{\text {water }}-U
$$

where $\mathrm{A}_{\text {conc }}$ and $\mathrm{A}_{\text {water }}$ are the cross-sectional areas of the concrete and the water above base. The uplift force, $\mathrm{U}$, is in turn a function of the uplift parameter $\mathrm{E}$, and the total heads at the driving-side and resisting-side corners of the base, $H_{D}$, and $H_{R}$, respectively:

$$
U=\left[H_{D}+(0.5)(1-E)\left(H_{R}-H_{R}\right)\right] \gamma_{W} B
$$

5.13. CSLIDE method. In the CSLIDE method, the factor of safety is directly determined using the computer program CSLIDE. The program takes the factor of safety as the ratio of the available soil and rock shear strength to the shear stress required for equilibrium of a group of soil wedges, water wedges, and structural wedges above the assumed failure planes. CSLIDE applies a trial factor of safety (equal for all soil and rock materials) to the strength parameters ' $c^{\prime}$ and tan $\phi^{\prime}$ in an iterative manner until a value is found which satisfies force equilibrium the assumed sliding mass. This value is taken as the actual factor of safety.

\section{Probabilistic Models.}

5.14. The mean and standard deviation of the two performance functions were determined using both the Taylor's series method and the point estimate method. These four combinations provided four estimates of the reliability index for each of the (A) pool and uplift level combinations for both peak and residual rock strength parameters, for a total of 24 reliability index values. Additionally, the (B) pool level and uplift combinations were analyzed using the simple method and peak strengths using both the Taylor's series and point estimate methods.

5.15. Simple method with Taylor's series. As described in paragraph 3.30, the expected value of the factor of safety is approximated by calculating the factor of safety 
taking all variables at their mean values:

$$
E[F S] \approx F S\left(E\left[c_{\text {rock }}\right], E\left[\tan \phi_{\text {rock }}\right], \ldots\right]
$$

A first order estimate of the variance of the factor of safety is obtained by summing the variances of the random variables each multiplied by the square of the partial derivative of the factor of safety with respect to the random variable. To account for correlation, a second summation is added. Thus:

$$
\operatorname{Var}[F S]=\sum\left(\frac{\partial F S}{\partial X_{i}}\right)^{2} \operatorname{Var}\left[X_{i}\right]+2 \sum \frac{\partial F S}{\partial X_{i}} \frac{\partial F S}{\partial X_{j}} \operatorname{Cov}\left(X_{i} X_{j}\right)
$$

For the simple method, the derivatives were obtained analytically. There is one covariance term for each combination $\left(X_{i}, X_{j}\right.$, where $i$ does not equal $j$ ) of random variables. As there are 6 random variables in the analysis, there are 15 combinations of two random variables that can be formed from six; thus there are 6 variance terms and 15 covariance terms in the above equation. However, as $\tan \phi_{\text {rock }}$ and $c_{\text {rock }}$ are the only correlated variables, all but one of the covariance term are zero. A detailed example of the analysis procedure is provided in Appendix A.

5.16 Simple method with point estimate method. The point estimate method has been summarized briefly in paragraphs 3.33 and is further discussed by Rosenblueth (1975, 1981) and Harr (1987). To obtain the probabilistic moments of the factor of safety, each random variable is represented by two values, or "point estimates," each with an associated probability concentration. For example, the random variable $\tan \phi$ may assume the values $\left(\tan \phi_{+}\right)$and $\left(\tan \phi_{-}\right)$with probabilities $P_{+}$and $P_{-}$, respectively. For symmetrically distributed random variables, as assumed herein, the point estimates of the random variables are located at the mean plus one standard deviation and the mean minus one standard deviation. For independent random variables, the probability concentrations for each point estimate for each random variable are 0.5 . Where two of the variables are correlated, such as $c$ and $\tan \phi$ herein, the product of their two point 
estimates changes from $(0.5)(0.5)$ to

$$
\left(\mathrm{P}_{\mathrm{c}_{+}}\right)\left(\mathrm{P}_{\tan \phi+}\right)=\left(\mathrm{P}_{\mathrm{c}_{-}}\right)\left(\mathrm{P}_{\tan \phi_{-}}\right)=(0.5)(0.5)+(0.25)\left(\rho_{\mathrm{c}, \tan \phi}\right)
$$

and

$$
\left(P_{c+}\right)\left(P_{\tan \phi}\right)=\left(P_{-}\right)\left(\begin{array}{l}
\tan \phi_{+} \\
)
\end{array}\right)(0.5)(0.5)-(0.25)\left(\rho_{c, \tan \phi}\right)
$$

For $\rho=-0.70$ these products are 0.425 and 0.075 as compared to 0.25 and 0.25 for the case of uncorrelated variables. The factor of safety is calculated for each possible combination of the plus and minus point estimates, which requires $2^{\mathrm{N}}$ analyses, where $\mathrm{N}$ is the number of random variables. The expected value of the factor of safety is obtained by weighting each factor of safety by the product of the corresponding probability concentrations and summing the results. For six random variables, 64 calculations of the factor of safety are required. The mean and standard deviation of the factor of safety is taken as the mean and standard deviation of the $2^{\mathrm{N}}$ point estimates. A convenient way to obtain the standard deviation is to determine the variance by squaring each factor of safety, finding the expected value of the squares, and using the following identity:

$$
\operatorname{Var}[F S]=E\left[F S^{2}\right]-(E[F S])^{2}
$$

The numerous analyses required were accomplished by writing a simple but custom computer program. A detailed example of the method is provided in appendix A.

5.17. CSLIDE method with Taylor's series. The analysis using CSLIDE with Taylor's series is similar in concept to that described above for the simple method, except that the factor of safety function is evaluated using CSLIDE. The required partial derivatives were obtained numerically as described in paragraph 3.31 by taking all random variables at their mean values except the variable for which the partial derivative is required. Two program runs were made with this random variable taken a uniform 
increment above and below its mean and the partial derivative was taken as the change in factor of safety divided by the difference of the two values used for the random variable. For functions that are non-linear with respect to one or more variables, the value of the partial derivative depends on the increment used. Although very small increments should normally be used to precisely estimate a derivative at a particular point, a broader increment equal to the standard deviation was used herein to better model the variability of the function over a broad range of the random variable. Thus the required partial derivatives were obtained as follows:

$$
\frac{\partial F S}{\partial X}=\frac{F S\left(X+\sigma_{X}\right)-F S\left(X-\sigma_{X}\right)}{2 \sigma_{X}}
$$

The use of Taylor's series with numerically estimated derivatives requires $2 \mathrm{~N}+1$ analyses, where $\mathrm{N}$ is the number of random variables. The $2 \mathrm{~N}$ runs are used to obtain the derivatives, and the additional run provides the mean. For six random variables, 13 runs of Taylors's series were required,

5.18. CSLIDE method with point estimate method. The combination of CSLIDE and point estimate method is analyzed similarly to that for the simple method, except that the function used for the factor of safety is obtained from CSLIDE. As six random variables would require 64 runs of CSLIDE, only the four most significant random variables were used, reducing the required runs to 16 . The variables $\gamma_{\text {soil }}^{\prime}$ and $\gamma_{\text {concrete }}$ were taken as deterministic, leaving the random variables $c_{\text {rock }}, \tan \phi_{\text {rock }}, E, \phi_{\text {soil }}^{\prime}$

5.19. Definition of Reliability Index. For all analyses, the reliability index is defined using the lognormal definition described in paragraph 3.35.

\section{$\underline{\text { Results }}$}

5.20. Results. Results of the analyses are shown in Tables 5.2 and 5.3 for assumptions of peak and residual strength, respectively. 


\section{Discussion}

5.21. Expected Values of Factor of Safety. For all combinations of deterministic and probabilistic models and strength assumptions, the greatest expected factor of safety is obtained for the high water case. The factor of safety is slightly somewhat lower for the normal operating case, and considerably lower (but more than adequate) for the maintenance (B) case. The minimum value of 2.33 is obtained using the simple method as the performance function, either probabilistic model, and assuming residual strengths. The minimum expected factor of safety for the peak strength assumption is 10.01 and occurs for similar assumptions. Such values are typically associated with well-performing structures and the structure considered has in fact performed well with regard to stability.

5.22. Reliability Indices. For the peak strength assumption, reliability indices are typically in the range 8-10 for the high water and normal operating cases, and 6 to 8 for the maintenance cases. These values indicate a high degree of reliability. The minimum value of 2.15 was obtained using the simple method as the performance function, using Taylor's series to obtain probabilistic moments, and assuming residual strength. Based on the history of the structure, it is not perceived that the use of residual strengths. values in fact reflect prevailing conditions; the analyses were performed to provide a comparison.

5.23. Effect of Performance Function. In some case, the CSLIDE method provided lower reliability indices that did the simple method. In other cases, the situation was reversed. When the point estimate method was used, the CSLIDE method generally provided higher reliability indicies.

5.24. Effect of Probabilistic Model. For the simple method, the Taylor's series and point estimate methods produce nearly identical results, which should be expected as the factor of safety for this method is a linear function. Results were close even though the Taylor's series used six random variables and the point estimate method only four. For the CSLIDE method, wherein the factor of safety function is nonlinear with respect to strength, the Taylor's series method produced lowere values for both the expected 
Table 5.2

\section{Locks and Dam No.2. Monolith M-16}

Results of Sliding Analyses Using Peak Strengths

\begin{tabular}{|c|c|c|c|c|c|}
\hline Condition & $\frac{\text { Deterministic }}{\underline{\text { Model }}}$ & $\frac{\text { Probabilistic }}{\underline{\text { Model }}}$ & $\mathrm{E}[\underline{\mathrm{FS}}]$ & $\underline{\sigma}_{\mathrm{FS}}$ & $\underline{B}$ \\
\hline \multirow{4}{*}{$\begin{array}{l}\text { Normal } \\
\text { operating (A) }\end{array}$} & Simple method & Taylor series & 28.96 & 10.17 & 9.70 \\
\hline & Simple method & Point estimate & 28.97 & 10.17 & 9.70 \\
\hline & CSLIDE & Taylor series & 30.00 & 11.31 & 9.02 \\
\hline & CSLIDE & Point estimate & 31.38 & 11.29 & 0.77 \\
\hline \multirow[t]{4}{*}{ Maintenance (A) } & Simple method & Taylor series & 13.47 & 4.49 & \\
\hline & Simple method & Point estimate & 13.48 & 4.49 & 7.86 \\
\hline & CSLIDE & Taylor series & 13.12 & 4.70 & 7.18 \\
\hline & CSLIDE & Point estimate & 13.77 & 4.70 & 8.61 \\
\hline \multirow{4}{*}{$\begin{array}{l}\text { High } \\
\text { Water (A) }\end{array}$} & Simple method & Taylor series & 33.13 & 12.42 & 9.47 \\
\hline & Simple method & Point estimate & 33.15 & 12.42 & 9.47 \\
\hline & CSLIDE & Taylor series & 35.77 & 13.98 & \\
\hline & CSLIDE & Point estimate & 37.32 & 13.95 & 10. \\
\hline Normal & Simple method & Taylor series & 22.47 & 8.22 & 0 \\
\hline Operation (B) & Simple method & Point estimate & 22.48 & 8.25 & 6.59 \\
\hline \multirow[t]{2}{*}{ Maintenance (B) } & Simple method & Taylor series & 10.01 & 3.49 & 54 \\
\hline & Simple method & Point estimate & 10.01 & 3.49 & \\
\hline
\end{tabular}


Table 5.3

Locks and Dam No.2, Monolith M-16

Results of Sliding Analyses Using Residual Strengths

Condition

Deterministic Model

Probabilistic

$\mathrm{E}[\underline{\mathrm{FS}}] \underline{\sigma}_{\mathrm{FS}}$

$\underline{\beta}$

Normal

operating (A)

Simple method Model

Simple method

Taylor series

$\begin{array}{ll}6.70 & 2.51\end{array}$

Point estimate

$6.73 \quad 2.52$

5.08

CSLIDE

Taylor series

$6.06 \quad 2.76$

3.95

CSLIDE

Point estimate

$6.60 \quad 2.75$

4.53

Maintenance (A)

Simple method
Simple method

Taylor series

$3.25 \quad 1.24$

3.01

Point estimate

$3.26 \quad 1.24$

3.02

CSLIDE

CSLIDE

Taylor series

$\begin{array}{ll}2.80 & 1.29\end{array}$

2.24

Point estimate

$3.09 \quad 1.31$

2.67

High

Water (A)

Simple method

Taylor series

$7.25 \quad 2.64$

5.44

Simple method

Point estimate

$7.28 \quad 2.65$

5.46

CSLIDE

CSLIDE

Taylor series

$\begin{array}{ll}6.94 & 3.20\end{array}$

4.20

Point estimate

$7.54 \quad 3.10$

4.91

Normal

Simple method

Taylor series

$\begin{array}{ll}5.01 & 2.20\end{array}$

4.40

Operation (B)

Simple method

Point estimate

$\begin{array}{ll}5.03 & 2.19\end{array}$

4.37

Maintenance (B)

Simple method

Taylor series

$\begin{array}{ll}2.33 & 1.53\end{array}$

2.15

Simple method

Point estimate

$2.33 \quad 1.52$

2.15 
factor of safety and the reliability index than did the point estimate method. For the CSLIDE method, the Taylor's series approach is more conservative. The differences arise because the probability of a high strength is reflected for in the Taylor's series method only as one linear addition to the variance term. On the other hand, with the point estimate method, half the numbers reflect a high expected strength and half reflect a low expected strength, and the expected value increases accordingly.

5.25. Contributions to Uncertainty. An advantage of the Taylor's Series approach is that the portion of the overall uncertainty contributed by each random variable can be explicitly determined. Recalling the expression for the variance of the factor of safety from paragraphs 3.30 and 5.15, it is obtained by summing variance of with each random variable multiplied by the partial derivative of the factor of safety with respect that to random variable. These terms thus reflect each variable relative contribution to total uncertainty. To illustrate, the values of the terms for the normal operating (A) case are as follows:

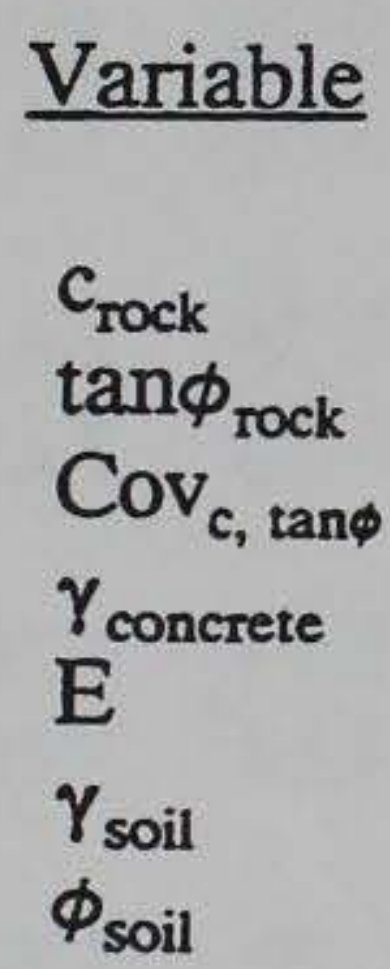

Total

\section{Variable Term}

147.02

16.01

$-67.92$

0.39

0.004

0.015

0.658

96.17

For the considered problem, over 98 percent of the total variance (uncertainty) is contributed by the uncertainty regarding the strength parameters of the foundation rock. 


\section{PART VI: DEVELOPMENT OF A METHODOLOGY FOR \\ OVERTURNING ANALYSIS: \\ LOCKS AND DAM NO. 2, MONOLITH M-16}

\section{Problem Description}

6.1. Locks and Dam No. 2 and monolith M-16 have been described in Part V. In this part, the same loading cases, water levels and uplift assumptions analyzed for stability against sliding are analyzed for stability against overturning. Again, several limit states and probabilistic models are considered for comparison.

\section{Characterization of Random Variables}

6.2. Random variables relevant to overturning analysis include the soil strength parameter $\phi_{\text {soil, }}$, the submerged density of the backfill soil, $\gamma_{\text {soil }}$, the density of concrete, $\gamma_{\text {concerete }}$ the uplift parameter $\mathrm{E}$, and a horizontal force $\mathrm{F}$ representing barge impact or a hawser force. The probabilistic moments of the five random variables are summarized in Table 6.1. The values for the first four random variables are the same as used for the sliding analyses. The lateral force $\mathrm{F}$ is taken to have an expected value of $1.0 \mathrm{kip}$ per lineal foot with a coefficient of variation of 50 percent. The expected value of $1.0 \mathrm{kip}$ per foot is consistent with previous analyses by the Corps of Engineers, and the 50 percent coefficient of variation implies a relatively high degree of uncertainty. Although the force $\mathrm{F}$ was taken as deterministic for sliding analysis, it is taken as probabilistic for overturning analysis due to its greater numerical significance and contribution to uncertainty for this case: it acts at a relatively long moment arm and the uncertainty associated with the strength of the base rock which dominated the sliding analysis does not enter into the overturning analysis. 
Table 6.1

Locks and Dam No. 2, Monolith M-16

Random Variables for Overturning Analysis

$\underline{\text { Variable }}$

Mean

$\underline{\sigma}$

$\underline{\mathrm{V}, \%}$

(1) $\gamma_{\text {soil }}^{\prime}$

$0.0755 \mathrm{kcf}$

0.003775

5

(2) $\phi_{\text {soil }}^{\prime}$

$33 \mathrm{deg}$

$3.3 \mathrm{deg}$

10

(2) $\tan \phi_{\text {soil }}$

0.6525

0.08209

12.58

(3) $\gamma_{\text {concrete }}$

$0.15 \mathrm{kcf}$

$.0075 \mathrm{kcf}$

5

(4 A) Uplift parameter, E

0.6667

0.1046

15.7

(4B)

0.250

0.1443

57.7

(5) Lateral force, F

$1.0 \mathrm{kips} / \mathrm{ft}$

0.5

50

\section{Performance Functions}

6.3. Two functions were used to characterize performance with respect to overturning: the overturning factor of safety and the location of the effective base resultant force. These are described below.

6.4. Overturning Factor of Safety. The free body analyzed consisted of all concrete, water and other materials between the vertical projections of the two ends of the base. The free body is illustrated in figures 6.1 through figure 6.3 for the three (A) conditions analyzed. Moments were calculated about a point of rotation at the edge of the base on the low water side and the safety factor was taken as the ratio of resisting moments to driving moments:

$$
F S=\frac{M_{R}}{M_{O}}
$$




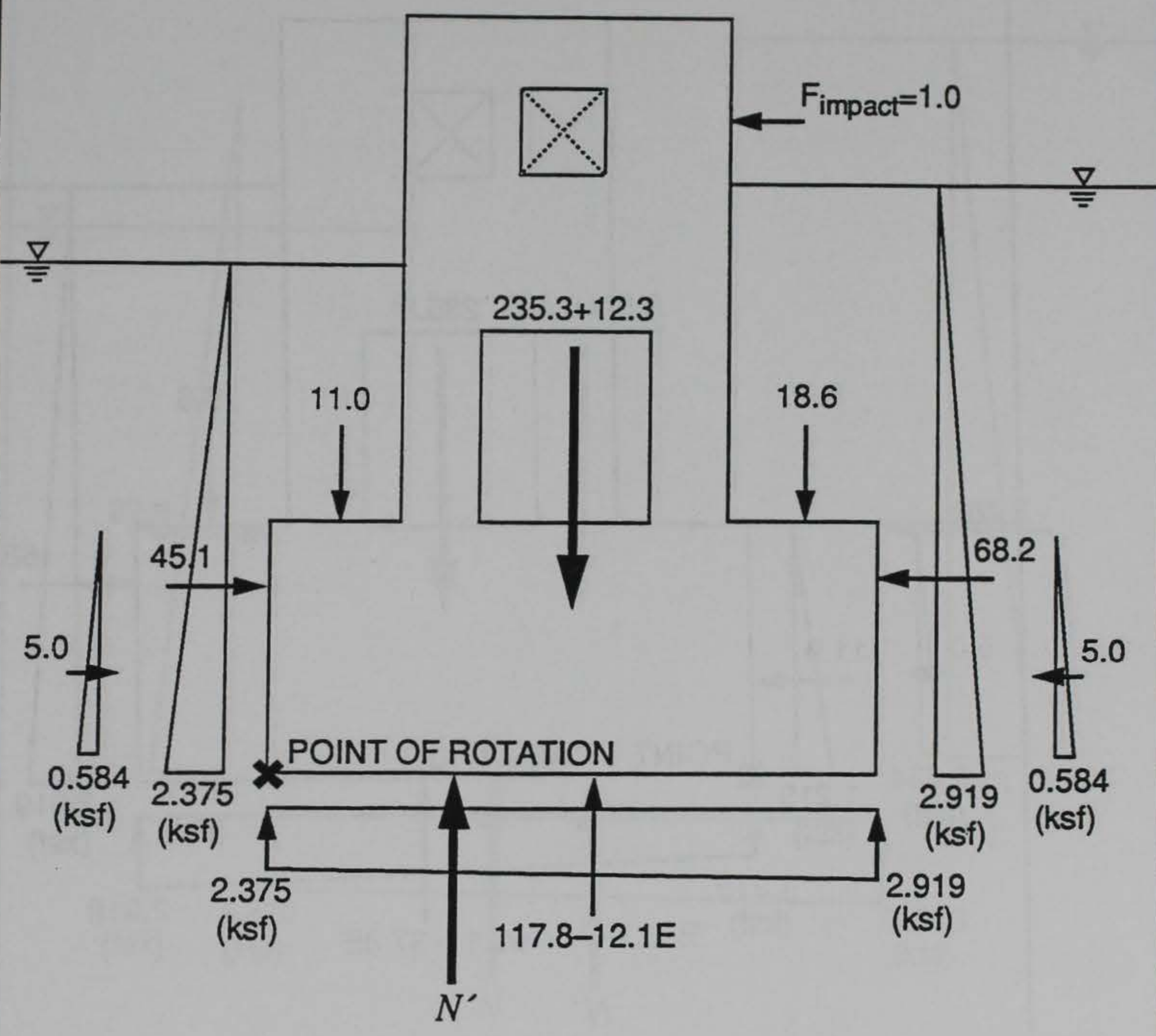

Forces in kips per lineal foot

Figure 6.1 Locks and Dam No. 2, Monolith M-16,Free Body Diagram Overturning Stability Analysis-Normal Operating 


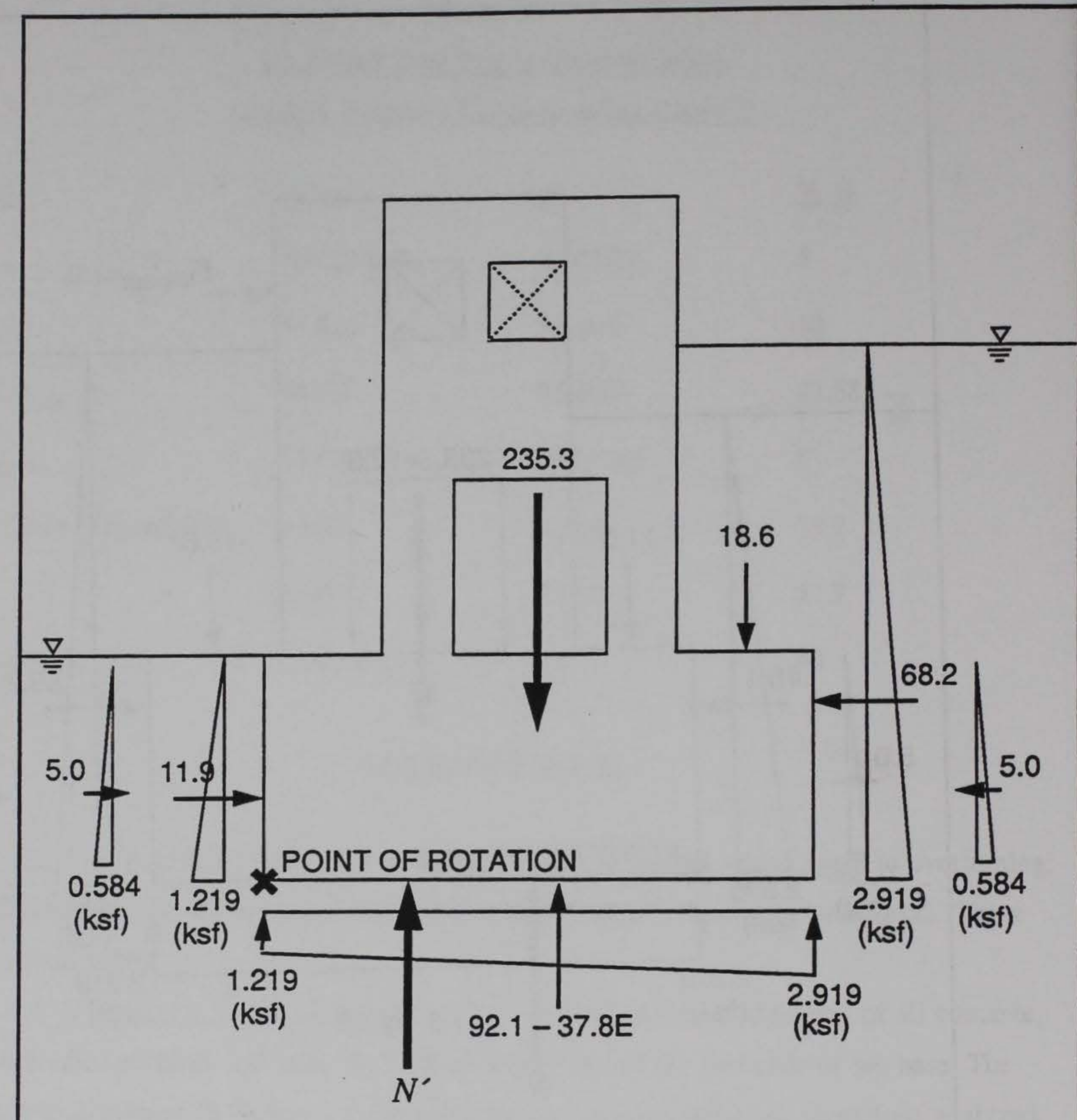

Forces in kips per lineal foot

Figure 6.2 Locks and Dam No. 2, Monolith M-16,Free Body Diagram Overturning Stability Analysis-Maintenance Condition 


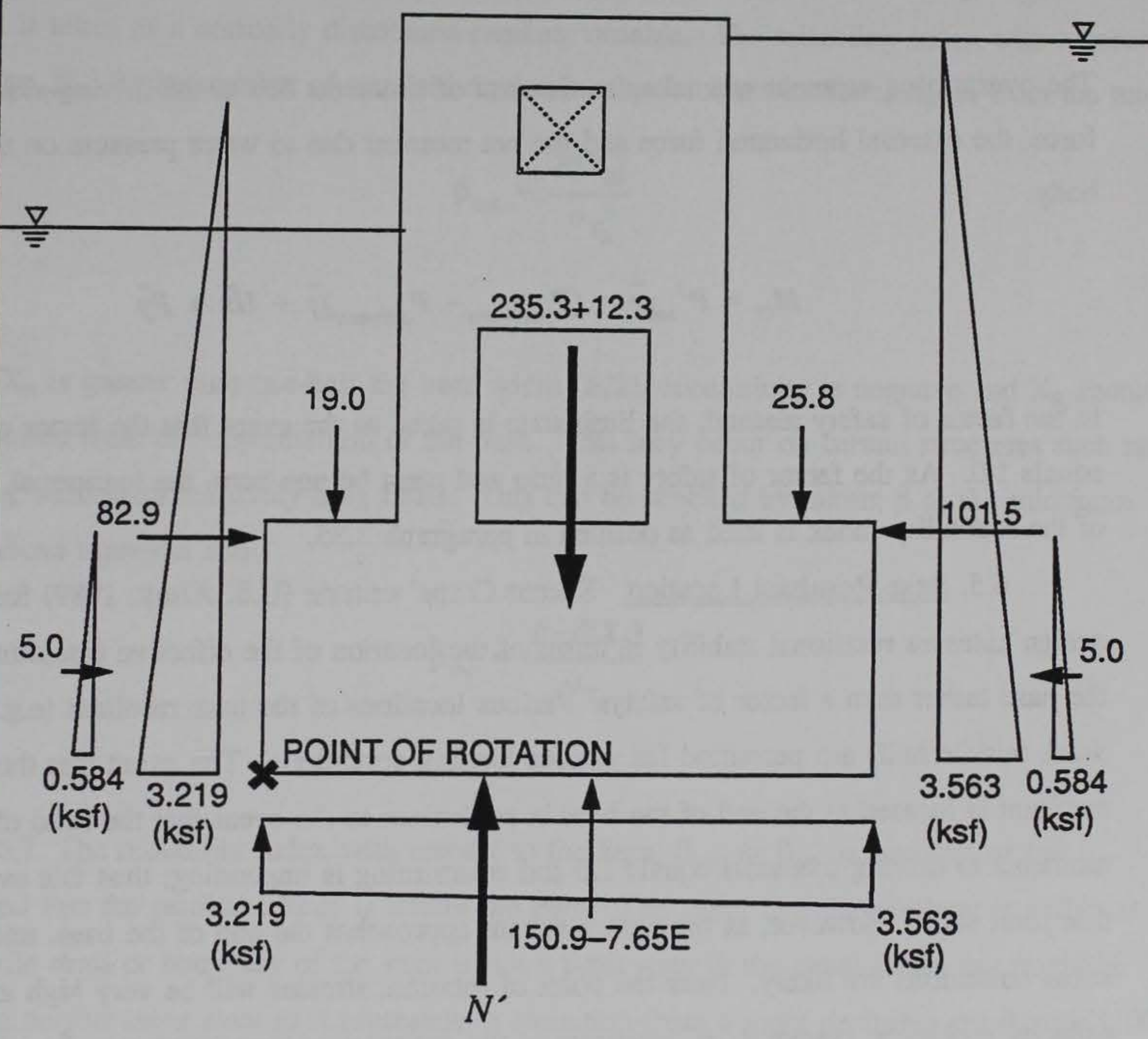

Forces in kips per lineal foot

Figure6.3 Locks and Dam No. 2, Monolith M-16,Free Body Diagram Overturning Stability Analysis-High Water Condition 
In the above equation, the resisting moment $M_{R}$ was taken as the sum of moments due to concrete weight, water weight, and resisting-side lateral soil force:

$$
M_{R}=\Sigma\left(W_{\text {conc }} \bar{x}\right)+\Sigma\left(W_{\text {wase }} \bar{x}\right)+P_{\text {soli }}^{\prime} \bar{y}
$$

The overturning moment was taken as the sum of moments due to the driving-side lateral soil force, the external horizontal force and the net moment due to water pressure on the free body:

$$
M_{O}=P_{\text {soli }}^{\prime} \bar{y}+\left(P_{\text {poohwater }}-P_{\text {tedhwater }}\right) \bar{y}+\overline{U \bar{x}}+F \bar{y}
$$

In the factor of safety method, the limit state is taken as the event that the factor of safety equals 1.0. As the factor of safety is a ratio and must be non-zero, the lognormal definition of the reliability index is used as defined in paragraph 3.35 .

\subsection{Base Resultant Location. Recent Corps' criteria (U.S. Army, 1989) for wall} design assesses rotational stability in terms of the location of the effective resultant force on the base rather than a factor of safety. Various locations of the base resultant (e.g., middlethird, middle half) are permitted for various loading conditions. The event that the base resultant is located at the end of the base is equivalent to the event that the ratio of resisting moments to driving moments equals 1.0 and overturning is impending; thus this event is a true limit state. However, as the base resultant approaches the end of the base, undesirable stress conditions are likely. Near the point of rotation, stresses will be very high and bearing capacity problems, cracking, or overstress of the structure or foundation may be of concern. At the opposite end of the base, stresses will be very low or zero. If the effective base pressure distribution is assumed to be linear, tensile stresses or separation of the base from the foundation will occur if the resultant is outside the middle third of the base (i.e., the kern)

6.6. Accordingly, several additional probabilistic measures were defined in terms of the base resultant location: the reliability index with respect the resultant being within the base, $\beta_{\text {toe }}$ the reliability index with respect to the resultant being within the kern (or $B / 3$ from the toe), $\beta_{\text {kem }}$ or $\beta_{1 / 3}$, and measures relative to the resultant being in the middle one-half $\left(\beta_{1 / 4}\right)$ 
and in the middle two-thirds $\left(\beta_{1 / 6}\right)$. To calculate these measures, these first the mean and standard deviation of the distance from the toe to the resultant force, $\mathrm{X}_{\mathrm{R}}$, are determined using the assumed conditions and random variables in conjunction with the Taylor's series or point estimate method. As the base resultant location, is a distance $X_{R}$ rather than a product or ratio, it is taken as a normally distributed random variable. The reliability index with respect to the toe, $\beta_{\text {toe }}$ is the number of standard deviations the resultant location, $X_{R}$, is from the toe:

$$
\beta_{\text {toe }}=\frac{E\left[X_{R}\right]}{\sigma_{X_{R}}}
$$

Where $X_{R}$ is greater than one-half the base width (B/2), eccentricity is negative and $X_{R}$ should be measured from the opposite end of the base. This may occur on certain structures such as retaining walls with relatively long heels. This can be checked by taking $\beta$ as the minimum of the above equation and

$$
\beta_{t o c}=\frac{B-E\left[X_{R}\right]}{\sigma_{X_{R}}}
$$

6.7. The reliability index with respect to the kern, $\beta_{\mathrm{kem}}$ or $\beta_{1 / 3}$, is measure of the likelihood that the resultant force is within the kern. The event that the resultant is within at the middle third or boundary of the kern is not a limit state in the usual sense, but might be termed a performance state as it represents a transition from a more desirable stress state (100 percent of the base in compression) to a less desirable stress state (less than 100 percent of the base in compression). Assuming the same normal distribution on the resultant force location, $\beta_{\text {kem }}$ measures the distance from the resultant to the nearest third point or kern boundary and is: 


$$
\beta_{\text {kem }}=\frac{E\left[X_{R}\right]-\frac{B}{3}}{\sigma_{X_{R}}}
$$

Continuing with the same reasoning,

$$
\begin{aligned}
& \beta_{1 / 4}=\frac{E\left[X_{R}\right]-\frac{B}{4}}{\sigma_{X_{R}}} \\
& \beta_{1 / 6}=\frac{E\left[X_{R}\right]-\frac{B}{6}}{\sigma_{X_{R}}}
\end{aligned}
$$

where $\beta_{1 / 4}$ and $\beta_{1 / 6}$ are measures of the likelihood that the resultant force is within the middle half and middle two-third of the base, respectively.

\section{Probabilistic Models}

6.8. The overturning analyses assume five random variables which were all taken as independent. The Taylor's series formulation is similar to that for sliding. For five random variables, the required five partial derivatives can be directly calculated analytically or numerically approximated using ten analyses. In the present case, they were obtained analytically. The point estimate method also follows the same formulation as for sliding; five random variables required 32 analyses. A detailed example of the method used is provided in Appendix B. 


\section{$\underline{\text { Results }}$}

6.9. Reliability Indices. The results of the overturning analyses are shown in Tables 6.2 through 6.4 .

\section{Table 6.2}

Locks and Dam No. 2, Monolith M-16,

Results of Overturning Analyses- Factor of Safety

\section{Condition}

Maintenance (A)

Normal Operating (A)

High Water (A)

Normal Operation (B)

Maintenance (B)
Probabilistic

Model

TS

PE

TS

PE

TS

PE

TS

PE

TS

PE
E[FS]

$\underline{\underline{\sigma}}_{P S}$

2.24

2.24

0.14

0.14

13.13

13.14

1.88

0.076

0.075

15.83

1.88

15.82

1.53

1.53

0.050

0.050

12.92

12.92

1.71

1.67

0.073

0.067

12.54

12.76

1.64

0.111

7.22

1.64

0.111

7.25 
Locks and Dam No. 2, Monolith M-16,

Results of Overturning Analyses- Resultant Location

Condition

Maintenance

(A)

Normal Operation

(A)

High Water

(A)

Normal Operation

(B)

Maintenance

(B)
Probabilistic

Model

TS

PE

TS

PE

TS

PE

TS

PE

TS

PE
$\left.\underline{\underline{E}} \underline{X}_{R}\right] \underline{\sigma}_{X R} \quad \underline{B}_{10 e} \quad \underline{B}_{1 / 6} \quad \underline{B}_{1 / 4} \quad \underline{B}_{\text {kerm }}$

$\begin{array}{llllll}17.75 & .36 & 48.8 & 28.4 & 18.2 & 8.01\end{array}$

$\begin{array}{llllll}17.73 & .37 & 48.3 & 28.1 & 18.0 & 7.88\end{array}$

$\begin{array}{llllll}19.04 & .27 & 71.6 & 43.6 & 29.7 & 15.8\end{array}$ $\begin{array}{llllll}19.02 & .27 & 71.0 & 43.3 & 29.4 & 15.6\end{array}$

$\begin{array}{llllll}18.74 & .26 & 71.7 & 43.3 & 29.1 & 15.0\end{array}$

$\begin{array}{llllll}18.72 & .26 & 71.1 & 42.9 & 28.9 & 14.8\end{array}$

\section{Discussion}

6.10. As might be expected for a simple concrete gravity structure with balanced soil loads on both sides, the $\beta$ values are in general quite high for most conditions even when $\beta_{\text {kem }}$ is considered. Although very large values are reported for comparisons, $\beta$ values above perhaps 8 to 10 have little meaning in the comparative sense; the structure is very reliable against overturning and expenditures for remedial work in this regard are not foreseen. For a few analyses, such as maintenance (B), negative values for $\beta_{\text {kem }}$ are calculated. These 
negative values imply that the resultant is more likely to be out side the kern for the considered conditions.

6.11. Effect of Probabilistic Model. The $\beta$ values determined by the Taylor's series method and the point estimate method are nearly equal in all cases. This is to be expected as the both the factor of safety and the resultant ratio are "well behaved" functions and not significantly non-linear.

6.12. Effect of Performance Function. Comparison of factors of safety vs $\beta$ values provides same insight regarding the effects of large and small uncertainty in the underlying variables; even a factor of safety as low as 1.50 may correspond to a very reliable situation $(\beta=13)$. This is due to the dominance of moments with low uncertainty (e.g water) over moments with high uncertainty (e.g soil). In conventional analysis, only the values of these moments are incorporated in the analysis and any measure of their uncertainty or likelihood is disregarded. Probabilistic analysis explicitly include such information. 


\section{PART VII: DEVELOPMENT OF A METHODOLOGY FOR \\ BEARING CAPACITY ANALYSIS \\ LOCKS AND DAM NO. 2, MONOLITH M-16}

\section{Problem Description}

7.1. Locks and Dam No. 2 and monolith M-16 have been described in detail in Part V. In this part, reliability against bearing capacity failure is evaluated for the three (A) loading conditions.

\section{Comments on Performance Mode}

7.2. In the formulation of the study, it was envisioned that a number of example analyses would be performed for sliding, overturning, and bearing capacity performance modes for several structures to serve as modes for further studies on other locks and dams. In the course of the study, it became evident that the selected structures were poor examples for bearing capacity analysis as they are founded on competent rock. These conditions presented several difficulties:

(1). Factors of safety calculated using conventional bearing capacity equations are extremely high (100 or more) and bearing failures in competent rock are not a realistic failure mode. No expenditures are foreseen to improve the bearing capacity of rock foundations.

(2). The bearing capacity factors $\mathrm{N}_{q}$ and $\mathrm{N}_{\gamma}$ are highly non-linear and become extremely large as $\phi$ values exceed 45 degrees. As the foundation rock strength parameters have both high expected values and high coefficients of variation, use of either the point estimate method or the Taylor's series method with numericallyobtained derivatives requires calculating bearing capacity for $\phi$ values as high as 80 degrees. This is a condition for which the equations and certain empirical terms were never intended. (For example, Meyerhof's $N_{\gamma}$ is equal to $\left(\mathrm{N}_{\mathrm{q}}-1\right) \tan (1.4 \phi)$ and for $\phi$ values greater than 60 degrees, $1.4 \phi$ exceeds 90 degrees).

To better assess how bearing capacity analysis can be performed probabilistically, two sets of analyses were performed: 
1. In the first set of analyses, the coefficient of variation of $\tan \phi$ was arbitrarily reduced from 45 percent to 30 percent, which was sufficient to prevent certain calculated values from approaching infinity.

2. In the second set of analyses, it was assumed that the monolith was on a sand foundation rather than competent rock. Although this has no physical significance to Locks and Dam No. 2, it provides a reasonable example of reliability analysis for bearing capacity.

\section{Performance Function}

7.3. All bearing capacity analyses were performed using Meyerhof's method which is consistent with procedures used in the program CBEAR (Mosher and Pace 1982); however, CBEAR was not used as it is not readily amenable to performing numerous runs with differing parameters. Rather, simple, special-purpose computer programs were developed. The ultimate bearing capacity can be expressed as:

$$
Q_{u 1 t}=B\left[C N_{c} F_{c d} F_{c i}+q_{\sigma} N_{q} F_{q d} F_{q i}+\frac{1}{2} B \gamma N_{\gamma} F_{\gamma d} F_{Y i}\right]
$$

The limit state was taken as the event that the factor of safety, or ratio of the ultimate bearing force $\mathrm{Q}_{\mathrm{ult}}$ to the effective base resultant force, $\mathrm{N}$, equals one.

\section{Bearing Capacity of Rock Foundation}

7.4. Random Variables. Nine random variables were considered in the bearing capacity analyses. Their values are summarized in Table 7.1. The effective soil density, $\boldsymbol{\gamma}$ ' is used to calculate the surcharge $q_{0}$ in the second term of the bearing capacity equation. The rock density, $\gamma_{\text {rock }}$, is converted to an effective density and used in the third term of the equation. The cohesion, $c$, is used in the first term. The friction angle $\phi_{\text {rock }}^{\prime}$ is used to evaluate the terms $\mathrm{N}_{c}, \mathrm{~N}_{\mathrm{q}}$, and $\mathrm{N}_{\varsigma}$. The concrete density, $\gamma_{\text {concrete }}$, the uplift parameter $\mathrm{E}$, 
Table 7.1

Locks and Dam No. 2. Monolith M-16

Random Variables for Bearing Analysis on Rock Foundation

$\underline{\text { Variable }}$

(1) $\gamma_{\text {soil }}^{\prime}$

(2) $\gamma_{\text {rock }}$

(3) $c_{\text {rock }}$

(peak)

(4) $\tan \phi_{\text {rock }}^{\prime}$

(4) $\phi^{\prime}$ rock

$\rho_{c . \phi \text { (peak) }}$

(5) $\gamma_{\text {concrete }}$

(6) Uplift parameter, E

(7) lateral force, $\mathrm{F}$

(8) resultant

location, $\mathrm{X}_{\mathrm{R}}$

\section{normal (A)}

maintenance $(A)$

high water $(A)$
Mean

$0.0755 \mathrm{kcf}$

0.147

$11.0 \mathrm{ksf}$

1.50

$54.66 \mathrm{deg}$

$.15 \mathrm{kcf}$

0.6667

$1.0 \mathrm{kip} / \mathrm{ft}$

$19.04 \mathrm{ft}$

17.75

18.74 $\underline{\sigma}$

0.003775

0.00735

0.77

0.450

7.926

$.0075 \mathrm{kcf}$

0.1047

0.50

(9) resultant

inclination, $\alpha$

$$
\text { normal (A) }
$$

maintenance $(A)$

high water (A)
$8.16 \mathrm{deg}$

16.73

7.25
0.267

0.364

0.261
14.5

5

15.7

50.0

$\underline{\mathrm{V}, \%}$

5

5

70

30

1.40

2.05

1.40

0.593

7.26

1.047

6.26

0.577

7.96 
and the lateral force, $\mathrm{F}$ are used to determine the magnitude of the effective base resultant force, $N$ '. The location and inclination of the base resultant force $X_{R}$ and $\alpha$, are taken as random variables with means and standard deviations obtained from the overturning analyses.

7.5 Results Results of the analyses are shown in Table 7.2. It will be noted that the $\beta$ values obtained using for the point estimate method are approximately twice as high as those from Taylor's series for the point estimate method. These differences are due to the calculated mean values of the ultimate bearing capacity being more than ten times greater for the point estimate method than for the Taylor's series method. With the Taylor's series method, the mean value of the function is obtained using a first-order approximation by evaluating the function with all random variables taken at their mean values. Due to the great degree of nonlinearity of the $\mathrm{N}_{q}$ and $\mathrm{N}_{\gamma}$ terms, the mean of the function is underestimated by such first order methods. With the point estimate method, the mean is taken as the mean of $2^{\mathrm{N}}$ function values obtained using the various point estimates; half the point estimates are one standard deviation above the mean and half are one standard deviation below. As the performance function is highly non-linear, the effect of the "plus" point estimates dominates, yielding a higher expected value.

\section{Bearing Capacity of Assumed Sand Foundation}

7.6. As discussed in paragraph 7.2, bearing capacity is not a performance mode of real concern for competent rock foundations and traditional bearing capacity equations such as Meyerhof's and others are not intended for rock materials. To provide a more representative example, analyses were repeated for an assumed foundation on clean sand. Table 7.3 summarizes results assuming foundation parameters $E[\phi]=32$ degrees and $V_{\phi}$ $=10$ percent. Similar analyses performed for expected $\phi$ values of 30 and 35 degrees and coefficients of variation of 5 and 15 percent produced similar results. As the expected value of $\phi$ is one typically used in bearing capacity calculations, and the coefficient of variation is small, the results of the Taylor's series and point estimate methods are much more consistent for this case. 
Table 7.2

Locks and Dam No. 2, Monolith M-16

Results of Bearing Analyses for Rock Foundation

\begin{tabular}{|c|c|c|c|c|c|c|}
\hline $\begin{array}{l}\text { Loading } \\
\text { Condition }\end{array}$ & Method & $\begin{array}{l}\underline{\mathrm{E}\left[\mathrm{O}_{\text {ult }}\right]} \\
\text { (kips/ft) }\end{array}$ & $\begin{array}{l}N^{\prime} \\
\text { (kips/ft) }\end{array}$ & $\underline{E[F S]}$ & $\begin{array}{l}\frac{\sigma_{\text {Qult }}}{\text { (kips/ft) }} \\
\underline{?}\end{array}$ & $\underline{\beta}$ \\
\hline Normal & Taylor's & 621,408 & 168 & 3,709 & $1,210,046$ & 5.93 \\
\hline Operating & $\mathrm{PE}$ & $9,145,500$ & 168 & 54,594 & $9,056,850$ & 12.33 \\
\hline \multirow{2}{*}{ Maintenance } & Taylor's & 417,780 & 187 & 2,232 & 787,670 & 5.63 \\
\hline & PE & $5,806,557$ & 187 & 31,025 & $5,768,565$ & 11.62 \\
\hline \multirow[t]{2}{*}{ High Water } & Taylor's & 627,622 & 147 & 4,283 & $1,220,328$ & 6.05 \\
\hline & $\mathrm{PE}$ & $5,185,996$ & 147 & 62,681 & $9,096,175$ & 12.48 \\
\hline
\end{tabular}

Table 7.3

Locks and Dam No. 2, Monolith M-16

Results of Bearing Analyses for Assumed Sand Foundation

\begin{tabular}{|c|c|c|c|c|c|c|}
\hline $\begin{array}{l}\text { Loading } \\
\text { Condition }\end{array}$ & Method & $\begin{array}{l}\underline{\mathrm{E}\left[\mathrm{Q}_{\text {ult }}\right]} \\
\underline{\text { (kips/ft) }}\end{array}$ & $\frac{\mathrm{N}^{\prime}}{(\text { kips/ft) }}$ & $\underline{E}[\mathrm{FS}]$ & $\begin{array}{l}\underline{\sigma}_{\text {Qult }} \\
\text { (kips/ft } \\
\end{array}$ & $\underline{\beta}$ \\
\hline Normal & TS & 17,158 & 168 & 102 & 7,497 & 10.72 \\
\hline Operating (A) & $\mathrm{PE}$ & 16,237 & 168 & 97 & 8,170 & 9.06 \\
\hline \multirow[t]{2}{*}{ Maintenance (A) } & TS & 12,395 & 187 & 66 & 5,746 & 9.19 \\
\hline & PE & 11,622 & 187 & 62 & 6,264 & \\
\hline \multirow[t]{2}{*}{ High Water (A) } & TS & 17,364 & 147 & 119 & 7,559 & 11. \\
\hline & $P E$ & 16,430 & 147 & 112 & 8,237 & \\
\hline
\end{tabular}




\section{Discussion}

7.7. The general bearing capacity equation is non-linear, and the effects of nonlinearity became much more pronounced as $\phi$ become large. The competent foundation rock on the Monongahela River have high $c$ and $\phi$ values but their magnitudes are quite uncertain, and thus these parameters have been assigned large coefficients of variation. Taken together, these three items lead to a situation for which the reliability analysis techniques in part 4 are not amenable. Calculated $\beta$ values differ greatly depending on the probabilistic method employed. For the highly-nonlinear conditions involved with the rock foundation, calculated values for mean and standard deviation of the ultimate bearing capacity were more than ten times greater for the point estimate method than for the Taylor's Series method. Comparison of the underlying assumptions of the two method suggests that the values obtained using the point estimate method are more correct. The Taylor's method neglects terms above the first order, which may be significant for non-linear equations. The point estimates method solution reflects some of the non-linearity in its use of point estimate above and below the mean. Based on the point estimate method, the reliability indices are above eleven, which indicates a high degree of reliability.

7.8. Some of the problems with non-linearity might be avoided using the iterative Hasofer-Lind mehtod (described in paragraph 3.36) to determine the reliability index. This was beyond the scope of the present study and it was also apparent that bearing capacity would not govern reliability.

7.9. For the assumed sand foundation, results of the Taylor's series and point estimate method were much more consistent.

7.10. The correlation of the strength parameters $c$ and $\phi$ greatly affects the results of the analysis. The more negatively correlated, the greater the reliability index. 


\section{PART VIII: CHARACTERIZATION OF ANCHOR RELIABILITY \\ FOR LOCKS AND DAM NO. 3}

\section{$\underline{\text { Introduction }}$}

8.1. Permanent anchorage to rock has been a common technique to remedy stability problems, including those at Corps' locks and dams. This part reviews the engineering aspects of ground anchors with a view toward defining the parameters necessary to quantitatively characterize their capacity as a component in sliding and overturning reliability analyses.

8.2. A condition survey and structural investigation of Locks and Dam 3 on the Monongahela River in the Pittsburgh District was conducted in 1974-1975. The investigation (USAEWES,1976) concluded that the locks and dam, the oldest in the Pittsburgh District, suffer a severe degree of deterioration that might accelerate. A major rehabilitation program was implemented in 1978-1980. Among the repairs was an attempt to improve the stability of several walls by the use of rock anchors.

8.3. Ground anchors are a relatively recent innovation for the solution of stability where uplift or overturning forces predominate (Hanna, 1982). Hanna defines an anchor as :

"a sub-structural member which transmits a tensile force from the main structure to the surrounding ground. The tensile force in the anchor is the necessary force for equilibrium between the anchor, the structure to which it is attached, and the ground in which the anchor is embedded."

Thus, ground or rock anchors are used to improve the overturning stability of lock walls by increasing the downward force acting on the wall. This, in turn, permits development of greater horizontal shear forces to resist sliding.

8.4. Although there are a number of types of ground anchors, this review focuses on the anchors that were installed at Locks and Dam No. 3. These anchors have the following 
characteristics:

a. They were intended to be permanent anchors.

b. They are anchored in rock.

c. The tendons are prestressed bars.

d. They are installed in a potentially aggressive environment.

e. The foundation rock may be of poor quality.

Regarding items d. and e above, the anchorage passes through a coal seam. Some statistics on the installation are summarized in Table 8.1 below. The monolith selected for analysis, M-20, is located in the middle wall between two locks.

Table 8.1

Characteristics of Anchors at Locks and Dam No. 3

\begin{tabular}{|c|c|c|c|c|c|}
\hline Wall & No. & Diam. & Prestress & Grout & Failure \\
\hline & & inches & Force, Kips & & $\underline{\text { Rate }}^{*}$ \\
\hline Flume & & 1.375 & 142.8 & Cement & \\
\hline Land & 23 & $1 "$ & 25 & Cement & \\
\hline Middle & 128 & $1.25^{\prime \prime}$ & 112.5 & Resin & $17 / 128$ \\
\hline River & 76 & $1.25^{\prime \prime}$ & 112.5 & Resin & $18 / 76$ \\
\hline
\end{tabular}

* Refers to (failed anchors / total anchors) at time of installation.

\section{Potential Failure Modes}

8.5. Littlejohn (1974) listed the following potential failure modes for potential ground anchors: 

a. Failure of the rock mass
b. Failure of the grout/rock bond
c. Failure of the grout/steel bond
d. Failure of the steel tendon

To assess the overall reliability of a ground anchor, these modes must be studied and carefully characterized. Some observation relevant to Locks and Dam 3 are discussed below:

8.6. Failure of rock mass. Rock masses commonly contain joints and fissures of unknown geometry that limit the application of simple methods to calculate the load capacity of the rock mass. Failure of the rock mass surrounding the anchor would reduce the anchor force, reducing the overall stability of the structure. The Engineering Condition Survey (USAEWES, 1976) for Lock and Dam No. 3 indicates that in many places, the rock was weathered or badly fractured. Borehole photo logs showed that the rock contained voids and had poor contact with the concrete foundation. Thus, there is some basis for concern regarding integrity of the rock mass. One common measure of the minimum capacity of a rock anchor is to assume the anchor resistance to be limited to the weight of rock lying within an inverted cone extending from the anchor tip to the foundation. Taking a cone with an apex angle of 60 degrees, the volume of rock is $0.346 \mathrm{~L}^{3}$, where $\mathrm{L}$ is the length of the bonded anchor. Taking the rock density as $168 \mathrm{pcf}$ and $\mathrm{L}$ as twenty feet, a minimum resistance of $465 \mathrm{kips}$ is obtained which is well above the $112.5 \mathrm{kip}$ force to which the anchors were initially stressed. However, a potentially corrosive thin coal seam may be present in the range 12 to $19 \mathrm{ft}$ beneath the structure. Assuming bonding above the coal only and taking $\mathrm{L}$ as $12 \mathrm{ft}$, only 100 kips would be available. Thus, the probability distribution on an anchor force depends on whether the coal seam is present and if so, whether the anchor has been corroded.

8.7. Failure of the grout/rock bond. When an anchor is loaded, stresses are transmitted from the grout column to the ground in the form of radial and shear stresses. At Locks and Dam No. 3, the anchors were injected in straight shafts, where the load transfer relies mainly on the development of skin friction or shear in the region of the grout/rock interface. The working bond stress is usually assumed to be uniformly distributed along the anchor length. 
However, some recent studies suggest that an exponential shape for the bond stress function provides a better estimate for the actual behavior of ground anchors. In any case, some of the grout at Locks and Dam No.3 is known to have been poorly mixed, and some grout holes were drilled over-size. As a result personnel familiar with the installation have expressed little confidence in the capacity of the grout/rock bond. As shown in Table 8.1, 17 of 128 anchors on the middle wall failed during initial testing, and these failures were considered to be the result of poor grouting (mixing and /or placement).

8.8. Failure of the grout/steel bond. The main function of the grout is to attach the steel tendons to the ground in the fixed anchor length (Hanna, 1982). Studies of the bond stresses between the grout and steel tendons have confirmed that bond for plain steel tendons depends primarily upon adhesion prior to slip and upon friction after slip occurs. An exponential function has been found to be the best-fit model to describe the bond stress at different points on the length of the anchor. Again, the known conditions of poor mixing and over-size holes at Locks and Dam 3 cast some doubt on the quality of the grout/steel bond.

8.9. Failure of steel tendons. Failure of steel tendons is in principle the same problem as it is for ordinary prestressed concrete structures, but for rock anchors the conditions are typically much more severe. The environment in which the anchors are set is generally more aggressive, with a high degree of humidity, and with likely presence of salt solutions. Corrosion and stress relaxation are considered the major reasons for the steel tendons failure in ground rock anchors. Ground anchors are subjected mainly to three different types of corrosion (Portier,1974):

(1). Corrosion by generalized dissolution (chemical corrosion): reduction in crosssection due to an attack by acids,

(2) Corrosion by pitting (electro-chemical corrosion): leads to formation of holes due to the presence of a foreign ion causing a local concentration of stresses, and

(3) Corrosion with crack formation under tension (physical corrosion): affects carbon steels subjected to a high tensile stress.

At Locks and Dam No.3, the anchors pass through a coal seam, and there is same doubt as to the integrity of the grout bond between the steel tendon and the corrosive coal. If the grout is not properly protecting the steel, corrosion may lead to a case of tendon failure in the future, 
or perhaps such failure may have already taken place.

\section{Uncertainty and Variability of Initial Anchor Load}

8.10. Typically anchors are stressed to a measured load at installation and locked off. Thus, the initial loads are known rather accurately and the coefficient of variation of the initial anchor load should be small, perhaps 5 percent.

\section{Variability of Load with Time}

8.11. Due to rock creep, the shrinkage and creeping of the structural concrete, and from the compression of the anchor root in the rock, stress relaxation occurs leading to a reduction in the tendon prestressing force. Hobst (1977) defined the ratio of the effective tendon force to the initial prestressing force as the coefficient of efficiency. A value of 0.7 was suggested for the coefficient of efficiency of ground anchors. A study by Littlejohn and Bruce (1979) on the long term behavior of rock anchors has provided significant and relevent information. Ten anchors were instrumented for a period up to 33,000 hours (3.7 years). The results showed two phases of prestressing losses with time; a rapid loss that occurs within the first 16 weeks, followed by a slower and uniform load loss.

8.12. The reduction in the tendon force can, to a large extent, be avoided if anchors are re-stressed after initial loading. It has been found that if prestressing is properly executed, the loss in the long run is minimal. For example, a reduction in stress of only $3 \%$ was found when anchors in sandstone of the Cheurfas Dam in Algeria anchors in sandstone were checked after 20 years of service (Hobst and Zajic, 1977); likewise, anchors in sandstone and shale at the Nosice Dam in Slovakia showed only a 2.4 per cent reduction in stress after 19 months of service. However, at Locks and Dam No.3, the anchors were apparently not restressed. 


\section{Considerations for Multiple Anchors}

8.13. Similar to the behavior of groups of closely-spaced pile, ground anchors placed closely will interact and the behavior of a typical ground anchor in a group will differ from that of an isolated anchor. Several studies on the issue confirmed that the load sharing amongst the anchors in a cluster is non-uniform and the load efficiency of a group of anchors is less than one. The French code of practice suggests a reduction factor as a function of the spacing between adjacent anchors and the radius of the cone of influence at the ground surface, (Hanna, 1982).

\section{Quantification of Anchor Uncertainty for Locks and Dam No.3}

8.14. Corrosion and Stress Relaxation. Corrosion and stress relaxation are considered the major reasons for force reduction of steel tendons in ground rock anchors. In order to account for these variabilities in the statistical description of rock anchor's behavior, the initial prestress and time variation thereof could be modeled as described below, based on studies by Mirza and MacGregor (1979), and Mirza and Kikuchi (1980).

8.15. Initial Prestressing Stress. If prestressing is properly executed, the actual initial prestressing force should match very closely the nominal initial prestressing force. As in the case of prestressed concrete, the initial prestressing force $\mathrm{P}_{\mathrm{i}}$ is the maximum operative force stressing the anchor during its life-time. At Lock and Dam No.3, $\mathrm{P}_{\mathrm{i}}$ will be assumed to be normally distributed with a mean of 112 kips and a standard deviation of 2.5 kips as shown on figure 8.2.

8.16. Prestressing-Time Relationship: Due to stress relaxation (creep) and steel corrosion, a negative exponential relationship may be assumed to represent the prestressing force at any time t. The relationship is proposed to be modeled by the form:

$$
P(t)=P_{(1)} \theta^{-b t^{0 . c b}}
$$


where $P(i)$ is the initial prestressing stress.

$\mathrm{b}$ is 0.02 ; a factor to represent the rate of prestressing loss. $(0.01-0.02)$ $t$ is time in years.

This function is plotted in figure 8.1. Assuming that the rate of the change of the prestressing loss will follow the relationship suggested, the actual prestressing force at any time $t$ could be assumed normally distributed with an expected value equal $\mathrm{P}(\mathrm{t})$ as calculated from equation above 1 , and a standard deviation equal to:

$$
\sigma_{p(t)}=\frac{E\left[P_{i}+3 \sigma_{p t}-E[P(t)\right.}{3 P_{1}}
$$

where $t$ : is the time in years. This assumption for $\sigma_{p(t)}$ provides two desired features: the standard deviation increases with time as the expected value decreases, but a reasonable upper bound (mean $+3 \sigma)$ remains constant.

8.17. Ground Anchor Head Location: It will assumed that all ground anchors were placed on the average in their intended locations using engineering surveying techniques. It will further be assumed that the deviation from the theoretical location in any direction is normally distributed with mean zero and a standard deviation of 0.40 inches. The resulting distribution is shown in figure 8.3.

8.18. Anchor Verticality: Very little information is known about this variable. However, transferring knowledge from to the research done in the area of pile construction (Wolff, 1990), as a first approximation, it would be reasonable to assume that the deviation from vertical will have a mean of zero and a standard deviation of 3 degrees. A normal distribution would be assumed and is shown in figure 8.4.

8.19. Probability of Functionality. The proposed time-variant characterization of anchor force is a set of conditional moments that are condtioned on the event that a given anchor is in fact functional and has not already failed due to causes listed in paragraph 8.5. At Locks and Dam No.3, there are expressed concerns relative to installation procedures and 


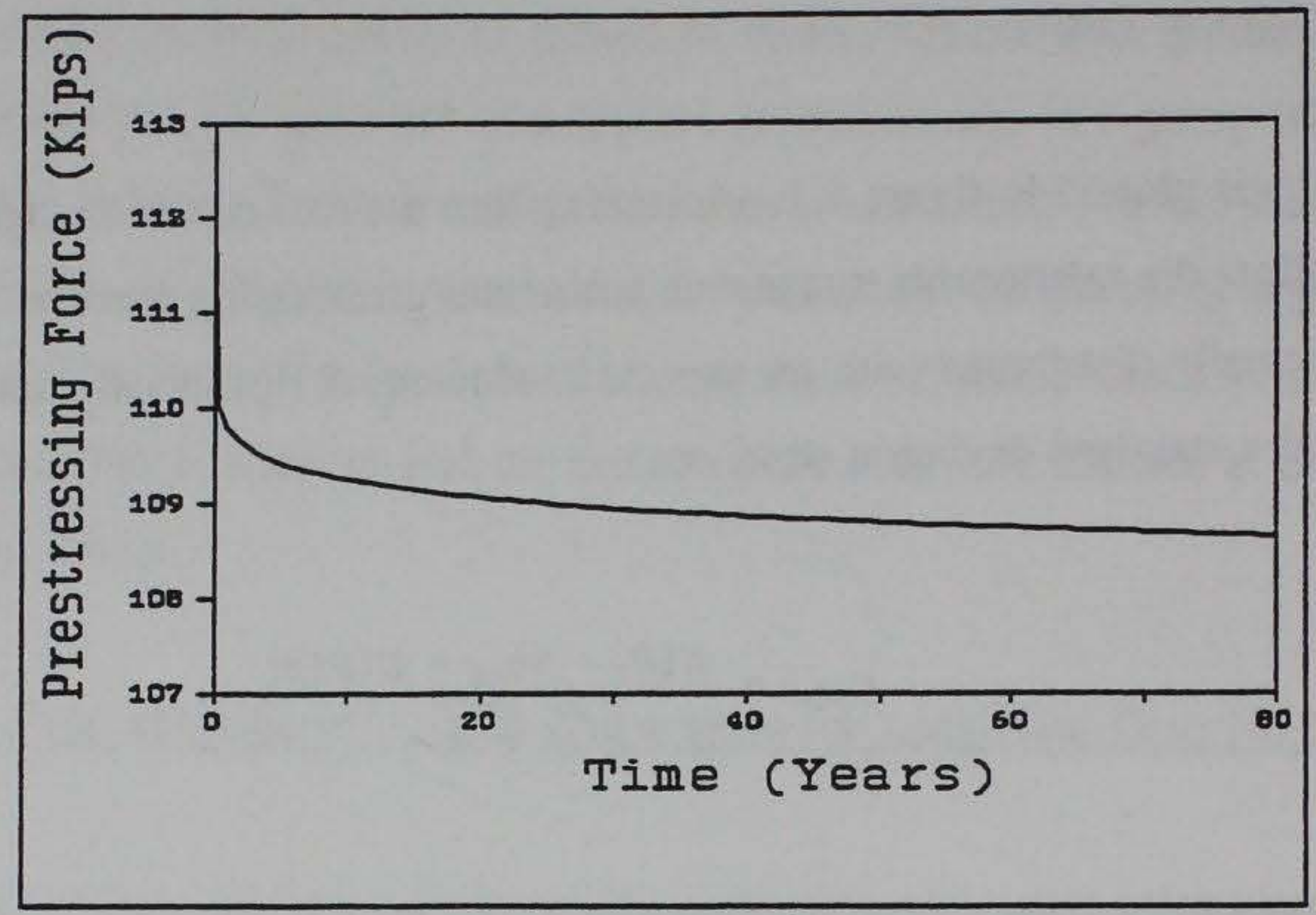

Figure 8.1 Assumed Variation of Expected Anchor Force with Time

Initial Prestressing N(112, 2.5)

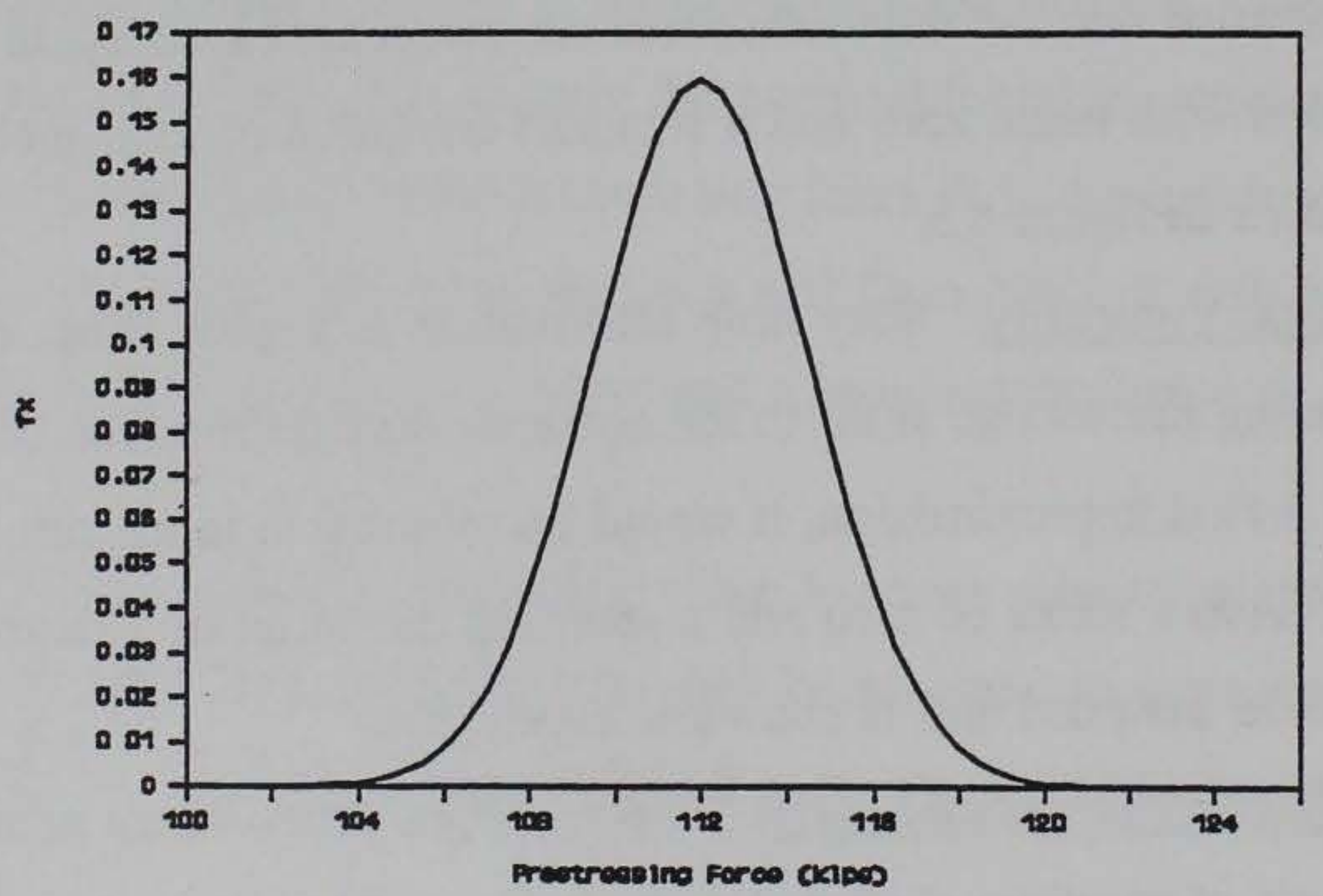

Figure 8.2 Assumed Distribution of Initial Prestressing Force 


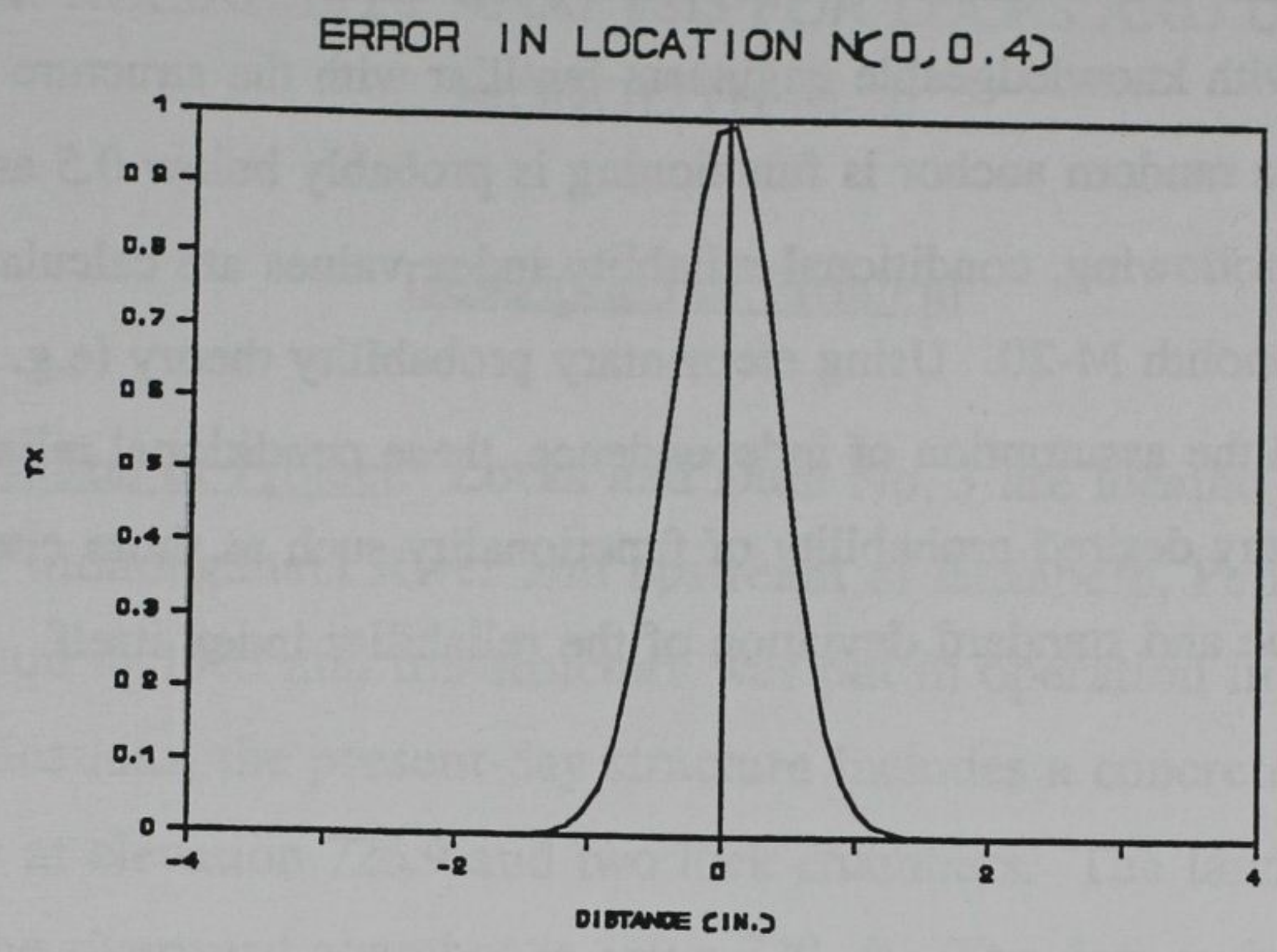

Figure 8.3 Assumed Distribution of Anchor Location at Top of Monolith

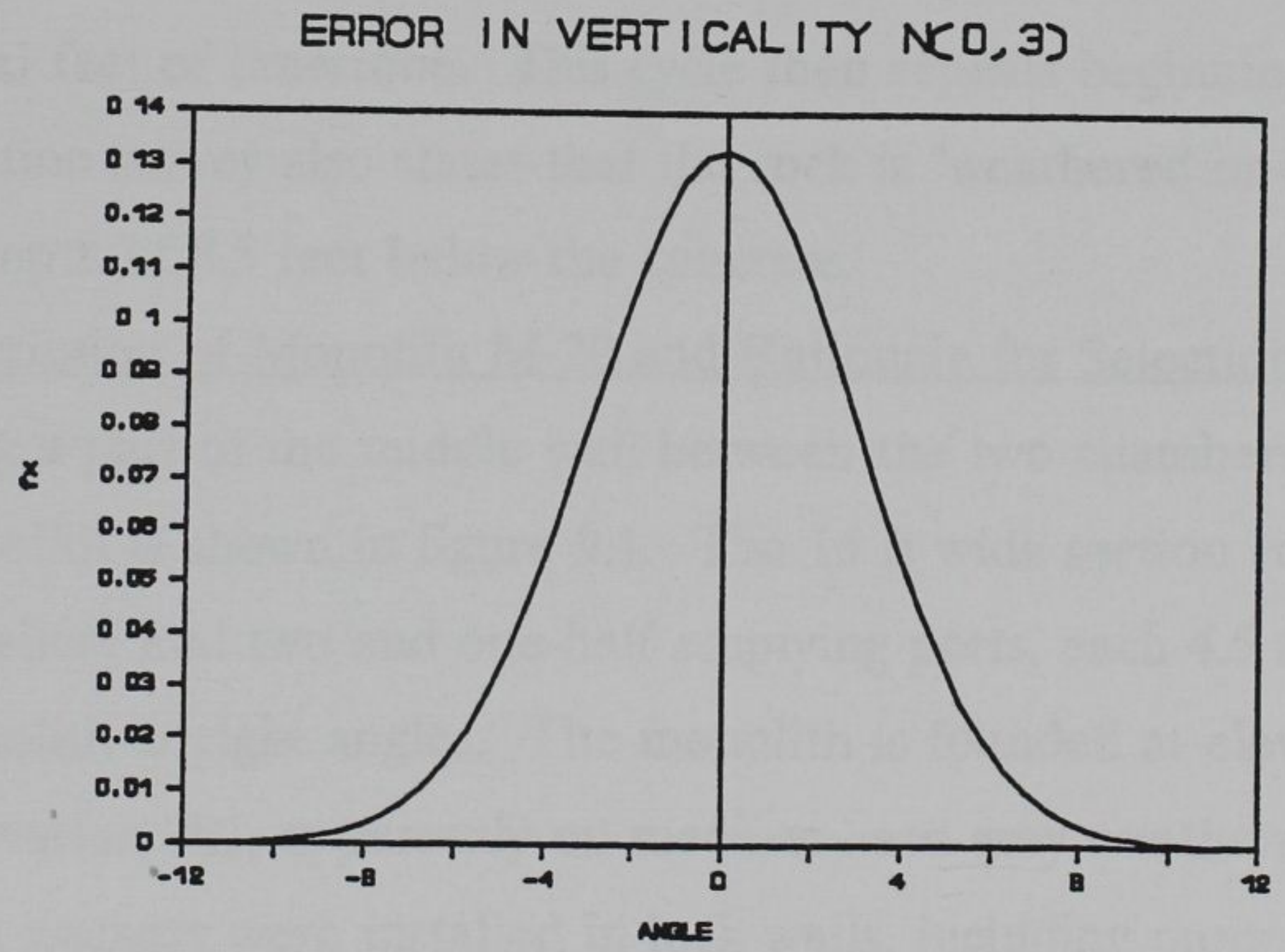

Figure 8.4. Assumed Distribution of Anchor Inclination 
corrosion potential and a number of anchors are known to have failed at installation. Conversations with knowledgeable engineers familiar with the structure suggest that the probability that a random anchor is functioning is probably below 0.5 and many be below 0.10 . In part 9 following, conditional reliablity index values are calculated for 0 to 6 anchors functional at monolith M-20. Using elementary probability theory (e.g. the binomial distribution) and the assumption of independence, these conditional reliability indices could be combined with any desired probability of functionality such as those cited above to determine an expected value and standard deviation of the reliability index itself. 
PART IX: RELIABILITY ANALYSIS FOR LOCKS AND DAM NO. 3, MONOLITH M-20

\section{Description of Problem}

9.1. Description of Project. Locks and Dam No. 3 are located at mile 23.8 above the mouth of the Monongahela River and upstream of Elizabeth, Pennsylvania. Construction was begun in 1905 and the structure was put in operation in 1907. After a number of modifications, the present-day structure includes a concrete overflow dam with a fixed crest at elevation 726.9 and two lock chambers. The landward chamber is $56 \times 720 \mathrm{ft}$ and the riverward chamber is $360 \times 720 \mathrm{ft}$. The dam is founded on piles driven into the river bottom alluvium; the locks and upper guide wall monoliths are founded on sedimentary rock. The foundation appendix to the condition survey (U.S. Army Waterways Experiment Station, 1976) describes a typical boring beneath the structure as encountering several feet of hard shale or siltstone, then a few feet of black carbonaceous fissile shale, then six to twelve inches of coal, another few feet of black shale, and several feet of limestone. This cycle then repeats beginning with the hard shale. The condition survey also states that the rock is "weathered or badelly fractured", for an average depth of 8.5 feet below the concrete.

9.2. Description of Monolith M-20 and Rationale for Selection. M-20 is a gravity monolith forming a part of the middle wall between the two chambers. A cross-section through the monolith is shown in figure 9.1. The $16 \mathrm{ft}$ wide section contains an eight foot wide pipe gallery and two and one-half emptying ports, each $4.5 \mathrm{ft}$ in diameter and crossing the monolith at right angles. The monolith is founded at elevation 704 with a center key to elevation 701 , apparently on medium-hard gray weathered silty shale. To enhance stability, anchors were installed in lock walls, including monolith M-20, in 1978. These anchors and concerns regarding their condition and adequacy have been described in Part VIII. Six anchors were installed in monolith M-20, four on the river side and two on the land side. Of the four on the river side, one failed during installation, two were installed satisfactorily with resin grout and one was installed satisfactorily using cement 


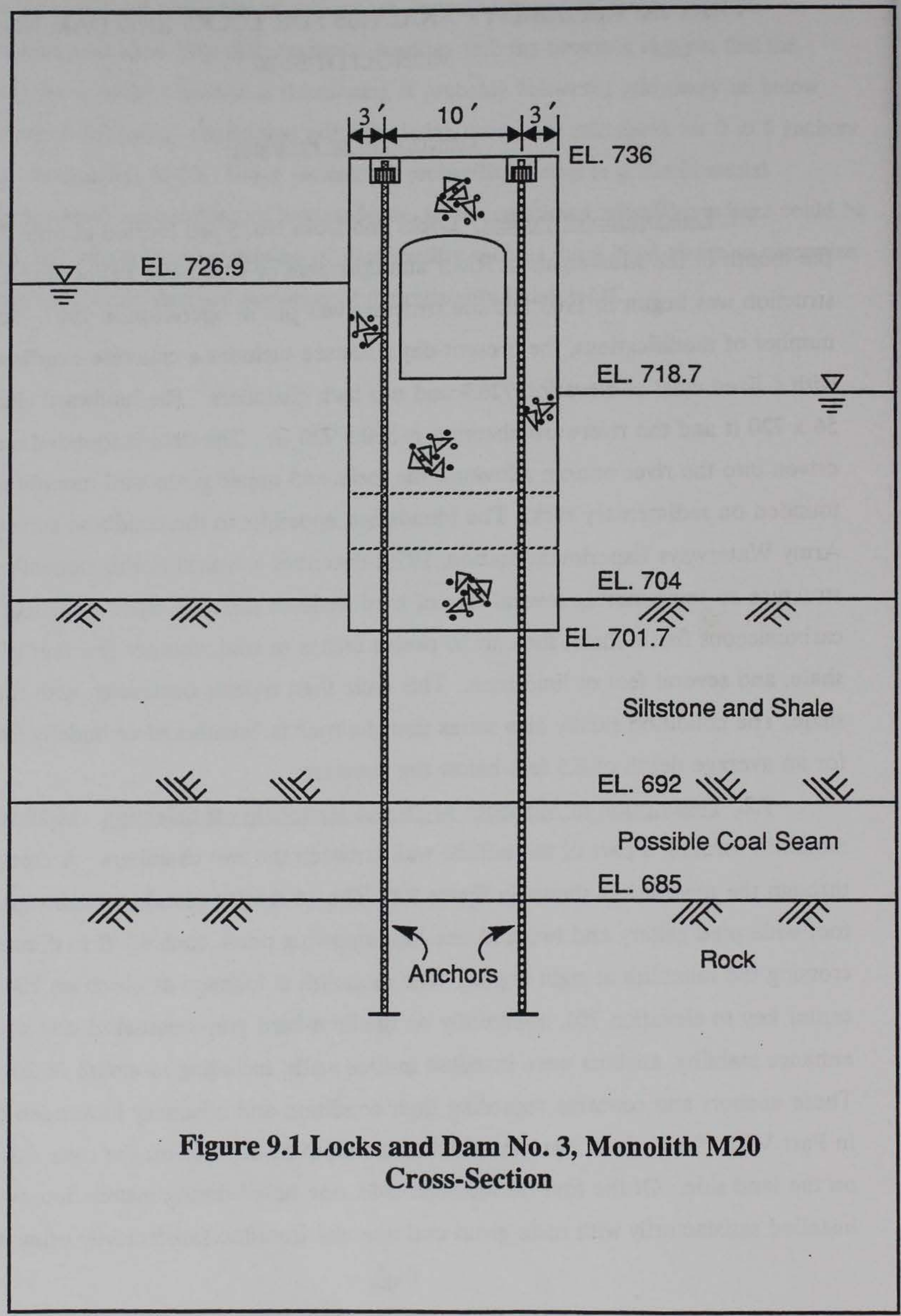


grout. Of the two on the landside, one is marked "Ok" on the as built drawing; it is understood that this means the anchor failed and was abandoned as the monolith was considered adequate without it.

9.3. Performance Modes. Monolith M-20 was analyzed for sliding stability and overturning stability using various numbers of assumed functional anchors.

9.4. Water Levels for Analysis. The following water levels were used for analysis:

$\begin{array}{llll}\text { Case } & \text { Upper Pool } & & \text { Lower Pool } \\ \text { Normal Operating } & 726.9 & 718.7 \\ \text { High Water } & 732.8 & 726.4 \\ \text { Maintenance (A) } & 726.4 & & 701.0 \text { (lock dewatered) } \\ \text { Maintenance (B) } & 732 & 701.0 \text { (lock dewatered) }\end{array}$

The normal operating case represents the usually-prevailing conditions at the lock. The high water case corresponds to water levels just before the locks would go out of operation. The maintenance (A) case corresponds to the lock chamber being dewatered for inspection or maintenance with the river at a normal level. The maintenance (B) case corresponds to the lock chamber dewatered with the river at a relatively high level. As M-20 is a middle wall monolith, the upper pool is assumed to act on one side of the monolith and the lower pool on the other side.

\section{Sliding Analysis}

9.5. Random Variables. Random variables used in the sliding analysis and their probabilistic moments are shown in table 9-1. As discussed in Part IV, results of shear tests on rock at Locks and Dam No. 3 are generally higher than for Locks and Dam No. 2; however, the condition survey indicates that rock in the first $8.5 \mathrm{ft}$ below the foundation is weathered and badly fractured. In the absence of any better way to quantify the strength of this zone, the same foundation rock strength parameters used for Locks and 
Dam No. 2 were used for Locks and Dam No. 3. The parameters used for concrete density are likewise the same as for Locks and Dam No.2. As further described in Part 8 , anchor force could be modeled as a random variable with moments that vary as a function of time. Because of the considerable uncertainty in the actual shape of the time-function at this structure, and uncertainty regarding whether the anchors are actually functioning, the expected value and standard deviation of the anchors force was taken essentially to be that at the time of installation, but different numbers of anchors were assumed functional. As the emphasis of this study was on the effects of the anchors, the uplift was taken to be deterministic.

Table 9.1

Locks and Dam No. 3, Monolith M-20

Random Variables for Sliding Analysis

$\underline{\text { Variable }}$

(1A) $c_{\text {rock }}$ (peak)

(2A) $\tan \phi_{\text {rock }}^{\prime}$ (peak)

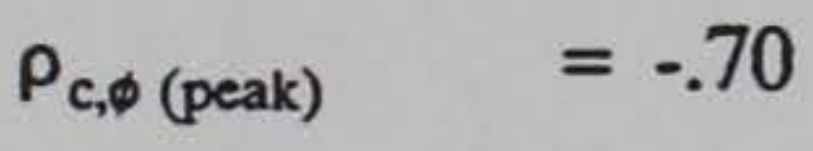

(1B) $c_{\text {rock }}$ (residual)

(2B) $\tan \phi_{\text {rock }}^{\prime}$ (residual)

(3) $\gamma_{\text {concrete }}$

(4) Anchor forces $\mathrm{T} 1$ and $\mathrm{T} 4$

(5) Lateral Force $\underline{\text { Mean }}$

$11.0 \mathrm{ksf}$

1.50

0

0.80

$.15 \mathrm{kcf}$

112 kips

per anchor

$0.80 \mathrm{kips} / \mathrm{ft}$ $\underline{\sigma}$

0.77

0.675

45

0

0

0.40

50

$.0075 \mathrm{kcf}$

5

2.24

2.0

0.40

50.0 
9.6. Results. Results of the sliding analyses are summarized in Table 9.2. Analyses were performed only using CSLIDE and the Taylor's Series method; at this structure, the primary focus was only to determine a representive values of the reliability index with and without anchors. Furthermore, it was known and confirmed that overturning was more concern than sliding. As shown in the table, $\beta$ values are above 10, indicating a high reliability against sliding.

\section{Table 9.2}

Locks and Dam No. 3, Monolith M-20

Sliding Analysis Using Peak Strengths

Condition $\frac{\text { Deterministic }}{\underline{\text { Model }}}$

Probabilistic

E[FS]

$\underline{\sigma}_{\mathrm{FS}} \quad \underline{B}$

Model

Normal

CSLIDE

Taylor series

24.31

$4.19 \quad 18.5$

Operating

(4 Anchors)

Maintenance

(4 anchors)

Maintenance

(no anchors)

CSLIDE

Taylor series

12.26

$4.49 \quad 14.5$

CSLIDE

Taylor series

6.03

$1.11 \quad 10.3$

\section{Overturning Analysis}

9.7. Random Variables. Random variables relevant to overturning analysis are shown in Table 9.3. The anchor location at the base of the monolith is taken to be an expected value of 3 feet from the face of the wall and a standard deviation of $0.09 \mathrm{ft}$. These values affect the moment arm of the resisting anchor force and are derived from the top location and vertically random variables described in Part 4. Other variables are 
assigned values consistent with previous analysis.

Table 9.3

Lock and Dam No. 3, Monolith M-20

Random Variables for Overturning Analysis

Variable

(1) $\gamma_{\text {concrete }}$

(2) Lateral Force

(3) Anchor Location feet from wall

(4) Anchor force

T1 through T4
Mean

$0.15 \mathrm{kcf}$

$0.80 \mathrm{kip} / \mathrm{ft}$

$3 \mathrm{ft}$

112 kip

per anchor
2.24

$\underline{\sigma}$

$\mathrm{V}, \%$

$0.0075 \mathrm{kcf} \quad 5$

0.40

50

0.09

3

2

9.8. Results. Results of the overturning analyses are summarized in Tables 9.4 and 9.5. Analyses were made assuming zero anchors, four anchors, and six anchors are functional. All analyses were made using the Taylor's series method. For the maintenance (A) case assuming no anchors functioning, $\beta_{\mathrm{FS}}=4.07$ and $\beta_{\text {toe }}=4.49$, which is just above the target value of 4.0 recommended in Part XIV of this report. As additional anchors are assumed functional, the reliability indices rise rapidly. For the Maintenance (B) case, reliability indices are negative even if all six of the original anchors were functional, and it is known with certainty two are not.

\section{Summary and Discussion}

9.9. Sliding. Reliability index values are high even if non-functional anchors are assumed.

9.10. Overturning. Comparison of results presented in table 9.4 and 9.5 indicate 
that the reliability indices $\beta_{\text {toe }}$ and $\beta_{\mathrm{FS}}$ are very sensitive to both water levels and the number of functional anchors. If the lock is dewatered to the (A) water levels, the reliability index would be just above a target value of 4.0 even if all anchors are functional. If more anchors are functional, the reliability index increases rapidly with the number of anchors. On the other hand, if the lock is dewatered at the (B) water levels, $\beta_{\text {toc }}$ and $\beta_{\mathrm{FS}}$ are negative even with six functional anchors, indicating that the monolith would be more likely to overturn than remain stable. The values of $\beta_{1 / 6}, \beta_{1 / 4}$, and $\beta_{\text {kern }}$ are likewise highly dependent on the number of functional anchors and water levels. It should be noted, however, that $\beta_{\text {kem }}$ is negative for all cases considered and $\beta_{1 / 4}$ is negative for all cases ( 4 or less anchors) considered. Thus, it can be said that there is a high probability the the resultant force would be outside the middle half of the base in any dewatered case.

9.11. Anchor Functionality. As has been described in Part VIII and demonstrated in Part IX, there is a high degree of uncertainty in the anchor forces due to probable poor installation (grouting) and potential for corrosion. In turn, the reliability indices for overturning are very sensitive to the number of functional anchors. Probabilistic methods are merely a formal and consistent mathematical means to express uncertainty in performance given some characterization of uncertainty in the underlying variables. In the present case, there is no real site-specific data on the post-installation behavior of the anchors in question, and the anchor forces and functionality could be better characterized by one of two means; either (1) physically testing a statistical sample of the anchors or (2) an "official" judgmental assignment of the probablistic moments by a consensus of experts based on a detailed review of the data and knowledge of the structure. 
Table 9.4

Locks and Dam No. 3, Monolith M-20

Results of Overturning Analyses- Factor of Safety

\begin{tabular}{|c|c|c|c|c|}
\hline Condition & $\frac{\text { Probabilistic }}{\underline{\text { Model }}}$ & E[FS] & $\underline{\sigma}_{\mathrm{FS}}$ & $\underline{\beta}_{\mathrm{FS}}$ \\
\hline Normal Operating & TS & - & - & - \\
\hline $\begin{array}{l}\text { Maintenance (A) } \\
\text { (no anchors) }\end{array}$ & TS & 1.10 & 0.026 & 4.07 \\
\hline $\begin{array}{l}\text { Maintenance (A) } \\
(3+1 \text { Anchors) }\end{array}$ & TS & 1.52 & 0.028 & 22.57 \\
\hline $\begin{array}{l}\text { Maintenance (A) } \\
\text { (4+2 Anchors) }\end{array}$ & TS & 1.69 & 0.029 & 30.26 \\
\hline $\begin{array}{l}\text { Maintenance (B) } \\
\text { (no anchors) }\end{array}$ & TS & - & - & - \\
\hline $\begin{array}{l}\text { Maintenance (B) } \\
(3+1 \text { Anchor) }\end{array}$ & TS & 0.907 & 0.017 & -5.27 \\
\hline $\begin{array}{l}\text { Maintenance (B) } \\
\text { (4+2 Anchor) }\end{array}$ & TS & 0.989 & 0.017 & -0.61 \\
\hline
\end{tabular}


Table 9.5

Locks and Dam No. 3, Monolith M-20 - Factor of Safety

Results of Overturning Analyses-Resultant Location

Condition

Probabilistic

$\underline{E}\left[\underline{X}_{R}\right] \underline{\sigma}_{X} \quad \underline{B}_{\text {toc }} \quad \underline{B}_{1 / 6} \quad \underline{B}_{1 / 4} \quad \underline{B}_{k e m}$

Normal Operating TS

Maintenance (A) TS

$\begin{array}{llllll}1.20 & 0.267 & 4.49 & -5.49 & -10.5 & -15.5\end{array}$

(no anchors)

Maintenance (A)

TS

$\begin{array}{llllll}3.89 & 0.110 & 35.4 & 11.12 & -1.00 & -13.2\end{array}$

(3+1 Anchors)

Maintenance (A)

TS

$\begin{array}{llllll}4.40 & 0.086 & 51.56 & 20.2 & 4.65 & -10.9\end{array}$

(4+2 Anchors)

Maintenance (B)

TS

(no anchors)

Maintenance (B)

TS

$\begin{array}{llllll}-1.70 & 0.373 & -4.57 & -11.7 & -15.3 & -24.0\end{array}$

(3+1 Anchors)

Maintenance (B)

TS (4+2 Anchors) 


\section{PART X: RELIABILITY ANALYSIS FOR LOCKS AND DAM NO. 3, MONOLITH L-8}

\section{Problem Description}

10.1. Monolith L-8 and Rationale for Selection. Locks and Dam No. 3 were previously described in Part IX. Monolith L-8 is a gravity monolith forming a part of the landside upper guidewall. A cross-section through the monolith is shown in figure 10.1 . The monolith is founded at elevation 709.1, apparently on weathered siltstone. The monolith is relatively slender, being 27 feet tall and only 14 feet wide at the base. As the water loads were the dominent load for previously considered structures, monolith L8 was selected for analyses as it is loaded by soil backfill.

10.2. Performance Modes. Monolith M-20 was analyzed for sliding stability, overturning stability, and bearing capacity.

10.3. Water Levels for Analysis. The following water levels were selected for analysis:

$\begin{array}{llll}\text { Case } & \text { Upper Pool } & & \text { Water in Backfill } \\ \text { Normal Operating } & 726.9 & & 727.9 \\ \text { High Water } & 732.8 & 733.8\end{array}$

The normal operating case represents the usually-prevailing conditions at the lock. The high water case corresponds to water levels just before the locks would go out of operation. As L-8 is an upper guide wall monolith, the maintenance case is not applicable. The water level in the backfill was assumed to be $1.0 \mathrm{ft}$ higher than the pool level for all analyses.

\section{Sliding Analysis}

10.4. Random Variables. The values of the moments of the random variables are 


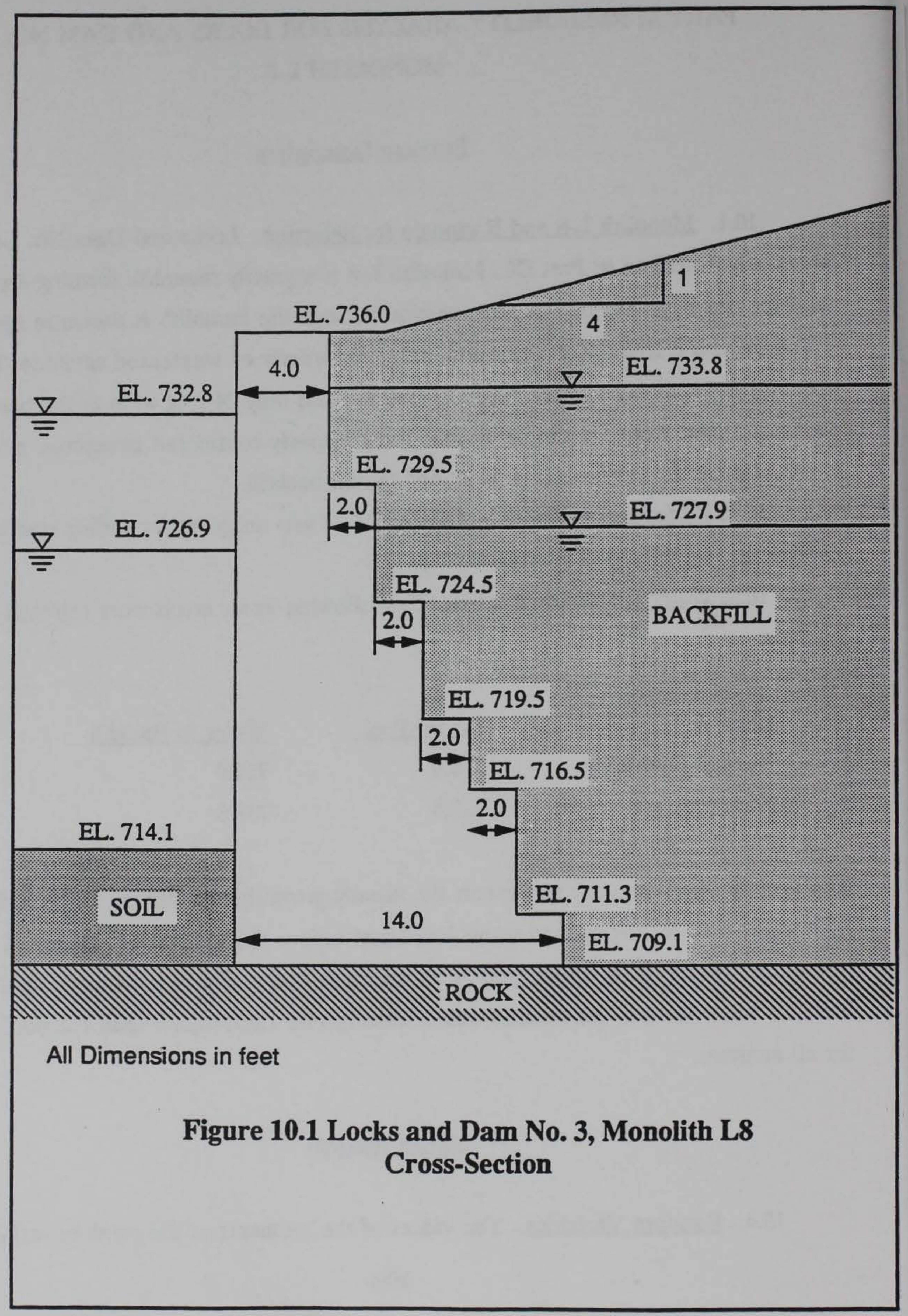


summarized in Table 10.1. Random variables relevant to sliding analysis are similar to those for Lock and Dam No.2, monolith M-16, with the addition of the wall friction angle, $\delta$, and a lateral pull force, F. The "wall friction" angle is in fact the assumed angle of the resultant of the normal and shear stresses developed in the backfill along a vertical plane, but is analogous to the concept of a wall friction angle for a vertical wall. The assigned expected value of 12 degrees and standard deviation of 3 degrees is based on the judgment that the common assumption of no vertical shear is unlikely to be representative of actual conditions; some vertical shear likely to develop but it may be considerable less than the shear strength $(\delta<<\phi)$. The probabilistic moments for the lateral force, $F$, which represents a hawser pull, are similar to those for previous overturning analysis. As the water level differential across the structure is small, the uplift parameter, E, was taken to have a deterministic value of zero.

10.5. Results. Sliding analysis were performed using both the simple method and CSLIDE method, and both the Taylor's series and point estimate methods. Results are summarized in Table 10.2 and 10.3. A typical free-body diagram is shown in Figure 10.2. Note that CSLIDE is not capable of modeling a wall friction angle thus $\delta$ was taken as zero for the CSLIDE analyses, reducing the number of random variables by one. As shown in Table 10.2, reliability index values for peak strength assumption were all above 5.5 , indicating the structure is reliable against sliding. It should also be noted that the differences in reliability index values are smaller than the differences in expected factor of safety for the two different performance function considered. Although $\beta$ values for residual strength assumptions are below 1.5 , these are not considered representative. 




Forces in kips per lineal foot

Figure 10.2 Locks and Dam No. 3, Monolith L8, Free Body Diagram Sliding Stability Analysis-Normal Operating w/ Hawser Force 
Table 10.1

Locks and Dam No. 3, Monolith L-8

Random Variables for Sliding Analysis

$\underline{\text { Variable }}$

Mean

$\underline{\sigma}$

$\underline{\mathrm{V}, \%}$

(1) $\gamma_{\text {soil }}$

$0.130 \mathrm{kcf}$

0.0065

5

(2) $\phi_{\text {soil }}^{\prime}$

$32 \mathrm{deg}$

$3.2 \mathrm{deg}$

10

(3) wall friction angle, $\delta$

$12 \mathrm{deg}$

$3.0 \mathrm{deg}$

25

(4A) $c_{\text {rock }}$

$11.0 \mathrm{ksf}$

7.70

70

(peak)

(5A) $\tan \phi_{\text {rock }}^{\prime}$

1.50

0.675

45

(peak)

(5A) $\phi^{\prime}$ rock

$52.416 \mathrm{deg}$

12.893

24.6

$\rho_{c, \phi \text { (peak) }}=-.70$

(4B) $c_{\text {rock }}$

(residual)

0

0

0

(5B) $\tan \phi_{\text {rock }}^{\prime}$

0.6322

0.3161

50

(residual)

(6) $\gamma_{\text {concrete }}$

$.145 \mathrm{kcf}$

$.00725 \mathrm{kcf}$

5

(7) Lateral Force, F

$1.0 \mathrm{kip} / \mathrm{ft}$

0.5

50 
Table 10.2

Locks and Dam No. 3, Monolith L-8

Sliding Analysis Using Peak Strengths

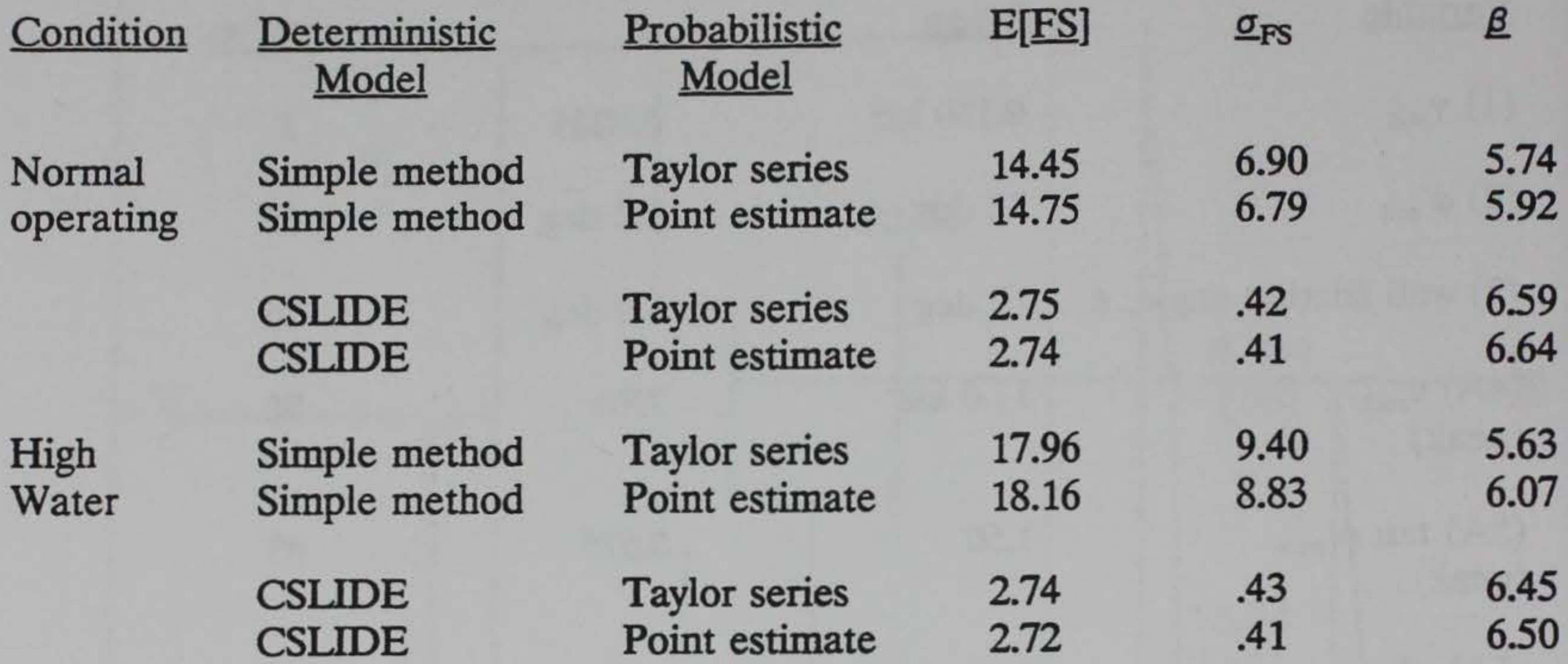

Table 10.3

Lock and Dam No.3, Monolith L-8

Sliding Analysis Using Residual Strengths

\begin{tabular}{|c|c|c|c|c|c|}
\hline Condition & $\frac{\text { Deterministic }}{\underline{\text { Model }}}$ & $\frac{\text { Probabilistic }}{\underline{\text { Model }}}$ & $\mathrm{E}[\underline{\mathrm{FS}}]$ & $\underline{\sigma}_{\mathrm{FS}}$ & $\underline{B}$ \\
\hline \multirow{4}{*}{$\begin{array}{l}\text { Normal } \\
\text { operating }\end{array}$} & Simple method & Taylor series & 1.77 & .86 & 1.01 \\
\hline & Simple method & Point estimate & 1.79 & .84 & 1.08 \\
\hline & CSLIDE & Taylor series & 1.14 & .29 & .54 \\
\hline & CSLIDE & Point estimate & 1.16 & .29 & .59 \\
\hline High & Simple method & Taylor series & 1.97 & 1.00 & \\
\hline \multirow[t]{3}{*}{ Water } & Simple method & Point estimate & 1.99 & .92 & \\
\hline & CSLIDE & Taylor series & 1.13 & .28 & 1 \\
\hline & CSLIDE & Point estimate & 1.15 & .28 & .56 \\
\hline
\end{tabular}




\section{Overturning Analysis}

10.6. Random Variables. The random variables relevant to overturning analysis are similar those for Locks and Dam No.2, monolith M-16, with the addition of the angle of mobilized vertical shear, $\delta$. Assumed values are summarized in Table 10.4. The expected value of -0.4 for the uplift parameter $E$ is chosen to be consistent with the finding from preliminary analysis that only about 60 percent of the base in compression. As described in Part IV, E $=0.0$ corresponds to a linear variation in uplift from headwater to tailwater, and $\mathrm{E}=-1.0$ corresponds to headwater pressure over the active base. Thus, $E=-0.4$ would approximately correspond to full headwater pressure over 40 percent of the base.

10.7 Assumptions. For the overturning analysis, at-rest conditions were assumed to prevail in the backfill, and the at-rest pressure coefficient was calculated using Jaky's formula:

$$
\mathrm{K}_{\mathrm{o}}=1-\sin \phi
$$

The horizontal earth force was taken as the integral of the horizontal effective earth pressure over the height of the wall. To account for likely presence of shear stresses on the vertical planes, the ratio of vertical shear stresses (and forces) to horizontal shear stresses ( and force) was presented by the random variable $\delta$. Thus, a vertical force $P_{v}$ is assumed on a vertical plane through the heel as:

$$
\mathbf{P}_{\mathbf{v}}=\mathbf{P}_{\mathrm{H}} \tan \delta
$$

10.8. Results. An example free-body diagram is shown in Figure 10.3. Results of the overturning analyses are summarized in Tables 10.5 and 10.6. The values for $\beta_{\mathrm{FS}}$ are in the range 4.0 to 5.0, and the values of $\beta_{\mathrm{TOE}}$ are in the range 3.0 to 6.0. Values of $\beta_{\text {TOE }}$ obtained using the less conservative point estimate method are above 4.5. Values for the performance-state measures $\beta_{1 / 6}, \beta_{1 / 4}$ and $\beta_{\text {kem }}$ are relatively low, indicating high probability that only a portion of the base is in compression. 


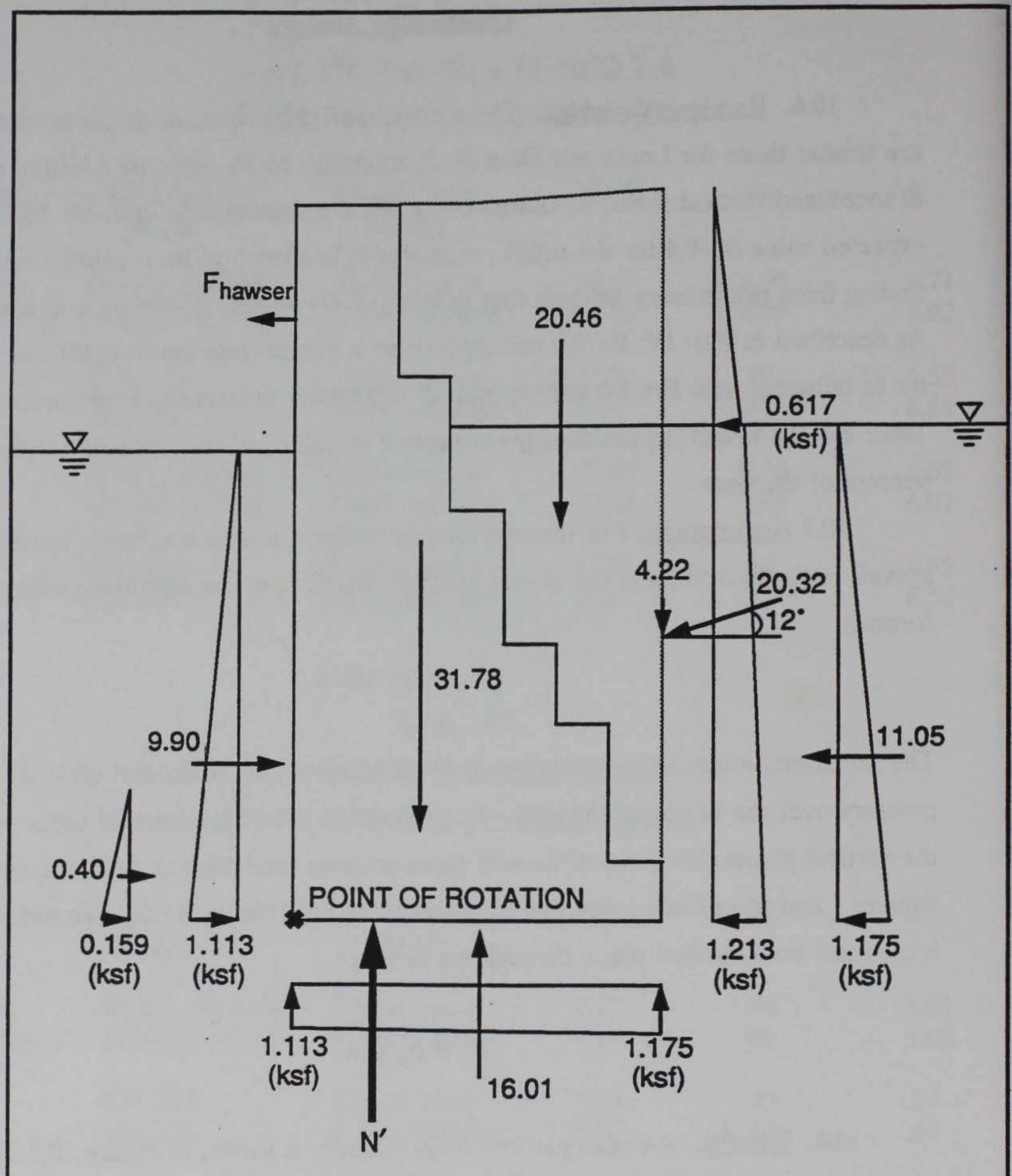

Forces in kips per lineal foot

Figure 10.3 Locks and Dam No. 3, Monolith L8, Free Body Diagram Overturning Stability Analysis-Normal Operating w/ Hawser Force 


\section{Table 10.4}

\section{Locks and Dam No. 3, Monolith L-8 \\ Random Variables for Overturning Analysis}

$\underline{\text { Variable }}$

(1) $\gamma_{\text {soil }}$

(2) $\phi_{\text {soil }}^{\prime}$

(3) $\delta$

(4) $\gamma_{\text {concrete }}$

(5) Lateral Force, F

(6) Uplift parameter, E
Mean

$0.130 \mathrm{kcf}$

$32 \mathrm{deg}$

$12 \mathrm{deg}$

$.145 \mathrm{kcf}$

$1.0 \mathrm{kip} / \mathrm{ft}$

$-0.4$ $\underline{\sigma}$

0.0065

$3.2 \mathrm{deg}$

$3.0 \mathrm{deg}$

$.00725 \mathrm{kcf}$

0.5

0.2
$\underline{\mathrm{V}, \%}$

5

10

25

5

50

50

\section{Bearing Capacity Analysis}

10.9. Random Variables for bearing capacity analysis are summarized in Table 10.7 and are consistent with values from previous analysis. The probabilistic moments for the location of the effective base resultant force, $X_{R}$ and its inclination $Q$, are obtained as output from the probabilistic overturning analysis. 
Table 10.5

Locks and Dam No. 3, Monolith M-20

Results of Overturning Analyses- Factor of Safety

Condition

Probabilistic

E[FS]

$\underline{\sigma}_{\mathrm{FS}}$

$\underline{\beta}_{\mathrm{FS}}$

Model

Normal

TS

1.38

.093

4.78

Normal

PE

1.39

.094

4.81

High

TS

1.25

.064

4.26

High

PE

1.25

.064

4.30

Table 10.6

Locks and Dam No, 3. Monolith M-20

Results of Overturning Analyses-Resultant Location

$\underline{\text { Condition }}$

Normal

Normal

High

High
Probabilistic Model

TS

PE

TS

PE
$\underline{E}\left[\underline{X}_{R}\right] \underline{\sigma}_{X} \quad \underline{B}_{t o c} \quad \underline{B}_{1 / 6} \quad \underline{B}_{1 / 4} \quad \underline{B}_{k e m}$

$\begin{array}{llllll}2.88 & .776 & 3.69 & 0.70 & -0.79 & -2.29\end{array}$

$\begin{array}{llllll}2.87 & .510 & 5.63 & 1.06 & -1.23 & -3.52\end{array}$

$\begin{array}{llllll}2.35 & .750 & 3.13 & 0.02 & 1.54 & -3.09\end{array}$

$\begin{array}{llllll}2.32 & .475 & 4.89 & 0.03 & -2.48 & -4.94\end{array}$ 
Table 10.7

\section{Locks and Dam No. 3, Monolith L-8}

Random Variables for Bearing Analysis

Variable
(1) $\gamma_{\text {soil }}$
(2) $\phi_{\text {soil }}^{\prime}$
(3) $\delta$

(4A) $c_{\text {rock }}$

(peak)

(5A) $\phi_{\text {rock }}^{\prime}$

(peak)

$\rho_{c, \tan \phi \text { (peak) }}=-.70$

(6) $\gamma_{\text {concrete }}$

(7) Lateral Force, F

(8) $X_{R}$

Normal

High Water

(9) $\theta$

Normal

High Water
Mean

$0.130 \mathrm{kcf}$

$32 \mathrm{deg}$

$12 \mathrm{deg}$

$11.0 \mathrm{ksf}$

$52.416 \mathrm{deg}$

$.145 \mathrm{kcf}$

$1.0 \mathrm{kip} / \mathrm{ft}$

$2.90 \mathrm{ft}$

$2.37 \mathrm{ft}$

$29.28 \mathrm{deg}$

$27.22 \mathrm{deg}$ $\underline{\sigma}$

0.0065

$3.2 \mathrm{deg}$

$3.0 \mathrm{deg}$

7.70

12.893

$.00725 \mathrm{kcf} \quad 5$

0.5

$.776 \mathrm{ft}$

$.744 \mathrm{ft}$

$0.0248 \mathrm{rad}$

$0.0253 \mathrm{rad}$
24.6

50

26.75
31.34

26.75
31.34

$\underline{\mathrm{V}, \%}$

5

10

25

70

5

4.85

5.32

10.10. Results of the bearing capacity analysis are summarized in Table 10.8. As was the case for monolith M-16 at Locks and Dam No.3, There is a wide variation in results due to the high degree of non-linearity of the performance function. In all cases, the reliability index exceeds 5.0 . 
Table 10.8

Locks and Dam No. 3, Monolith L-8

Results of Bearing Analyses

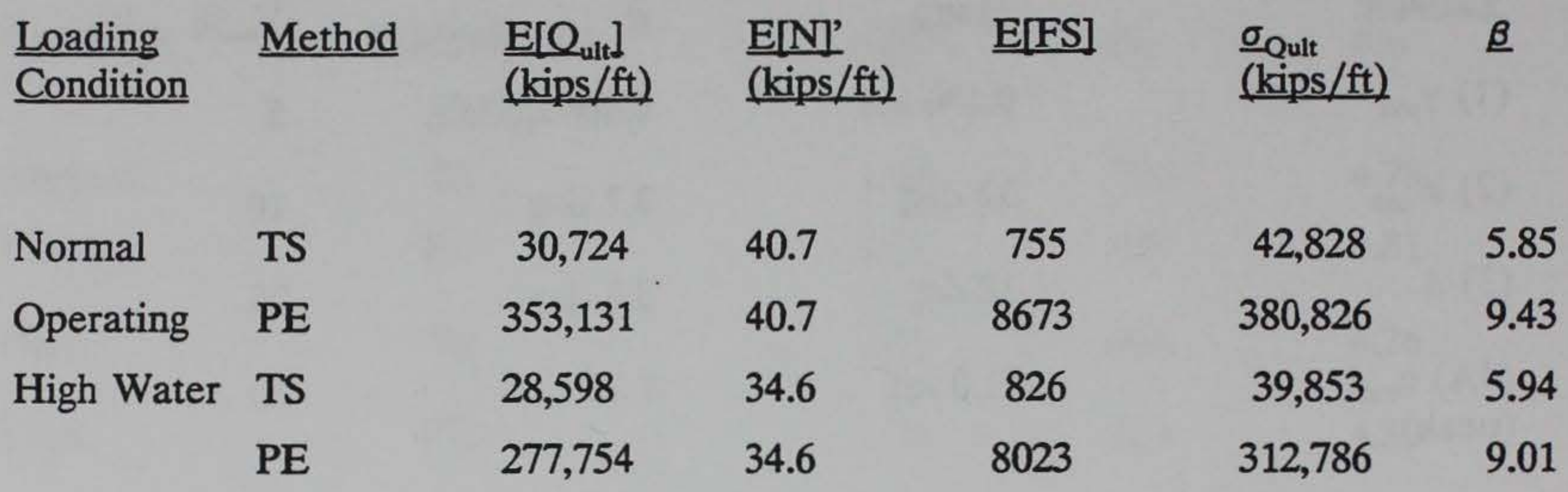

\section{Summary and Discussion}

10.11. Sliding. Based on reliability indices above 5.5 for the peak strength assumption, the monolith is considered reliable against sliding. It was found that reliability index values obtained using different performance functions were more consistent than expected factors of safety obtained using different performance functions.

10.12. Overturning. Reliability Index values $\beta_{\mathrm{FS}}$ and $\beta_{\text {toe }}$ were, for the most part, just above the 4.0 value recommended as a target value in Part XIV. However; there is a high probability that part of the base is not in compression.

10-13. Bearing Capacity. As was the case for monolith M-16 at Locks and Dam No.3, reliability index values vary widely depending on the probabilistic model, but in all cases are sufficiently high. 


\section{Problem Description}

11.1. Description of Project. Locks and Dam No.4 are located at mile 41.5 on the Monongahela River between Charleroi and Monessen, Pennsylvania. The Locks and Dam were reconstructed from an earlier structure in 1931-1932. In 1967, the dam was again reconstructed to raise the pool six feet. A related reconstruction of the lock was completed in 1964.

11.2. Description of Dam Pier Monolith 3 and Rationale for Selection. A crosssection of dam pier monolith 3 is shown in figure 11.1. The monolith has a heavy concrete base which passes through 25 to 34 feet of river alluvium and about 9 feet of clayey shale above its founding elevation of 681.0, apparently on red and gray shale. Data from boring FL-1, between the dam structure and lock, is described in the condition survey (Wong, et. al, undated) as indicating good contact between the rock and the concrete. Dam pier 3 was selected for analysis to provide an example of a very safe and reliable structure for calibrating the proposed procedure.

11.3 Performance Modes. Pier 3 was analyzed for three performance modes; sliding, overturning, and bearing capacity.

11.4 Water Levels for Analysis. The following water level were used for analysis:

$\begin{array}{llll}\text { Case } & \text { Upper Pool } & & \text { Water in Backfill } \\ \text { Normal Operating } & 743.5 & & 726.9 \\ \text { Maintenance } & 743.5 & 726.9\end{array}$

The normal operating case reflects the usually-prevailing conditions at the structure. The maintenance case reflects the same water levels, but with one gatebay dewatered for gate maintenance. This has the effect of reducing the weight of the monolith. 


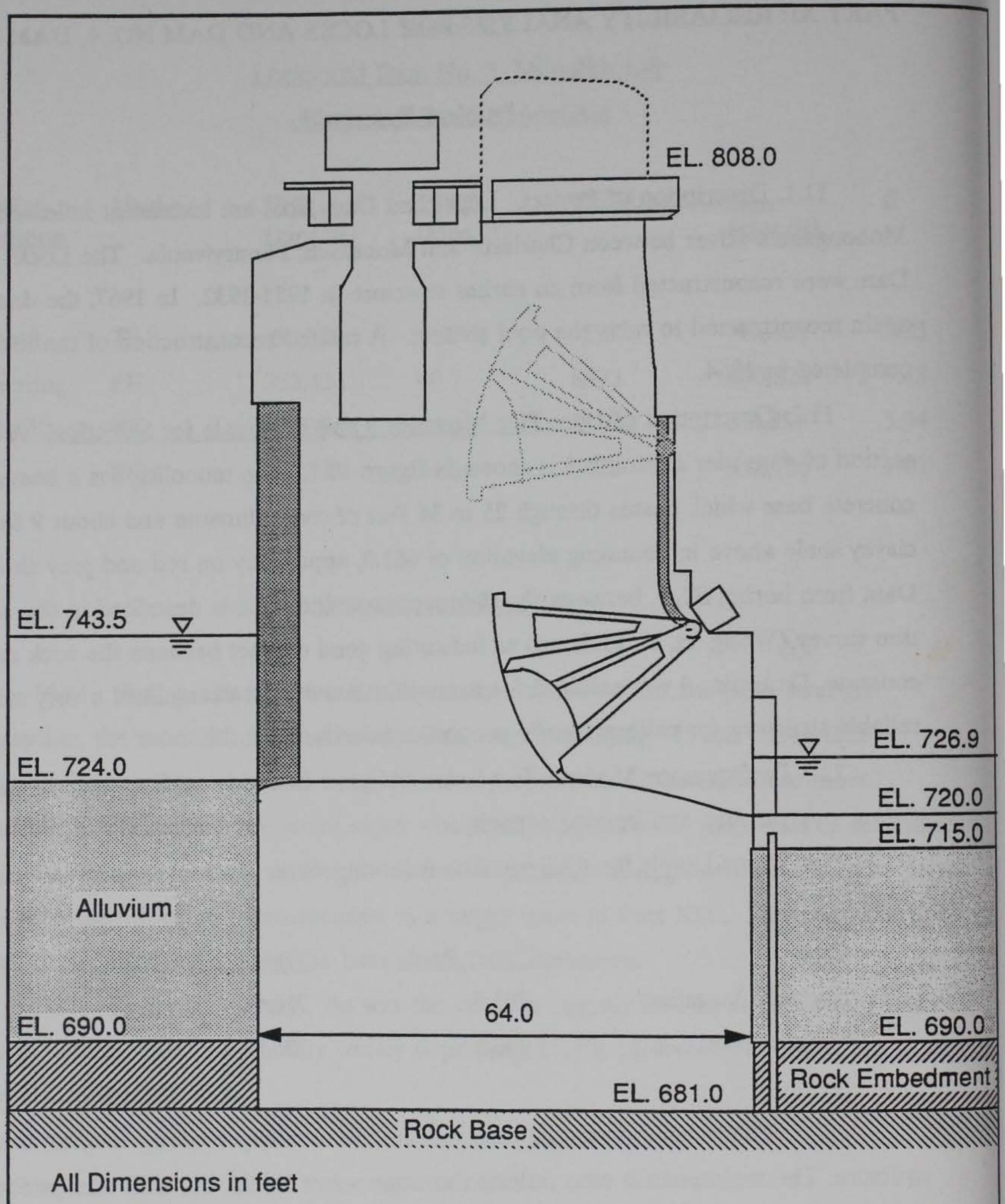

Figure 11.1 Locks and Dam No. 4, Dam Piers Cross-Section 


\section{Sliding Analysis}

11.5 Random Variables. Ten random variables were used in the sliding analysis; these are summarized in Table 11.1. Random variables (1) and (2) reflect properties of the riverbed alluvium which were assigned based on experience. The dam foundation was constructed by excavating through clayey shale to more competent shale. Random variables (3) and (4) represent the properties of the upper clay shale; the properties of the red and gray shale foundation rock are represented by random variables (5) and (6). The peak strengths of the foundation rock are assumed the same as at previous structures; the residual strengths are based on site-specific data only. The total weight of the entire 30 foot monolith wide is represented by the random variable W (7). Its expected value is taken as 649.3 kips for the normal operating case and 661.0 kips for the maintenance case. Its coefficient of variation of 5 percent was assigned to be consistent with the values used for concrete density in previous analysis. The impact force (8) of $5.0 \mathrm{kip} / \mathrm{ft}$ is higher than lateral force assumed in previous analyses because it represents a head-on impact to a pier rather than a side-on impact or pull at a lock wall. The wind force (9) is obtained as a total force from a $114 \mathrm{ft}$ width of the service bridge transmitted to the 30 feet wide monolith. The wind force acting on the narrow pier itself is negligible. 
Table 11.1

\section{Locks and Dam No.4, Dam Pier 3}

\section{Random Variables for Sliding Analysis}

$\underline{\text { Variable }}$

Alluvium
(1) $\gamma_{\text {soil }}$
(2) $\phi_{\text {soil }}^{\prime}$

Rock embedment

$(3 \mathrm{~A}) \mathrm{c}_{\text {rock }}$
(peak)

(4A) $\tan \phi_{\text {rock }}^{\prime}$
(peak)

(4A) $\phi^{\prime}$ rock

$\rho_{c, \phi \text { (peak) }}=-.70$

(3B) $c_{\text {rock }}$

(4B) $\tan \phi_{\text {rock }}^{\prime}$

(residual)

(4B) $\phi^{\prime}$ rock
(residual)

Rock at base

${\text { ( } 5 \mathrm{~A}) \mathrm{c}_{\text {rock }}}^{\text {peak) }}$

(6A) $\tan \phi_{\text {rock }}^{\prime}$

(peak)

$(6 \mathrm{~A}) \phi^{\prime}$ rock

$0.125 \mathrm{kcf}$

$32 \mathrm{deg}$

0.0065

5

$3.2 \mathrm{deg}$

10

$12.0 \mathrm{ksf}$

6.0

50

1.35

0.608

45

$49.767 \mathrm{deg}$

13.173

26.5

0

0

0

1.35

$16.648 \mathrm{deg}$

3.151

18.927
$11.0 \mathrm{ksf}$

1.50

$52.416 \mathrm{deg}$

12.893

24.6

7.70

70

0.675

45
45

0.608

v. \%

0

$\rho_{c, \phi \text { (peak) }}=-.70$

(5B) $c_{\text {rock }}$
(residual)

0 


\section{Table 11.1 (cont'd) \\ Locks and Dam No.4, Dam Pier 3 \\ Random Variables for Sliding Analysis}

\begin{tabular}{|c|c|c|c|}
\hline Variable & Mean & $\underline{\sigma}$ & $\underline{\mathrm{V}, \%}$ \\
\hline $\begin{array}{l}\text { (6B) } \tan \phi_{\text {rock }}^{\prime} \\
\text { (residual) }\end{array}$ & 0.5 & 0.125 & 25 \\
\hline $\begin{array}{l}\text { (6B) } \phi^{\prime} \text { rock } \\
\text { (residual) }\end{array}$ & $16.648 \mathrm{deg}$ & 3.151 & 18.927 \\
\hline (7) Weight, W & W kip/ft & $0.05 \mathrm{~W}$ & 5 \\
\hline (8) Impact Force, $F_{\text {impact }}$ & $5.0 \mathrm{kip} / \mathrm{ft}$ & 2.5 & 50 \\
\hline (9) Wind Force, $F_{\text {wind }}$ & $58.8 \mathrm{kips} / 30 \mathrm{ft}$ & $11.8 / 30$ & 20 \\
\hline (10) Uplift factor, E & 0.6667 & 0.105 & 15.7 \\
\hline
\end{tabular}

11.6. Results. Sliding analyses were performed using the simple method in combination with both the Taylor's series and the point estimate method and the CSLIDE method the Taylor's Series method only. Results of the sliding analyses are summarized in Table 11.2 and 11.3. Typical free body diagrams are shown in Figures 11.2 and 11.3.

Reliability indices were found to be on the order of 10 assuming peak strength parameters and 5 assuming residual strength parameters. Residual strength conditions are not realistic as their use would imply pre-existing planes across bedding planes in the clayshale embedment material. As previously observed for other structures, reliability index values are reasonably consistent even where different considered performance functions yield very different expected factor of safety. 


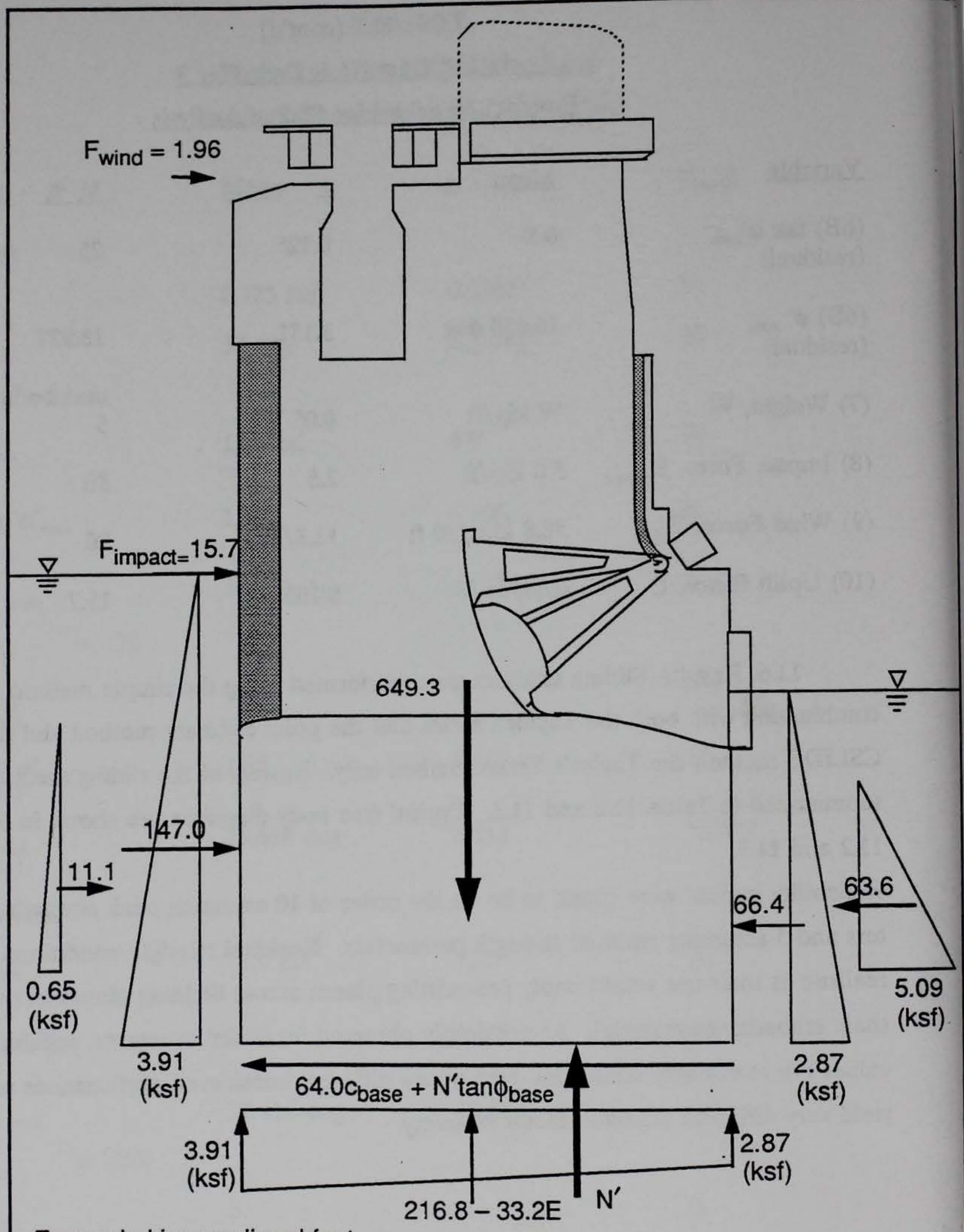

Forces in kips per lineal foot

Figure 11.2 Locks and Dam No. 4, Dam Piers, Free Body Diagram Sliding Stability Analysis-Normal Operating w/ Impact Force 


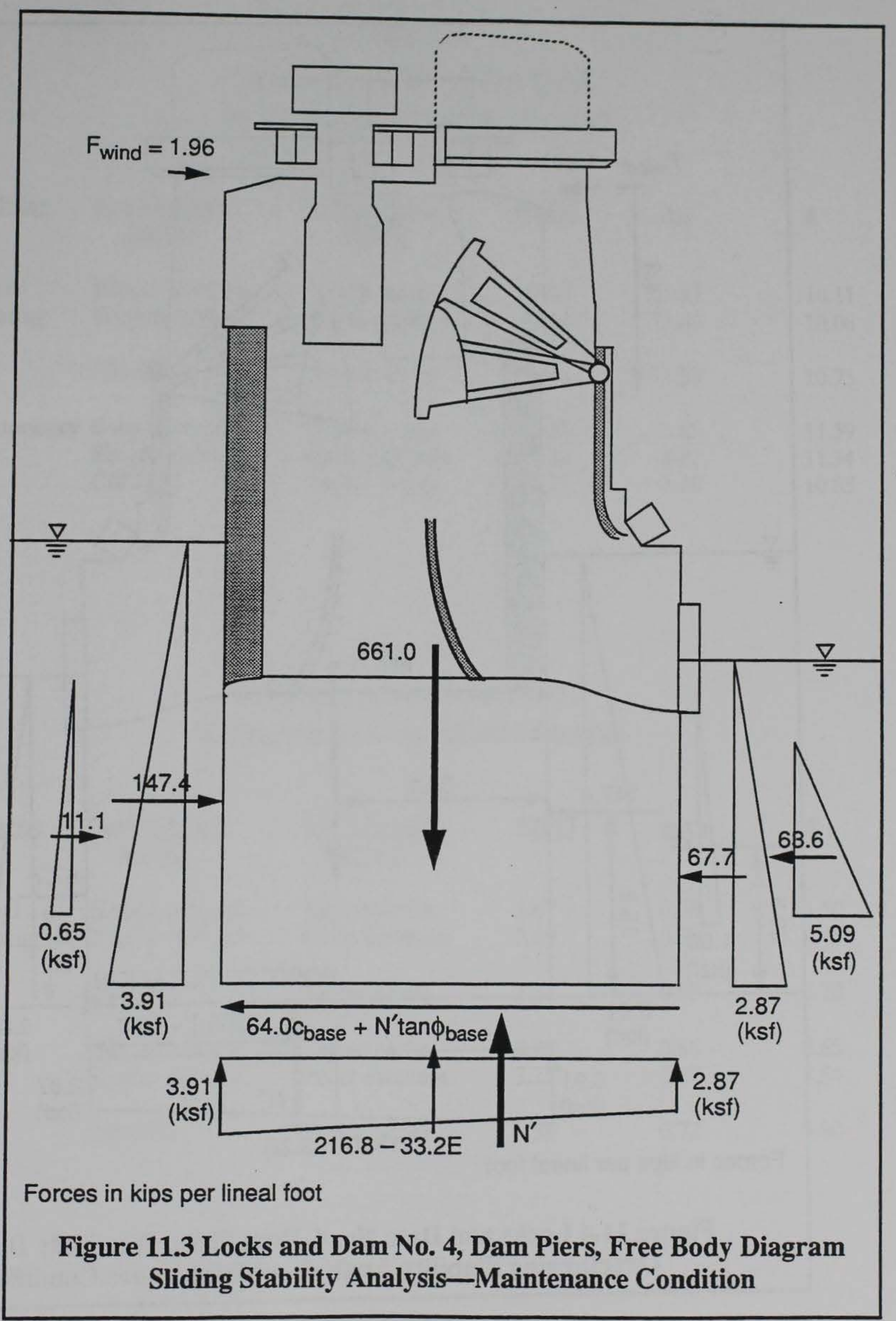




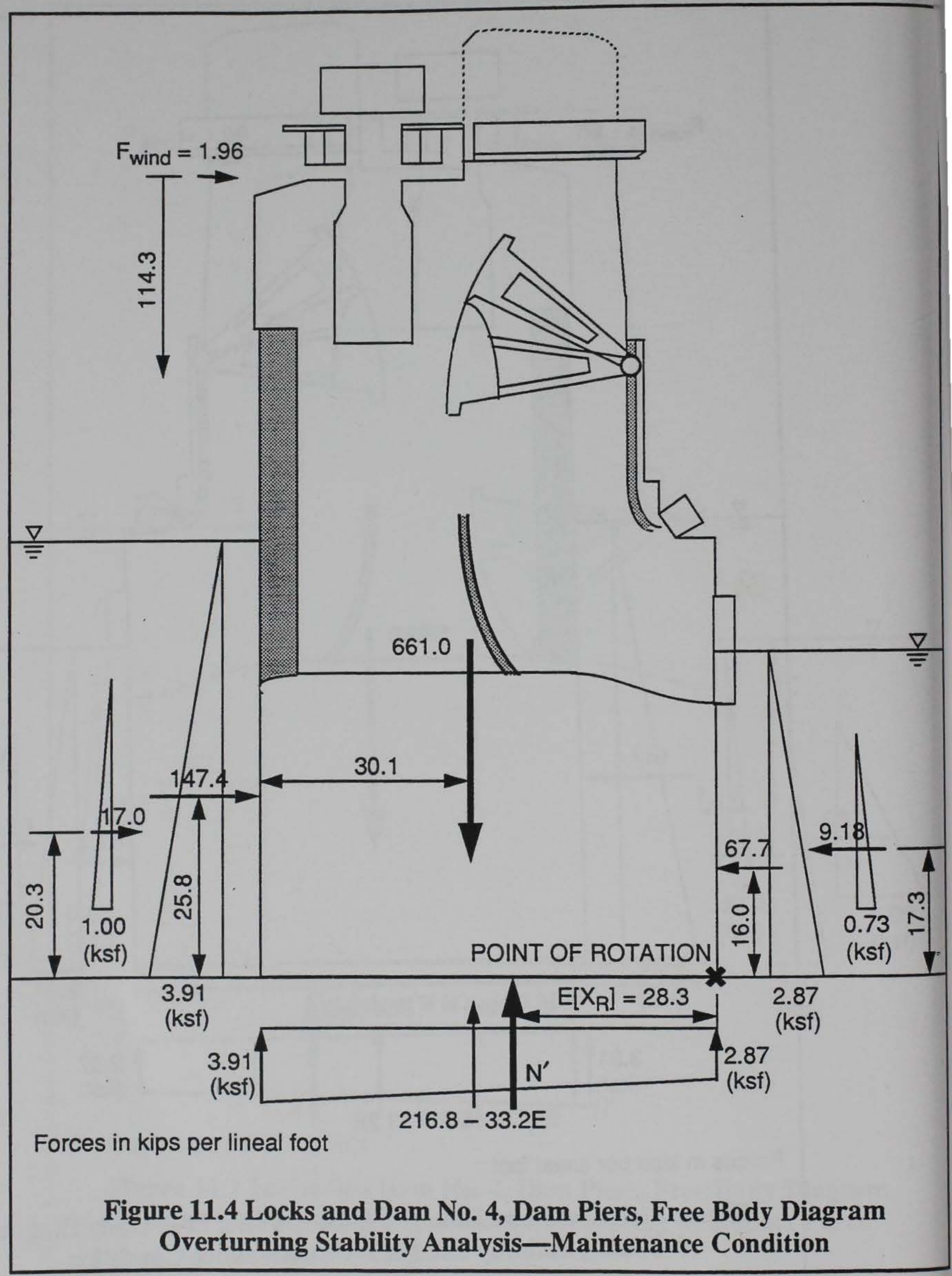


Table 11.2

Locks and Dam No. 4, Dam Pier 3

Sliding Analysis Using Peak Strengths

\begin{tabular}{|c|c|c|c|c|c|}
\hline Condition & $\frac{\text { Deterministic }}{\underline{\text { Model }}}$ & $\frac{\text { Probabilistic }}{\underline{\text { Model }}}$ & $\mathrm{E}[\underline{\mathrm{FS}}]$ & $\underline{\sigma}_{\mathrm{FS}}$ & $\underline{\beta}$ \\
\hline \multirow{3}{*}{$\begin{array}{l}\text { Normal } \\
\text { operating }\end{array}$} & Simple method & Taylor series & 13.27 & 3.41 & 10.11 \\
\hline & Simple method & Point estimate & 13.34 & 3.45 & 10.06 \\
\hline & CSLIDE & Taylor series & 19.91 & 5.55 & 10.73 \\
\hline \multirow[t]{3}{*}{ Maintenance } & Simple method & Taylor series & 15.82 & 3.85 & 11.39 \\
\hline & Simple method & Point estimate & 15.82 & 3.87 & 11.34 \\
\hline & CSLIDE & Taylor series & 20.21 & 5.60 & 10.85 \\
\hline
\end{tabular}

Table 11.3

Locks and Dam No 4, Dam Pier 3

Sliding Analysis Using Residual Strengths

\begin{tabular}{|c|c|c|c|c|c|}
\hline Condition & $\frac{\underline{\text { Deterministic }}}{\underline{\text { Model }}}$ & $\frac{\text { Probabilistic }}{\underline{\text { Model }}}$ & $\mathrm{E}[\underline{\mathrm{FS}}]$ & $\underline{\sigma}_{\mathrm{FS}}$ & $\underline{B}$ \\
\hline \multirow{3}{*}{$\begin{array}{l}\text { Normal } \\
\text { operating }\end{array}$} & Simple method & Taylor series & 2.67 & 0.58 & 4.50 \\
\hline & Simple method & Point estimate & 2.69 & 0.59 & 4.45 \\
\hline & CSLIDE & Taylor series & 3.31 & 0.69 & 5.70 \\
\hline \multirow{3}{*}{$\begin{array}{l}\text { High } \\
\text { Water }\end{array}$} & Simple method & Taylor series & 3.20 & 0.66 & 5.65 \\
\hline & Simple method & Point estimate & 3.21 & 0.67 & 5.54 \\
\hline & CSLIDE & Taylor series & 3.39 & 0.72 & 5.80 \\
\hline
\end{tabular}




\section{Overturning Analysis}

11.7 Random Variables. Random variables relevant to overturning analysis are similar to those for sliding analysis; however, the strength of the founding material does not enter the analysis. Assigned values are summarized in Table 11.4. For overturning, the alluvial soil in the embedment zone is assumed to be in an at-rest condition both upstream and downstream of the structure. The clay-shale rock in the embedment zone is assumed to be cracked away from the structure and the overlying alluvial soil is assumed to extend to the base of the structure. The assumed moments for the uplift parameter, E, reflect an assumption of reduced uplift due to head loss through the embedment material.

Table 11.4

Locks and Dam No. 3, Dam Pier 3

Random Variables for Overturning Analysis

$\underline{\text { Variable }}$

(1) $\gamma_{\text {soil }}$

(2) $\phi_{\text {soil }}^{\prime}$

(3) Weight, W

(4) Impact Force, $F_{\text {impact }}$

(5) Wind Force, $F_{\text {wind }}$

(6) Uplift factor, E
Mean

$0.125 \mathrm{kcf}$

$32 \mathrm{deg}$

W kip/ft

$1.0 \mathrm{kip} / \mathrm{ft}$

$58.8 \mathrm{kips} / 30 \mathrm{ft}$

0.6667 $\underline{\sigma}$

0.0065

$3.2 \mathrm{deg}$

$0.5 \mathrm{~W}$

0.5

0.105
50

20

$\mathrm{v}, \%$

5

10

5

15.7

11.8. Results. Results of the overturning analyses are summarized in Table 11.4. A typical fee body diagram is shown in Figure 11.4 The reliability indices $\beta_{\mathrm{FS}}$ and $\beta_{\text {toe, }}$ associated with true limit states, all exceed 10.0 , indicating very high reliability. Like 


\section{Table 11.5 \\ Locks and Dam No. 4, Dam Pier 3 \\ Results of Overturning Analyses - Factor of safety}

\begin{tabular}{|c|c|c|c|c|}
\hline Condition & $\frac{\text { Probabilistic }}{\text { Model }}$ & E[FS] & $\underline{\sigma}_{F S}$ & $\underline{\beta}_{\mathrm{FS}}$ \\
\hline Normal & TS & 2.39 & .126 & 16.6 \\
\hline Normal & PE & 2.39 & .126 & 16.6 \\
\hline Maintenance & TS & 2.11 & .147 & 10.7 \\
\hline Maintenance & PE & 2.11 & .148 & 10.7 \\
\hline
\end{tabular}

Table 11.6

Locks and Dam No. 4, Dam Pier 3

Results of Overturning Analyses - Resultant Location

Condition

Normal

Normal

Maintenance

Maintenance
Probabilistic

Model

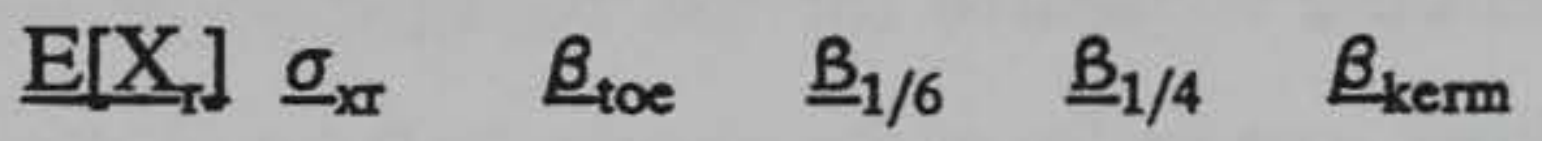

TS

PE

TS

PE $\begin{array}{llllll}25.61 & 1.24 & 20.6 & 12.02 & 7.73 & 3.44\end{array}$

$\begin{array}{llllll}25.56 & 1.25 & 20.4 & 11.90 & 7.64 & 3.38\end{array}$

$\begin{array}{llllll}28.32 & 0.44 & 63.9 & 39.86 & 27.82 & 15.8\end{array}$

$\begin{array}{llllll}28.29 & 0.45 & 63.6 & 39.56 & 27.58 & 15.6\end{array}$ 
wise, most of the performance state measures $\beta_{1 / 4}$ and $\beta_{1 / 6}$ are high, indicating a high probability that the most or all of the base is in compression.

\section{Bearing Capacity Analysis}

11.9. Random Variables. Ten random variables were used for the bearing capacity analyses. The moments for these variables are consistent with previous analyses. Their assumed values are shown in Table 11.7.

11.10. Results. Results of the bearing capacity analyses are shown in Table 11.8. As was previously observed for other structures, results are highly dependent on the probabilistic model used due to the non-linearity of the performance function. The results for the point estimate method are considered more correct. Where this method was used, the reliability index was approximately 8.0 , indicating high reliability.

\section{Summary and Discussion}

11.11. Dam pier 3 was selected for analysis to provide an example of a very safe and reliable structure for the calibration of target reliability index values. With reliability indices generally at or above 10.0 for sliding, 10.0 for overturning, and 8.0 for bearing capacity, it is indeed very reliable. 
Table 11.7

\section{$\underline{\text { Locks and Dam No.4, Dam Pier } 3}$}

Random Variables for Bearing Analysis

Variable
(1) $\gamma_{\text {soil }}$
(2) $\phi_{\text {soil }}^{\prime}$
(3) $c_{\text {rock }}$ (peak)

(4) $\phi_{\text {rock }}^{\prime}$ (peak)

$\rho_{\mathrm{c}, \phi \text { (peak) }}=-.70$
Mean

$0.125 \mathrm{kcf}$

$32 \mathrm{deg}$

$11.0 \mathrm{ksf}$

$54.66 \mathrm{deg}$

W kip/ft

$1.0 \mathrm{kip} / \mathrm{ft}$

$58.8 \mathrm{kips} / 30 \mathrm{ft}$

0.6667

Maintenance

(9) $\delta$

Normal

Maintenance
1.243

4.05

$25.61 \mathrm{ft}$

$28.32 \mathrm{ft}$

0.443

1.56

$11.09 \mathrm{deg}$

$10.81 \mathrm{deg}$

0.0178 red $\quad 8.67$

$\begin{array}{ll}0.0024 & 1.29\end{array}$
0.105

5

50

20

15.7 v. $\%$

5

10

70

14.5 
Table 11.8

Locks and Dam No.3. Dam Pier 3

Results of Bearing Analyses

\begin{tabular}{|c|c|c|c|c|c|}
\hline $\begin{array}{l}\text { Loading } \\
\text { Condition }\end{array}$ & Method & $\begin{array}{l}\frac{\mathrm{E}\left[\mathrm{Q}_{\text {utt }}\right]}{\text { (kips) }} \\
\text { kis }\end{array}$ & $\frac{\text { E[N]] }}{\text { (kips) }}$ & E[FS] & $\begin{array}{l}\frac{\sigma_{\text {Oult }}}{\text { (kips/ft) }} \\
\text { 等 }\end{array}$ \\
\hline Normal & TS & 839,239 & 13,638 & 61.5 & $1,766,361$ \\
\hline Operating & PE & $20,722,800$ & 13,638 & 1519 & $20,781,060$ \\
\hline High Water & $\begin{array}{l}\text { TS } \\
\text { PE }\end{array}$ & $\begin{array}{c}992,028 \\
24038290\end{array}$ & $\begin{array}{l}13,990 \\
13090\end{array}$ & $\begin{array}{l}70.9 \\
178 ?\end{array}$ & $\begin{array}{r}2,123,658 \\
2,837270\end{array}$ \\
\hline
\end{tabular}




\section{Problem Description}

12.1. Description of Project. Gray's Landing Locks and Dam is a new structure on the Monongahela River at mile 82.0. It replaces Lock and Dam No. 7 some 3 miles upstream at Gray's Landing, Pennsylvania. Project data used for the analyses herein was taken from Design Memorandum No. 4, Feature Design Memorandum, (U.S. Army Engineer District, Pittsburgh, 1987)

12.2. Description of Monolith L-20 and Rationale for Selection. The purpose for analyzing a monolith at Gray's Landing was to determine the reliability index values that would be obtained for a modern structure designed to current Corps' criteria. A cross-section of the selected monolith, L-20, is shown in figure 12.1. The monolith is a land wall chamber monolith 62 feet high with a 37 foot wide base. It is embedded 26 feet in rock on the landside and $\mathbf{1 2 . 5}$ feet on the chamber side, and has 36 feet of additional soil backfill on the landside. In contrast to previously considered structures, a thorough geologic investigation had been performed and the foundation rock mapped into a number of distinct layers or groups. Samples assigned for testing had been matched to these numbered units, as were rock strata in each boring. As a result, the foundation materials at the monolith are reasonably well known.

12.3. Performance Modes. Monolith L-20 was analyzed for sliding, overturning, and bearing capacity.

12.4. Water Levels for Analysis. The following water levels were considered for analysis:

Case

Normal Operating

Maintenance

High Water

\section{Water in Chamber Water in Backfill}

763.0

743.5

792.0
763.0

769.5

793.0

The normal operating case represents normally-prevailing conditions at the lock. The maintenance case represents a dewatered lock condition, and the high water conditions 





model a flood to the top of the lock walls.

\section{Sliding Analysis}

12.5. Random Variables. Ten random variables were used in the sliding analyses. The probabilistic moments assigned to these random variables are summarized in Table 12.1, and are based on information from the Feature Design Memorandum, engineering judgment, and consistency with previous analyses. Of particular interest are the parameters for the various rock units. At Gray's Landing, the rock in question had been delineated into five numbered units or strata, and sufficient test data were available to perform a regression analysis on test data from each unit. After this was done, to simplify the probabilistic analysis, moments were assigned for the rock embedment variables (3) and (4) based on the test statistics for units 2 and 3 taken together, and for the base rock variables (5) and (6) based on the test statistics for units 4 and 5 taken together. 
Table 12.1

Gray's Landing Lock and Dam, Monolith L-20

Random Variables for Sliding Analysis

c

Variable

Mean

$\underline{\sigma}$

$\underline{\mathrm{V}, \%}$

(1) $\gamma_{\text {soil }}$

$0.125 \mathrm{kcf}$

0.00625

5

(2) $\phi_{\text {soil }}^{\prime}$

$32 \mathrm{deg}$

$3.2 \mathrm{deg}$

10

Rock embedment

$(3 \mathrm{~A}) \mathrm{c}_{\text {rock }}$
(peak)

$2.5 \mathrm{ksf}$

1.75

70

(4A) $\tan \phi_{\text {rock }}^{\prime}$

1.70

0.765

45

(peak)

(4A) $\phi^{\prime}$ rock

55.77

11.266

20.2

$\rho_{c, \phi \text { (peak) }}=-.70$

(3B) $c_{\text {rock }}$

(4B) $\tan \phi^{\prime}$ rock (residual)

0.68

0.350

51.41

(4B) $\phi_{\text {rogk }}^{\prime}$

$32 \mathrm{deg}$

14.4

45

Rock at base

(5A) $c_{\text {rock }}$
(peak)

$35.0 \mathrm{ksf}$

24.5

70

(6A) $\tan \phi_{\text {rock }}^{\prime}$ (peak)

1.50

0.675

45

(6A) $\phi^{\prime}$ rock

$52.6 \mathrm{deg}$

11.90

22.6

$\rho_{c, \phi \text { (peak) }}=-.70$

(5B) $c_{\text {rock }}$

0

0

0 
Table 12.1 (cont'd)

\section{Gray's Landing Lock and Dam, Monolith L-20 \\ Random Variables for Sliding Analysis}

$\begin{array}{llll}\text { Variable } & \underline{\text { Mean }} & \underline{\sigma} & \underline{\mathrm{V}, \%} \\ \begin{array}{l}\text { (6B) tan } \phi_{\text {rock }}^{\prime} \\ \text { (residual) }\end{array} & 1.112 & 0.685 & 61.61 \\ \begin{array}{l}\text { (6B) } \phi^{\prime} \text { rock } \\ \text { (residual) }\end{array} & 42 \mathrm{deg} & 18.9 & 45 \\ \begin{array}{l}\text { (7) } \gamma_{\text {rock }} \\ \text { (8) } \gamma_{\text {conc }}\end{array} & 0.165 & 0.00825 & 5 \\ \text { (9) Pull Force, F } & 1.0 \mathrm{kip} / \mathrm{ft} & 0.5 & 5 \\ \text { (10) Uplift factor, E } & 0.6667 & 0.0075 & 50\end{array}$

12.6. Results. Results of the sliding analyses are summarized in Tables 12.2 and 12.3. Typical freebody diagrams are shown in Figures 12.2 and 12.3. For peak strength assumptions, values of $\beta$ are above 6.0 for the simple method and above 5.0 for the CSLIDE method, indicating a high reliability. For residual strength assumptions, expected values for the factor of safety are above 2.0 for all methods and cases, which would be considered acceptable in deterministic analyses. However, reliability index values are as low as 1.36 . This arises due to the high coefficients of variation associated with the rock friction angles. As reduction of strength to the residual condition would require prior cross-bed shear planes in the embedment rock, the these low $\beta$ values are not considered representative of the actual reliability. 


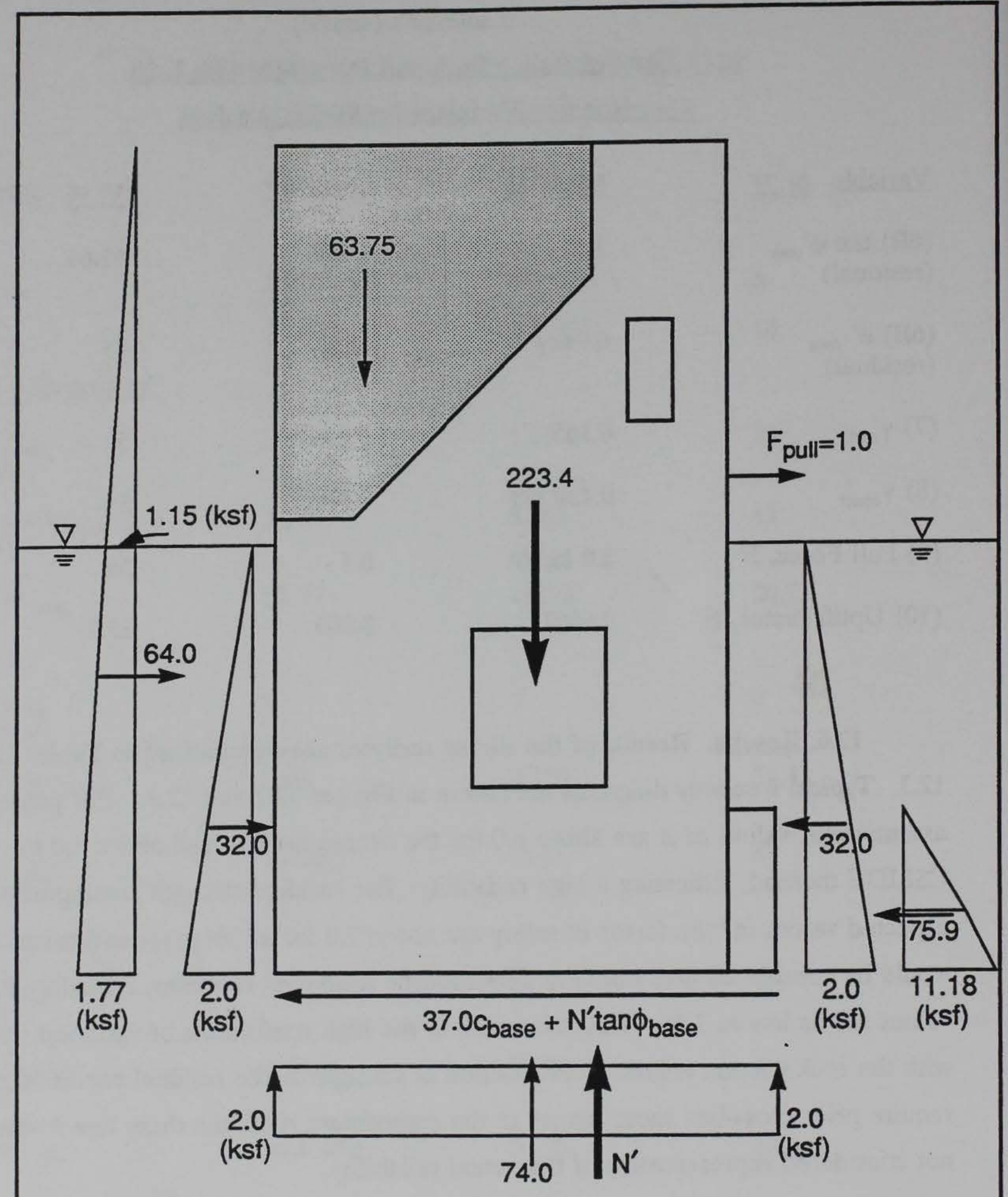

Forces in kips per lineal foot

Figure 12.2 Grays Landing Locks and Dam, L20, Free Body Diagram -Sliding Stability, Normal Operating w/ Hawser Force 


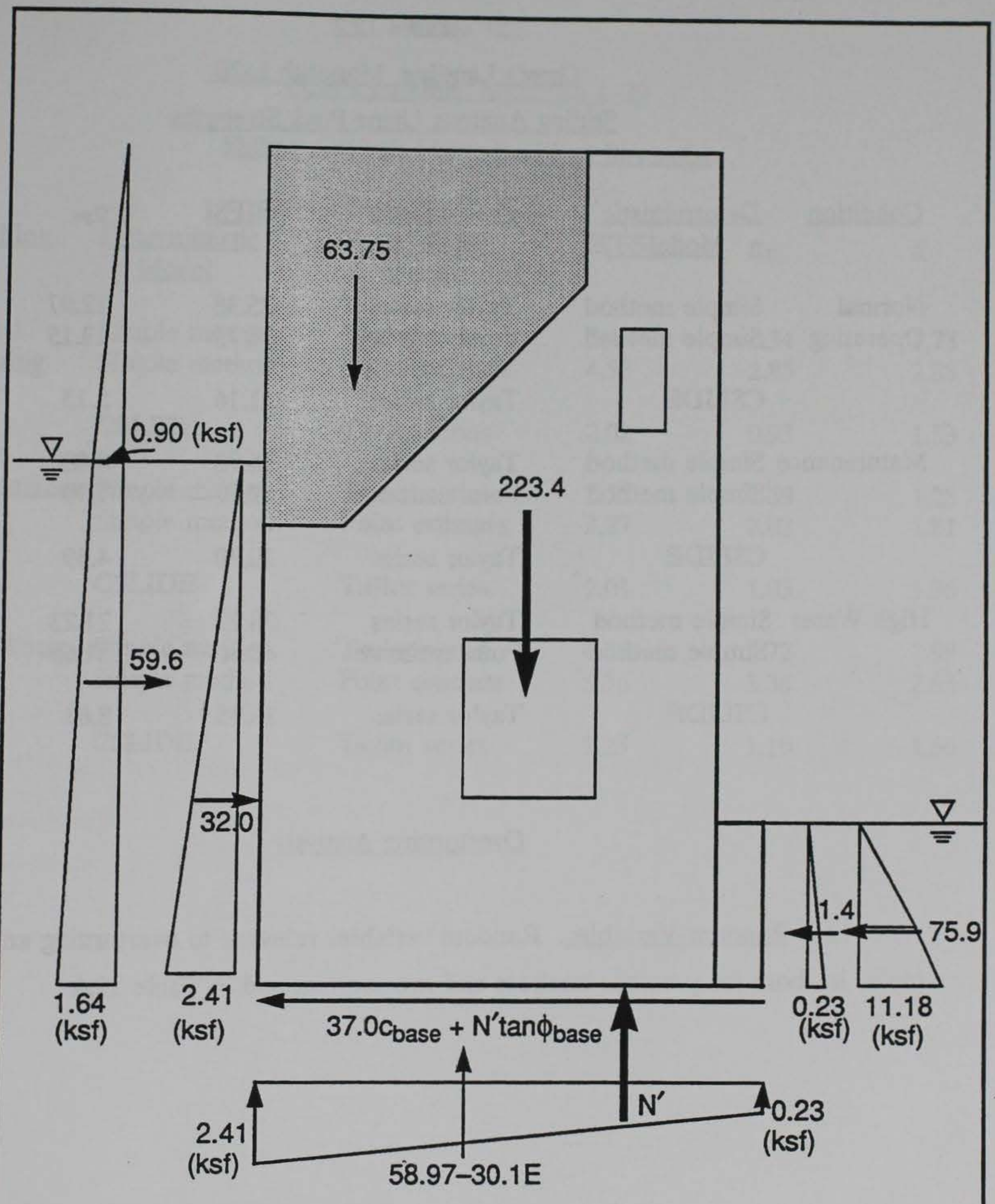

Forces in kips per lineal foot

Figure 12.3 Grays Landing Locks and Dam, L20, Free Body Diagram -Sliding Stability, Maintenance Condition 
Table 12.2

Gray's Landing, Monolith L-20

Sliding Analysis Using Peak Strengths

\begin{tabular}{|c|c|c|c|c|c|}
\hline Condition & $\frac{\text { Deterministic }}{\underline{\text { Model }}}$ & $\frac{\text { Probabilistic }}{\underline{\text { Model }}}$ & $\mathrm{E}[\underline{\mathrm{FS}}]$ & $\underline{\sigma}_{\mathrm{FS}}$ & $\underline{B}$ \\
\hline Normal & Simple method & Taylor series & 25.38 & 12.97 & 6.47 \\
\hline \multirow[t]{2}{*}{ Operating } & Simple method & Point estimate & 26.78 & 13.15 & 6.84 \\
\hline & CSLIDE & Taylor series & 11.16 & 5.13 & 5.25 \\
\hline \multirow[t]{3}{*}{ Maintenance } & Simple method & Taylor series & 16.78 & 8.03 & \\
\hline & Simple method & Point estimate & 17.57 & 7.99 & \\
\hline & CSLIDE & Taylor series & 10.20 & 4.39 & \\
\hline \multirow[t]{3}{*}{ High Water } & Simple method & Taylor series & 38.29 & 21.23 & \\
\hline & Simple method & Point estimate & 40.30 & 21.65 & \\
\hline & CSLIDE & Taylor series & 16.95 & 8.81 & \\
\hline
\end{tabular}

Overturning Analysis

12.7. Random Variables. Random variables relevant to overturning analysis are similar to those for previous analyses and are summarized in Table 12.4. 
Table 12.3

Gray's Landing, Monolith L-20

Sliding Analysis Using Residual Strengths

\begin{tabular}{|c|c|c|c|c|c|}
\hline Condition & $\frac{\text { Deterministic }}{\underline{\text { Model }}}$ & $\frac{\text { Probabilistic }}{\underline{\text { Model }}}$ & $\mathrm{E}[\underline{\mathrm{FS}}]$ & $\underline{\sigma}_{\mathrm{FS}}$ & $\underline{\beta}$ \\
\hline \multirow{3}{*}{$\begin{array}{l}\text { Normal } \\
\text { operating }\end{array}$} & Simple method & Taylor series & 3.48 & 2.34 & 1.73 \\
\hline & Simple method & Point estimate & 4.53 & 2.85 & 2.33 \\
\hline & CSLIDE & Taylor series & 2.02 & 0.93 & 1.53 \\
\hline \multirow[t]{3}{*}{ Maintenance } & Simple method & Taylor series & 2.55 & 1.69 & 1.25 \\
\hline & Simple method & Point estimate & 3.27 & 2.02 & 1.81 \\
\hline & CSLIDE & Taylor series & 2.01 & 1.03 & 1.36 \\
\hline \multirow[t]{3}{*}{ High Water } & Simple method & Taylor series & 4.05 & 2.72 & 1.99 \\
\hline & Simple method & Point estimate & 5.36 & 3.36 & 2.63 \\
\hline & CSLIDE & Taylor series & 2.25 & 1.10 & 1.66 \\
\hline
\end{tabular}


Table 12.4

Gray's Landing, Monolith L-20

Random Variables for Overturning Analysis

$\underline{\text { Variable }}$

Mean

$\underline{\sigma}$

$\underline{\mathrm{V}, \%}$

(1) $\gamma_{\text {soil }}$

$0.125 \mathrm{kcf}$

0.00625

5

(2) $\phi_{\text {soil }}^{\prime}$

$32 \mathrm{deg}$

$3.2 \mathrm{deg}$

10

Rock embedment

(3) $\phi^{\prime}$ rock

52.416

12.892

24.6

(4) $\gamma_{\text {conc }}$

$0.150 \mathrm{kcf}$

0.0075

5

(5) Pull Force, F

$1.0 \mathrm{kip} / \mathrm{ft}$

0.5

50

(6) Uplift factor, E

0.6667

0.105

15.7

12.8. Results. Results of the overturning analyses are summarized in Tables $\mathbf{1 2 . 5}$ and 12.6. A typical free-body diagram is shown in Figure 12-4. Values for $\beta_{\mathrm{FS}}$ exceed 6.0 for all considered conditions, and exceed 8.0 when vertical shear is assumed on a vertical plane through the heel. Values for $\beta_{\text {toe }}$ exceed 8.0 for all considered conditions. Some of the values for $\beta_{1 / 4}$ and $\beta_{\text {kem }}$ are negative, indicating a relatively high probability that the entire monolith base is not in compression. 


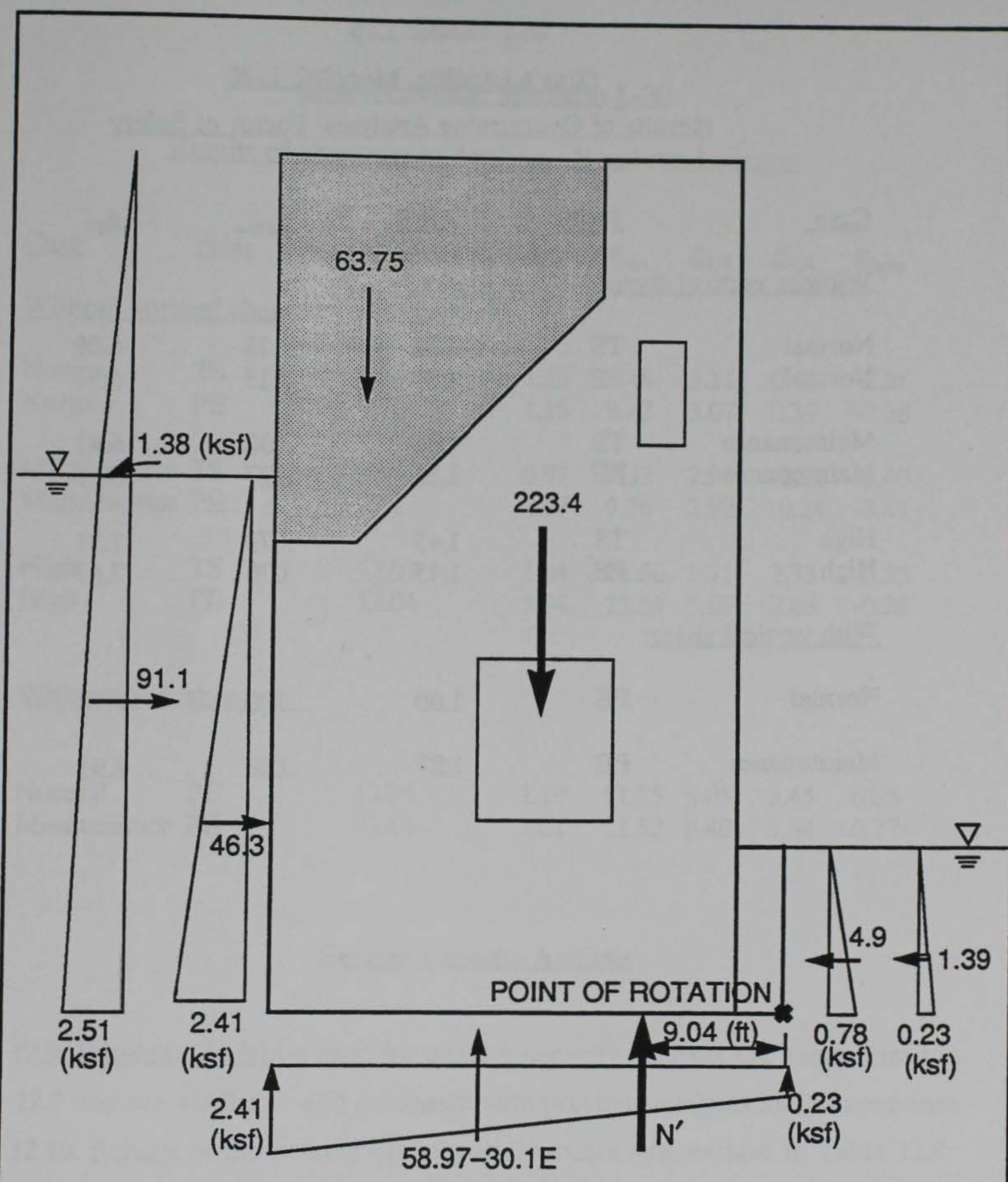

Forces in kips per lineal foot

Figure 12.4 Grays Landing Locks and Dam, L20, Free Body Diagram -Overturning Stability, Maintenance Condition 
Table 12.5

Gray's Landing, Monolith L-20

Results of Overturning Analyses- Factor of Safety

Case

$\underline{\text { Prob }}$

E[FS]

$\underline{\sigma}_{\mathrm{FS}}$

$\underline{\beta}_{\mathrm{FS}}$

Without vertical shear:

Normal

TS

1.58

.118

6.09

Normal

PE

1.59

.115

6.32

Maintenance

TS

1.66

.130

.127

6.42

Maintenance

PE

1.66

6.67

High

TS

1.45

.073

7.31

High

PE

1.45

.070

7.67

With vertical shear:

Normal

PE

1.80

.120

8.77

Maintenance

PE

1.87

.132

8.91 
Table 12.6

\section{Gray's Landing, Monolith L-20}

Results of Overturning Analyses- Resultant Location

\begin{tabular}{|c|c|c|c|c|c|c|c|}
\hline$\underline{\text { Case }}$ & $\underline{\text { Prob }}$ & $\underline{E}\left[X_{r}\right]$ & $\underline{\sigma}_{\mathrm{Xr}}$ & $\underline{B}_{t o c}$ & $\underline{\beta}_{1 / 6}$ & $\underline{\beta}_{1 / 4}$ & $\underline{\beta}_{\text {kern }}$ \\
\hline \multicolumn{8}{|c|}{ Without vertical shear } \\
\hline Normal & TS & 9.74 & 1.15 & 8.48 & 3.11 & 0.42 & -2.26 \\
\hline Normal & $\mathrm{PE}$ & 9.70 & 1.15 & 8.42 & 3.07 & 0.39 & -2.28 \\
\hline \multirow{2}{*}{\multicolumn{2}{|c|}{$\begin{array}{l}\text { Maintenance TS } \\
\text { Maintenance PE }\end{array}$}} & 9.04 & 0.97 & 9.32 & 2.96 & -0.22 & -3.40 \\
\hline & & 9.01 & 0.97 & 9.26 & 2.92 & -0.24 & -3.41 \\
\hline High & TS & 12.07 & 1.04 & 11.66 & 5.71 & 2.73 & -0.25 \\
\hline High & PE & 12.04 & 1.04 & 11.54 & 5.63 & 2.68 & -0.28 \\
\hline
\end{tabular}

With vertical shear

$\begin{array}{llllllll}\text { Normal } & \text { PE } & 13.34 & 1.19 & 11.25 & 6.05 & 3.45 & 0.85 \\ \text { Maintenance PE } & 12.61 & 1.01 & 12.52 & 6.40 & 3.34 & 0.27\end{array}$

\section{Bearing Capacity Analysis}

12.9. Random Variables used for bearing capacity analyses are summarized in Table 12.7 and are similar to and consistent with previous analyses and assumptions. 12.10. Results of the bearing capacity analyses are summarized in Table 12.8 . Consistent with previous analyses, reliability index values are very high (above 6.0) and values obtained using the point estimate method are much higher than those obtained using the Taylor's series method. 
Table 12.7

\section{Gray's Landing, Monolith L-20}

Random Variables for Bearing Analysis

\section{Variable}

(1) $\gamma_{\text {soil }}$

(2) $\phi_{\text {soil }}^{\prime}$

(3) $c_{\text {rock emb }}$

(4) $\tan \phi_{\text {rock emb }}^{\prime}$

(4) $\phi^{\prime}$ rock emb

$\rho_{c, \phi}=-.70$

(5) $c_{\text {rock base }}$

(6) $\phi^{\prime}$ rock base

$\rho_{c, \phi}=-.70$

(7) $\gamma_{\text {rockbase }}$

(8) $\gamma_{\text {conc }}$,

(9) Pull Force, F

(10) Uplift factor, E

(11) $X_{R}$

Normal

Maintenance

High Water

(12) $\delta$

Normal

Maintenance

High Water
Mean

$0.125 \mathrm{kcf}$

$32 \mathrm{deg}$

$2.5 \mathrm{ksf}$

1.70

52.416

$35.0 \mathrm{ksf}$

$52.416 \mathrm{deg}$

0.165

$0.150 \mathrm{kcf}$

$1.0 \mathrm{kip} / \mathrm{ft}$

0.6667

$9.736 \mathrm{ft}$

9.041

12.075

$27.83 \mathrm{deg}$

28.27

22.10 $\underline{\sigma}$

0.00625

$3.2 \mathrm{deg}$

1.75

0.765

12.892

24.6

5

10

70

45
$\underline{\mathrm{V}, \%}$

24.5

70

12.892

24.6
$0.00825 \quad 5$

$\begin{array}{ll}0.0075 & 5\end{array}$

0.5

50

0.105

15.7

$1.148 \mathrm{ft}$

11.79

0.970

1.035

10.73

8.57

10.15

7.59

13.04 
Table 12.8

Gray's Landing, Monolith L-20

Results of Bearing Analyses

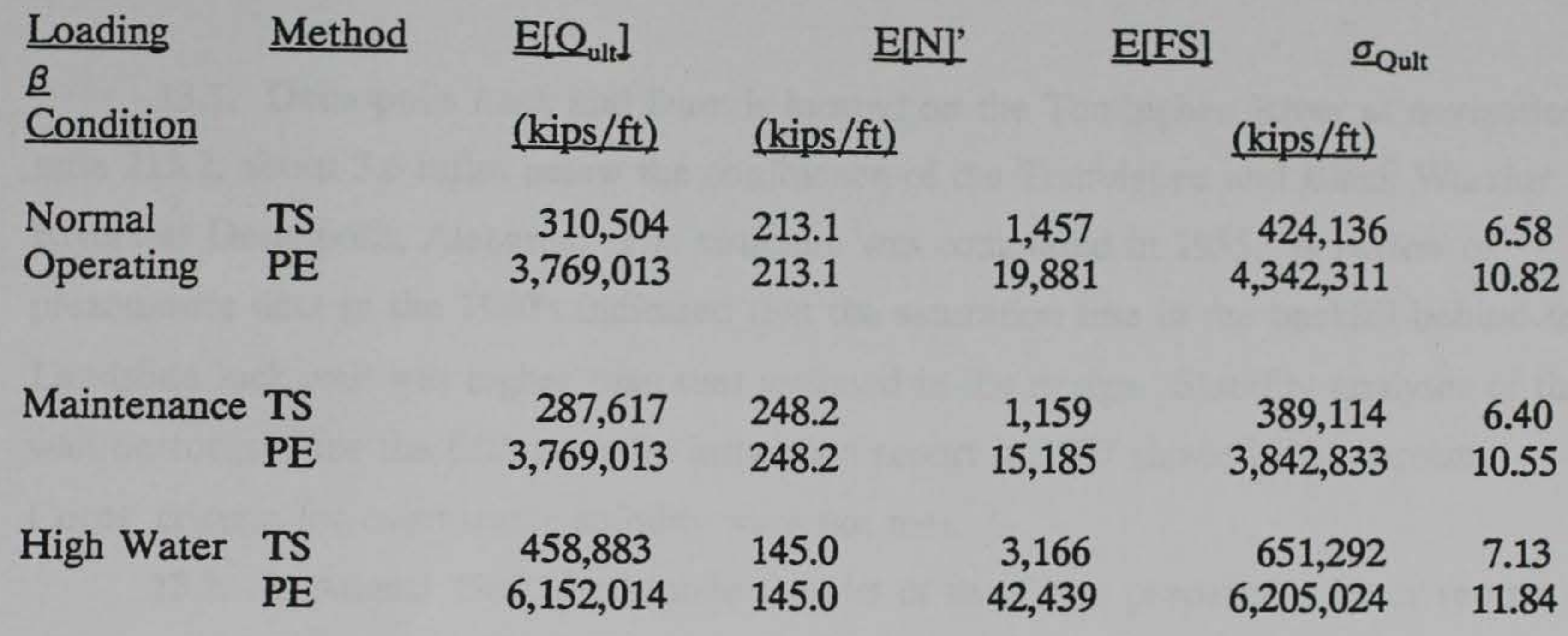

\section{Summary and Discussion}

12.11 Gray's Landing Locks and Dam, Monolith L-20, was chosen to provide calibration data reflective of a modern, well-designed structure. In this regard, it was found to have reliability index values above 5.0 for sliding, 6.0 for overturning, and 6.0 for bearing capacity. 
PART XIII: RELIABILITY ANALYSIS FOR DEMOPOLIS LOCKS AND DAM, MONOLITH L-17

\section{Problem Description}

13.1. Demopolis Lock and Dam is located on the Tombigbee River at navigation mile 213.2, about 3.6 miles below the confluence of the Tombigbee and Black Warrior Rivers at Demopolis, Alabama. The structure was completed in 1955. A review of piezometric data in the 1980's indicated that the saturation line in the backfill behind the Landslide lock wall was higher than that assumed in the design. Stability analyses of the wall performed for the fifth periodic inspection report in 1987 showed that current Corps' criteria for overturning stability were not met.

13.2. In August 1989, the Mobile District of the Corps prepared a letter report (U.S. Army Corps of Engineers, Mobile, 1989) proposing the removal of 20 feet of backfill and provision of a drainage system. These alterations would reduce the overturning moment on the land wall and obtain a more favorable location for the effective resultant force on the base. Specifically, the letter report indicated that for monolith $\mathrm{L}$ 17, 43.4 percent of the base would be in compression for the normal operating condition, while criteria required at least 75 percent of the base in compression. The letter report provided a case history of a situation where an unsatisfactory stability condition was identified and remedial action was taken based on the results of deterministic analyses. Accordingly, monolith L-17 was selected for probabilistic analyses to evaluate the difference in reliability before and after removal of the backfill as well as the contributions to reliability related to uncertainty in the uplift and vertical shear. These comparative analyses should provide some information to calibrate target reliability index values to be associated with both structures in need of remedial action and satisfactory structures.

13.3. A representative cross-section of monolith $\mathrm{L}-17$ is shown in figure 13.1. The lock backfill consists of a medium to high plasticity clay (CL to $\mathrm{CH}$ ) down to elevation 47 and then a silty, clayey sand (SC to SM) down to elevation 12 . The monolith is founded seven feet below the top of the chalk at elevation 5. Originally, the backfill 


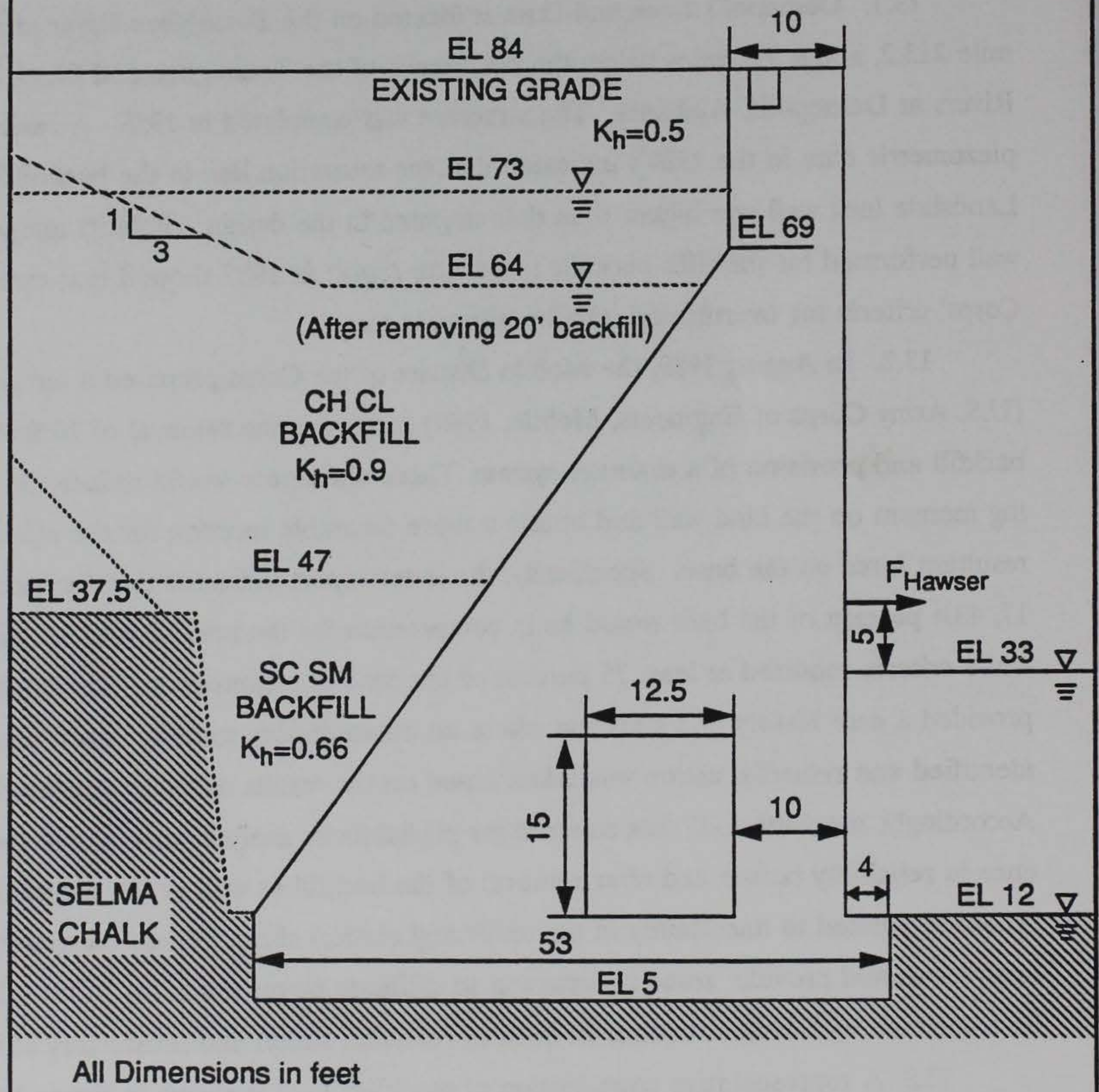

Figure 13.1. Demopolis Locks and Dam, L17 Cross-Section 
extended to the top of the lock wall at el. 84. Twenty feet of this material was removed as shown by dashed line in figure 13.1 .

13.4. Water Levels for Analysis. The following water levels were used for analyses.

$\begin{array}{lcc}\frac{\text { Case }}{\text { Before removal of the backfill }} & \text { Water in Chamber } & \text { Water in Backfill } \\ \text { Normal Operating } & 33.0 & \\ \text { Maintenance } & 12.0 & 73.0 \\ \text { High Water } & 83.0 & 73.0\end{array}$

After removal of the backfill

Normal Operating

33.0

64.0

Maintenance

12.0

64.0

High Water

83.0

84.0

\section{Sliding Analysis}

13.5. Random Variables. Random variables used in the sliding analysis were characterized by the values shown in Table 13.1. The expected value for soil density is consistent with the design value in the Mobile District's letter report. The expected value of the soil friction angle is consistent with the drained friction angle given in the letter report; however, no $\mathrm{c}$ value is used in the present analysis in order to model a drained sliding condition. The physical significance of the cohesion given in the report in the letter context of a sliding analysis is not clear and inclusion of a cohesion component in the backfill would reduce the tendency to slide. The expected value of the developed angle of vertical shear (or wall friction), $\delta$, is based on judgment and is consisted with that used for Lock and Dam No. 3. The expected values for the peak strength parameters for the foundation material, the Demopolis chalk, are based on the reported 
Table 13.1

Demopolis Locks and Dam. Monolith L-17

Random Variables for Sliding Analysis

$\underline{\text { Variable }}$

(1) $\gamma_{\text {soil }}$

(2) $\phi_{\text {soil }}^{\prime}$

(3) $\delta$

(4A) $c_{\text {rock }}$ (peak)

(5A) $\tan \phi_{\text {rock }}^{\prime}$ (peak)

(5A) $\phi$ ' rock (peak)

$\rho_{c, \phi \text { (peak) }}=-.70$

(4B) $c_{\text {rock }}$

(residual)

(5B) $\tan \phi_{\text {rock }}^{\prime}$

(residual)

(5B) $\phi^{\prime}$ rock (residual)

(6) $\gamma_{\text {concrete }}$

(7A) Uplift Factor, E

(8) Lateral Force, F

(9) Saturation level $\underline{\text { Mean }}$

$0.125 \mathrm{kcf}$

$30.0 \mathrm{deg}$

$12.0 \mathrm{deg}$

$30.0 \mathrm{ksf}$

0.61

$30.0 \mathrm{deg}$

11.46

0

0

0.5

1.429

35

$25.2 \mathrm{deg}$

8.02

31.84

$0.150 \mathrm{kcf}$

0.0075

5

$-0.40$

0.20

50.0

1.000

0.500

50.0

el. 68

6.8
V. \%

5

10

25

70

45

38.2 
averaged results of triaxial compression tests. The expected value of the residual friction angle, $\phi_{\text {res }}$, is based on the letter report (U.S. Army, Mobile 1989). The expected values of the uplift factor, E, corresponds to the assumption that part of the base is not in compression. The hawser pull force, $\mathrm{F}$, and the density of concrete are consistent with previous analyses. The standard deviations and coefficients of variation for the parameters are based on judgment and experience and are generally consistent with previous analyses.

13.6. Results. Results of the sliding analysis are summarized in Tables 13.2 through 13.5. Typical free body diagrams are shown in Figures 13.2 and 13.3. For the peak strength assumption, the minimum reliability index increased from 3.49 to 4.19 , an increase of 0.70 ; values for other cases and for residual strength assumptions increased similarly. 


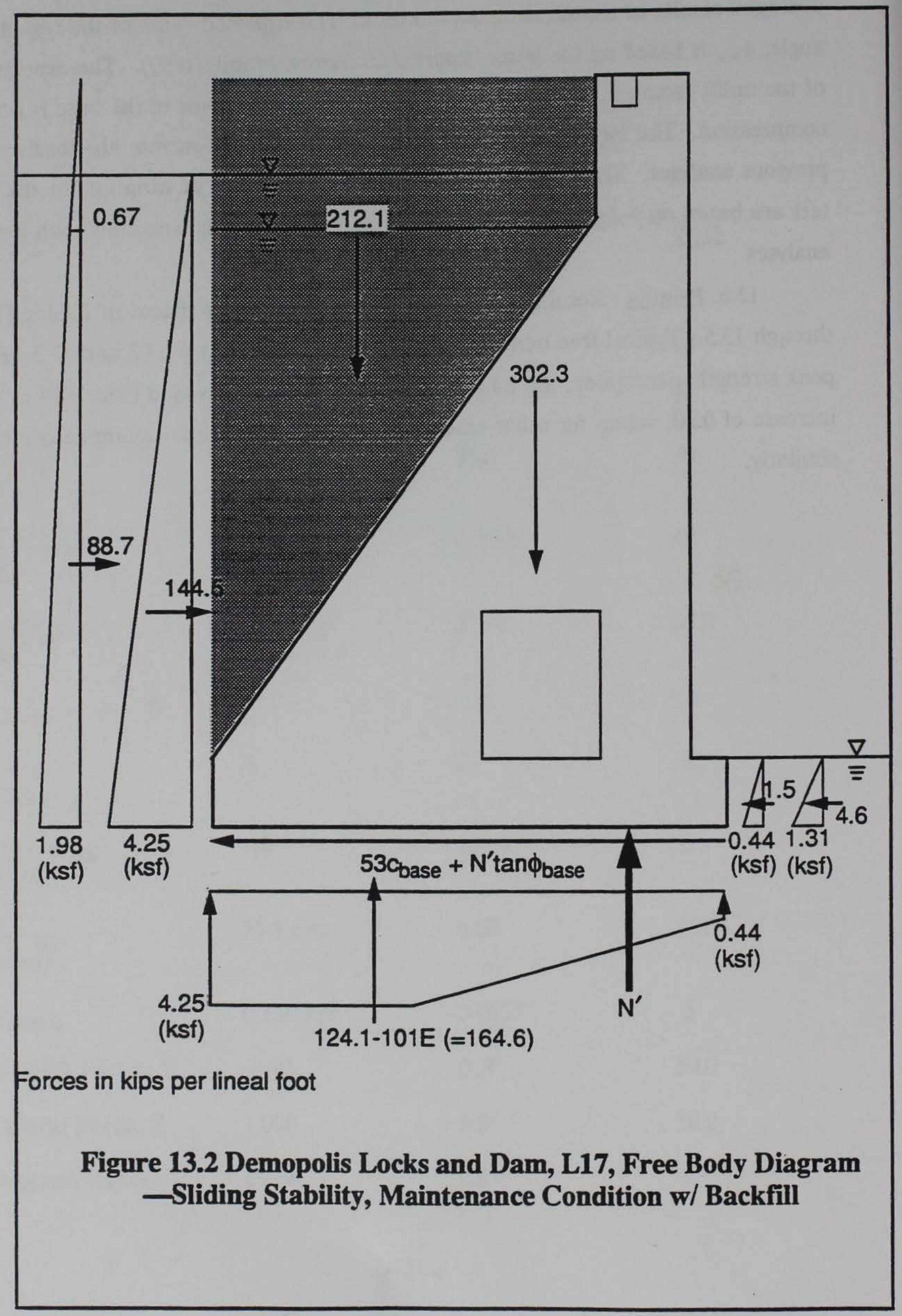




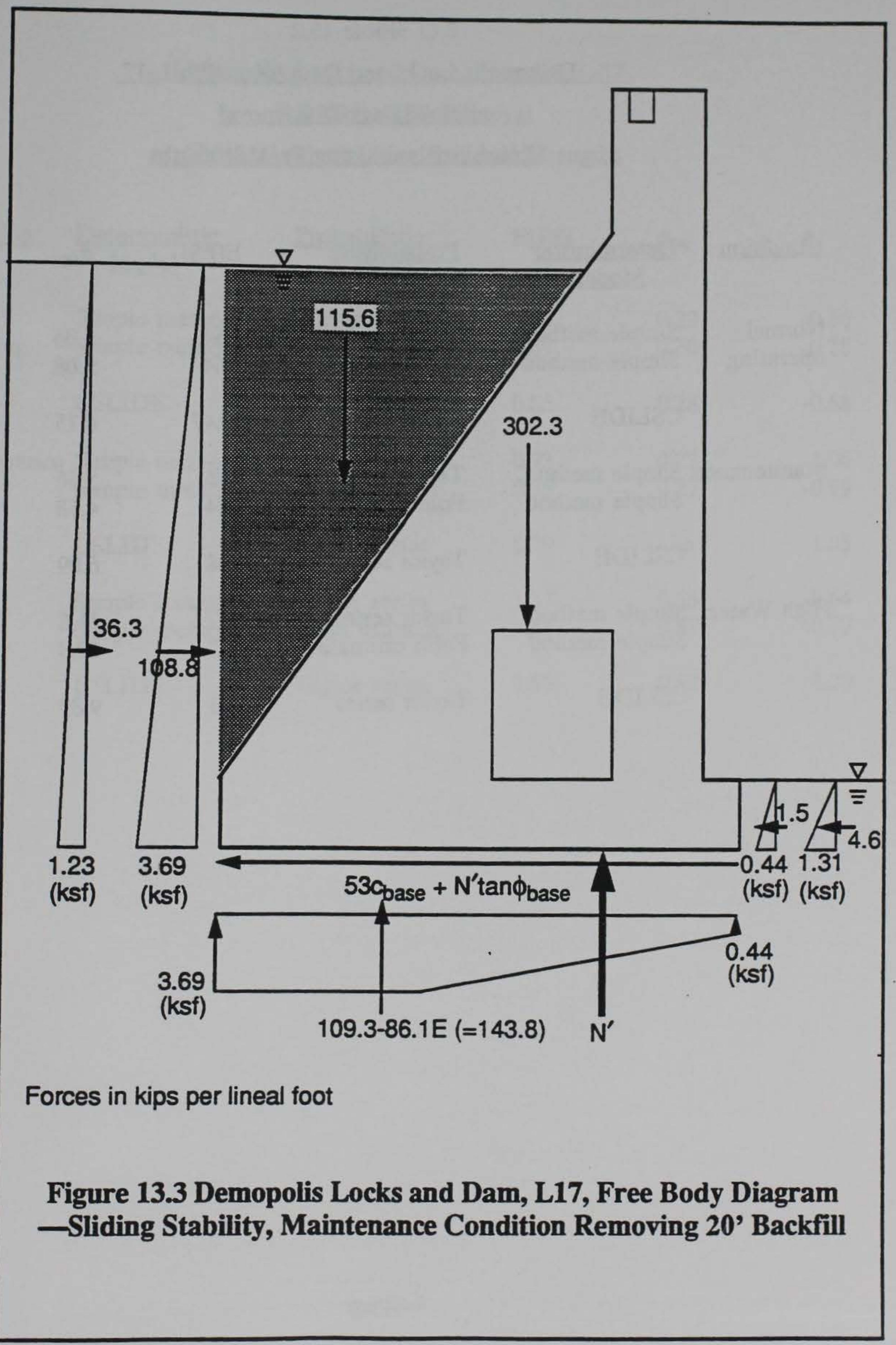


Table 13.2

Demopolis Locks and Dam, Monolith L-17

Before Backfill Removal

Sliding Analysis Using Peak Strengths

\begin{tabular}{|c|c|c|c|c|c|}
\hline Condition & $\frac{\text { Deterministic }}{\underline{\text { Model }}}$ & $\frac{\text { Probabilistic }}{\underline{\text { Model }}}$ & $\mathrm{E}[\underline{\mathrm{FS}}]$ & $\underline{\sigma}_{\mathrm{FS}}$ & $\underline{B}$ \\
\hline \multirow{3}{*}{$\begin{array}{l}\text { Normal } \\
\text { operating }\end{array}$} & Simple method & Taylor series & 8.54 & 5.05 & 3.65 \\
\hline & Simple method & Point estimate & 8.64 & 5.08 & 3.69 \\
\hline & CSLIDE & Taylor series & 10.47 & 6.15 & 4.05 \\
\hline \multirow{3}{*}{ Maintenance } & Simple method & Taylor series & 7.76 & 5.56 & 3.49 \\
\hline & Simple method & Point estimate & 7.84 & 4.58 & 3.53 \\
\hline & CSLIDE & Taylor series & 9.98 & 6.09 & 1.81 \\
\hline \multirow[t]{3}{*}{ High Water } & Simple method & Taylor series & 18.7 & 11.8 & .69 \\
\hline & Simple method & Point estimate & 19.3 & 12.3 & 17 \\
\hline & CSLIDE & Taylor series & 16.3 & 9.89 & 72 \\
\hline
\end{tabular}


Table 13.3

Demopolis Locks and Dam, Monolith L-17

Before Backfill Removal

Sliding Analysis Using Residual Strengths

\begin{tabular}{|c|c|c|c|c|c|}
\hline Condition & $\frac{\text { Deterministic }}{\underline{\text { Model }}}$ & $\frac{\text { Probabilistic }}{\underline{\text { Model }}}$ & $\mathrm{E}[\underline{\mathrm{FS}}]$ & $\underline{\sigma}_{\mathrm{FS}}$ & $\underline{B}$ \\
\hline \multirow[t]{2}{*}{$\begin{array}{l}\text { Normal } \\
\text { operating }\end{array}$} & $\begin{array}{l}\text { Simple method } \\
\text { Simple method }\end{array}$ & $\begin{array}{l}\text { Taylor series } \\
\text { Point estimate }\end{array}$ & $\begin{array}{l}0.78 \\
0.81\end{array}$ & $\begin{array}{l}0.29 \\
0.30\end{array}$ & $\begin{array}{l}-0.86 \\
-0.78\end{array}$ \\
\hline & CSLIDE & Taylor series & 0.85 & 0.28 & -0.68 \\
\hline \multirow[t]{2}{*}{ Maintenance } & $\begin{array}{l}\text { Simple method } \\
\text { Simple method }\end{array}$ & $\begin{array}{l}\text { Taylor series } \\
\text { Point estimate }\end{array}$ & $\begin{array}{l}0.73 \\
0.75\end{array}$ & $\begin{array}{l}0.27 \\
0.27\end{array}$ & $\begin{array}{l}-1.06 \\
-0.99\end{array}$ \\
\hline & CSLIDE & Taylor series & 0.79 & -.26 & -1.05 \\
\hline \multirow[t]{2}{*}{$\begin{array}{l}\text { High } \\
\text { Water }\end{array}$} & $\begin{array}{l}\text { Simple method } \\
\text { Simple method }\end{array}$ & $\begin{array}{l}\text { Taylor series } \\
\text { Point estimate }\end{array}$ & $\begin{array}{l}1.37 \\
1.44\end{array}$ & $\begin{array}{l}0.55 \\
0.57\end{array}$ & $\begin{array}{l}-0.64 \\
-0.77\end{array}$ \\
\hline & CSLIDE & Taylor series & 1.59 & 0.52 & 1.29 \\
\hline
\end{tabular}


Table 13.4

Demopolis Locks and Dam, Monolith L-20

After Backfill Removal

Sliding Analysis Using Peak Strengths

Condition Deterministic Model

Normal Simple method operating Simple method

CSLIDE

Maintenance Simple method

Simple method

CSLIDE

High Water Simple method

Simple method

CSLIDE
Probabilistic

Model

Taylor series

14.40

14.45

8.77

9.22

4.46

Point estimate

Taylor series

11.6

5.74

7.41

7.80

5.25

41.78

52.56

26.53

28.33

18.1

10.6

Taylor series

5.06 
Table 13.5

Demopolis Locks and Dam, Monolith L-17

After Backfill Removal

Sliding Analysis Using Residual Strengths

Condition Deterministic

Model

Normal operating

Simple method

Simple method

CSLIDE

Maintenance Simple method

Simple method

CSLIDE

High

Water
Simple method

Simple method

CSLIDE $\frac{\text { Probabilistic }}{\underline{\text { Model }}}$

Taylor series

Point estimate

Taylor series

Taylor series

Point estimate

0.93

0.95

0.34

0.35

$-0.40$

$-0.33$

Taylor series

Taylor series

Point estimate

Taylor series

\subsection{7}

2.67

1.44
0.39

0.40

0.05

$\underline{B}$ 
also taking wall friction as a random variable with the same values previously used for Locks and Dam No.3, monolith L-8.

Table 13.6

Demopolis Locks and Dam, Monolith L-17

Random Variables for Overturning Analysis

Variable

(1) $\gamma_{\text {soil }}$

(2) $K_{H}$

(3) $\delta$

(4) $\gamma_{\text {concrete }}$

(5) Uplift Factor, E

(6) Lateral Force, F

(7) Water in backfill $\underline{\text { Mean }}$

$0.125 \mathrm{kcf}$

0.5

0.9

0.66

$12.0 \mathrm{deg}$

$0.150 \mathrm{kcf}$

$-0.40$

1.0 kip

el. 68 $\underline{\sigma}$

0.00625

0.05

0.09

0.066

3.0

0.0075

0.20

0.50

6.8
$\underline{\mathrm{V}, \%}$

5

10

10

10

25

5

50

50

13.8. Results. Results of the overturning analysis are summarized in Tables $\mathbf{1 3 . 7}$ and 13.8. Typical free-body diagrams are shown in figures 13.4 and 13.5. In all cases, removal of the backfill significantly increased the reliability index values. In the case of $\beta_{\mathrm{FS}}$, the minimum value rose from 0.22 to 5.29 while the factor of safety increased only the minimum value of $\beta_{\text {toe }}$ increased from 0.25 to 4.85 . Even with the backfill removed, however, some values of $\beta_{\text {kern }}$ remain negative. 







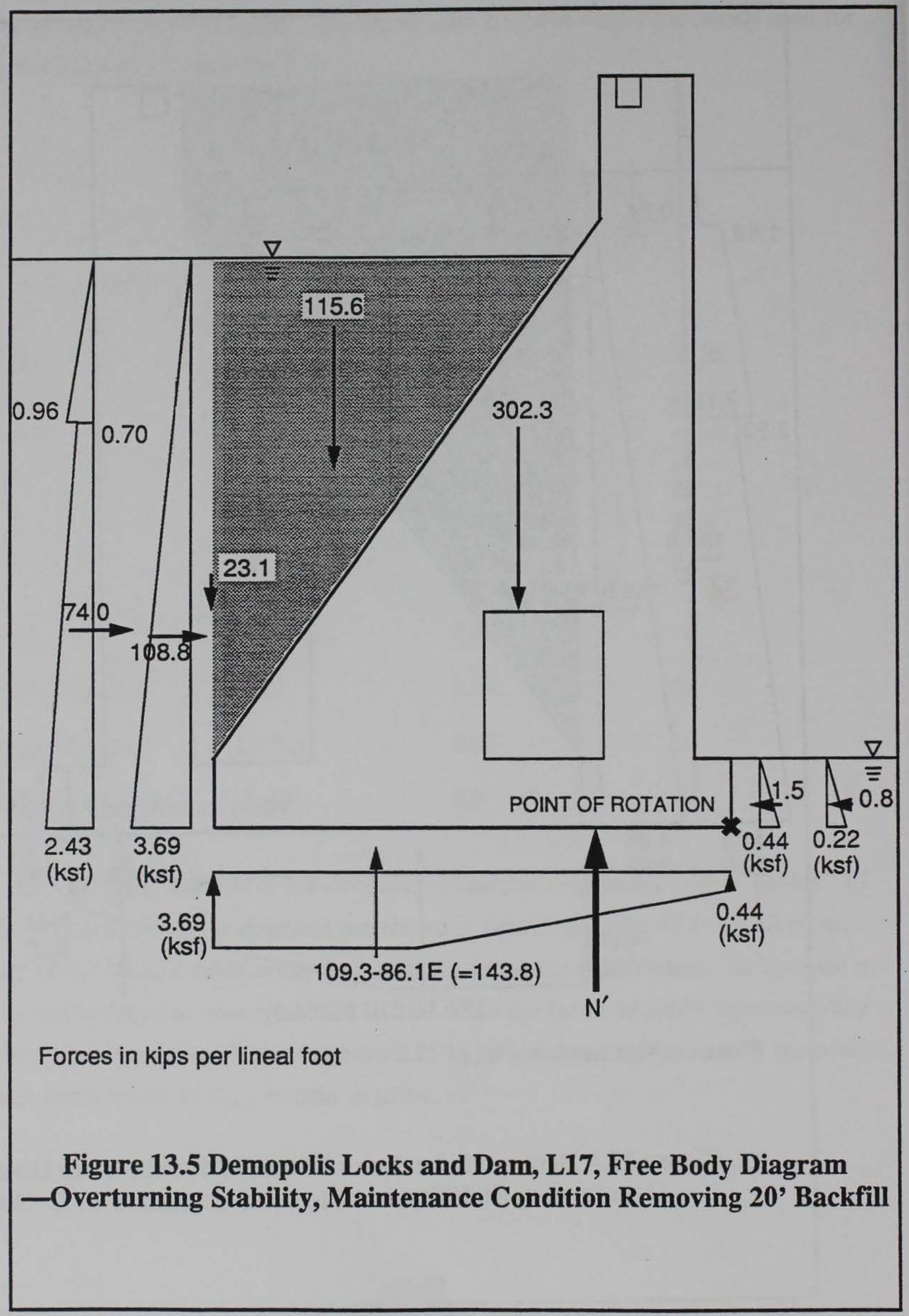


Table 13.7

\section{Demopolis Locks and Dam Monolith L-17}

Results of Overturning Analyses-Factor of Safety

Before backfill removal; without wall friction

$\begin{array}{lllll}\text { Case } & \underline{\text { Prob }} & \underline{\text { E[FS] }} & \underline{\sigma}_{\text {FS }} & \underline{\beta}_{\text {FS }} \\ \text { Normal } & \text { TS } & 1.03 & .056 & 0.51 \\ \text { Normal } & \text { PE } & 1.05 & .057 & 0.79 \\ \text { Maint } & \text { TS } & 1.01 & .060 & 0.22 \\ \text { Maint } & \text { PE } & 1.05 & .062 & 0.79 \\ \text { High } & \text { TS } & 1.15 & .064 & 2.53 \\ \text { High } & \text { PE } & 1.17 & .065 & 2.78\end{array}$

Before backfill removal; with wall friction

$\begin{array}{lllll}\text { Normal } & \text { TS } & 1.18 & .062 & 3.07 \\ \text { Normal } & \text { PE } & 1.19 & .062 & 3.35 \\ \text { Maint } & \text { TS } & 1.16 & .067 & 2.58 \\ \text { Maint } & \text { PE } & 1.20 & .069 & 3.13 \\ \text { High } & \text { TS } & 1.32 & .068 & 5.29 \\ \text { High } & \text { PE } & 1.33 & .068 & 5.57\end{array}$

After backfill removal; without wall friction

$\begin{array}{llllr}\text { Normal } & \text { TS } & 1.37 & .058 & 7.35 \\ \text { Normal } & \text { PE } & 1.38 & .059 & 7.70 \\ \text { Maint } & \text { TS } & 1.34 & .075 & 5.29 \\ \text { Maint } & \text { PE } & 1.40 & .078 & 6.00 \\ \text { High } & \text { TS } & 1.51 & .045 & 13.55 \\ \text { High } & \text { PE } & 1.52 & .045 & 14.07\end{array}$

After backfill removal; with wall friction

$\begin{array}{llllr}\text { Normal } & \text { TS } & 1.47 & .064 & 8.86 \\ \text { Normal } & \text { PE } & 1.49 & .064 & 9.13 \\ \text { Maint } & \text { TS } & 1.45 & .081 & 6.51 \\ \text { Maint } & \text { PE } & 1.50 & .085 & 7.15 \\ \text { High } & \text { TS } & 1.60 & .049 & 15.39 \\ \text { High } & \text { PE } & 1.62 & .049 & 15.77\end{array}$


Table 13.8

Demopolis Locks and Dam Monolith L-17

Results of Overturning Analyses-Resultant Location

Before backfill removal; no wall friction

$\underline{\text { Case }} \quad \underline{\text { Prob }} \underline{E[X r]} \underline{\sigma}_{X r}-\underline{B}_{t o c} \quad \underline{B}_{1 / 6} \quad \underline{B}_{1 / 4} \quad \underline{B}_{k e r n}$

$\begin{array}{llllllll}\text { Normal } & \text { TS } & 1.23 & 2.27 & 0.54 & -3.34 & -5.28 & -7.23\end{array}$

$\begin{array}{llllllll}\text { Normal } & \text { PE } & 1.70 & 2.22 & 0.77 & -3.22 & -5.21 & -7.20\end{array}$

$\begin{array}{llllllll}\text { Maint } & \text { TS } & 0.60 & 2.41 & 0.25 & -3.41 & -5.24 & -7.07\end{array}$

$\begin{array}{llllllll}\text { Maint } & \text { PE } & 1.72 & 2.25 & 0.76 & -3.16 & -5.13 & -7.09\end{array}$

$\begin{array}{llllllll}\text { High } & \text { TS } & 7.27 & 2.56 & 2.84 & -0.61 & -2.34 & -4.06\end{array}$

$\begin{array}{llllllll}\text { High } & \text { PE } & 7.75 & 2.25 & 3.04 & -0.42 & -2.15 & -3.89\end{array}$

Before backfill removal; with wall friction

$\begin{array}{llllllll}\text { Normal } & \text { TS } & 7.40 & 2.36 & 3.13 & -0.61 & -2.48 & -4.35\end{array}$

$\begin{array}{llllllll}\text { Normal } & \text { PE } & 7.81 & 2.12 & 3.69 & -0.48 & -2.56 & -4.65\end{array}$

$\begin{array}{llllllll}\text { Maint } & \text { TS } & 6.61 & 2.60 & 2.54 & -0.86 & -2.56 & -4.25\end{array}$

$\begin{array}{llllllll}\text { Maint } & \text { PE } & 7.50 & 2.09 & 3.58 & -0.69 & -2.75 & -4.86\end{array}$

$\begin{array}{llllllll}\text { High } & \text { TS } & 15.19 & 2.53 & 6.00 & 2.51 & 0.77 & -0.98\end{array}$

$\begin{array}{llllllll}\text { High } & \text { PE } & 15.60 & 2.51 & 6.21 & 2.69 & 0.94 & -0.82\end{array}$

After backfill removal; without wall friction

$\begin{array}{llllllll}\text { Normal } & \text { TS } & 11.56 & 1.50 & 7.72 & 1.82 & -1.13 & -4.08\end{array}$

$\begin{array}{llllllll}\text { Normal } & \text { PE } & 11.92 & 0.85 & 14.14 & 3.70 & -1.52 & -6.73\end{array}$

$\begin{array}{llllllll}\text { Maint } & \text { TS } & 10.42 & 2.15 & 4.85 & 0.74 & -1.32 & -3.38\end{array}$

$\begin{array}{lllllllll}\text { Maint } & \text { PE } & 11.26 & 0.95 & 11.79 & 2.54 & -2.54 & -6.71\end{array}$

$\begin{array}{llllllll}\text { High } & \text { TS } & 20.12 & 0.72 & 28.04 & 15.73 & 9.57 & 3.42\end{array}$

$\begin{array}{llllllll}\text { High } & \text { PE } & 20.12 & 0.68 & 30.37 & 17.29 & 10.74 & 4.20\end{array}$

After backfill removal; with wall friction

$\begin{array}{llllclll}\text { Normal } & \text { TS } & 14.71 & 1.70 & 8.64 & 3.45 & 0.86 & -1.74 \\ \text { Normal } & \text { PE } & 15.02 & 0.99 & 15.14 & 2.23 & 1.78 & -2.67 \\ \text { Maint } & \text { TS } & 13.46 & 2.39 & 5.63 & 1.93 & 0.09 & -1.76 \\ \text { Maint } & \text { PE } & 14.09 & 1.02 & 13.88 & 5.18 & 0.83 & -3.52 \\ \text { High } & \text { TS } & 23.16 & 1.07 & 22.44 & 14.17 & 10.03 & 5.89 \\ \text { High } & \text { PE } & 24.23 & 1.04 & 23.19 & 14.74 & 10.51 & 6.28\end{array}$


13.9. The analysis of monolith $\mathrm{L}-17$ provided an illustration of how reliability index values may increase due to a remedial alteration of a structure. Removal of $20 \mathrm{ft}$ of backfill resulted in a substantial increase in reliability index values, especially for overturning analyses, even though increases in factor of safety were relatively small. 


\section{PART XIV: DISCUSSION, CONCLUSIONS AND RECOMMENDATIONS}

\section{Introduction}

14.1. This final part is organized into three sections. In the Discussion, the results of all sliding and overturning analyses are combined in order to assess overall trends in the relationships among the various performance functions, limit states, and probabilistic models considered in the analyses. In the Conclusions, the major findings from all of the previous parts are briefly repeated. Finally in the Recommendations, suggestions are made for follow-on studies.

\section{Discussion}

14.2. Sliding Analyses. In all, 117 separate sliding analyses were made using various combinations of water levels, uplift assumptions, strength characterization (peak vs. residual), performance functions (simple vs. CSLIDE) and probabilistic models (Taylor's series vs. point estimate). Each of these analyses provided an expected value for the factor of safety and a reliability index. A spreadsheet summarizing these results was constructed and is printed in Table 14.1. From the spreadsheet, two plots were constructed (figures 14.1 and 14.2). In figure 14.1, the reliability index $\beta$ is plotted versus the expected value of the factor of safety on log-log scales. From the table and this figure, several observations can be made:

1. In a very general sense, the reliability index and factor of safety tend to increase together; however, there can be very different values of the reliability index for a given factor of safety, and vice versa. A primary factor in the scatter appears to be the difference between soil loads and water loads, which are treated the same in deterministic analyses, but have very different degrees of uncertainty.

2. Where peak strengths were assumed, all calculated $\beta$ values were above 3.5 and most values were above 4.0. For cases with the reliability index in the range 4.0 to 6.0 , the factor of safety varied in the range 2 to 20 , apparently due to different levels of uncertainty in the parameters as stated above. 
3. None of the structures exhibited a low $\beta$ value or a low factor of safety for assumed conditions (i.e., strengths, anchor forces) that are considered representative of actual conditions at the structure.

4. Based on the above, it would appear that a $\beta$ value greater than 4.0 indicates a structure that is highly reliable against sliding and that a value above 3.0 indicates a structure that probably has satisfactory reliability against sliding.

\subsection{Effect of Performance Function for Sliding. Regarding the effect of the} performance function (i.e. simple method vs CSLIDE), neither of the two functions considered results in consistently greater or smaller reliability index values. Differences are typically within 1.0 unit, although the difference is greater in some cases. Assuming that prioritization for investment is based on broad categories of beta values (e.g. remedial action for $\beta$ less than 2.0, further investigation for $\beta$ less than 4.0 ), and small differences in values are not afforded undue significance, it appears that values obtained using the two performance functions are sufficiently similar that use of either model would lead to similar engineering decisions.

\subsection{Effect of Probabilistic Model for Sliding. The effect of the two different} probabilistic models may be assessed from figure 14.2 , wherein the reliability index value obtained from the point estimate method is plotted against that obtained from the Taylor's series method. The diagonal line corresponds to the condition that results are equal. For linear performance functions, the results should be equal. Non-linearity is introduced by the $\phi$ parameter for earth pressures in the simple method and by the definition of the factor of safety in the CSLIDE method wherein the factor of safety is applied to $\tan \phi$ of all materials. For these cases, the point estimate method typically yields a somewhat greater reliability index than does Taylor's series. This can be explained as follows: as $\phi$ or $\tan \phi$ increases, the safety factor increases at a greater rate; in such cases, the point estimate method reflects some of the non-linearity and yields a greater value for the expected value of the factor of safety than does the Taylor's series method, which obtains the expected value of the factor of safety using mean values of the parameters. Although the point estimate results are considered to be more correct than the Taylor's series expansion about the mean, the Taylor's series method is 


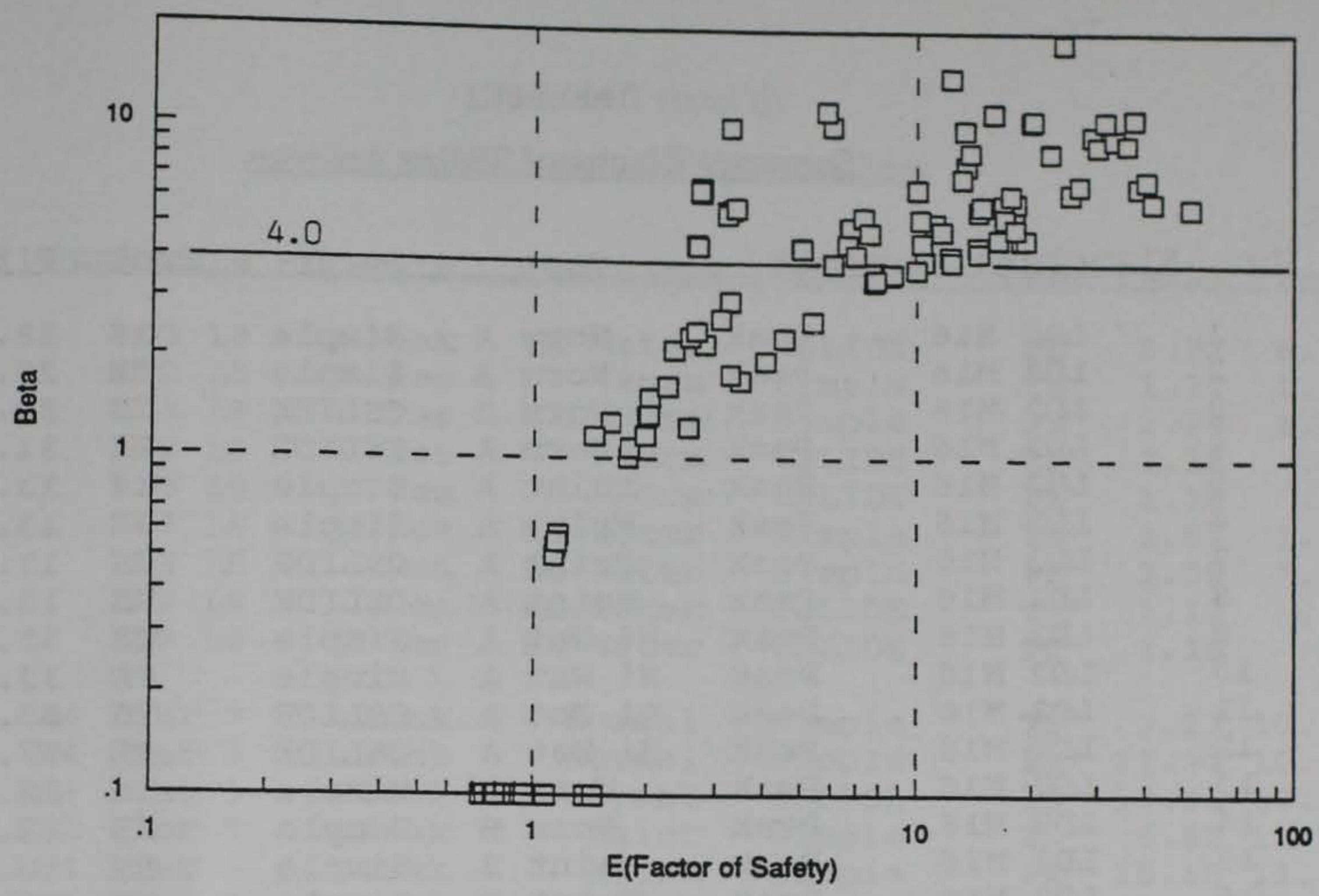

Figure 14.1 Sliding - Beta vs. Factor of Safety

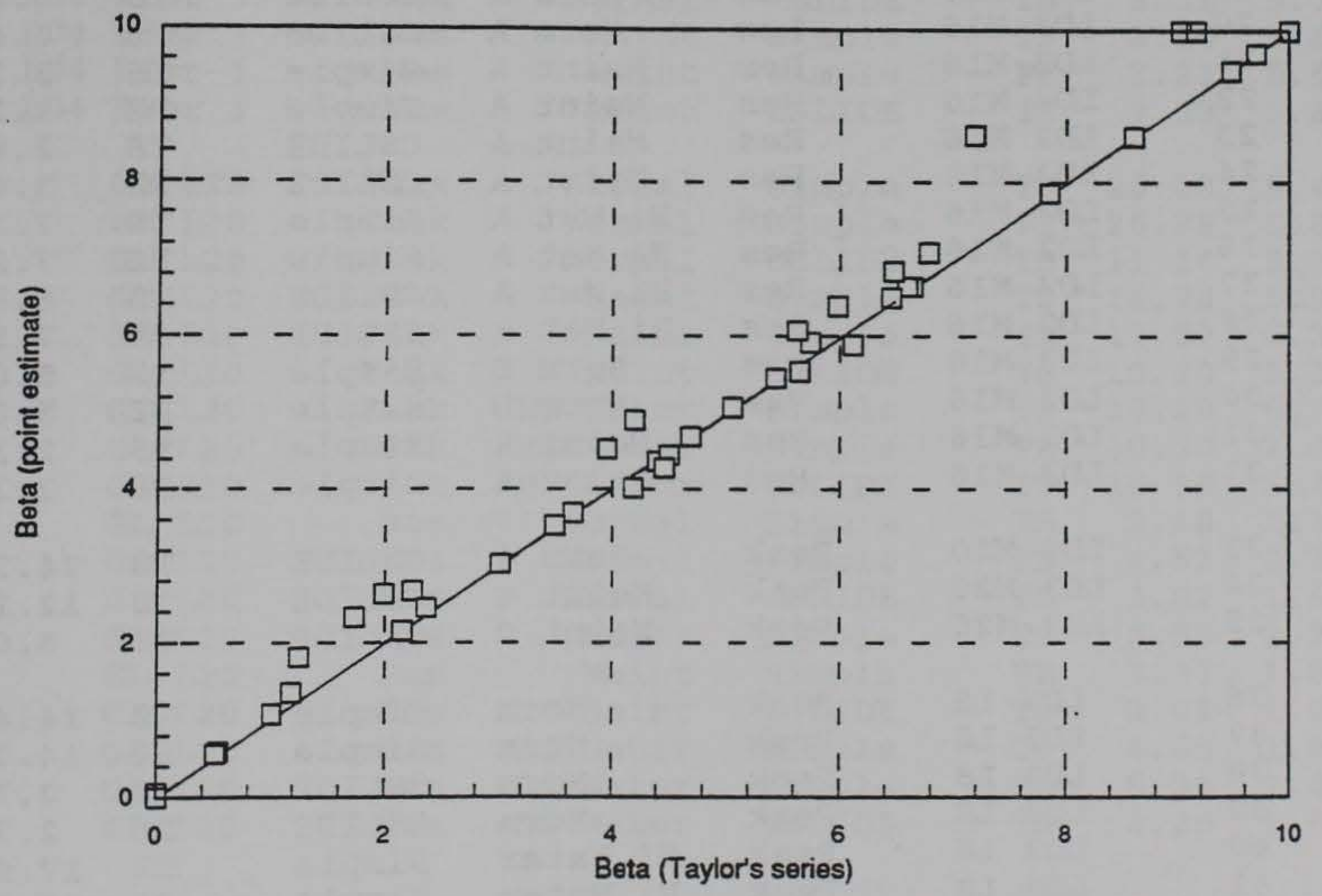

Figure 14.2 Sliding - Beta (Point Estimate) vs Beta (Taylor's series) 
Table 14.1

Summary Results of Sliding Analyses

Case

Perf

Prob

Beta

$\begin{array}{rrr}1 & \text { LD2 } & \text { M16 } \\ 2 & \text { LD2 } & \text { M16 } \\ 3 & \text { LD2 } & \text { M16 } \\ 4 & \text { LD2 } & \text { M16 } \\ 5 & \text { LD2 } & \text { M16 } \\ 6 & \text { LD2 } & \text { M16 } \\ 7 & \text { LD2 } & \text { M16 } \\ 8 & \text { LD2 } & \text { M16 } \\ 9 & \text { LD2 } & \text { M16 } \\ 10 & \text { LD2 } & \text { M16 } \\ 11 & \text { LD2 } & \text { M16 } \\ 12 & \text { LD2 } & \text { M16 } \\ 13 & \text { LD2 } & \text { M16 } \\ 14 & \text { LD2 } & \text { M16 } \\ 15 & \text { LD2 } & \text { M16 } \\ 16 & \text { LD2 } & \text { M16 } \\ 17 & \text { LD2 } & \text { M16 } \\ 18 & \text { LD2 } & \text { M16 } \\ 19 & \text { LD2 } & \text { M16 } \\ 20 & \text { LD2 } & \text { M16 } \\ 21 & \text { LD2 } & \text { M16 } \\ 22 & \text { LD2 } & \text { M16 } \\ 23 & \text { LD2 } & \text { M16 } \\ 24 & \text { LD2 } & \text { M16 } \\ 25 & \text { LD2 } & \text { M16 } \\ 26 & \text { LD2 } & \text { M16 } \\ 27 & \text { LD2 } & \text { M16 } \\ 28 & \text { LD2 } & \text { M16 } \\ 29 & \text { LD2 } & \text { M16 } \\ 30 & \text { LD2 } & \text { M16 } \\ 31 & \text { LD2 } & \text { M16 } \\ 32 & \text { LD2 } & \text { M16 } \\ 33 & \text { LD3 } & \text { M20 } \\ 34 & \text { LD3 } & \text { M20 } \\ 35 & \text { LD3 } & \text { M20 } \\ 36 & \text { LD3 } & \text { L8 } \\ 37 & \text { LD3 } & \text { L8 } \\ 38 & \text { LD3 } & \text { L8 } \\ 39 & \text { LD3 } & \text { L8 } \\ 40 & \text { LD3 } & \text { L8 } \\ 41 & \text { LD3 } & \text { L8 } \\ 42 & \text { LD3 } & \text { L8 } \\ & & \end{array}$

\section{Peak \\ Peak \\ Peak \\ Peak \\ Peak \\ Peak \\ Peak \\ Peak \\ Peak \\ Peak \\ Peak \\ Peak \\ Peak \\ Peak \\ Peak \\ Peak \\ Res \\ Res \\ Res \\ Res \\ Res \\ Res \\ Res \\ Res \\ Res \\ Res \\ Res \\ Res \\ Res \\ Res \\ Res \\ Res}

Peak

Peak

Peak

Peak

Peak

Peak

Peak

Peak

Peak

Peak
Norm A Norm A Norm A Norm A Maint $A$ Maint $A$ Maint A Maint $A$ $\mathrm{Hi}$ Wat $\mathrm{A}$ $\mathrm{Hi}$ Wat $\mathrm{A}$ Hi Wat $A$ $\mathrm{Hi}$ wat $\mathrm{A}$ Norm B Norm B Maint $B$ Maint B Norm $A$ Norm A Norm A Norm A Maint $A$ Maint $A$ Maint $A$ Maint $A$ Hi Wat A Hi Wat $A$ Hi Wat A $\mathrm{Hi}$ Wat $\mathrm{A}$ Norm B Norm B Maint $A$ Maint A

\section{Norm 4} Maint 4 Maint 0

Norm
Norm
Norm
Norm

$\mathrm{Hi}$ Water

Hi Water

$\mathrm{Hi}$ Water
Simple Simple CSLIDE CSLIDE Simple Simple CSLIDE CSIIDE Simple Simple CSIIDE CSIIDE

Simple Simple Simple Simple Simple

Simple

CSLIDE CSLIDE

Simple Simple CSLIDE CSLIDE Simple Simple CSLIDE CSLIDE Simple Simple Simple Simple

CSLIDE CSLIDE CSLIDE

Simple Simple CSLIDE CSLIDE Simple Simple CSLIDE

$\begin{array}{lrr}\text { TS } & 28.96 & 9.70 \\ \text { PE } & 28.97 & 9.70 \\ \text { TS } & 30.00 & 9.02 \\ \text { PE } & 31.38 & 10.77 \\ \text { TS } & 13.47 & 7.85 \\ \text { PE } & 13.48 & 7.86 \\ \text { TS } & 13.12 & 7.18 \\ \text { PE } & 13.77 & 8.61 \\ \text { TS } & 33.13 & 9.47 \\ \text { PE } & 33.15 & 9.47 \\ \text { TS } & 35.77 & 9.15 \\ \text { PE } & 37.32 & 10.94 \\ \text { TS } & 22.47 & 8.60 \\ \text { PE } & 22.48 & 6.59 \\ \text { TS } & 10.01 & 6.64 \\ \text { PE } & 10.01 & 6.64 \\ \text { TS } & 6.70 & 5.06 \\ \text { PE } & 6.73 & 5.08 \\ \text { TS } & 6.06 & 3.95 \\ \text { PE } & 6.60 & 4.53 \\ \text { TS } & 3.25 & 3.01 \\ \text { PE } & 3.26 & 3.02 \\ \text { TS } & 2.80 & 2.24 \\ \text { PE } & 3.09 & 2.67 \\ \text { TS } & 7.25 & 5.44 \\ \text { PE } & 7.28 & 5.46 \\ \text { TS } & 6.94 & 4.20 \\ \text { PE } & 7.54 & 4.91 \\ \text { TS } & 5.01 & 4.40 \\ \text { PE } & 5.03 & 4.37 \\ \text { TS } & 2.33 & 2.15 \\ \text { PE } & 2.33 & 2.15 \\ & & \end{array}$

TS TS $12.26 \quad 14.50$ TS $6.03 \quad 10.30$

$\begin{array}{lrr}\text { TS } & 14.45 & 5.74 \\ \text { PE } & 14.75 & 5.92 \\ \text { TS } & 2.75 & 6.59 \\ \text { PE } & 2.74 & 6.64 \\ \text { TS } & 17.96 & 5.63 \\ \text { PE } & 18.16 & 6.07 \\ \text { TS } & 2.74 & 6.45\end{array}$


Table 14.1 (cont'd)

Summary Results of Sliding Analyses

\begin{tabular}{|c|c|c|c|c|c|c|c|c|}
\hline No & St? & ucture & Strength & Case & Perf & Prob & $E[F S]$ & Beta \\
\hline 43 & & LD3 L8 & Peak & Hi water & CSLIDE & $\mathrm{PE}$ & 2.72 & 6.50 \\
\hline 44 & & LD3 L8 & Res & Norm & Simple & TS & 1.77 & 1.01 \\
\hline 45 & & LD3 L8 & Res & Norm & Simple & PE & 1.79 & 1.08 \\
\hline 46 & & LD3 L8 & Res & Norm & CSLIDE & TS & 1.14 & .54 \\
\hline 47 & & LD3 L8 & Res & Norm & CSLIDE & PE & 1.16 & .59 \\
\hline 48 & & LD3 L8 & Res & $\mathrm{Hi}$ Water & Simple & TS & 1.97 & 1.18 \\
\hline 49 & & LD3 L8 & Res & Hi Water & Simple & $\mathrm{PE}$ & 1.99 & 1.35 \\
\hline 50 & & LD3 L8 & Res & Hi Water & CSLIDE & TS & 1.13 & .51 \\
\hline 51 & & LD3 L8 & Res & Hi Water & CSLIDE & PE & 1.15 & .56 \\
\hline 52 & LD4 & Pier 3 & Peak & Normal & Simple & TS & 3.27 & 10.11 \\
\hline 53 & LD4 & Pier 3 & Peak & Normal & Simple & $\mathrm{PE}$ & 13.34 & 10.06 \\
\hline 54 & LD4 & Pier 3 & Peak & Normal & CSLIDE & TS & 19.91 & 10.73 \\
\hline 55 & LD4 & Pier 3 & Peak & Maint & Simple & TS & 5.82 & 11.39 \\
\hline 56 & LD4 & Pier 3 & Peak & Maint & Simple & PE & 15.82 & 11.34 \\
\hline 57 & LD4 & Pier 3 & Peak & Maint & CSLIDE & TS & 20.21 & 10.85 \\
\hline 58 & LD4 & Pier 3 & Res & Normal & Simple & TS & 2.67 & 4.50 \\
\hline 59 & LD4 & Pier 3 & Res & Normal & Simple & PE & 2.69 & 4.45 \\
\hline 60 & LD4 & Pier 3 & Res & Normal & CSLIDE & TS & 3.31 & 5.70 \\
\hline 61 & LD4 & Pier 3 & Res & Maint & Simple & TS & 3.20 & 5.65 \\
\hline 62 & LD4 & Pier 3 & Res & Maint & Simple & $\mathrm{PE}$ & 3.21 & 5.54 \\
\hline 63 & LD4 & Pier 3 & Res & Maint & CSLIDE & TS & 3.39 & 5.80 \\
\hline 64 & & GL L20 & Peak & Normal & Simple & TS & 25.38 & 6.47 \\
\hline 65 & & GL L20 & Peak & Normal & Simple & $\mathrm{PE}$ & 26.78 & 6.84 \\
\hline 66 & & GL L20 & Peak & Normal & CSLIDE & TS & 11.16 & 5.25 \\
\hline 67 & & GL L20 & Peak & Maint & Simple & TS & 16.78 & 5.98 \\
\hline 68 & & GL L20 & Peak & Maint & Simple & $\mathrm{PE}$ & 17.57 & 6.39 \\
\hline 69 & & GL L20 & Peak & Maint & CSLIDE & TS & 10.20 & 5.39 \\
\hline 70 & & GL L20 & Peak & Hi Water & Simple & TS & 38.29 & 6.78 \\
\hline 71 & & GL L20 & Peak & $\mathrm{Hi}$ Water & Simple & $\mathrm{PE}$ & 40.30 & 7.09 \\
\hline 72 & & GL L20 & Peak & Hi Water & CSLIDE & TS & 16.95 & 5.44 \\
\hline 73 & & GL L20 & Res & Normal & Simple & TS & 3.48 & 1.73 \\
\hline 74 & & GL L20 & Res & Normal & Simple & $\mathrm{PE}$ & 4.53 & 2.33 \\
\hline 75 & & GL L20 & Res & Normal & CSLIDE & TS & 2.02 & 1.53 \\
\hline 76 & & GL L20 & Res & Maint & Simple & TS & 2.55 & 1.25 \\
\hline 77 & & GL L20 & Res & Maint & Simple & $\mathrm{PE}$ & 3.27 & 1.81 \\
\hline 78 & & GL L20 & Res & Maint & CSLIDE & TS & 2.01 & 1.36 \\
\hline 79 & & GL L20 & Res & Hi Water & Simple & TS & 4.05 & 1.99 \\
\hline 80 & & GL L20 & Res & Hi Water & Simple & $\mathrm{PE}$ & 5.36 & 2.63 \\
\hline 81 & & GL L20 & Res & Hi Water & CSLIDE & TS & 2.25 & 1.66 \\
\hline
\end{tabular}


Table 14.1 (cont'd)

Summary Results of Sliding Analyses

No Structure Strength Case Perf Prob E[FS] Beta

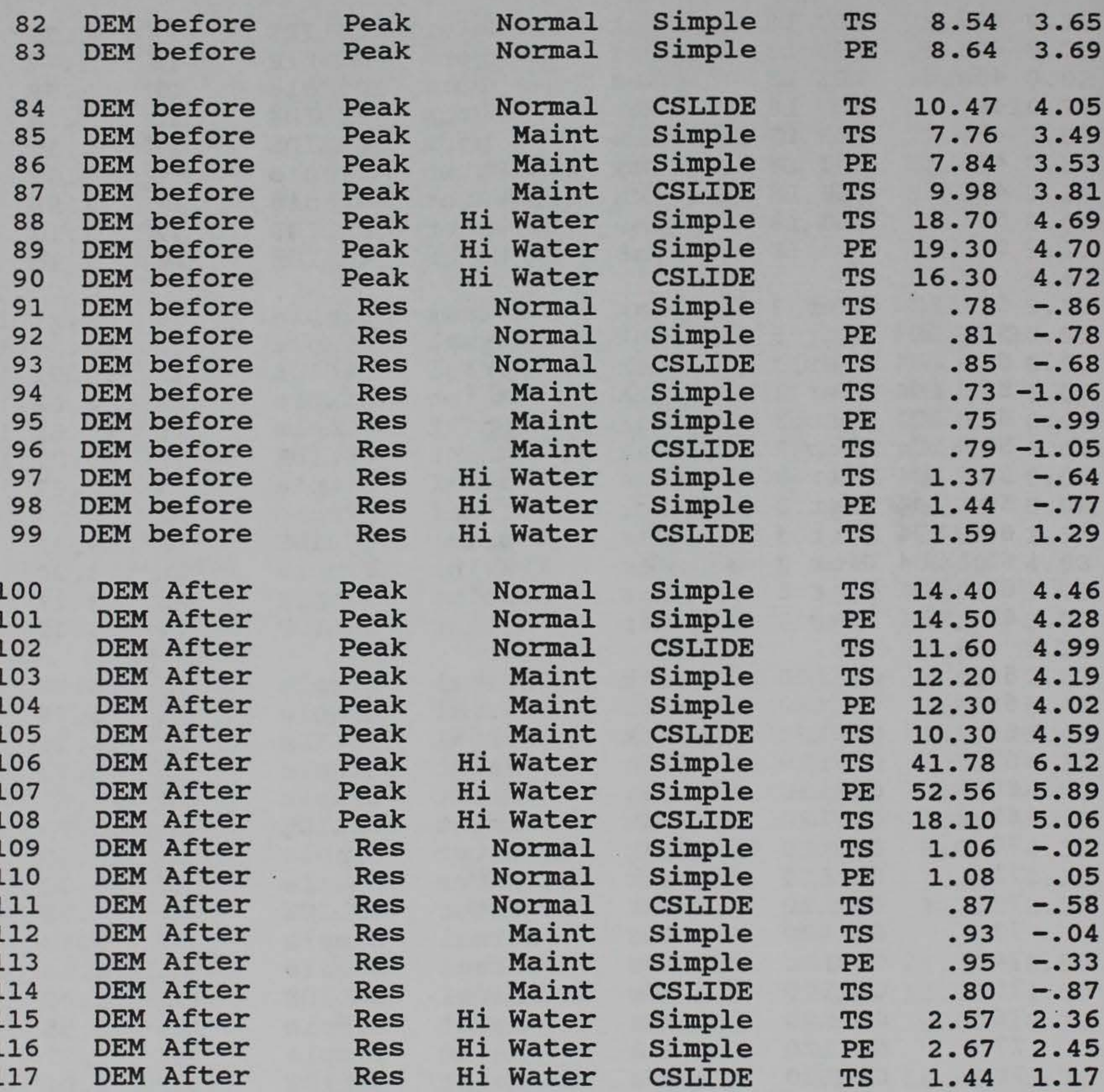


generally slightly conservative and has computational advantages when more than three random variables are involved.

14.5. Overturning Analyses. In all, 55 separate overturning analyses were made using various combinations of water levels, uplift assumptions, performance functions (factor of safety vs. location of resultant) and probabilistic models (Taylor's series vs. point estimate). Each of these analyses produced an expected value for the factor of safety and five different reliability index values, $\beta_{\mathrm{FS}}, \beta_{\mathrm{toe}}, \beta_{1 / 6}, \beta_{1 / 4}$, and $\beta_{\mathrm{kem}}$, for a total of 275 reliability indices. A spreadsheet summarizing these results was constructed and is printed in Table 14.2. From the spreadsheet, a summary plot was constructed (Figure 14.3), showing the five reliability index values versus the expected value of the factor of safety. From the table and the figure, several observations can be made:

1. For factors of safety from 1.0 to $1.5, \beta_{\text {toe }}$ varies somewhat linearly with factor of safety from zero to about 6.0. For factors of safety above $1.5, \beta_{\text {toe }}$ varies widely, but remains above about 6.0 .

2. There is reasonably good agreement between $\beta_{\mathrm{FS}}$ and $\beta_{\text {toe }}$, which might be expected as they have a common limit state: the factor of safety will be 1.0 when the resultant force is at the toe.

3. For the structures considered, the resultant force is typically more likely to be outside the kern than inside, which is expressed as a negative value for $\beta_{\text {kern }}$.

4. Structures having values for $\beta_{\text {toe }}$ and/or $\beta_{\mathrm{FS}}$ above about 4.0 appear to be highly reliable with respect to rotational stability. However, for these conditions, values for $\beta_{1 / 6}, \beta_{1 / 4}$, and $\beta_{\text {kem }}$ may be low or negative, implying that the entire base is not in compression. In such cases, the effect of the uplift pressure assumptions should be carefully reviewed and the foundation conditions should be carefully evaluated with respect to possible excessive bearing pressures.

\subsection{Effect of Performance Function for Overturning. The reliability index} values for the factor of safety $\left(\beta_{\mathrm{FS}}\right)$ and for the event that the resultant force is within the toe $\left(\beta_{\text {toe }}\right)$ agree reasonably well when considered in the context of how they might be used for investment decisions. In a number of cases, calculated values are very different but both so high as to indicate no remedial action need be considered (e.g., 15.83 vs. 71). 


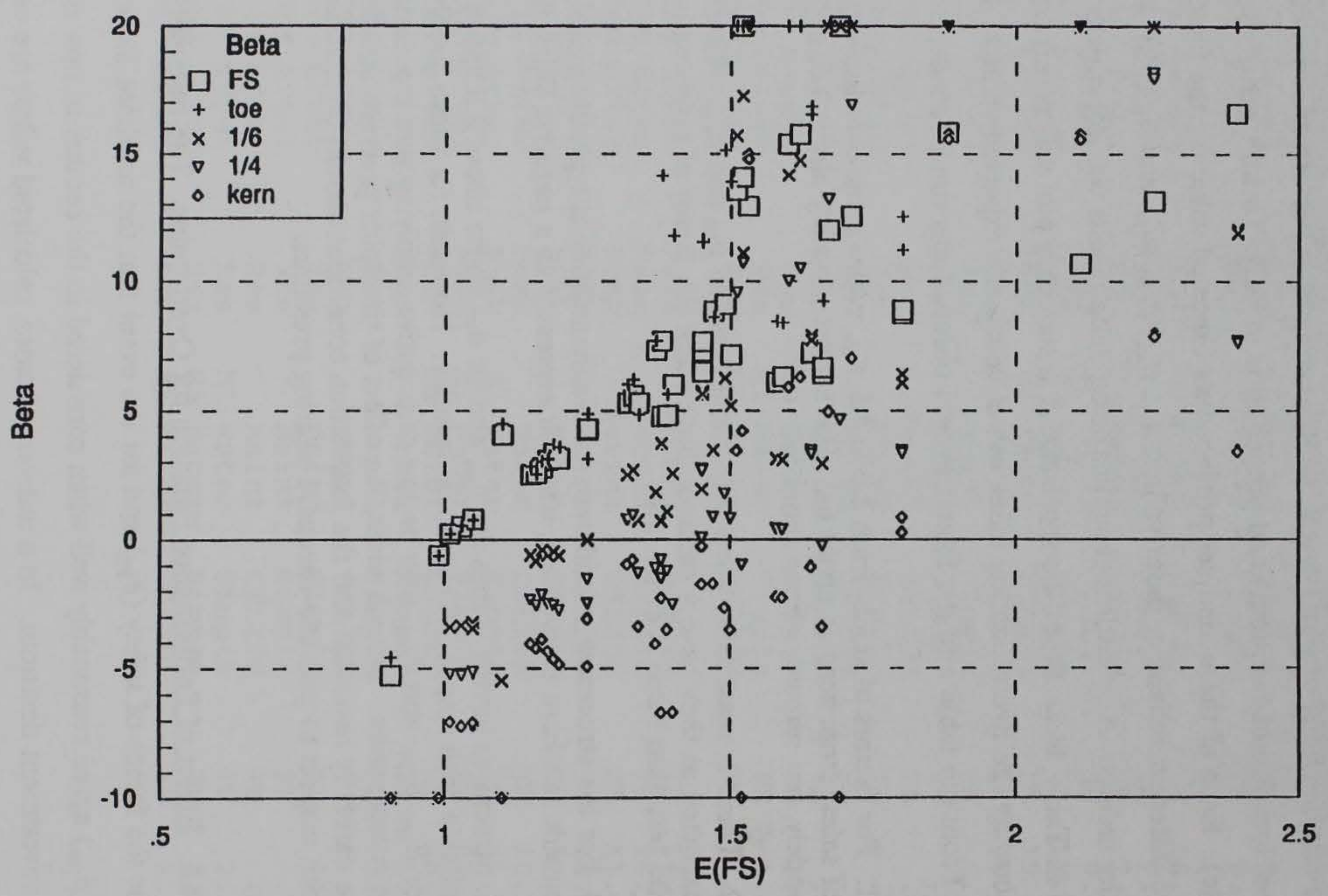

Figure 14.3 Overturning -- Betá vs. Expected Factor of Safety 
Where values are such that action may be considered, or was in fact taken, values are more similar (e.g., 3.07 vs. 3.13 , etc. at Demopolis before removing fill). As the two reliability indices approach 1.0 , the difference tends to reduce as the two limit states are equivalent.

14.7. The remaining reliability indices $\left(\beta_{1 / 6}, \beta_{1 / 4}\right.$, and $\left.\beta_{\mathrm{kem}}\right)$ are expressions of reliability with respect to performance states rather than limit states and by definition will be successively smaller and may be negative. They do not measure reliability with respect to overturning in the traditional sense but are measures of how well a structure is geometrically proportioned relative to distributing its loads over the foundation. As such, low values should indicate to the analyst the need to very carefully consider in a second analysis the certainty or uncertainty of the uplift assumptions and the implications of the implied pressures on the foundation.

14.8. Effect of Probabilistic Model for Overturning. As was noted for sliding, the Taylor's series and point estimate method produce very similar results and the point estimate method usually (but not always) tends to result in slightly higher reliability index values where non-linearity is introduced in the performance function from the material strength parameters. Based on the results, it appears either model can be used and that the Taylor's series approach offers computational advantage when the number of random variables exceeds three. 
Table 14.2

Summary Results of Overturning Analyses

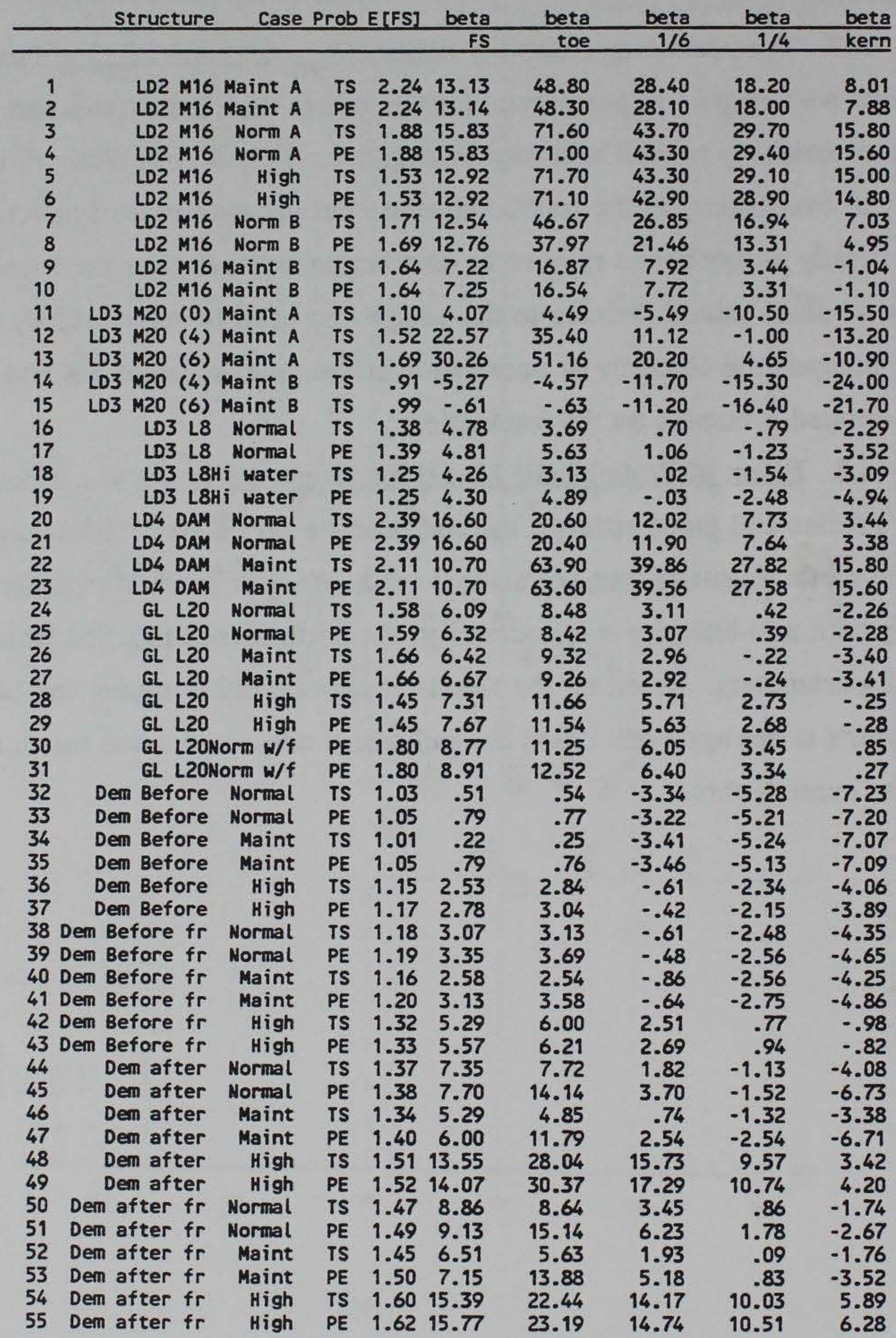




\section{Conclusions}

14.7 Following the general order of the topics in the report, the following conclusions can be drawn:

1. Suitability of Approach. Existing methods of structural reliability analysis can be adapted to the evaluation of navigation structures for the purpose of ranking the need for investment in remedial action.

2. Advantage of Approach. The use of probabilistic methods, specifically the treatment of parameters as random variables and the expression of reliability as an index value, appears to have advantage over purely deterministic methods. Although results from both approaches may depend on the judgment of individual engineers, the certainty or uncertainty of such judgments is explicitly and formally included in the probabilistic method. Thus, decisions made on reliability index ranking should be inherently more rationally supported than those based on deterministic methods alone.

3. Background. The probabilistic approach has been developing for over forty years, there are numerous examples in the literature (which have been only cursorily reviewed for this study) and applications to practice have been rapidly increasing in the past ten years. It is appropriate and timely to begin application of such methods to evaluation of navigation structures.

4. Reliability Index. For reasons discusses at length in Part 3, an appropriate characterization of reliability for navigation structures is the reliability index as defined in terms of the lognormal distribution. An exception is for the location of the effective base resultant force where the definition based on the normal distribution is recommended. The reliability index is preferred over actual probability values due to the lack of knowledge regarding the true distribution of the performance function. If highly non-linear performance functions are of concern, such as that for bearing capacity, the iterative Hasofer-Lind definition should be further investigated.

5. Correlation between $\phi$ and $c$ parameters. The $\phi$ and $c$ parameters are known to be negatively correlated, and data reviewed for this study confirmed this. Taking such correlation as zero may lead to an underestimate of reliability.

6. Probabilistic Models. For linear performance functions, the Taylor's series method and the point estimate method yield similar values for the reliability index. For the non-linear performance functions investigated, where the nonlinearity was primarily due to soil and rock strength, the point estimate method 
usually led to a somewhat greater reliability index than the Taylor's series method. The Taylor's series method is slightly conservative and has computational advantage when more than three random variables are involved.

7. Foundation rock strength. There is considerable scatter in rock strength data, leading to high coefficients of variation. The strength at a given confining pressure is less uncertain than the values of $c$ and $\phi$ that combine to provide that strength. Accordingly, there is negative correlation between $c$ and $\phi$. Linear regression techniques described in Part 4 can provide an appropriate characterization of the strength of the tested samples. Given the usual approach to sampling and testing, the uncertainty regarding the in-situ strength may in fact be greater than that obtained from statistical analysis of the test data. Furthermore, it may be argued that usual sampling and testing is biased in favor of good samples, or alternatively, in favor of bad samples. Much remains to be done to develop rational procedures for expressing rock strength probabilistically.

\section{Spatial correlation of rock strength parameters. In this study, variance of the} strength parameters was not reduced to account for spatial correlation effects. Expressed another way, this infers that the average strength of a potential sliding surface is as uncertain as the strength obtained in a test of a random sample, or that the correlation distance is large relative to the dimensions of a typical sliding problem. If in fact the correlation distance is smaller, then the actual reliability indices are greater than the values calculated. The approach used in conservative but merits further study.

\section{Modeling of Uplift Conditions. The random variable E, as defined in Part 5,} provides a convenient means to define the uplift force and its pressure distribution, for any condition ranging from full headwater across the base through tailwater across the base, including the commonly-assumed linear variation. Additional research is required to assess site-specific and typical values for this variable and gain better understanding how it affects reliability.

10. Characterization of Anchor Force For well-installed anchors, the initial load is known with a high degree of certainty as it is measured at installation. Anchor force will reduce with time; however, anchors re-stressed shortly after installation typically show very little (a few percent) reduction in load after relatively long periods. For the anchors at Lock and Dam No. 3, there is considerable concern by Corps personnel regarding the quality of the grout-steel bond, the quality of the grout-rock bond, and potential corrosion of the steel tendons from adjacent coal seams. In such cases, the probabilistic moments of the anchor force are conditional moments, conditioned on the event that the anchors are still functioning. The probability of this event in turn, can only be assessed by (1) anchor testing, which would be difficult as the anchor heads are encased in concrete, or (2) judgmental assessment by personnel knowledgeable about the installation. 
11. Reliability of Considered Structures on Monongahela River - Sliding. The reliability index with regard to sliding for the considered structures on the Monongahela River was found to be above 5.0 in all cases where peak strength was assumed and above 6.0 in most cases. Comparison analyses were made assuming residual strength conditions, but such conditions are not considered relevant in view of the demonstrated performance of the structures. Allowing for some possible bias in the sampling and testing, and the possibility of some loading more critical than those considered, it is likely that the reliability index is above 4.0 for sliding in any case of interest.

\section{Reliability of Considered Structures on Monongahela River - Overturning.} For monolith M-16 at Locks and Dam No. 2, dam pier 3 at Locks and Dam No. 4 , and monolith L-20 at Gray's Landing Locks and Dam, the reliability indices $\beta_{\mathrm{FS}}$ and $\beta_{\text {toe }}$ are above 6.0 for all cases and the structures appear to be highly reliable against overturning. For monolith L-8 at Locks and Dam No. 3, these reliability indices are in the range 3.0 to 5.0 and a lower degree of reliability is indicated. Given the apparently acceptable behavior of these monoliths, these findings are consistent with the recommendation for a target reliability index of 4.0 given below. For monolith M-20 at Locks and Dam No. 3, these reliability indices are highly dependent on water levels and the number of anchors considered operative. If the anchors are operative and the lock is dewatered under the assumed water levels (A), analyses indicate a high reliability ( $\beta$ is greater than 20 ). On the other hand, if the anchors are not operative, the $\beta$ value for the (A) conditions drops to about 4.0. If the lock were dewatered at the (B) water level conditions, the reliability indices would be negative even with functioning anchors, indicating that the monoliths would be more likely to be unstable than stable for such conditions.

\section{Reliability of Considered Structures on Monongahela River - Bearing Capaci-} ty. The reliability analyses for bearing capacity, with the exception of the Taylor's series method for the dam pier at Locks and Dam 4, found $\beta$ values in excess of 5.0. Although no problem with bearing capacity is foreseen at the structures studies, the numerical results should be not be assigned much significance as the relatively high degree of non-linearity in the bearing capacity equations combined with the high expected values and high coefficients of variation of strength parameters led to considerable differences in results across methods. Further studies should be made before recommending a general method for assessing bearing capacity.

14. Improvement in Reliability due to modifications at Demopolis Lock and Dam. Before removal of the fill at Demopolis, sliding reliability indices were above 3.5. After removal of the fill, these values increased about 0.7 units and were above 
4.0. Before removal of the fill, reliability indices for overturning $\beta_{\mathrm{FS}}$ and $\beta_{\text {toe }}$ were in the range 2.5 to 3.5 , and as low as 0.2 if vertical shear in the backfill was neglected. Removal of the fill typically increased these values on the order of 4.0 units, and reliability indices were above 5.5 ( 4.5 if vertical shear was neglected). It is concluded that the removal of the backfill increased the reliability by a very great degree even though the calculated factors of safety increased by only relatively small amounts (e.g., 1.45 vs. 1.19 ).

15. Sliding Analyses - Target Reliability Indices. Based on the summary analyses in the Discussion above, the following target reliability indices are recommended:

$\beta>4.0$
$3.0<\beta<4.0$
$\beta<3.0$

Structure is apparently highly reliable with respect to sliding.

Structure may be marginally reliable with respect to sliding. Additional data, tests or investigations should be considered to determine if uncertainty in the relevant variables can be reduced.

Structure is comparatively less reliable than well-performing Corps structures and should be given a high priority for investigation and possible remedial action.

16. Overturning Analyses -Target reliability indices with respect to limit state. Based on the summary analyses in the Discussion above, the following target reliability analyses are recommended, where $\beta$ is taken as $\beta_{\mathrm{FS}}$ or $\beta_{\text {toe }}$ :
$\beta>4.0$
$3.0<\beta<.4 .0$
Structure is apparently highly reliable with respect to overturning.

$\beta<3.0$
Structure may be marginally reliable with respect to overturning. Additional data, tests or investigations should be considered to determine if uncertainty in the relevant variables can be reduced.
Structure is comparatively less reliable than well-per- forming Corps structures and should be given a high priority for investigation and possible remedial action.

17. Overturning Analyses -Target reliability indices with respect to performance state. Values obtained for $\beta_{1 / 6}, \beta_{1 / 4}$, and $\beta_{\text {kern }}$ represent assessments of the likelihood that the effective base resultant force falls within various regions of the 
base. These regions do not correspond to limit states but rather represent points along a continuum of base pressure conditions and in turn structural proportionality ranging from a well-proportioned structure to a poorly-proportioned structure. No specific target values are recommended by the authors for these $\beta$ values. Rather, they might be considered as indicators of the relative need to further assess the assumed uplift conditions and the implications of high foundation stresses. Target values, if assigned, appear at this point to be a policy decision rather than a calibration problem.

18. Implementation of Procedures It is the understanding of the authors that the procedures demonstrated herein are being recommended for immediate implementation for assessment and ranking of navigation structures by Corps personnel. Although it is concluded that the procedures demonstrated are conceptually sound and have advantages over deterministic methods, it should be understood that the combination of additional research and additional analyses of actual structures by the Corps will undoubtedly lead to refinement of these techniques and identify additional questions for consideration. For example, much remains to be learned and studied regarding inherent uncertainty in various parameters, correlation among parameters, spatial correlation effects, model uncertainty in the performance functions, applicability and advantage of advanced probabilistic models, and continuation of the calibration process.

\section{$\underline{\text { Recommendations }}$}

14.8 Based on the findings and conclusions of this study, the following recommendations are made:

1. The Corps of Engineers should begin "beta testing" the developed procedures using their own personnel and additional sites to better understand the demonstrated methods, their advantages and remaining shortcomings, and the need for additional research.

2. Based on the experiences from this study, additional research and development appears warranted in a number of areas, including the following:

Improved procedures for calculating the reliability index for non-linear performance functions.

Characterization of correlation between parameters and spatial correlation of individual parameters.

Improvement of Corps' computer programs to readily accomodate probabi- 
listic procedures.

Application of newly-developing probabilistic techniques to reduce computational effort where large numbers of random variables are involved.

Appropriate characterization of certain random variables where prior studies are lacking, such as uplift, impact loads, and confidence in anchor performance.

Appropriate characterization of the time-dependent random variable, such as anchor force when subjected to creep and/ or corrosion. 


\section{REFERENCES}

Ang, A. H.-S., et. al, (1979), "Development of a Systems Risk Methodology for Single and Multi-Modal Transportation Systems," Final Report, Contract DOT-OS-50238, Washington, D.C., July, 1979.

Ang, A. H.-S., and Tang, W. H., (1975), "Probability Concepts in Engineering Planning and Design," Volume I: Basic Principles. John Wiley and Sons.

Ang, A. H.-S., and Tang, W. H., (1984), "Probability Concepts in Engineering Planning and Design," Volume II: Decision,Risk, and Reliability, John Wiley and Sons.

Benjamin, J. and C. A. Cornell, (1970), "Probability, Statistics, and Decision for Civil Engineers," McGraw-Hill, New York.

Draper, N. R., and Smith, H., Applied Regression Analysis, John Wiley and Sons, Inc., New York.

Ellingwood, B., MacGregor, J.G., Galambos, T. V., and Cornell, C. A., (1978), "Probability Based Load Criteria: Load Factors and Load Combinations," ASCE Journal of the Structural Division, Vol. 108, No. ST5, May 1982, pp. 978-997.

Ellingwood, B., Galambos, T. V., MacGregor, James G., and Cornell, C. A., (1980), "Development of a Probability Based Load Criterion for American National Standard A58; Building Code Requirements for Minimum Design Loads in Buildings and Other Structures," U.S. Department of Commerce, National Bureau of Standards NBS Special Publication 577, June 1980.

Freudenthal, A. M., (1947), "The Safety of Structures," Transactions, ASCE, Vol 112, 1947, pp. 125-159.

Freudenthal, A. M., (1956), "Safety and the Probability of Structural Failure," ASCE Transactions, Vol. 121, 1956, pp. 1337-1397.

Freudenthal, A. M., (1961) "Safety, Reliability and Structural Design," ASCE Journal of the Structural Division, Vol 87, No. ST3, March 1961, pp. 1-16

Freudenthal, A. M., Garrelts, J. M., and Shinozuka, M. (1966). "The Analysis of Structural Safety," ASCE, Journal of the Structural Division, Vol 92, No. ST1, Feb. 1966, pp. $267-$ 325.

Galambos, T. V., (1988), "Reliability of Structural Steel Systems," Structural Engineering Report No. 88-06, University of Minnesota, August 1988, sponsored by the American Iron and Steel Institute. 
Galambos, et. al, (1978), "Eight Collected Papers on Load and Resistance Factor

Design," Journal of the Structural Division, ASCE, Vol. 104, no. ST9, Sept., 1978.

Galambos, T. V., Ellingwood, B., MacGregor, J.G., and Cornell, C. A., (1982), "Probability Based Load Criteria: Assessment of Current Design Practice," ASCE Journal of the Structural Division, Vol. 108, No. ST5, May 1982, pp. 959-977.

Hanna, T.H., (1982), Foundations in Tension-Ground Anchors, McGraw Hill. First ed., 1982.

Harr, M.E. (1987), Reliability Based Design in Civil Engineering, McGraw-Hill, New York Harr, M. E., (1989), "Probabilistic Estimates for Multivariate Analysis," Applied Mathematical Modeling, Vol 13, May, 1989, pp. 313-318.

Hasofer, A. M., and Lind, N., (1974), "An Exact and Invariant First-Order Reliability Format," Journal of Engineering Mechanics, ASCE, Vol. 100, No. EM1, February 1974, pp. 111-121.

Hart, Gary C., (1982), Uncertainty Analysis, Loads, and Safety in Structural Engineering, Prentice-Hall, Englewood Cliffs, N.J., 224 pp.

Hobst, L., (1977), "Anchoring in Rocks, "In Developments in Geotechnical Engineering 13, EISEVIER Scientific Publishing Company, New York.

Littlejohn, G.S., (1974), " Rock anchors-some design considerations, "A paper presented to the Seventh Congress of the Federation Internationale de la Precontrainte, New York, May 1974.

Littlejohn, G. S., et Bruce, D. A., (1976). Rock Anchors: State of the Art. Part 3. Stressing and testing. Ground Engineering, 9(4): 33-44.

Littlejohn, G. S., et Bruce, D. A. (1977). Rock Anchors: State of the Art. Foundation Publication Ltd., Brentwood, Essex, Angleterre.

Littlejohn, G. S., et Bruce, D. A. (1979). Long-term performance of high capacity rock anchors at Davenport. Ground Engineering, 12(7):25-33.

McCann, M.W., (1987), "Probabilistic Risk Assessment of Locks and Dams - Methodology," report prepared for Department of the Army, Waterways Experiment Station by Jack R. Benjamin \& Associates, May 1987 (Report JBA 158-020-01)

McCann, M.W., and Boissonade, A.C., (1987), "Probabilistic Risk Assessment of Emsworth Locks and Dams, Ohio River," report prepared for Department of the Army, Waterways Experiment Station by Jack R. Benjamin \& Associates, November 1987 (Report JBA 158-020-02) 
Mirza, S.A., Kikuchi, D.K., MacGregor, J.G., (1979), "Flexural Strength Reduction Factor of Bonded Prestressed Concrete Beams," ACI Journal, July-August, 1980, PP. 237-246.

Mirza, S.A., MacGregor, J.G., "Variations in Dimensions of Reinforced Concrete Members," Journal of the Structural Division, ASCE, Vol. 105, No. ST4, Proc. Paper 14495, April, 1979, PP. 751-766.

Mirza, S.A., MacGregor, J.G., "Variability of Mechanical Properties of Reinforcing Bars," Journal of the Structural Division, ASCE, Vol. 105, No. ST5, Proc. Paper 14590, May,1979, PP. 921-937.

Moses, F., and Verma, D., (1987), "Load Capacity Evaluation of Existing Bridges," National Cooperative Highway Research Program Report 310, Transportation Research Board, National Research Council, Washington, DC, December 1987.

Mosher, R. and Pace, M.E., (1982), "User Guide: Computer Program For Bearing Capacity Analysis of Shallow Foundation," U.S. Army Engineer Waterways Experimentation Station, Vicksburg, June 1982.

Ostermayer, H. 1974. Construction, Carrying Behavior and Creep Characteristics of Ground Anchors. Proceedings, The Institution of Civil Engineers, London, pp. 144-151.

Portier, J.L., "Protection of Tie-backs Against Corrosion," A paper presented to the Seventh Congress of the Federation Internationale de la Precontrainte, New York, May 1974.

Pace, M. E., and Noddin, V. R., (1987), "Sliding Stability of Concrete Structures (CSLIDE)," Instruction Report ITL-87-5, Department of the Army, Waterways Experiment Station, Vicksburg, Mississippi.

Rosenblueth, E. (1975), "Point Estimates for Probability Moments," Proceedings, National Academy of Science, USA, 72(10)

Rosenblueth, E. (1981), "Two-Point Estimates in Probabilities," Applied Mathematical Modeling, vol. 5

Tarricone, P., (1991), "Trouble on the Waterways," Civil Engineering, February 1991, pp. $52-56$.

U.S. Army Engineer District, Pittsburgh (1987), "Gray's Landing Lock and Dam Monongahela River, Design Memorandom No.4, Feature Design Memorandum, July 1987.

U.S. Army Corps of Engineers, Mobile District (1989), "Letter Report for remedial Excavation at Demopolis Lock," August 1989.

U.S. Army Engineer Waterways Experiment Station, (1976), "Engineering Condition 
Survey and Structural Investigation of Locks and Dam No. 3, Monongahela River." sponsored by U.S. Army Engineer District, Pittsburgh.

U. S. Army, Office of the Chief of Engineers, (1981), "Sliding Stability for Concrete Structures," ETL 1110-2-256, Washington, DC.

U. S. Army, Office of the Chief of Engineers, (1989), "Retaining and Flood Walls" EM 1110-2-2502, Washington, DC.

Wolff, T. F., (1985), "Analysis and Design of Embankment Dam Slopes: A Probabilistic Approach," thesis submitted to the faculty of Purdue University in partial fulfillment of the requirements for the degree of Doctor of Philosophy, May 1985.

Wolff, T. F., (1991), "Embankment Reliability versus Factor of Safety: Before and After Slide Repair," International Journal for Numerical and Analytical Methods in Geomechanics, Vol15 No.1, January 1991, pp. 41-50.

Wolff, T. F., and Harr, M.E., (1987), "Slope Design for Earth Dams," in Reliability and Risk Analysis in Civil Engineering 2, Proceedings of the Fifth International Conference on Applications of Statistics and Probability in Soil and Structural Engineering, Vancouver, BC, Canada, May, 1987, pp. 725 - 732

Wolff, T. F., Hempen, G. L., Dirnberger, M. M., and Moore, B. H., (1988), "Probabilistic Analysis of Earthquake-Induced Pool Release," Second International Conference on Case Histories in Geotechnical Engineering, University of Missouri - Rolla, June 1988, pp. 787-794.

Wolff, T.F., (1990), "PILINT: A Software Package Designed for Pile Interference Analysis," Research Report Prepared for U.S. Army Engineer Waterways Experiment Station by Michigan State University, April 1990.

Woodward-Clyde Consultants (1981), "Final Report: Geotechnical Safety Program, Phase II, Clarence Cannon Dam," Prepare for U.S. Army Corps of Engineers, St.Louis, November 1981.

Wong, G. S., Stowe, R. L., Tom, J. G., Ahlvin, J. C., and Rowe, G., (undated), "Condition Survey of Locks No. 4, Monongahela River," Structures Laboratory, U.S. Army Engineer Waterways Experiment Station, Vicksburg, MS, prepared for U.S. Army Engineer District, Pittsburgh.

Wong, G. S., Stowe, R. L., Ahlvin, J. C., and Tom, J. G., (1988), "Condition Survey of Lock No. 2, Monongahela River," Structures Laboratory, U.S. Army Engineer Waterways Experiment Station, Vicksburg, MS, prepared for U.S. Army Engineer District, Pittsburgh. 


\section{Appendix A \\ Example Sliding Analysis \\ Locks and Dam No. 2, Monolith M-16}

The cross-section of Locks and Dam No. 2, Monolith M-16 is illustrated in Figure A-1 below (maintenance condition).

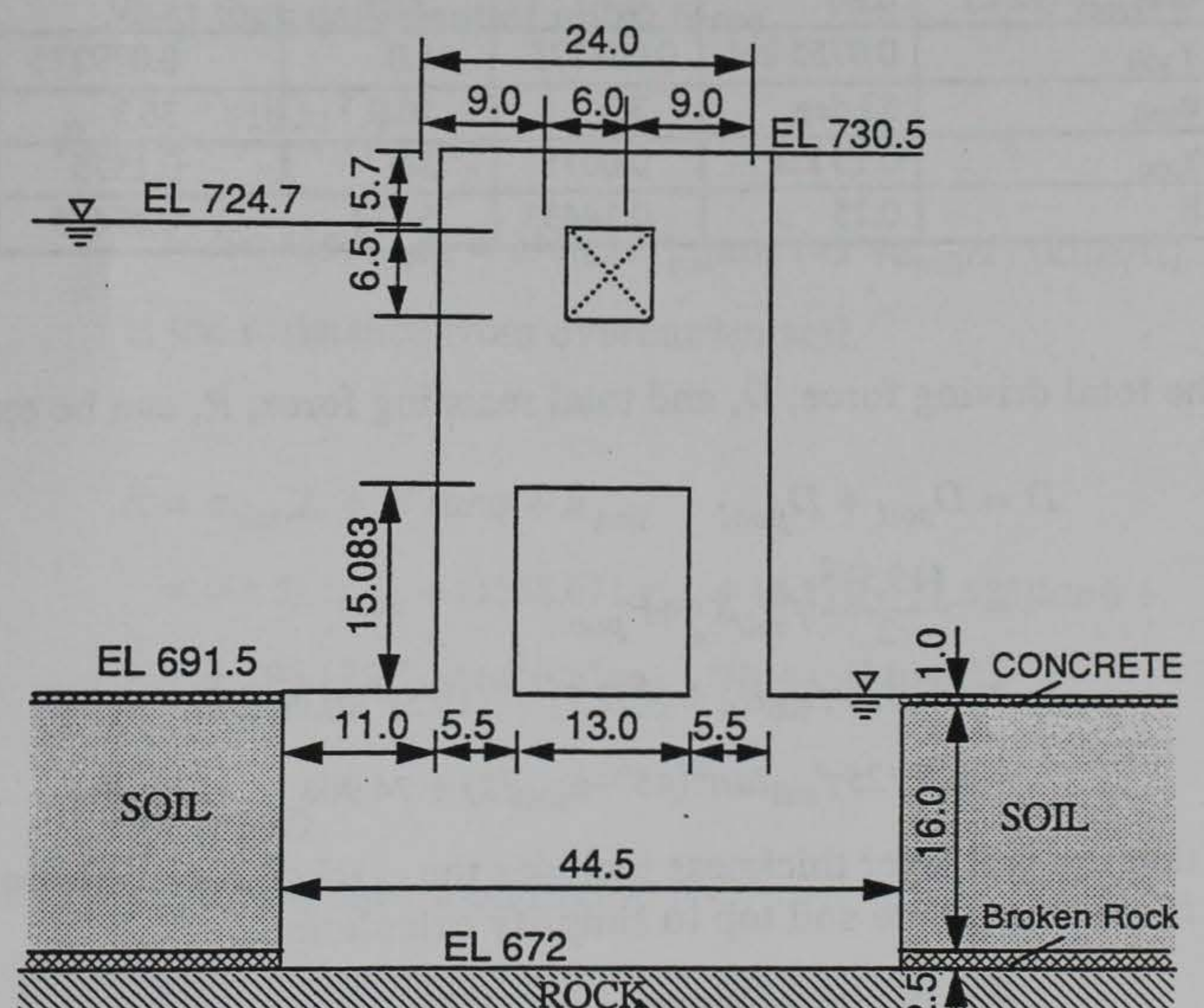

Dimensions in feet

Figure A-1 Locks \& Dam \#2, Monolith M16, Cross-Section Maintenance Condition 
Using the Simple Method to calculate the sliding stability, the random variables and their statistical properties are listed in Table A-1.

Table A-1 Random Variables Used in Sliding Analysis, L\&D No. 2, M16

\begin{tabular}{|l|l|l|l|l|l|}
\hline Variable & Mean & $\sigma$ & $\mathrm{V}(\%)$ & Mean $+\sigma$ & Mean $-\sigma$ \\
\hline \hline$c_{\text {rock }}($ Max. $)$ & $11.0 \mathrm{ksf}$ & 7.7 & 70.0 & 18.7 & 3.3 \\
\hline $\tan \phi_{\text {rock }}$ (Max.) & 1.50 & 0.675 & 45.0 & 2.175 & 0.825 \\
\hline$\rho_{\text {c,tan }}=-0.70$ & & & & & \\
\hline$c_{\text {rock }}$ (Res.) & 0.0 & & & & \\
\hline $\tan \phi_{\text {rock }}($ Res. $)$ & 0.80 & 0.40 & 50.0 & 1.20 & 0.40 \\
\hline$\gamma_{\text {soil }}^{\prime}$ & $0.0755 \mathrm{kcf}$ & 0.003775 & 5.0 & 0.079275 & 0.071725 \\
\hline$\phi_{\text {soil }}$ & $33 \mathrm{deg}$ & 3.3 & 10.0 & 36.3 & 29.7 \\
\hline$\gamma_{\text {con }}$ & $0.15 \mathrm{kcf}$ & 0.0075 & 5.0 & 0.1575 & 0.1425 \\
\hline $\mathrm{E}$ & 0.25 & 0.14435 & 57.74 & 0.39435 & 0.10565 \\
\hline
\end{tabular}

The total driving force, $D$, and total resisting force, $R$, can be expressed as

$$
\begin{aligned}
D & =D_{\text {soil }}+D_{\text {pool }} \\
& =\frac{(19.5)^{2}}{2} \gamma_{\text {soil }}^{\prime} K_{a}+P_{\text {poo }} \\
& =190.125 \gamma_{\text {soil }}^{\prime} K_{a}+\left[(52.7)^{2}-(19.5)^{2}\right](0.0625) / 2 \\
& =190.125 \gamma_{\text {soil }}^{\prime} \tan ^{2}\left(45^{\circ}-\phi_{\text {soil }} / 2\right)+74.908 \quad(\mathrm{kips} / \mathrm{ft})
\end{aligned}
$$

Note that the soil layer thickness includes the cracked rock portion $(2.5 \mathrm{ft})$ and the $1 \mathrm{ft}$ concrete at the soil top to simplify calculation.

$$
R=c_{\text {base }} L+N^{\prime} \text { tan } \phi+R_{\text {soil }}
$$

where

$$
\begin{aligned}
L & =B=44.5 \mathrm{ft} \text { is the length of sliding surface of the base; } \\
N^{\prime} & =W_{\text {concrete }}+W_{w}-U \\
& =1568.671 \gamma_{\text {con }}+22.825-\frac{\left(H_{h}+H_{l}\right)-\left(H_{h}-H_{l}\right) E}{2} \gamma_{w} B \\
& =1568.671 \gamma_{\text {con }}+22.825-100.4+46.17 \mathrm{E} \\
& \left.=1568.671 \gamma_{\text {con }}+46.17 \mathrm{E}-77.575 \quad \text { (kips/ft }\right)
\end{aligned}
$$


is the effective vertical force on the base,

where

$W_{\text {concrete }}$ is the weight of monolith;

$W_{w}$ is the weight of water on the monolith;

$U$ is hydraulic uplift force;

$H_{h}$ and $H_{l}$ are the upper and lower pool levels, respectively,

$\gamma_{w}$ is the unit weight of water; and

$E$ is the coefficient of uplift force,

and

$$
\begin{aligned}
R_{\text {soil }} & =\frac{(19.5)^{2}}{2} \gamma_{\text {soil }}^{\prime} K_{p} \\
& =190.125 \gamma_{\text {soil }}^{\prime} K_{p}=190.125{\gamma_{\text {soil }}^{\prime}}^{\prime} \tan ^{2}\left(45^{\circ}+\phi_{\text {soil }} / 2\right)(\mathrm{kips} / \mathrm{ft})
\end{aligned}
$$

is the resistance from overburden soil.

Therefore,

$$
\begin{aligned}
R= & c_{\text {base }} L+N^{\prime} \tan \phi+R_{\text {soil }} \\
= & (44.5) c_{\text {base }}+\left[1568.671 \gamma_{\text {con }}+46.17 \mathrm{E}-77.575\right] \tan \phi+ \\
& +190.125 \gamma_{\text {soil }}^{\prime} \tan ^{2}\left(45^{\circ}+\phi_{\text {soil }} / 2\right) \quad(\mathrm{kips} / \mathrm{ft})
\end{aligned}
$$

and

$$
F S=R / D
$$

The free body diagram is shown on Figure A-2.

\section{Calculations}

-Taylor's Series Method:

The equations used in Taylor's series method are

$$
\begin{aligned}
& E[F S(x)] \approx F S\left(E\left[x_{i}\right]\right) \\
& \qquad \operatorname{Var}(F S) \approx \sum_{i=1}^{n}\left(\frac{\partial F S}{\partial x_{i}}\right)^{2} \sigma_{x_{i}}^{2}+2 \sum_{i=1, i<j}^{n} \frac{\partial F S}{\partial x_{i}} \frac{\partial F S}{\partial x_{j}} \rho_{x_{i} x_{j}} \sigma_{x_{i}} \sigma_{x_{j}}
\end{aligned}
$$




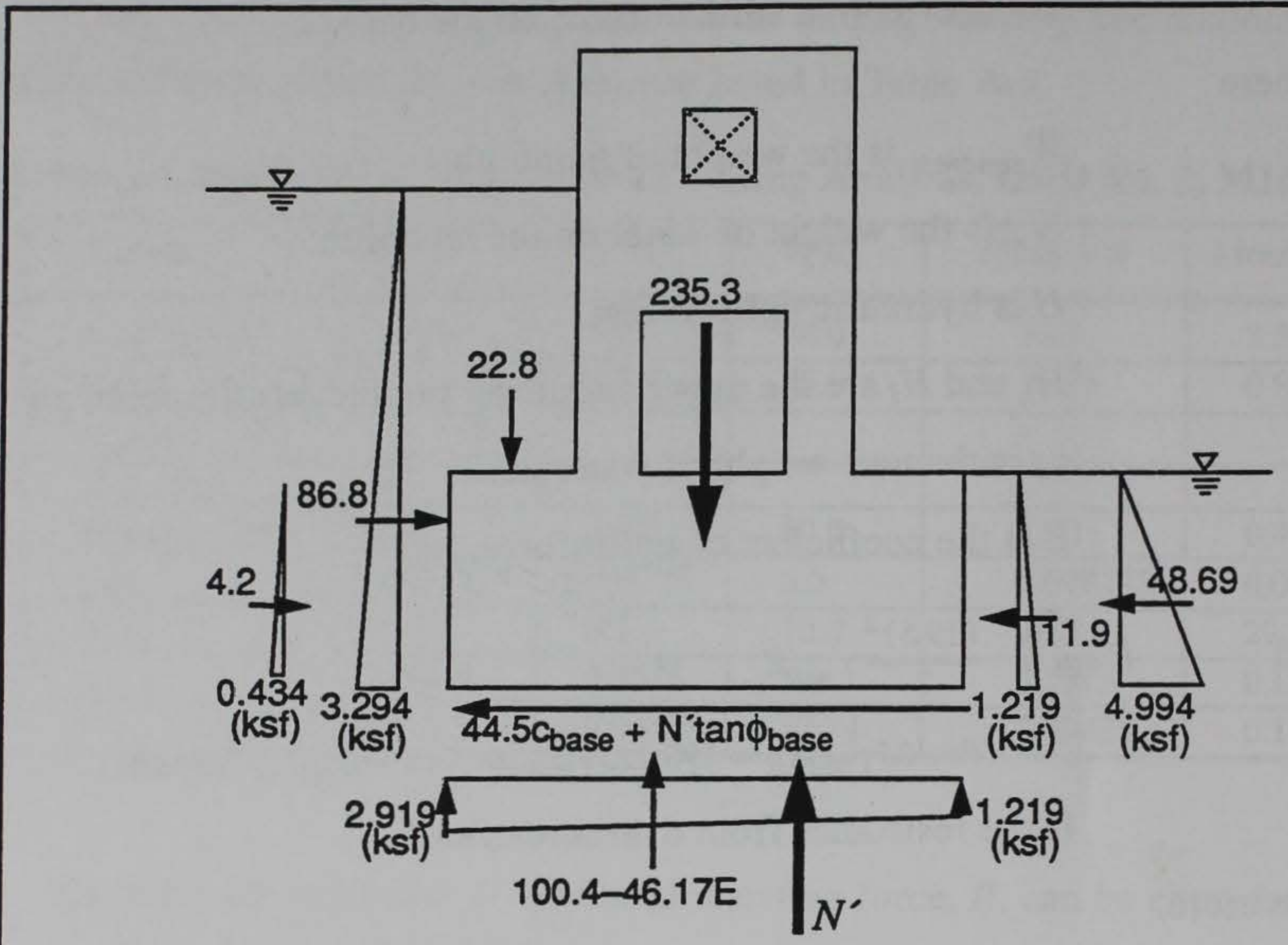

Forces in kips per lineal foot

Figure A-2 Locks and Dam No. 2, Monolith M-16,Free Body Diagram Sliding Stability Analysis-Maintenance Condition

and

$$
\begin{aligned}
& \beta_{\text {normal }}=\frac{E[F S]-1}{\sigma_{F S}} \\
& \beta_{\text {lognormal }}=\frac{\ln \left(\frac{E[F S]}{\sqrt{1+V_{F S}^{2}}}\right)}{\sqrt{\ln \left(1+V_{F S}^{2}\right)}}
\end{aligned}
$$




$$
\begin{aligned}
& E[F S] \approx E[R] / E[D]=E\left[c_{\text {base }} L+N^{\prime} \tan \phi+R_{\text {soil }}\right] / E\left[D_{\text {soil }}+D_{\text {pool }}\right] \\
&=\left[489.5+(169.268) \tan \phi_{\text {rock }}+48.69\right] /(4.23+74.91) \\
&=792.09 / 79.14 \approx 10.01 \\
& \frac{\partial}{\partial c} F S=\frac{44.5}{D}=44.5 / 79.14=0.5623(1 / \mathrm{ksf}) \\
& \frac{\partial}{\partial \tan \phi} F S=\frac{N^{\prime}}{D}=169.268 / 79.14=2.1388
\end{aligned}
$$$$
\frac{\partial}{\partial \gamma_{\text {soil }}^{\prime}} F S=\frac{190.125}{D^{2}}\left[D \tan ^{2}\left(45^{\circ}+\frac{\phi_{\text {soil }}}{2}\right)-R \tan ^{2}\left(45^{\circ}-\frac{\phi_{\text {soil }}}{2}\right)\right]=1.06071 / \mathrm{kcf}
$$

$$
\frac{\partial}{\partial \phi_{\text {soil }}} F S=\frac{190.125 \gamma_{\text {soil }}^{\prime}}{D^{2}}\left[D \frac{\partial R}{\partial \phi_{\text {soil }}}-R \frac{\partial D}{\partial \phi_{\text {soil }}}\right]=
$$

$$
=\frac{190.125 \gamma_{\text {soil }}}{D^{2}}\left[D \tan \left(\frac{\pi}{4}+\frac{\phi_{\text {soil }}}{2}\right) \sec ^{2}\left(\frac{\pi}{4}+\frac{\phi_{\text {soil }}}{2}\right)+R \tan \left(\frac{\pi}{4}-\frac{\phi_{\text {soil }}}{2}\right) \sec ^{2}\left(\frac{\pi}{4}-\frac{\phi_{\text {soil }}}{2}\right)\right]
$$

$=0.1910(1 / \mathrm{rad})$

$$
\begin{aligned}
\frac{\partial}{\partial \gamma_{\text {con }}} F S & =\frac{(1568.671) \tan \phi_{\text {base }}}{D}=29.7321 / \mathrm{kcf} \\
\frac{\partial}{\partial E} F S= & \frac{(46.17) \tan \phi_{\text {base }}}{D}=0.875 \\
\operatorname{Var}(F S) & =[(0.5623)(7.7)]^{2}+[(2.1388)(0.675)]^{2}+[(1.0607)(0.00375)]^{2}+ \\
& +[(0.1910)(3.3 \pi / 180)]^{2}+[(29.732)(0.0075)]^{2}+[(0.875)(0.14435)]^{2} \\
& +2(-0.7)(0.5623)(2.1388)(7.7)(0.675) \\
& =18.746+2.084+1.6 \times 10^{-5}+1.21 \times 10^{-4}+0.0497+0.0160-8.751 \\
& =12.145
\end{aligned}
$$

$\sigma_{F S}=3.485 \quad V_{F S}=34.82$

$\beta_{\text {normal }}=(10.01-1.0) / 3.485 \approx 2.59$ 


$$
\beta_{\log \text { normal }}=\frac{\ln \left(\frac{10.01}{\sqrt{1+(0.3482)^{2}}}\right)}{\sqrt{\ln \left(1+(0.3482)^{2}\right)}} \approx 6.64
$$

-Point Estimate Method (PEM)

The equations used in PEM are:

$$
\begin{aligned}
& E[F S]=\Sigma P_{\mathrm{i}} F S( \pm, \pm, \pm, \ldots \pm) \\
& E\left[F S^{2}\right]=\Sigma P_{i} F S^{2}( \pm, \pm, \pm, \ldots \pm)
\end{aligned}
$$

and

$$
\operatorname{Var}(F S)=E\left[F S^{2}\right]-(E[F S])^{2}
$$

where

$P_{i}$ are coefficients of point values of $F S$; and

$F S( \pm, \pm, \pm, \ldots \pm)$ are the values of $F S$ at certain points at which the $x_{i}$ have values $x_{i} \pm \sigma_{x_{i}}$

For the given problem, let

$$
x_{1}=c_{\text {base }}, x_{2}=\tan \phi_{\text {base }}, x_{3}=\gamma_{c o n}, x_{4}=\gamma_{\text {soil }}, x_{5}=\phi_{\text {soil }} \text {, and } x_{6}=E,
$$

then

$$
\begin{aligned}
& \mathrm{P}++\ldots=\frac{1}{2^{6}}\left(1+\rho_{\mathrm{c}, \tan \phi}\right)=(1.0-0.7) /(64)=0.0046875 \\
& \mathrm{P}--\ldots=\frac{1}{2^{6}}\left(1+\rho_{\mathrm{c}, \tan \phi}\right)=(1.0-0.7) /(64)=0.0046875 \\
& \mathrm{P}+\ldots=\mathrm{P}-\ldots=\frac{1}{2^{6}}\left(1-\rho_{\mathrm{c}, \tan \phi}\right)=(1.0+0.7) /(64)=0.0265625
\end{aligned}
$$

where the "... " means other possible combinations of $x_{3}, x_{4}, x_{5}$ and $x_{6}$. The calculation results are listed in Table A-2. next page. 
Table A-2. Reliability Index Calculation Results of Sliding Analysis for Locks and Dam No. 2, Monolith M-16, Maintenance Condition

\begin{tabular}{|c|c|c|c|c|c|}
\hline$x_{1}, x_{2}, x_{3}, x_{4}, x_{5}, x_{6}$ & $\mathbf{P}_{\mathrm{i}}$ & $\mathrm{FS}_{\mathrm{i}}$ & $\mathrm{FS}_{\mathrm{i}}^{2}$ & $\mathrm{FS}_{\mathrm{i}} * \mathrm{P}_{\mathrm{i}}$ & $\mathrm{FS}_{\mathrm{i}}^{2} * \mathrm{P}_{\mathrm{i}}$ \\
\hline,,,,,++++++ & 0.0046875 & 16.49355 & 272.0371 & .077614 & 1.27517 \\
\hline,,,,,-+++++ & 0.0265625 & 7.793545 & 60.73934 & .207016 & 1.61339 \\
\hline,,,,,+-++++ & 0.0265625 & 13.27675 & 176.2722 & .352664 & 4.68223 \\
\hline,,,,,--++++ & 0.0046875 & 4.576751 & 20.94665 & .021454 & .098187 \\
\hline,,,,,++-+++ & 0.0046875 & 15.84383 & 251.0271 & .074273 & 1.17669 \\
\hline,,,,,-+-+++ & 0.0265625 & 7.143833 & 51.03434 & .189758 & 1.35560 \\
\hline,,,,,+--+++ & 0.0265625 & 13.03031 & 169.789 & .346118 & 4.51002 \\
\hline,,,,,---+++ & 0.0046875 & 4.330308 & 18.75157 & .020298 & .087898 \\
\hline,,,,,+++-++ & 0.0046875 & 16.49949 & 272.2332 & .077341 & 1.27609 \\
\hline,,,,,-++-++ & 0.0265625 & 7.758669 & 60.19694 & .206090 & 1.59898 \\
\hline,,,,,+-+-++ & 0.0265625 & 13.2676 & 176.0293 & .352421 & 4.67578 \\
\hline,,,,,--+-++ & 0.0046875 & 4.526782 & 20.49176 & .021219 & .096055 \\
\hline,,,,,++--++ & 0.0046875 & 15.84673 & 251.1189 & .074282 & 1.17712 \\
\hline,,,,,-+--++ & 0.0265625 & 7.105909 & 50.49394 & .188751 & 1.34125 \\
\hline,,,,,+---++ & 0.0265625 & 13.02001 & 169.5205 & .345844 & 4.50289 \\
\hline,,,,---+++ & 0.0046875 & 4.279183 & 18.31141 & .020059 & .085835 \\
\hline,,,,,++++-+ & 0.0046875 & 16.06472 & 258.0751 & .075303 & 1.20973 \\
\hline,,,,,-+++-+ & 0.0265625 & 7.497675 & 56.21514 & .199157 & 1.49322 \\
\hline,,,,,+-++-+ & 0.0265625 & 12.89709 & 166.3348 & .342579 & 4.41827 \\
\hline,,,,,--++-+ & 0.0046875 & 4.330044 & 18.74928 & .020297 & .087887 \\
\hline,,,,,++-+-+ & 0.0046875 & 15.42493 & 237.9284 & .072304 & 1.11529 \\
\hline,,,,,-+-+-+ & 0.0265625 & 6.857893 & 47.0307 & .182163 & 1.24925 \\
\hline,,,,,+--+-+ & 0.0265625 & 12.65441 & 160.134 & .336133 & 4.25356 \\
\hline,,,,,---+-+ & 0.0046875 & 4.087368 & 16.70657 & .019160 & .078312 \\
\hline,,,,,+++--+ & 0.0046875 & 16.10906 & 259.5017 & .075511 & 1.21641 \\
\hline,,,,,-++--+ & 0.0265625 & 7.489833 & 56.0976 & .198949 & 1.49009 \\
\hline,,,,,+-+--+ & 0.0265625 & 12.92213 & 166.9814 & .343244 & 4.43544 \\
\hline,,,,,--+--+ & 0.0046875 & 4.302907 & 18.51501 & .020170 & .086789 \\
\hline,,,,++--++ & 0.0046875 & 15.46538 & 239.1779 & .072494 & 1.12115 \\
\hline,,,,,-+---+ & 0.0265625 & 6.846154 & 46.86983 & .181851 & 1.24498 \\
\hline,,,,,+----+ & 0.0265625 & 12.67798 & 160.7311 & .336759 & 4.26942 \\
\hline,,,,,-----+ & 0.0046875 & 4.058753 & 16.47347 & .019125 & .077219 \\
\hline,,,,,+++++- & 0.0046875 & 16.12551 & 260.032 & .075588 & 1.21890 \\
\hline,,,,,-++++- & 0.0265625 & 7.425506 & 55.13814 & .197240 & 1.46461 \\
\hline,,,,,+-+++- & 0.0265625 & 13.13715 & 172.5848 & .348956 & 4.58428 \\
\hline,,,,,--+++- & 0.0046875 & 4.43715 & 19.6883 & .020799 & .092289 \\
\hline,,,,,++-++- & 0.0046875 & 15.4758 & 239.5003 & .072543 & 1.12266 \\
\hline,,,,,-+-++- & 0.0265625 & 6.775795 & 45.91139 & .179982 & 1.21952 \\
\hline,,,,,+--++- & 0.0265625 & 12.89071 & 166.1704 & .342409 & 4.41690 \\
\hline,,,,--+++- & 0.0046875 & 4.190708 & 17.56203 & .019644 & .082322 \\
\hline
\end{tabular}


Table A-2 (cont'd)

\begin{tabular}{|c|c|c|c|c|c|}
\hline$x_{1}, x_{2}, x_{3}, x_{4}, x_{5}, x_{6}$ & $\mathbf{P}_{\mathbf{i}}$ & $\mathrm{FS}_{\mathbf{i}}$ & $\mathrm{FS}_{\mathrm{i}}^{2}$ & $\mathrm{FS}_{\mathrm{i}} * \mathrm{P}_{\mathrm{i}}$ & $\mathrm{FS}_{\mathrm{i}}^{2} * \mathrm{P}_{\mathrm{i}}$ \\
\hline,,,,,+++-+- & 0.0046875 & 16.12973 & 260.1681 & .075618 & 1.21954 \\
\hline,,,,,-++-+- & 0.0265625 & 7.388904 & 54.5959 & .196268 & 1.45020 \\
\hline,,,,,+-+-+- & 0.0265625 & 13.12735 & 172.3273 & .348695 & 4.57744 \\
\hline,,,,,--+-+- & 0.0046875 & 4.386526 & 19.24161 & .020562 & .090195 \\
\hline,,,,,++--+- & 0.0046875 & 15.47697 & 239.5365 & .072548 & 1.12283 \\
\hline,,,,,-+--+- & 0.0265625 & 6.736144 & 45.37563 & .178929 & 1.20529 \\
\hline,,,,,+---+- & 0.0265625 & 12.87975 & 165.888 & .342118 & 4.40640 \\
\hline,,,,,----+- & 0.0046875 & 4.138927 & 17.13072 & .019401 & .080300 \\
\hline,,,,,++++-- & 0.0046875 & 15.7023 & 246.5623 & .073605 & 1.15576 \\
\hline,,,,,-+++-- & 0.0265625 & 7.135262 & 50.91196 & .189530 & 1.35235 \\
\hline,,,,,+-++-- & 0.0265625 & 12.75962 & 162.8078 & .338927 & 4.32458 \\
\hline,,,,,--++-- & 0.0046875 & 4.192576 & 17.5777 & .019653 & .082396 \\
\hline,,,,,++-+-- & 0.0046875 & 15.06252 & 226.8795 & .070606 & 1.06350 \\
\hline,,,,,-+-+-- & 0.0265625 & 6.49548 & 42.19125 & .172536 & 1.12071 \\
\hline,,,,,+--+-- & 0.0265625 & 12.51694 & 156.6738 & .332481 & 4.16165 \\
\hline,,,,,---+-- & 0.0046875 & 3.949901 & 15.60172 & .018515 & .073133 \\
\hline,,,,,+++--- & 0.0046875 & 15.74444 & 247.8873 & .073802 & 1.16197 \\
\hline,,,,,-++--- & 0.0265625 & 7.125212 & 50.76865 & .189263 & 1.34854 \\
\hline,,,,,+-+--- & 0.0265625 & 12.78383 & 163.4262 & .339570 & 4.31101 \\
\hline,,,,,--+--- & 0.0046875 & 4.164602 & 17.34391 & .019522 & .081300 \\
\hline,,,,,++---- & 0.0046875 & 15.10076 & 228.0329 & .070785 & 1.06890 \\
\hline,,,,,-+---- & 0.0265625 & 6.481533 & 42.01027 & .172166 & 1.11590 \\
\hline,,,,,+----- & 0.0265625 & 12.53967 & 457.2434 & .333085 & 4.17678 \\
\hline \multirow[t]{2}{*}{,,,,-----} & 0.0046875 & 3.920448 & 15.36991 & .018377 & .072047 \\
\hline & & & & $\Sigma \overline{10.01371}$ & $\Sigma 1 \overline{12.4514}$ \\
\hline
\end{tabular}

The final results:

$E[F S]=\Sigma\left(F S_{i} * P_{i}\right)=10.01371 \approx 10.01$

$E\left[F S^{2}\right]=\Sigma\left(F S_{i}^{2} * P_{i}\right)=112.4513$

$\operatorname{Var}(F S)=E\left[F S^{2}\right]-(E[F S])^{2}=112.4513-(10.01371)^{2}=12.176912$

$\sigma_{F S}=3.48957 \quad V_{F S}=34.85 \%$

$\beta_{\text {normal }}=(10.01-1.0) / 3.48957 \approx 2.58$

$\beta_{\text {lognormal }}=\frac{\ln \left(\frac{10.01}{\sqrt{1+(0.3485)^{2}}}\right)}{\sqrt{\ln \left(1+(0.3485)^{2}\right)}} \approx 6.64$ 


\section{Appendix B \\ Example Overturning Analysis Locks and Dam No. 2, Monolith M-16}

The cross-section of Locks and Dam No. 2, Monolith M-16 is illustrated in Figure B-1 in Appendix A, page A-1(maintenance condition).

Using the Simple Method to calculate the overturning stability, the random variables and their statistical properties are listed in Table B-1.

Table B-1 Random Variables Used in Overturning Analysis, L\&D No. 2, M16

\begin{tabular}{|l|l|l|l|l|l|}
\hline Variable & Mean & $\sigma$ & $\mathrm{V}(\%)$ & Mean $+\sigma$ & Mean $-\sigma$ \\
\hline \hline$\gamma_{\text {soil }}$ & $0.0755 \mathrm{kcf}$ & 0.003775 & 5.0 & 0.079275 & 0.071725 \\
\hline$\phi_{\text {soil }}$ & $33 \mathrm{deg}$ & 3.3 & 10.0 & 36.3 & 29.7 \\
\hline$\gamma_{\text {con }}$ & $0.15 \mathrm{kcf}$ & 0.0075 & 5.0 & 0.1575 & 0.1425 \\
\hline $\mathrm{E}$ & 0.25 & 0.14435 & 57.74 & 0.39435 & 0.10565 \\
\hline
\end{tabular}

Let the right edge of the base be the rotating point. The overturning moment, $M_{O}$, and resisting moment, $M_{R}$, can be expressed as

$$
\begin{aligned}
M_{O}= & M_{\text {pool }}+M_{\text {soil }, D}+M_{\text {uplift }} \\
= & \frac{\left[(52.7)^{3}-(19.5)^{3}\right]}{6} \gamma_{w}+\frac{(17)^{2}}{2}\left(\frac{17}{3}+2.5\right) \gamma_{\text {soil }}^{\prime} K_{0}+ \\
& +(19.5)(44.5) \gamma_{w}(44.5 / 2)+\frac{1}{2}(1-E)(52.7-19.5)(44.5) \gamma_{w} \frac{2}{3}(44.5) \\
= & 1447.38+1180.08 \gamma_{\text {soil }}^{\prime}\left(1-\sin \phi_{\text {soil }}\right)+2576.39-1369.67 E \\
= & 1180.08 \gamma_{\text {soil }}^{\prime}\left(1-\sin \phi_{\text {soil }}\right)-1369.67 E+4023.77 \\
M_{R}= & M_{\text {con }}+M_{w}+M_{\text {soil }, R} \\
= & 34377.239 \gamma_{\text {con }}+(52.7-19.5)(11.0) \gamma_{\mathrm{w}}(11.0 / 2+33.5)+1180.08 \gamma_{\text {soil }}^{\prime}\left(1-\sin \phi_{\text {soil }}\right) \\
= & 34377.239 \gamma_{\text {con }}+1180.08 \gamma_{\text {soil }}^{\prime}\left(1-\sin \phi_{\text {soil }}\right)+890.175
\end{aligned}
$$

The free body diagram is shown on Figure B-2. 


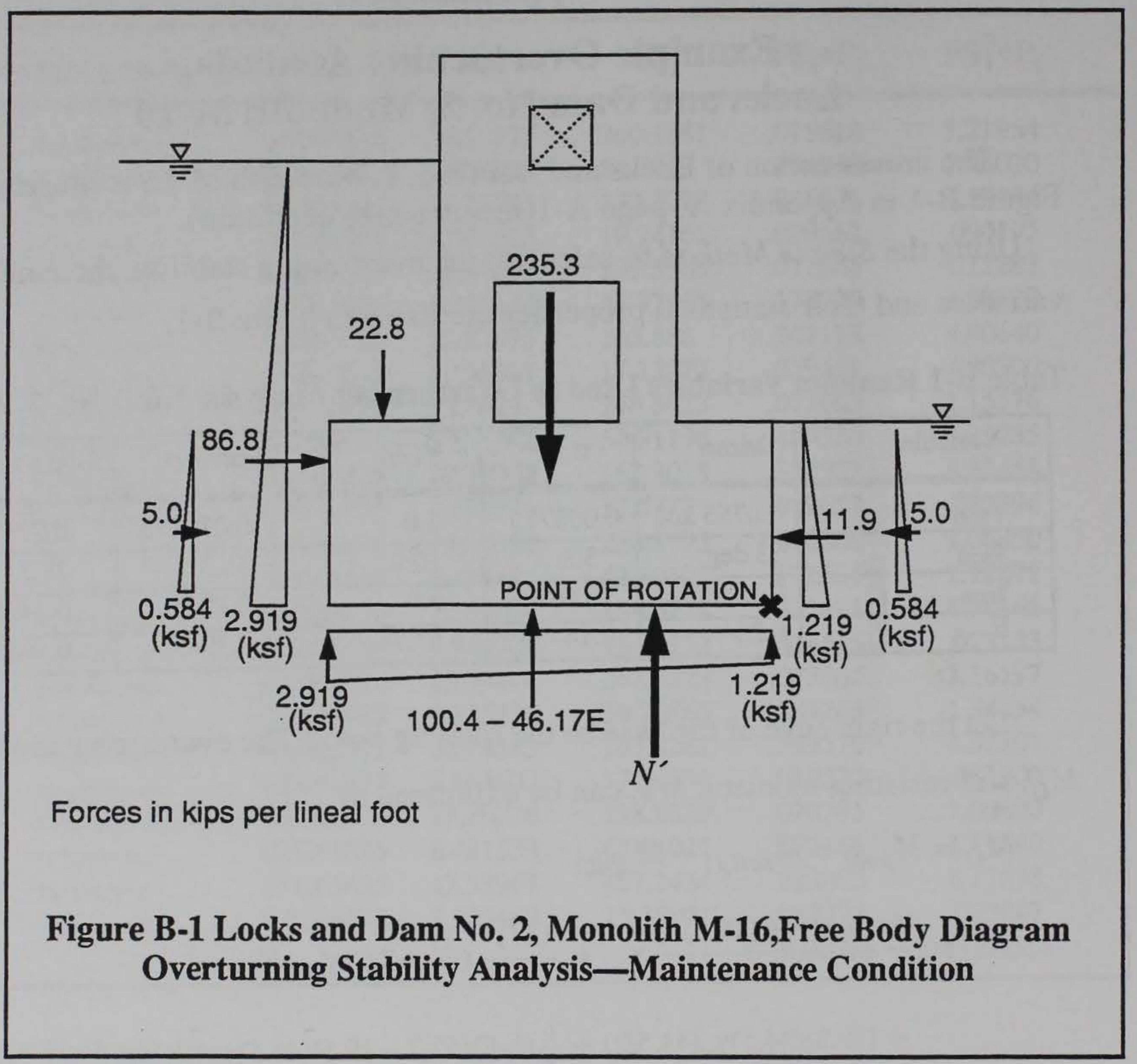

\section{Calculations}

Two criteria used in overturning stability analysis, the resultant, $X_{R}$, and $F S$. The $X_{R}$ is defined as

$$
X_{R}=\Sigma M / N^{\prime}=\left(M_{R}-M_{O}\right) / N^{\prime}
$$

and

$$
F S=M_{R} / M_{O}
$$

The criteria of $X_{R}$ are $X_{R} \geq B / 3\left(\beta_{\mathrm{ken}}\right), X_{R} \geq B / 4\left(\beta_{\mathrm{B} / 4}\right), X_{R} \geq B / 6\left(\beta_{\mathrm{B} / 6}\right)$ or $X_{R}$ is 
at the toe $\left(\beta_{\text {toe }}\right)$. The criterion of $F S$ is $F S \geq 1.0$.

Note that

$$
\begin{array}{rlrl}
\Sigma M & =M_{R}-M_{O} \\
& =34377.239 \gamma_{c o n}+1369.67 E-3133.595 & & (\text { kips.ft/ft) } \\
& N^{\prime}=1568.671 \gamma_{c o n}+46.17 E-77.575 & (\text { kips/ft) (See Appendix A) }
\end{array}
$$

and

-Taylor's Series Method:

\section{$\underline{\operatorname{Resultant}} X_{\underline{R}}$}

$$
\begin{aligned}
E\left[X_{R}\right] & \approx E[\Sigma M] / E\left[N^{\prime}\right] \\
& =2365.4 / 169.27 \approx 13.97
\end{aligned}
$$

$$
P C \%=3 X_{R} / B(100)=3(13.97)(100) /(44.5) \approx 94.18 \%
$$

$P C \%$ is the percentage of the base which is under compression.

$$
\begin{gathered}
\frac{\partial}{\partial \gamma_{c o n}} X_{R}=\frac{(34377.239) N^{\prime}-(1568.671) \Sigma M}{N^{\prime 2}}=73.589 \\
\frac{\partial X_{R}}{\partial E}=\frac{(1369.67) N^{\prime}-(46.17) \Sigma M}{N^{\prime 2}}=4.28 \\
\begin{aligned}
& \operatorname{Var}\left(X_{R}\right)=[(73.589)(0.0075)]^{2}+\left[(4.28)((0.14435)]^{2}\right. \\
&=0.3071+0.3817=0.6888 \\
& \sigma_{\mathrm{X}_{\mathrm{R}}}=0.8299 \quad V_{\mathrm{X}_{\mathrm{R}}}=5.94 \%
\end{aligned}
\end{gathered}
$$

For normal distribution of $X_{R}$ :

$$
\begin{aligned}
& \beta_{\text {toe }}=13.97 / 0.8299 \approx 16.83 \\
& \beta_{B / 6}=(13.97-44.5 / 6) / 0.8299 \approx 7.90 \\
& \beta_{b / 4}=(13.97-44.5 / 4) / 0.8299 \approx 3.43 \\
& \beta_{\text {ken }}=(13.97-44.5 / 3) / 0.8299 \approx-1.04
\end{aligned}
$$

Note that the negative value of $\beta_{\text {kern }}$ reflects the base is not $100 \%$ in compression. 
$\underline{F S}$

$$
\begin{aligned}
& E[F S] \approx E\left[M_{R}\right] / E\left[M_{O}\right]=6087.33 / 3721.92 \approx 1.6355 \\
& \frac{\partial}{\partial \gamma_{\text {con }}} F S=\frac{34377.239}{M_{O}}=9.2364 \\
& \frac{\partial}{\partial \gamma_{\text {soil }}^{\prime}} F S=\frac{(1180.0833)\left(1-\sin \phi_{\text {soil }}\right)\left(M_{O}-M_{R}\right)}{M_{O}^{2}}=-0.09176 \\
& \begin{aligned}
\frac{\partial}{\partial \phi_{\text {soil }}} F S= & \frac{(-1180.0833) \gamma_{\text {soil }}^{\prime} \cos \phi_{\text {soil }}\left(M_{O}-M_{R}\right)}{M_{O}^{2}}=0.012759 \\
\frac{\partial}{\partial E} F S= & \frac{(1369.67) M_{R}}{M_{O}^{2}}=0.60188 \\
\operatorname{Var}(F S) & =[(9.2364)(0.0075)]^{2}+[(-0.09176)(0.00375)]^{2}+ \\
& +\left[(0.012759)((3.3 \pi / 180)]^{2}+[(0.60188)(0.14435)]^{2}\right. \\
& =0.004799+1.184 \times 10^{-7}+5.400 \times 10^{-7}+0.007548 \\
& =0.012348
\end{aligned}
\end{aligned}
$$

$$
\begin{aligned}
& \sigma_{F S}=0.11112 \quad V=6.794 \% \\
& \beta_{\text {normal }}=(1.6355-1) / 0.11112 \approx 5.72 \\
& \beta_{\text {log normal }}=\frac{\ln \left(\frac{1.6355}{\sqrt{1+0.06794^{2}}}\right)}{\sqrt{\ln \left(1+0.06794^{2}\right)}} \approx 7.22
\end{aligned}
$$

-Point Estimate Method (PEM)

The equations used in PEM are:

$$
\begin{aligned}
& E\left[X_{R}\right]=\Sigma P_{\mathrm{i}} X_{R}( \pm, \pm, \pm, \ldots \pm) \\
& E\left[X_{R}^{2}\right]=\Sigma P_{i} X_{R}^{2}( \pm, \pm, \pm, \ldots \pm)
\end{aligned}
$$

and

$$
\operatorname{Var}\left(X_{R}\right)=E\left[X_{R}^{2}\right]-\left(E\left[X_{R}\right]\right)^{2}
$$


where

$P_{i}$ are coefficients of point values of $X_{R}$; and

$X_{R}( \pm, \pm, \pm, \ldots \pm)$ are the values of $X_{R}$ at certain points at which the $x_{i}$ have values $x_{i} \pm \sigma_{x_{i}}$

The equations for $F S$ are similar.

For the given problem, let

$x_{1}=\gamma_{\text {con, }}, x_{2}=\gamma_{\text {soil }}, x_{3}=\phi_{\text {soil }}, x_{4}=E$, and notice that they are independent,

then

$$
P_{i}=1 / 2^{2}=0.25 \text { for } X_{R} \quad \text { and } P_{i}=1 / 2^{4}=0.0625 \text { for } F S \text {. }
$$

The calculation results see tables B-2 and B-3.

Table B-2. Reliability Index Calculation Results of Overturning Analysis for Locks and Dam No. 2, Monolith M-16, Maintenance Condition- $\mathrm{X}_{\mathrm{R}}$

\begin{tabular}{|c|c|c|c|}
\hline $\mathrm{x}_{1}, \mathrm{x}_{4}$ & $P_{i}$ & $\mathrm{X}_{\mathrm{R}, \mathrm{i}}$ & $\mathrm{X}_{\mathrm{R}, \mathrm{i}}^{2}$ \\
\hline,++ & 0.25 & 15.02952 & 225.8864 \\
\hline,-+ & 0.25 & 14.04262 & 197.1953 \\
\hline,+- & 0.25 & 13.91062 & 193.5053 \\
\hline \multirow[t]{2}{*}{,--} & 0.25 & $\underline{12.66197}$ & $\underline{160.3254}$ \\
\hline & & $\Sigma 55.64473$ & $\sum 776.9124$ \\
\hline
\end{tabular}

The final results of $X_{R}$ :

$$
\begin{aligned}
& E\left[X_{R}\right]=\Sigma\left(X_{R, i} * P_{i}\right)=P_{i} \Sigma X_{R, i}=(55.64473)(0.25) \approx 13.9112 \\
& E\left[X_{R}^{2}\right]=\Sigma\left(X_{R, i}^{2} * P_{i}\right)=P_{i} \Sigma X_{R, i}^{2}=(776.9124)(0.25) \approx 194.2281 \\
& \operatorname{Var}\left(X_{R}\right)=E\left[X_{R}{ }^{2}\right]-\left(E\left[X_{R}\right]\right)^{2}=194.2281-(13.9112)^{2}=0.7071 \\
& \sigma_{\mathrm{FS}}=0.84089 \quad \mathrm{~V}_{\mathrm{FS}}=6.04 \% \\
& P C \%=3 X_{R} / B(100)=3(13.91)(100) /(44.5) \approx 93.78 \%
\end{aligned}
$$

For normal distribution of $X_{R}$ :

$$
\begin{aligned}
& \beta_{\text {toe }}=13.91 / 0.8409 \approx 16.54 \\
& \beta_{B / 6}=(13.91-44.5 / 6) / 0.8409 \approx 7.72 \\
& \beta_{b / 4}=(13.91-44.5 / 4) / 0.8409 \approx 3.31 \\
& \beta_{\text {ken }}=(13.91-44.5 / 3) / 0.8409 \approx-1.10
\end{aligned}
$$


Table B-3. Reliability Index Calculation Results of Overturning Analysis for Locks and Dam No. 2, Monolith M-16, Maintenance Condition-FS

\begin{tabular}{|cccc|}
\hline $\mathrm{x}_{1}, \mathrm{x}_{2}, \mathrm{x}_{3}, \mathrm{x}_{4}$ & $\mathrm{P}_{\mathrm{i}}$ & $\mathrm{FS}_{\mathrm{i}}$ & $\mathrm{FS}_{\mathrm{i}}^{2}$ \\
\hline \hline,,,++++ & 0.0625 & 1.800997 & 3.243589 \\
,,,-+++ & 0.0625 & 1.654578 & 2.737628 \\
,,,+-++ & 0.0625 & 1.801824 & 3.246571 \\
,,,--++ & 0.0625 & 1.655254 & 2.739867 \\
,,,++-+ & 0.0625 & 1.798948 & 3.236212 \\
,,,-+-+ & 0.0625 & 1.652903 & 2.732090 \\
,,,+--+ & 0.0625 & 1.799966 & 3.239877 \\
,,,---+ & 0.0625 & 1.653736 & 2.734842 \\
,,,+++- & 0.0625 & 1.619195 & 2.621793 \\
,,,-++- & 0.0625 & 1.487557 & 2.212825 \\
,,,+-+- & 0.0625 & 1.619770 & 2.623655 \\
,,,--+- & 0.0625 & 1.488009 & 2.214172 \\
,,,++-- & 0.0625 & 1.617771 & 2.617182 \\
,,,-+-- & 0.0625 & 1.486435 & 2.209489 \\
,,,+-- & 0.0625 & 1.618479 & 2.619473 \\
,,,---- & 0.0625 & 1.486993 & $\underline{2.211147}$ \\
& & $\Sigma 26.242415$ & $\mathbf{2} 3.240412$ \\
\hline
\end{tabular}

The final results:

$$
\begin{aligned}
& E[F S]=\Sigma\left(F S_{i} * P_{i}\right)=P_{i} \Sigma F S_{i}=(26.242415)(0.0625) \approx 1.64015 \\
& E\left[F S^{2}\right]=\Sigma\left(F S_{i}^{2} * P_{i}\right)=P_{i} \Sigma F S_{i}^{2}=(43.240412)(0.0625) \approx 2.702525 \\
& \operatorname{Var}(F S)=E\left[F S^{2}\right]-(E[F S])^{2}=2.702525-(1.64015)^{2} \approx 0.012433 \\
& \sigma_{\mathrm{FS}}=0.1115 \quad \mathrm{~V}_{\mathrm{FS}}=6.80 \% \\
& \beta_{\text {normal }}=(1.64-1.0) / 0.1115 \approx 5.74 \\
& \beta_{\text {lognomal }}=\frac{\ln \left(\frac{1.64}{\sqrt{1+(0.068)^{2}}}\right)}{\sqrt{\ln \left(1+(0.068)^{2}\right)}} \approx 7.25
\end{aligned}
$$




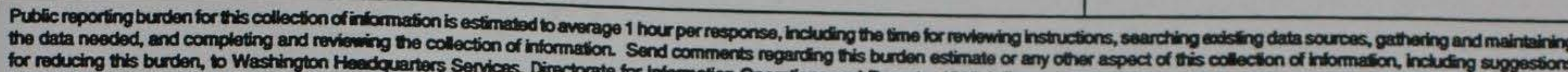

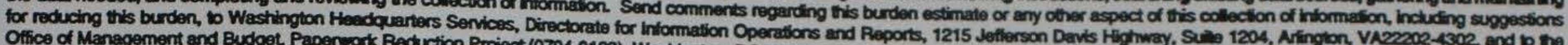
Office of Management and Budget, Papenwork Reduction Project (0704-0188), Washington, DCE20503.

\begin{tabular}{|l|l|l|}
\hline 1.AGENCY USE ONLY (Leave blank) & $\begin{array}{c}\text { 2.REPORT DATE } \\
\text { December } 1992\end{array}$ & $\begin{array}{c}\text { 3.REPORT TYPE AND DATES COVERED } \\
\text { Final report }\end{array}$
\end{tabular}

4.TITLE AND SUBTTILE

Engineering Reliability of Navigation Structures

5.FUNDING NUMBERS

6.AUTHOR(S)

Thomas F. Wolff, Weijun Wang

7.PERFORMING ORGANIZATION NAME(S) AND ADDRESS(ES)

Michigan State University

8.PERFORMING ORGANIZATION REPORT NUMBER

East Lansing, MI 48864

9.SPONSORINGMONITORING AGENCY NAME(S) AND ADDRESS(ES)

U.S. Army Corps of Engineers, Washington, DC 20314-1000

U.S. Army Engineer Waterways Experiment Station

3909 Halls Ferry Road, Vicksburg, MS 39180-6199

10.SPONSORINGMONITORING

AGENCY REPORT NUMBER

Contract Report

ITL-92-4

\section{SUPPLEMENTARY NOTES}

Available from National Technical Information Service, 5285 Port Royal Road, Springfield, VA 22161.

\section{2a.DISTRIBUTIONAVAILABIUTY STATEMENT}

Approved for public release; distribution is unlimited.

12b.DISTRIBUTION CODE

\section{ABSTRACT (Maximum 200 words)}

This report summarizes the results of a research effort to develop probability-based methods for expressing the structural reliability of gravity monoliths at navigation locks and dams. Existing reliability analysis techniques for civil engineering structures were adapted to the specific details of navigation structures. Using site-specific data, evaluations were made for the reliability of a number of structures with respect to sliding, overturning, and bearing capacity. Four of these structures are located on the Monongahela River in Pennsylvania and one structure is located on the Tombigbee River in Alabama. Based on the results of these studies, conclusions and recommendations are made for the reliability evaluation of similar Corps structures and use of such results for prioritizing rehabilitation investment decisions.

\section{SUBJECT TERMS}

Gravity structures

Reliability
Resultant location analysis

Sliding analysis
15.NUMBER OF PAGES

211

16.PRICE CODE

$$
\text { 1) }
$$

\section{SECURITY CLASSIFICATION OF REPORT}

UNCLASSIFIED
18.SECURITY CLASSIFICATION OF THIS PAGE

UNCLASSIFIED
19.SECURTY CLASSIFCATION OF ABSTRACT 